\title{
Ethanol and intestinal barrier : human intervention and mechanistic in vitro studies
}

Citation for published version (APA):

Elamin, E. E. (2014). Ethanol and intestinal barrier : human intervention and mechanistic in vitro studies. [Doctoral Thesis, Maastricht University]. Datawyse / Universitaire Pers Maastricht. https://doi.org/10.26481/dis.20140123ee

Document status and date:

Published: 01/01/2014

DOI:

10.26481/dis.20140123ee

Document Version:

Publisher's PDF, also known as Version of record

\section{Please check the document version of this publication:}

- A submitted manuscript is the version of the article upon submission and before peer-review. There can be important differences between the submitted version and the official published version of record.

People interested in the research are advised to contact the author for the final version of the publication, or visit the DOI to the publisher's website.

- The final author version and the galley proof are versions of the publication after peer review.

- The final published version features the final layout of the paper including the volume, issue and page numbers.

Link to publication

\footnotetext{
General rights rights.

- You may freely distribute the URL identifying the publication in the public portal. please follow below link for the End User Agreement:

www.umlib.nl/taverne-license

Take down policy

If you believe that this document breaches copyright please contact us at:

repository@maastrichtuniversity.nl

providing details and we will investigate your claim.
}

Copyright and moral rights for the publications made accessible in the public portal are retained by the authors and/or other copyright owners and it is a condition of accessing publications that users recognise and abide by the legal requirements associated with these

- Users may download and print one copy of any publication from the public portal for the purpose of private study or research.

- You may not further distribute the material or use it for any profit-making activity or commercial gain

If the publication is distributed under the terms of Article $25 \mathrm{fa}$ of the Dutch Copyright Act, indicated by the "Taverne" license above, 
Ethanol and intestinal barrier: human

intervention and mechanistic

in vitro studies 
(C) Copyright Elhaseen Elamin, Maastricht 2014

ISBN 9789461592941

Cover design: Khaya Ludidi

Layout: Tiny Wouters

Printing: Datawyse | Universitaire Pers Maastricht

The studies in this thesis have been supported by Top Institute Food Nitrition, Wageningen, the Netherlands 


\section{Ethanol and intestinal barrier: human intervention and mechanistic \\ in vitro studies}

PROEFSCHRIFT

ter verkrijging van de graad van doctor aan de Universiteit Maastricht, op gezag van de Rector Magnificus, Prof. dr. L. L. G. Soete, volgens het besluit van het College van Decanen, in het openbaar te verdedigen op donderdag 23 januari 2014 om 14.00 uur door

Elhaseen Elesaid Elamin 
Promotor:

Prof. dr. A.A.M. Masclee

Copromotor:

Dr. D. M. A. E. Jonkers

Beoordelingscommissie:

Prof. dr. C. H. C. Dejong, (voorzitter)

Prof. dr. J. P. H. Drenth, UMC Radboud, Nijmegen

Prof. dr. J. W. M. Heemskerk

Prof. dr. F. C. S. Ramaekers

Prof. dr. H. K. Seitz, Krankenhaus Salem der Evang, Heidelberg,

Duitsland 


\section{Contents}

Chapter 1 General introduction

Chapter 2 Ethanol metabolism and its effects on the intestinal 19 epithelial barrier

Chapter 3 Ethanol impairs intestinal barrier function in humans through mitogen activated protein kinase signaling: a combined in vivo and in vitro approach

Chapter 4 Effects of ethanol and acetaldehyde on tight junction integrity: in vitro study in a three dimensional intestinal epithelial cell culture model

Chapter 5 Fatty acid ethyl esters induce intestinal epithelial barrier dysfunction via a reactive oxygen species-dependent mechanism in a three-dimensional cell culture model

Chapter 6 Activation of the epithelial to mesenchymal transition factor Snail mediates acetaldehyde-induced intestinal epithelial barrier disruption

Chapter 7 Intracellular calcium release-induced Rho/ROCK activation mediates ethanol-induced intestinal epithelial tight junction disruption

Chapter 8 Cytotoxicity and metabolic stress induced by acetaldehyde in intestinal LS174T globlet-like cells

Chapter 9 Short chain fatty acids activate adenosine monophosphate-activated protein kinase and ameliorate ethanol-induced intestinal barrier dysfunction in Caco- 2 cell monolayers

Chapter 10 General discussion

Summary

Samenvatting

Acknowledgement

Curriculum Vitae 



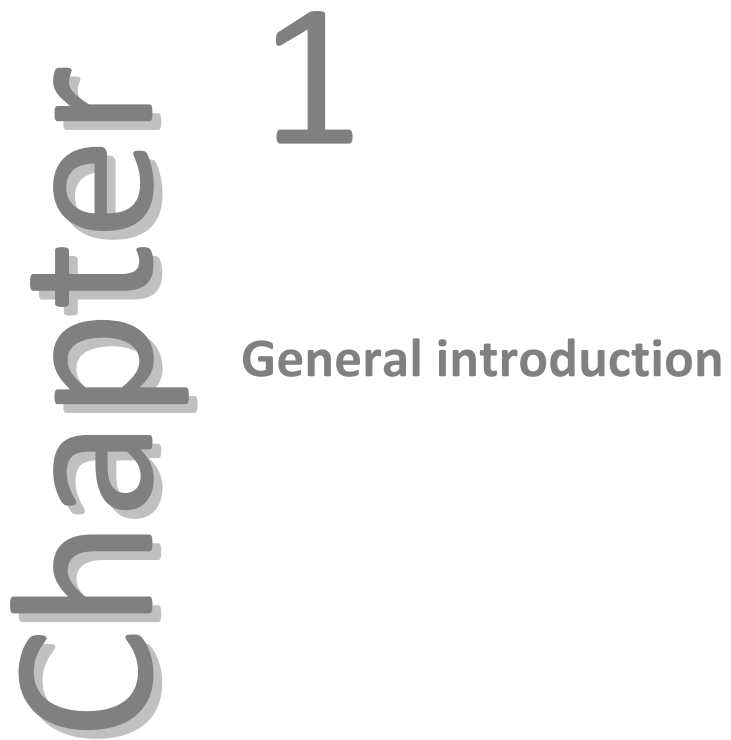




\section{Ethanol (ethyl alcohol) consumption}

Ethanol $\left(\mathrm{C}_{2} \mathrm{H}_{5} \mathrm{OH}\right)$, the main constituent of alcohol containing beverages, is by far the most commonly used 'stimulant' or 'drug' ${ }^{1}$. Ethanol consumption is increasing worldwide ${ }^{2}$ and is a major risk factor for several chronic and malignant diseases (e.g. liver and pancreatic diseases and colorectal carcinoma) in the Western Pacific, America and in Europe ${ }^{2,3}$. Therefore, ethanol abuse and its negative health and social consequences represent major threats to global public health ${ }^{4,5}$. The average amount of ethanol consumed and drinking patterns vary between geographical areas, being highest in Europe and Northern America, and lowest in the Eastern Mediterranean countries $^{2}$. According to estimates of the World Health Organization (WHO), about two billion people worldwide consume alcoholic drinks on a regular basis. In 2005, the global level of alcohol consumption was equal to 6.13 litres of pure alcohol per person aged 15 years or older per capita per year ${ }^{2}$. The amount of ethanol in a standard drink varies between countries, but on average, one standard drink contains approximately $12 \mathrm{~g}$ ethanol, which is provided by $360 \mathrm{ml}$ of beer, $150 \mathrm{ml}$ of wine, or $45 \mathrm{ml}$ of liquor ${ }^{6,7}$. Although low to moderate consumption (1-2 standard drinks per day; $<50 \mathrm{~g} /$ day) may decrease the risk of cardiovascular diseases ${ }^{8,9}$, moderate ethanol intake has been associated with increased risk of many gastrointestinal (GI) disorders including alcoholic liver disease (ALD) and GI carcinogenesis ${ }^{10}$. Furthermore, ALD remains a major cause of morbidity and mortality worldwide ${ }^{10}$, with a complex pathophysiology that involves many contributing factors, including genetics, gender, ethnicity and consumption patterns ${ }^{11,12}$.

\section{Ethanol absorption and metabolism}

Following oral intake, ethanol is rapidly absorbed in the upper GI tract, mainly in the stomach and small intestine, and is thereafter distributed throughout body fluids in direct proportion to blood levels ${ }^{13}$. Its absorption is influenced by several factors including concentration in the beverage, gender, body composition, medications used, genetic makeup and ethnicity, resulting in large interindividual variations in ethanol metabolism ${ }^{14}$. Ethanol is metabolized, mainly in the liver via oxidative and nonoxidative pathways. Oxidatively, ethanol is converted into acetaldehyde by the cytosolic enzyme alcohol dehydrogenase $(A D H)$, the microsomal ethanol oxidizing system/cytochrome P450 2E1/CYP 2 E1 and peroxisomal catalase (Figure 1.1) ${ }^{15}$. Acetaldehyde is highly reactive, toxic and carcinogenic. Fast elimination of acetaldehyde occurs mainly in the liver via its oxidation into acetate, primarily by mitochondrial aldehyde dehydrogenase (ALDH), which finally enters the carboxylic cycle to be oxidized into carbon dioxide and water (Figure 1.1) ${ }^{15}$. In the liver, only the cytosolic ALDH1 and the mitochondrial ALDH2 isozymes metabolize acetaldehyde ${ }^{16,17}$. Interindividual variations in rate of absorption, distribution, and elimination con- 
tribute significantly to clinical conditions observed after ethanol consumption ${ }^{18,19}$. In addition to gender and drinking pattern, these variations have also been attributed to genetic factors. For example, genetic polymorphism of the ALDH2 gene is present in about $50 \%$ of Asians, resulting in the allelic variants $A L D H 2 * 1$ and $A L D H 2 * 2$ which is virtually inactive ${ }^{20,}{ }^{21}$. Non-oxidatively, ethanol is metabolized into either phosphatidylethanol via phospholipase $D^{15}$ or into fatty acid ethyl esters (FAEEs) after esterification with fatty acids by FAEE synthase (Figure 1.1) ${ }^{22,23}$. Compared to the oxidative, non-oxidative ethanol metabolism is minimal but can be maximal when oxidative pathways are inhibited in long-term ethanol abuse ${ }^{5}$. The role of FAEEs and phosphatidylethanol on ethanol-induced gastrointestinal epithelial damage remains to be further investigated.

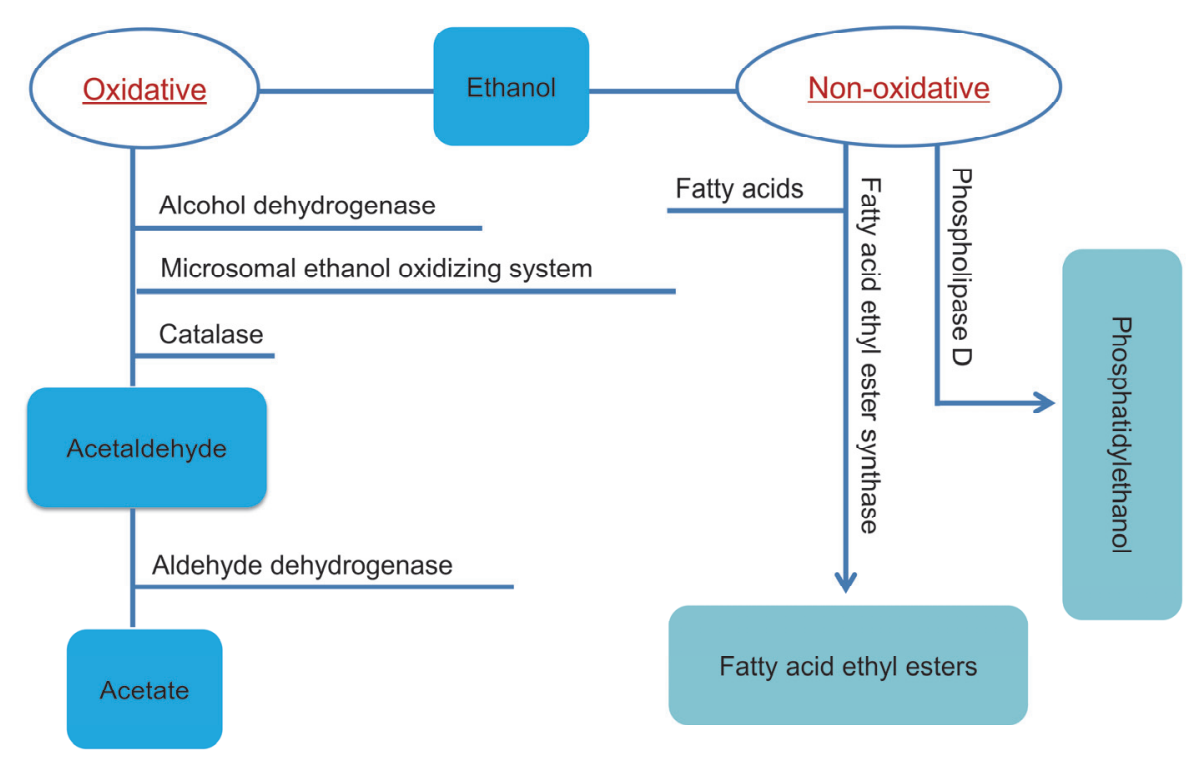

Figure 1.1 Oxidative and non-oxidative pathways of ethanol metabolism.

\section{Ethanol-related GI diseases}

Ethanol can reach all parts of the GI tract, either via oral consumption or via diffusion from the vascular space, and is metabolized throughout its length. Therefore, ethanol and its metabolites are injurious to the whole Gl tract and can influence several functions including absorption ${ }^{24}$ and motility ${ }^{25-27}$. Ethanol consumption has been linked to a number of $\mathrm{Gl}$ cancers including oesophageal, pancreatic and colorectal 
carcinoma $^{28}$. Although ethanol is not a major carcinogenic, it promotes carcinogenesis through its local effects or via its metabolites, especially by the mutagenic acetaldehyde $^{29}$. Moreover, ethanol, acetaldehyde, and FAEEs have been implicated in cellular damage associated with ethanol-induced pancreatitis ${ }^{30}$ and alcoholic liver disease $(A L D)^{31}$. ALD remains an important cause of morbidity and mortality worldwide $^{10}$, with a complex pathophysiology encompassing factors related to genetics, gender, ethnicity, consumption patterns affecting absorption and metabolism of ethanol ${ }^{11,12}$. In addition to direct deleterious effects on hepatocytes ${ }^{32}$, ethanol and acetaldehyde-induced intestinal barrier dysfunction and subsequent translocation of gut-derived endotoxin into the portal circulation is considered one of the key mechanisms involved in the pathogenesis of $A L D^{33}$.

\section{Intestinal barrier function}

Intestinal mucosal barrier consists of a monolayer of epithelial cells, covered by a mucus layer underlined by numerous immune cells present in the lamina propria, and is essential for maintenance of intestinal homeostasis and host health ${ }^{34}$. The mucus coat is composed of mucin glycoproteins, trefoil factors and other proteins secreted by intestinal epithelium such as secretory immunoglobulin $A(\operatorname{sg} A)$ and acts as extrinsic barrier that limits intestinal colonization, and thereby restricting bacterial attachment to the epithelium and preventing mechanical damage ${ }^{35}$. The barrier is regulated by intercellular apical junctional complex (AJC) of proteins, which permits passive entry of nutrients, ions, and water and restricts paracellular permeability of allergens, bacteria and their products such as endotoxins and peptidoglycans ${ }^{36}$. The AJC consists of tight junctions (TJs) and its subjacent adherens junctions (AJs), which seal the space between epithelial cells ${ }^{37}$ and maintain cell-cell contacts, respectively ${ }^{38}$ (Figure 1.2). The TJs are composed of transmembrane proteins including occludin and claudin family and interact with cytoplasmic plaque proteins such as zonula occludens family (ZO-1, ZO-2, ZO-3) ${ }^{39}$. Zona occludens link the TJs and AJs to cytoskeletal proteins such as microtubules and F-actin ${ }^{40}$ and thereby mediating attachment of the AJC to the perijunctional actomyosin ring, resulting in stabilization of apical junctions dynamics (Figure 1.2$)^{39,41}$. The AJs are composed of the transmembrane protein E-cadherin which associates with the cytoplasmic proteins $\mathrm{P} 120-, \alpha-, \beta$-catenin (Figure $1.2)^{38}$. In addition to the TJ and AJ, intestinal epithelium is coated by a thick mucus layer secreted by goblet cells ${ }^{42,43}$.

The AJC is highly dynamic structure and can be rapidly and reversibly disassembled by various physiological and pathological stimuli ${ }^{43}$ and during epithelial to mesenchymal transition ${ }^{44}$. The assembly of the TJ is modulated by a number of intracellular second messengers such as intracellular calcium ${ }^{45}$ and signaling pathways including myosin 
light chain kinase $(\mathrm{MLCK})^{46}$, mitogen-activated protein kinases (MAPKs) ${ }^{47}$ and Rho GTPases $^{48}$.

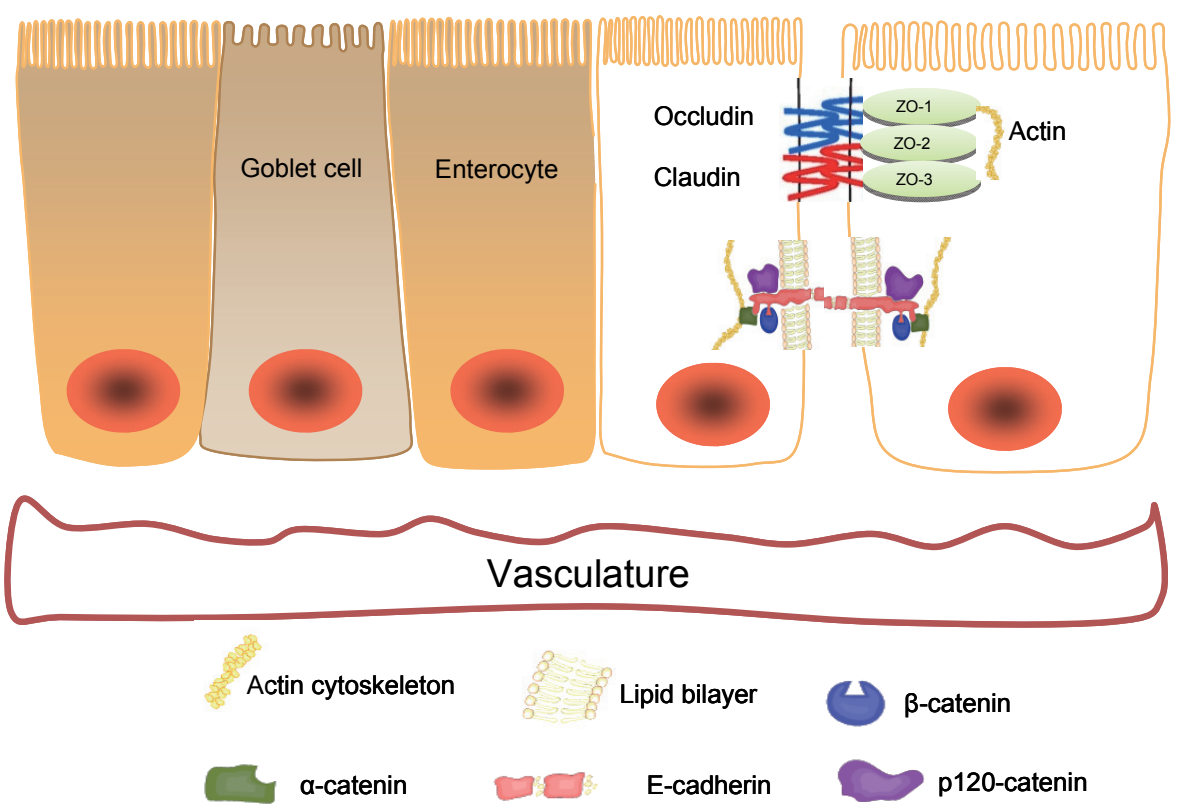

Figure 1.2 Schematic representation of the intestinal epithelial barrier.

Intestinal epithelial barrier integrity can be assessed by evaluating structure and function of the TJs. The morphological structure of the TJs can be examined in intestinal mucosal biopsies using freeze fracture $^{49}$ and transmission electron microscopy ${ }^{50}$. Furthermore, expression of TJs and its associated proteins in tissue samples and cell cultures can be evaluated at the protein level by immunohistochemistry, immunocytochemistry and Western blotting, and at gene level by means of quantitative polymerase chain reaction ${ }^{51,52}$. In addition to structural analyses, functionality of TJs are often used to evaluate intestinal epithelial barrier integrity, by culturing intestinal epithelial cells in vitro or mounting intestinal mucosa in Ussing chambers ex vivo and subsequent measurement of transepithelial electrical resistance (TEER) and/or permeation of specific markers such as fluorescein isothiocyanate-labeled dextran 4 KD (FITC-D4) ${ }^{53,54}$. In vivo, permeability of intestinal epithelial barrier can be determined non-invasively by measuring urinary recovery of orally administered inert test markers (sugars including monosaccharides and disaccharides, i.e. rhamnose and lactulose, respectively, polyethylene glycol, radioactively labelled chromium-EDTA) or by assessing the sequelae of barrier dysfunction, such as changes in serum/plasma D-lactate ${ }^{55}$ and endotoxins levels ${ }^{55-58}$. 
Because of individual variation in pre- and post-absorption processes, calculation of the ratio of urinary recovery of two marker molecules is considered to be a better measure of intestinal permeability than the urinary recovery of only a single molecule. Therefore, a solution of two different-sized sugars is used to assess changes in intestinal permeability. Measuring intestinal permeability by determining the urinary lactulose/rhamnose and sucralose/erythritol excretion ratios is thought to be a valid index for evaluation of small intestinal and colon permeability, respectively, and to discriminate significantly between normal and moderately increased permeability in healthy humans with sufficient sensitivity ${ }^{59}$.

\section{Ethanol and intestinal barrier function}

Evidence on injurious effects of ethanol on intestinal epithelial integrity has largely been obtained in animal and in vitro models. For example, chronic ethanol gavage in rats and in mice ${ }^{60}$ has been demonstrated to increase intestinal permeability to various macromolecules including endotoxin ${ }^{4,61,62}$. In vitro studies carried out in Caco-2 cell monolayers have further confirmed that ethanol induces loss of TJ integrity, thereby disrupting intestinal barrier function ${ }^{63-66}$. In addition, the oxidative metabolite acetaldehyde has also been shown to disrupt the TJ and AJ integrity and consequently, increased intestinal epithelial permeability ${ }^{54,67-69}$. However, effects of ethanol non-oxidative metabolites such as FAEEs on intestinal barrier function are yet to be determined. Furthermore, the majority of the in vitro studies were performed with relatively high concentrations ranging between 200$3000 \mathrm{mmol} / /$ ( $1-15 \%)$ ethanol $^{66,70}$ and 100-700 $\mu \mathrm{mol} / \mathrm{l}$ acetaldehyde ${ }^{71}$.

Studies in humans are limited and have predominantly focused on long-term ethanol consumption and upper GI permeability. These studies have reported that ethanol induces intestinal mucosal damage and increases small intestinal permeability in chronic alcoholics ${ }^{72-76}$. An increase in intestinal permeability following ingestion of $19 \mathrm{~g}$ ethanol has also been reported when polyethylene glycol (PEG) 400 was used as a permeability probe in healthy volunteers ${ }^{72}$. Moreover, moderate ethanol consumption has been reported to increase liver enzyme activities with increasing body mass index (BMI), and thereby increasing the risk of alcohol-related fatty liver disease $^{77}$. Although ethanol is consumed on a daily basis by a large fraction of people, studies on effects of moderate ethanol intake on small and large intestinal barrier function are limited.

The exact mechanism by which ethanol induces intestinal barrier disruption is not fully understood and thought to involve multiple distinct mechanisms ${ }^{32}$. The majority of mechanistic studies have been performed in vitro, demonstrating that ethanol induces intestinal barrier dysfunction via mechanisms involving inducible nitric oxide 
synthase (iNOS)-induced oxidative stress and activation of myosin light chain kinase $(\mathrm{MLCK})^{66}$ with subsequent disruption of the TJ and F-actin cytoskeleton ${ }^{64,78}$. Further mechanistic studies have shown that acetaldehyde-induced intestinal barrier dysfunction is associated with redistribution of ZO1 and occludin, E-cadherin and $\beta$-catenin and reorganization of actin cytoskeleton ${ }^{67,68}$. However, the precise mechanisms involved in effects of the non-oxidative metabolites and moderate ethanol consumption on $\mathrm{TJ}$ integrity remain elusive.

\section{Aims and outline of the thesis}

Ethanol is widely consumed, especially in moderate dosages, and is a well-known risk factor for several GI and liver diseases. Ethanol-induced intestinal mucosal damage and subsequent increase in intestinal permeability ${ }^{53,61,74,76,79,80}$ is one of the important mechanisms by which ethanol contributes to the pathogenesis of $\operatorname{ALD}^{33,72,73,75,76}$ and may enhance susceptibility to carcinogens. The main goals of the studies described in this thesis were to evaluate effects of administration of moderate ethanol dosage on small and large intestinal permeability in humans, and to study effects of ethanol and its metabolites including acetaldehyde and FAEEs on intestinal epithelial barrier function, aiming to elucidate possible mechanisms in vivo and in vitro. As important determinants of barrier integrity, functionality of the TJs is a key object of the studies reported in this thesis.

First, in chapter 2, the recent knowledge regarding ethanol metabolism in the GI tract and its effects on intestinal barrier function have been reviewed. Next, effects of a moderate ethanol dose (i.e. equivalent to $20 \mathrm{~g} \sim 2$ standard drinks) on GI permeability were investigated in healthy volunteers in a randomized placebo controlled crossover designed study. After intraduodenal administration of ethanol, effects on small intestinal and colon permeability, as well as on $\mathrm{TJ}$ in duodenal biopsies were evaluated (chapter 3), including additional in vitro experiments exploring involvement of mitogen activated protein kinase. Chapter 4 presents an in vitro study comparing effects of different concentrations of ethanol and its oxidative metabolite acetaldehyde on epithelial integrity, using a newly established three dimensional (3D) intestinal cell culture model. In this study, the role of hyperacetylation of microtubules on ethanol- and acetaldehyde-induced barrier dysfunction was also examined. Using the same model, effects of the non-oxidative metabolites FAEEs (i.e. ethyl ester oleate and ethyl ester palmitate) on TJ integrity and cellular oxidative stress were investigated (chapter 5). Thereafter, role of the epithelial to mesenchymal transition factor Snail on acetaldehyde-induced disruption of the TJ in the conventional two dimensional (2D) cell culture model of Caco-2 cells is reported in chapter 6 . Besides oxidative stress and intracellular calcium, Rho kinase has also been reported to modulate epithelial barrier function. Chapter 7 describes the role of intracellular calcium in Rho kinase-mediated ethanol-induced barrier dysfunction. In 
addition to the TJ structure and functionality, mucus secreted by goblet cell is another important part of the mucosal barrier that could be affected by ethanol. In chapter 8 effects of acetaldehyde on cellular metabolic stress and cytotoxicity in goblet cells are reported. Since ethanol and acetaldehyde are noxious to the colon and increased short chain fatty acids (SCFAs) production in the large intestine is suggested to be beneficial for colon homeostasis, an in vitro study on effects of SCFAs on ethanolinduced barrier disruption is described in chapter 9. Finally, the major findings of all studies are reviewed and integrated, and implications for future research are discussed in chapter 10. 


\section{References}

1. Silva JM, Mendez MM, Gonzalo $\mathrm{M}$, et al. [J-curve between alcohol consumption and carotid atherosclerosis in patients with dyslipidemia]. An Med Interna 2000;17:582-7.

2. WHO Global Status Report on Alcohol 2004. Geneva: Department of Mental Health and Substance Abuse: World Health Organisation, 2004.

3. Rehm J, Rehn N, Room R, et al. The global distribution of average volume of alcohol consumption and patterns of drinking. Eur Addict Res 2003;9:147-56.

4. Rehm J, Gmel G, Sempos CT, et al. Alcohol-related morbidity and mortality. Alcohol Res Health 2003; 27:39-51.

5. Rehm J, Room R, Monteiro M, et al. Alcohol as a risk factor for global burden of disease. Eur Addict Res 2003;9:157-64.

6. Zakhari S, Gordis E. Moderate drinking and cardiovascular health. Proc Assoc Am Physicians 1999;111:148-58.

7. Gu JW, Elam J, Sartin A, et al. Moderate levels of ethanol induce expression of vascular endothelial growth factor and stimulate angiogenesis. Am J Physiol Regul Integr Comp Physiol 2001;281:R365-72.

8. Kiechl S, Willeit J, Rungger G, et al. Alcohol consumption and atherosclerosis: what is the relation? Prospective results from the Bruneck Study. Stroke 1998;29:900-7.

9. Sacco RL, Elkind M, Boden-Albala B, et al. The protective effect of moderate alcohol consumption on ischemic stroke. JAMA 1999;281:53-60.

10. Mandayam S, Jamal MM, Morgan TR. Epidemiology of alcoholic liver disease. Semin Liver Dis 2004;24: 217-32.

11. Deltenre P, Mathurin P. Epidemiology of alcoholic liver disease and new challenges. Gastroenterol Clin Biol 2009;33:1147-50.

12. Gramenzi A, Caputo F, Biselli M, et al. Review article: alcoholic liver disease--pathophysiological aspects and risk factors. Aliment Pharmacol Ther 2006;24:1151-61.

13. Crabb DW, Bosron WF, Li TK. Ethanol metabolism. Pharmacol Ther 1987;34:59-73.

14. Lieber CS. Metabolism of alcohol. Clin Liver Dis 2005;9:1-35.

15. Zakhari S. Overview: how is alcohol metabolized by the body? Alcohol Res Health 2006;29:245-54.

16. Yin SJ, Chou FJ, Chao SF, et al. Alcohol and aldehyde dehydrogenases in human esophagus: comparison with the stomach enzyme activities. Alcohol Clin Exp Res 1993;17:376-81.

17. Dong YJ, Peng TK, Yin SJ. Expression and activities of class IV alcohol dehydrogenase and class III aldehyde dehydrogenase in human mouth. Alcohol 1996;13:257-62.

18. Li TK, Yin SJ, Crabb DW, et al. Genetic and environmental influences on alcohol metabolism in humans. Alcohol Clin Exp Res 2001;25:136-44.

19. Freudenheim JL, Ambrosone CB, Moysich KB, et al. Alcohol dehydrogenase 3 genotype modification of the association of alcohol consumption with breast cancer risk. Cancer Causes Control 1999;10: 369-77.

20. Gmel G, Heeb JL, Rehm J. Research and the alcohol industry. Addiction 2003;98:1773-4; discussion 1774-5.

21. Li TK, Bosron WF. Genetic variability of enzymes of alcohol metabolism in human beings. Ann Emerg Med 1986;15:997-1004.

22. Lange LG. Non-oxidative ethanol metabolism by fatty acid ethyl ester synthase. Alcohol Alcohol Suppl 1991;1:103-5.

23. Best CA, Laposata M. Fatty acid ethyl esters: toxic non-oxidative metabolites of ethanol and markers of ethanol intake. Front Biosci 2003;8:e202-17.

24. Pfeiffer $\mathrm{A}$, Schmidt $\mathrm{T}$, Vidon $\mathrm{N}$, et al. Absorption of a nutrient solution in chronic alcoholics without nutrient deficiencies and liver cirrhosis. Scand J Gastroenterol 1992;27:1023-30.

25. Mezey E, Seitz HK, Kommerell B, Baaklini GY, et al. Effect of ethanol on intestinal morphology, metabolism, and function. Alcohol-Related Diseases in Gastroenterology 1985:342-60.

26. Bouchoucha $M$, Nalpas $B$, Berger $M$, et al. Recovery from disturbed colonic transit time after alcohol withdrawal. Dis Colon Rectum 1991;34:111-4.

27. Robles EA, Mezey $\mathrm{E}$, Halsted $\mathrm{CH}$, et al. Effect of ethanol on motility of the small intestine. Johns Hopkins Med J 1974;135:17-24. 
28. Bujanda L. The effects of alcohol consumption upon the gastrointestinal tract. Am J Gastroenterol 2000;95:3374-82.

29. Janszky I, Mukamal KJ, Orth-Gomer K, et al. Alcohol consumption and coronary atherosclerosis progression--the Stockholm Female Coronary Risk Angiographic Study. Atherosclerosis 2004;176: 311-9.

30. Vonlaufen A, Wilson JS, Pirola RC, et al. Role of alcohol metabolism in chronic pancreatitis. Alcohol Res Health 2007;30:48-54.

31. Rao RK, Seth A, Sheth P. Recent Advances in Alcoholic Liver Disease I. Role of intestinal permeability and endotoxemia in alcoholic liver disease. Am J Physiol Gastrointest Liver Physiol 2004;286:G881-4.

32. Purohit V, Bode JC, Bode C, et al. Alcohol, intestinal bacterial growth, intestinal permeability to endotoxin, and medical consequences: Summary of a symposium. Alcohol 2008;42:349-61.

33. Keshavarzian A, Holmes EW, Patel M, et al. Leaky gut in alcoholic cirrhosis: a possible mechanism for alcohol-induced liver damage. Am J Gastroenterol 1999;94:200-7.

34. Mankertz J, Schulzke JD. Altered permeability in inflammatory bowel disease: pathophysiology and clinical implications. Curr Opin Gastroenterol 2007;23:379-83.

35. Phalipon A, Cardona A, Kraehenbuhl JP, et al. Secretory component: a new role in secretory IgAmediated immune exclusion in vivo. Immunity 2002;17:107-15.

36. Matter K, Balda MS. Signalling to and from tight junctions. Nat Rev Mol Cell Biol 2003;4:225-36.

37. Tsukita S, Furuse M, Itoh M. Multifunctional strands in tight junctions. Nat Rev Mol Cell Biol 2001;2: 285-93.

38. Cooper DE, Goff DC, Jr, Bell RA, et al. Is insulin sensitivity a causal intermediate in the relationship between alcohol consumption and carotid atherosclerosis?: the insulin resistance and atherosclerosis study. Diabetes Care 2002;25:1425-31.

39. Van Itallie CM, Anderson JM. The molecular physiology of tight junction pores. Physiology (Bethesda) 2004;19:331-8.

40. Shen L, Weber CR, Raleigh DR, et al. Tight junction pore and leak pathways: a dynamic duo. Annu Rev Physiol 2011;73:283-309.

41. Kao WH, Puddey IB, Boland LL, et al. Alcohol consumption and the risk of type 2 diabetes mellitus: atherosclerosis risk in communities study. Am J Epidemiol 2001;154:748-57.

42. Deplancke B, Gaskins HR. Microbial modulation of innate defense: goblet cells and the intestinal mucus layer. Am J Clin Nutr 2001;73:1131S-1141S.

43. Temelkova-Kurktschiev T, Henkel E, Koehler C, et al. Light-to-moderate alcohol consumption, risk factor profile and early atherosclerosis: the RIAD study. Atherosclerosis 2001;156:239-40.

44. Eigenbrodt ML, Mosley TH, Jr., Hutchinson RG, et al. Alcohol consumption with age: a cross-sectional and longitudinal study of the Atherosclerosis Risk in Communities (ARIC) study, 1987-1995. Am J Epidemiol 2001;153:1102-11.

45. Samak G, Narayanan D, Jaggar JH, et al. CaV1.3 channels and intracellular calcium mediate osmotic stress-induced $\mathrm{N}$-terminal c-Jun kinase activation and disruption of tight junctions in Caco-2 Cell monolayers. J Biol Chem 2011;286:30232-43.

46. Blair SA, Kane SV, Clayburgh DR, et al. Epithelial myosin light chain kinase expression and activity are upregulated in inflammatory bowel disease. Lab Invest 2006;86:191-201.

47. Samak G, Aggarwal S, Rao RK. ERK is involved in EGF-mediated protection of tight junctions, but not adherens junctions, in acetaldehyde-treated Caco-2 cell monolayers. Am J Physiol Gastrointest Liver Physiol 2011;301:G50-9.

48. Gopalakrishnan S, Raman N, Atkinson SJ, et al. Rho GTPase signaling regulates tight junction assembly and protects tight junctions during ATP depletion. Am J Physiol 1998;275:C798-809.

49. Staehelin LA, Mukherjee TM, Williams AW. Freeze-etch appearance of the tight junctions in the epithelium of small and large intestine of mice. Protoplasma 1969;67:165-84.

50. Goodenough DA, Revel JP. A fine structural analysis of intercellular junctions in the mouse liver. J Cell Biol 1970;45:272-90.

51. Tang VW. Proteomic and bioinformatic analysis of epithelial tight junction reveals an unexpected cluster of synaptic molecules. Biol Direct 2006;1:37.

52. Noth R, Lange-Grumfeld J, Stuber E, et al. Increased intestinal permeability and tight junction disruption by altered expression and localization of occludin in a murine graft versus host disease model. BMC Gastroenterol 2011;11:109. 
53. Ferrier L, Berard F, Debrauwer L, et al. Impairment of the intestinal barrier by ethanol involves enteric microflora and mast cell activation in rodents. Am J Pathol 2006;168:1148-54.

54. Rao RK. Acetaldehyde-induced increase in paracellular permeability in Caco-2 cell monolayer. Alcohol Clin Exp Res 1998;22:1724-30.

55. Grootjans J, Thuijls G, Verdam F, et al. Non-invasive assessment of barrier integrity and function of the human gut. World J Gastrointest Surg 2010;2:61-9.

56. Menzies IS. Intestinal permeability in coeliac disease. Gut 1972;13:847.

57. Menzies IS, Laker MF, Pounder R, et al. Abnormal intestinal permeability to sugars in villous atrophy. Lancet 1979;2:1107-9.

58. Bjarnason I, MacPherson A, Hollander D. Intestinal permeability: an overview. Gastroenterology 1995;108:1566-81.

59. van Nieuwenhoven MA, Geerling BJ, Deutz NE, et al. The sensitivity of the lactulose/rhamnose gut permeability test. Eur J Clin Invest 1999;29:160-5.

60. Lambert JC, Zhou Z, Wang L, et al. Prevention of alterations in intestinal permeability is involved in zinc inhibition of acute ethanol-induced liver damage in mice. J Pharmacol Exp Ther 2003;305:880-6.

61. Worthington BS, Meserole L, Syrotuck JA. Effect of daily ethanol ingestion on intestinal permeability to macromolecules. Am J Dig Dis 1978;23:23-32.

62. Mathurin P, Deng QG, Keshavarzian A, et al. Exacerbation of alcoholic liver injury by enteral endotoxin in rats. Hepatology 2000;32:1008-17.

63. Banan A, Fields JZ, Decker $\mathrm{H}$, et al. Nitric oxide and its metabolites mediate ethanol-induced microtubule disruption and intestinal barrier dysfunction. J Pharmacol Exp Ther 2000;294:997-1008.

64. Banan A, Choudhary S, Zhang Y, et al. Ethanol-induced barrier dysfunction and its prevention by growth factors in human intestinal monolayers: evidence for oxidative and cytoskeletal mechanisms. J Pharmacol Exp Ther 1999;291:1075-85.

65. Banan A, Smith GS, Deshpande Y, et al. Prostaglandins protect human intestinal cells against ethanol injury by stabilizing microtubules: role of protein kinase $C$ and enhanced calcium efflux. Dig Dis Sci 1999;44:697-707.

66. Ma TY, Nguyen D, Bui V, et al. Ethanol modulation of intestinal epithelial tight junction barrier. Am J Physiol 1999;276:G965-74.

67. Sheth $\mathrm{P}$, Seth $\mathrm{A}$, Thangavel $\mathrm{M}$, et al. Epidermal growth factor prevents acetaldehyde-induced paracellular permeability in Caco-2 cell monolayer. Alcohol Clin Exp Res 2004;28:797-804.

68. Seth A, Basuroy S, Sheth P, et al. L-Glutamine ameliorates acetaldehyde-induced increase in paracellular permeability in Caco-2 cell monolayer. Am J Physiol Gastrointest Liver Physiol 2004; 287:G510-7.

69. Atkinson KJ, Rao RK. Role of protein tyrosine phosphorylation in acetaldehyde-induced disruption of epithelial tight junctions. Am J Physiol Gastrointest Liver Physiol 2001;280:G1280-8.

70. Asai K, Buurman WA, Reutelingsperger CP, et al. Modular effects of estradiol on ethanol-induced apoptosis in human intestinal epithelial cells. Scand J Gastroenterol 2005;40:326-35.

71. Rao RK. Acetaldehyde-induced barrier disruption and paracellular permeability in Caco-2 cell monolayer. Methods Mol Biol 2008;447:171-83.

72. Robinson GM, Orrego $\mathrm{H}$, Israel $\mathrm{Y}$, et al. Low-molecular-weight polyethylene glycol as a probe of gastrointestinal permeability after alcohol ingestion. Dig Dis Sci 1981;26:971-7.

73. Bode C, Kugler V, Bode JC. Endotoxemia in patients with alcoholic and non-alcoholic cirrhosis and in subjects with no evidence of chronic liver disease following acute alcohol excess. J Hepatol 1987;4: 8-14.

74. Keshavarzian A, Fields JZ, Vaeth J, et al. The differing effects of acute and chronic alcohol on gastric and intestinal permeability. Am J Gastroenterol 1994;89:2205-11.

75. Bjarnason I, Peters TJ, Wise RJ. The leaky gut of alcoholism: possible route of entry for toxic compounds. Lancet 1984;1:179-82.

76. Parlesak A, Schafer C, Schutz T, et al. Increased intestinal permeability to macromolecules and endotoxemia in patients with chronic alcohol abuse in different stages of alcohol-induced liver disease. J Hepatol 2000;32:742-7.

77. Fanning AS, Jameson BJ, Jesaitis LA, et al. The tight junction protein ZO-1 establishes a link between the transmembrane protein occludin and the actin cytoskeleton. J Biol Chem 1998;273:29745-53. 
78. McCarroll JA, Phillips PA, Park S, et al. Pancreatic stellate cell activation by ethanol and acetaldehyde: is it mediated by the mitogen-activated protein kinase signaling pathway? Pancreas 2003;27:150-60.

79. Keshavarzian A, Farhadi A, Forsyth $\mathrm{CB}$, et al. Evidence that chronic alcohol exposure promotes intestinal oxidative stress, intestinal hyperpermeability and endotoxemia prior to development of alcoholic steatohepatitis in rats. J Hepatol 2009;50:538-547.

80. Millan MS, Morris GP, Beck IT, et al. Villous damage induced by suction biopsy and by acute ethanol intake in normal human small intestine. Dig Dis Sci 1980;25:513-25. 


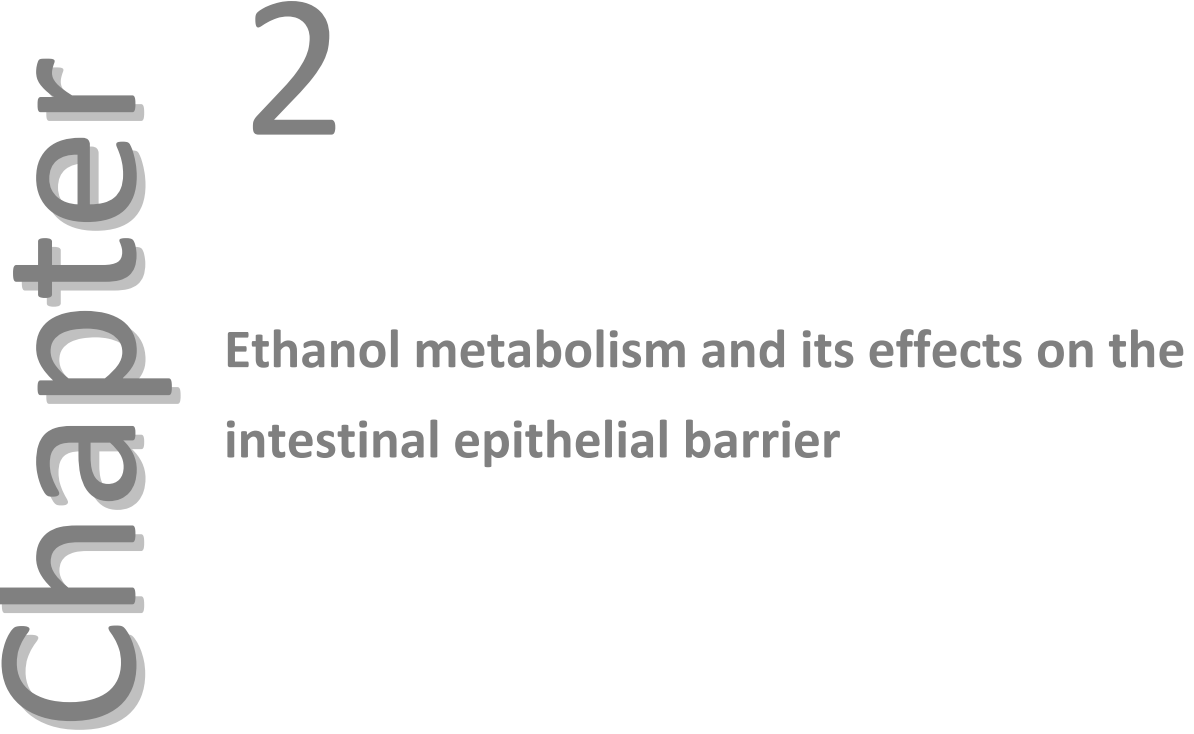

Elhaseen Elamin, Ad Masclee, Jan Dekker and Daisy Jonkers

Nutrition Reviews 2013:71:483-499 


\section{Abstract}

Ethanol is widely consumed and is associated with an increasing global health burden. Several reviews have addressed the effects of ethanol and its oxidative metabolite, acetaldehyde, on the gastrointestinal tract (GI), focusing on carcinogenic effects or alcoholic liver disease. However, both the oxidative and the nonoxidative metabolites of ethanol can affect the epithelial barrier of the small and large intestines, thereby contributing to $\mathrm{Gl}$ and liver diseases. This review outlines the possible mechanisms of ethanol metabolism as well as the effects of ethanol and its metabolites on the intestinal barrier. Limited studies in humans and supporting in vitro data have indicated that ethanol as well as mainly acetaldehyde can increase small intestinal permeability. Limited evidence also points to increased colon permeability following exposure to ethanol or acetaldehyde. In vitro studies have provided several mechanisms for disruption of the epithelial barrier, including activation of different cell-signaling pathways, oxidative stress, and remodeling of the cytoskeleton. Modulation via intestinal microbiota, however, should also be considered.

In conclusion, ethanol and its metabolites may act additively or even synergistically in vivo. Therefore, in vivo studies investigating the effects of ethanol and its byproducts on permeability of the small and large intestines are warranted. 


\section{Introduction}

Beverages containing ethanol (i.e. ethyl alcohol) are widely consumed in many parts of the world, creating an increasing global health burden. It has been estimated that around two billion people drink ethanol on a regular basis ${ }^{1}$. Ethanol consumption has long been recognized as a major cause of liver disease ${ }^{2-4}$, but it can also affect the gastrointestinal (GI) tract and is associated with the development of oral, esophageal, and colorectal cancers ${ }^{5}$. Ethanol as well as its metabolites can cause damage that includes decreased intestinal motility, cytotoxic and mutagenic effects ${ }^{5-7}$. Another important effect is the ethanol-induced disruption of the epithelial barrier of the GI tract $^{\underline{8}}$. Studies performed in humans $s^{9,10}$, but mostly in animals ${ }^{11-13}$, have shown that both short- and long-term ethanol administration can result in increased intestinal permeability, which will ultimately enhance the translocation of luminal antigens (e.g. bacteria and endotoxins) into the portal circulation ${ }^{14,15}$, can activate Kupffer cells, subsequently leading to cytokine release, which results in hepatocellular injury and, consequently, alcoholic liver disease $(A L D)^{16,17}$. Data from human and animal studies indicate that increased intestinal permeability is also involved in inflammatory intestinal disorders such as inflammatory bowel disease ${ }^{18}$ and irritable bowel syndrome $^{19}$. Finally, decreased epithelial barrier function can result in increased susceptibility to carcinogens and thereby may contribute to the increased risk of alcohol-related cancers of the GI tract $^{20-23}$.

Studies on the effects of ethanol intake on the intestinal epithelial barrier often focus on the small intestine, but ethanol and its metabolites can also reach the large intestine, depending on dosage, absorption, and metabolism ${ }^{24}$. Ethanol can be metabolized oxidatively and nonoxidatively, resulting in acetaldehyde, fatty acid ethyl esters (FAEEs), and phosphatidylethanol (PEth) ${ }^{25}$. Many previous reviews have addressed the effects of ethanol and its main metabolite, acetaldehyde, on the GI tract, focusing on either carcinogenic effects or ALD. However, reviews on the effects of ethanol and all its (oxidative and nonoxidative) metabolites on small and large intestinal barrier function, as well as possible mechanisms of action, are limited.

This review aims to provide a broader understanding of the effects of ethanol and its oxidative and nonoxidative metabolites on intestinal barrier function. First, ethanol absorption and metabolism will be discussed, with a special focus on the GI tract. Subsequently, the effects of methanol and its metabolites on small and large intestinal barrier function, along with possible mechanisms of action, will be reviewed. 


\section{Absorption and metabolism of ethanol}

Pharmacokinetic studies have shown large individual variations in the absorption, distribution, and elimination of ethano $\left.\right|^{26,27}$. After oral ingestion, ethanol is absorbed from the GI tract by simple diffusion due to its small molecular size, moderate lipid solubility, and excellent water solubility ${ }^{28}$. Minimal absorption occurs in the mouth and esophagus, and about $20 \%$ and $70 \%$ is absorbed through the stomach and the proximal small intestine, respectively, indicating that the majority of ingested ethanol is absorbed before it reaches the colon ${ }^{29,30}$. A small proportion of ethanol is excreted unchanged: $1-5 \%$ via the lungs, $0.1-0.5 \%$ in sweat, and $0.5-2 \%$ in urine ${ }^{30,31}$. The rate of ethanol absorption in the $\mathrm{Gl}$ tract depends on several factors, including rate of gastric emptying, sex body mass index, presence of food in the stomach, and ethanol dosage and concentration ${ }^{32,33}$. After being absorbed, ethanol reaches the circulation and is rapidly distributed throughout the body fluids, with the rate of distribution related mainly to the water content of various tissues and organs ${ }^{32}$. Therefore, in the terminal ileum and colon, ethanol concentrations approximate those in blood ${ }^{24,34,35}$. In general, the body water content is lower in females, which contributes to higher blood ethanol concentrations in women than in men after ingestion of similar doses per kilogram of body weight ${ }^{36,37}$.

\section{Oxidative metabolism of ethanol}

Although the majority of absorbed ethanol (i.e. 90-98\%) is metabolized in the liver, metabolism also occurs in the tissues of the Gl tract, including the oral cavity, the esophagus, the stomach, and the small and large intestines ${ }^{30,38-41}$. Ethanol is metabolized oxidatively into acetaldehyde by alcohol dehydrogenase (ADH), which is located in the cytosol of hepatocytes, by the microsomal ethanol oxidizing system (MEOS) cytochrome P450 2E1 (CYP2E1) in the microsomes, and by catalase in the peroxisomes (Figure 2.1) ${ }^{25,30}$. Of these, ADH is the main enzyme involved, and 10 isoenzymes (grouped into 5 classes) with varying kinetic properties, substrates specificities, and tissue distributions have been reported (Table 2.1) $)^{25,30,42-44}$. Class I $\mathrm{ADH}$ enzymes (with a low $\mathrm{Km}$ ) are highly expressed in the liver, but ADH expression has also been reported in intestinal epithelial cells, being higher in the villous tip than in the crypt region ${ }^{45}$. The mucosa of the oral cavity, esophagus, and stomach is characterized by a high expression of class IV $\mathrm{ADH}^{46-48}$. The esophagus has the highest $A D H$ activity in the Gl tract, similar to that of the liver and approximately four times that of the stomach ${ }^{49}$. In small and large intestinal mucosa, class I ADH is predominant, with a $\mathrm{Km}$ of $1-2 \mathrm{mM}$ for ethano ${ }^{39}$. Interestingly, the activity of rectal $A D H$ was found to be comparable to the activity of gastric $A D H$, suggesting that ethanol can be effectively metabolized to acetaldehyde in the rectal mucosa ${ }^{40}$. Evidence from both human and animal studies indicates that ethanol undergoes a first-pass metabolism in the stomach and liver, resulting in a significant decrease in 
the ethanol concentration reaching the blood. An important role of the stomach is indicated by a clear decrease in first-pass metabolism after gastrectomy, after direct intraduodenal ethanol administration ${ }^{50}$, and in subjects with accelerated gastric emptying $^{33}$. Gastric first-pass metabolism occurs predominantly by mucosal class IV $\mathrm{ADH}$ isoenzymes, especially $\sigma-\mathrm{ADH}^{39,51-53}$. The $\sigma-\mathrm{ADH}$ activity is lower in women than in men and, together with the lower body water content of women, contributes to the higher susceptibility of females to the injurious effects of ethanol ${ }^{54-56}$.

The CYP2E1-dependent MEOS, a pathway for ethanol metabolism that is present in several different cells, including hepatocytes, accounts for less than $10 \%$ of ethanol metabolism under normal conditions ${ }^{57}$. The MEOS becomes active only when high concentrations of ethanol $(\mathrm{Km} \mathrm{7-10} \mathrm{mM)} \mathrm{are} \mathrm{present,} \mathrm{and} \mathrm{its} \mathrm{activity} \mathrm{is} \mathrm{increased}$ during chronic alcohol consumption ${ }^{58}$. It plays a key role in the pathogenesis of ethanol-related diseases and carcinogenesis, as it potentiates the generation of free radicals and activates several xenobiotics, including carbon tetrachloride, to form potentially carcinogenic products ${ }^{57,59}$. Catalase is also able to oxidize ethanol, generating acetaldehyde and water in the presence of hydrogen peroxide $\left(\mathrm{H}_{2} \mathrm{O}_{2}\right)^{25}$. Although catalase activity has been observed in human gastric and intestinal mucosa, no data from human studies in vivo are available on its role in ethanol metabolism ${ }^{60}$.

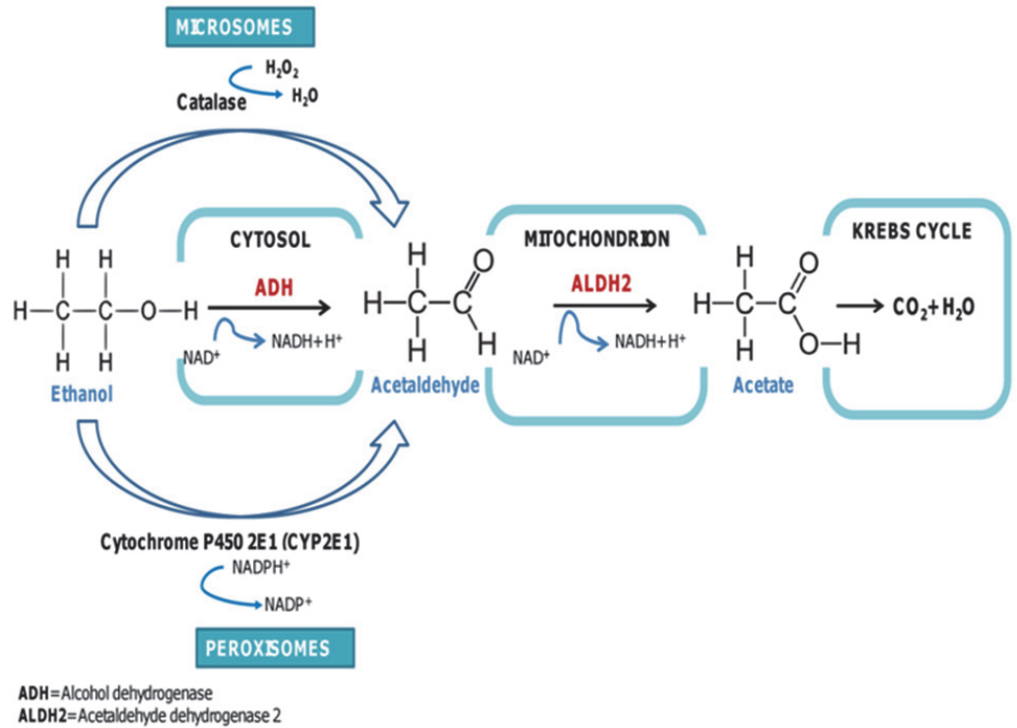

Figure 2.1 Oxidative ethanol metabolism in the liver cells (hepatocytes). Adapted from Zakhari ${ }^{25}$. 
Table 2.1 Kinetic properties and tissue distribution of ADH isoenzymes.

\begin{tabular}{llllll}
\hline Class & Gene & Protein & $\mathrm{Km}(\mathrm{mM})$ & $\mathrm{V}_{\max }\left(\mathrm{min}^{-1}\right)$ & Tissue distribution \\
\hline I & $A D H 1 A^{*}$ & $\alpha$ & 4.0 & 30 & Liver, small and large intestines \\
& $A D H 1 B^{*} 1$ & $\beta 1$ & 0.05 & 4.0 & Liver, lung, kidney \\
& $A D H 1 B^{*} 2$ & $\beta 2$ & 0.9 & 350 & Liver, lung, kidney \\
& $A D H 1 B^{*} 3$ & $B 3$ & 40.0 & 300 & Liver, lung, kidney \\
& $A D H 1 C^{*} 1$ & $\gamma 1$ & 1.0 & 90 & Liver, stomach \\
& $A D H 1 C^{*} 2$ & $\gamma 2$ & 0.6 & 40 & Liver, stomach \\
II & $A D H 4$ & $\pi$ & 30.0 & 20 & Liver \\
III & $A D H 5$ & $\chi$ & $>1,000$ & 100 & Gingiva, tongue \\
IV & $A D H 7$ & $\sigma(\mu)$ & 30.0 & 800 & Liver, esophagus, stomach \\
$\mathrm{V}$ & $A D H 6$ & & Unknown & Unknown & Liver, stomach \\
\hline
\end{tabular}

Acetaldehyde is rapidly metabolized in the liver and, to a lesser extent, in the oral cavity, esophagus, stomach, intestine, and pancreas via oxidation by aldehyde dehydrogenase (ALDH) into acetate (Figure 2.1) (6,47 $^{4}$. Acetate is conjugated to form acetyl coenzyme $A$ and is oxidized, mainly in the skeletal muscles, into $\mathrm{CO}_{2}$ and $\mathrm{H}_{2} \mathrm{O}_{2}{ }^{61}$.

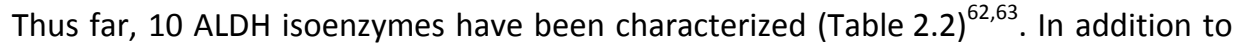
being expressed in the liver, class I ADH isoenzymes are also expressed in gastric epithelial cells and in the small and large intestines. They possess a low $\mathrm{Km}$ (0.6-4 $\mathrm{mM}$ ) and a high maximal velocity. Therefore, they oxidize ethanol, even at low concentrations, at a constant rate ${ }^{25,64}$. Since mucosal ALDH activity is lower than ADH activity in the large intestine, accumulation of the reactive and toxic metabolite, acetaldehyde, is highly expected ${ }^{41,65}$.

Ethanol metabolism varies between different ethnic groups. For instance, the variant allele of $A D H, A D H 1 C^{*} 1$, is more frequent in Asians than in Caucasians or Africans, and Asians metabolize ethanol more readily into acetaldehyde, resulting in accumulation of the latter ${ }^{66,67}$. In addition, the variant allele $A L D H 2 * 2$ which encodes an inactive subunit of the enzyme ALDH2, is dominant and highly prevalent (28-45\%) in Asians but is rare in other ethnicities ${ }^{64}$.

Homozygous carriers of the $A L D H 2 * 2$ allele lack ALDH2 activity and consequently experience strong facial flushing and physical discomfort due to high blood acetaldehyde levels following ethanol consumption ${ }^{68}$. These adverse effects are less severe in heterozygous carriers, who have $10-50 \%$ ALDH2 activity, but these carriers are also at increased risk of developing ethanol-related $\mathrm{Gl}$ cancers because they can metabolize only small amounts of acetaldehyde ${ }^{68-70}$.

Apart from those who consume large amounts of ethanol ( $>80 \mathrm{~g} /$ day) or engage in binge drinking (i.e. more than five drinks [ $>100 \mathrm{~g}]$ within $2 \mathrm{~h}$ ), many people worldwide consume moderate amounts of alcohol ( 2 standard drinks) on a regular (i.e. at least weekly) basis ${ }^{32,71}$. Concentrations of ethanol after consuming two standard drinks (i.e. 
total of $28 \mathrm{~g}$ of ethanol) in luminal contents are found to be approximately $6.5-9.4 \mathrm{~g} / \mathrm{dl}$ in the stomach, $0.38 \mathrm{~g} / \mathrm{dl}$ in the jejunum, and $0.1-0.2 \mathrm{~g} / \mathrm{dl}$ in the ileum as well as in the colon $^{24}$.

Table 2.2 Distribution of ALDH isoenzymes among different body tissues and organs.

\begin{tabular}{llll}
\hline Class & Gene & Allele & Tissue distribution \\
\hline I & ALDH1 & ALDH1 & Liver, stomach, brain (cytosol) \\
II & $A L D H 2$ & $A L D H 2^{* 1}$ & Liver (mitochondrion) \\
& & $A L D H 2^{*} 2$ & Liver, stomach (mitochondrion) \\
III & $A L D H 3$ & $A L D H 3$ & Stomach, lung, liver (cytosol) \\
IV & $A L D H 4$ & $A L D H 5$ & Liver, kidney (mitochondrion) \\
V & $A L D H 5$ & $A L D H 6$ & Testes, liver, brain, stomach (mitochondrion) \\
VI & $A L D H 6$ & $A L D H 7$ & Salivary gland, stomach (cytosol) \\
VII & $A L D H 7$ & $A L D H 8$ & Kidney, lung (microsomes) \\
V1II & $A L D H 8$ & $A L D H 9$ & Parotid gland (microsomes) \\
XI & $A L D H 9$ & $A L D H 10$ & Liver, kidney, muscle (cytosol) \\
$\mathrm{X}$ & $A L D H 10$ & & Liver, heart (mitochondrion) \\
\hline
\end{tabular}

\section{Nonoxidative metabolism of ethanol}

While most studies have focused on oxidative metabolism, ethanol can also be metabolized nonoxidatively via at least two pathways (Figure 2.2). First, ethanol may react with membrane phospholipids. Phospholipase D catalyzes transphosphatidylation, thereby generating PEth, an abnormal phospholipid ${ }^{25,72}$. Since the PEth is not a normal constituent of membranes, it is poorly metabolized and, upon intracellular accumulation, disrupts the cell signaling that normally restricts proliferation in different tissues, including intestinal epithelial cells ${ }^{73}$. With a half-life of 4 days, PEth can be detected in blood and is considered a sensitive biomarker for both long-term and heavy ethanol consumption ( $>50 \mathrm{~g} /$ day) as well as for moderate alcohol consumption $(40 \mathrm{~g} / \text { day })^{74-78}$. Furthermore, PEth has also been detected in rat small intestine ${ }^{79}$ and human colonic tissue ${ }^{80}$. One hour after intake of ethanol $(50-140 \mathrm{~g} / \mathrm{dl})$, serum PEth concentration has been found in the range of $45-138 \mathrm{ng} / \mathrm{ml}$, reaching maximum concentrations of $74-237 \mathrm{ng} / \mathrm{ml}$ after between 3 days and 6 days $^{76}$.

Secondly, ethanol may react with free fatty acids in a reaction catalyzed by fatty acid ethyl ester (FAEE) synthase $e^{25,72}$ and cholesterol esterase ${ }^{72,81}$, generating FAEEs ${ }^{72,82}$. FAEEs can also be generated by transesterification of ethanol and fatty acyl-coenzyme $A$ in a reaction catalyzed by acyl-coenzyme $A$ : ethanol $O$-acyltransferase ${ }^{72,83}$. FAEEs have been detected in hair, heart, leukocytes, brain, adipose tissue, and meconium ${ }^{84-90}$. In the GI tract, FAEEs have been found to accumulate in the pancreas and the liver ${ }^{91,92}$. Since fatty acids and ethanol are absorbed by intestinal mucosa, the intestine is considered to be another site where FAEE synthesis can occur ${ }^{83}$. FAEE synthase activity with subsequent FAEE synthesis has been demonstrated in duodenal mucosa $^{83}$. However, little is known about the concentrations of FAEEs present in the 
intestine after ethanol intake and their local effects on intestinal cell physiology. FAEEs have a half-life ranging between $16 \mathrm{~h}$ and $99 \mathrm{~h}$ and can therefore also be used as biomarkers for prior ethanol ingestion ${ }^{93,94}$.
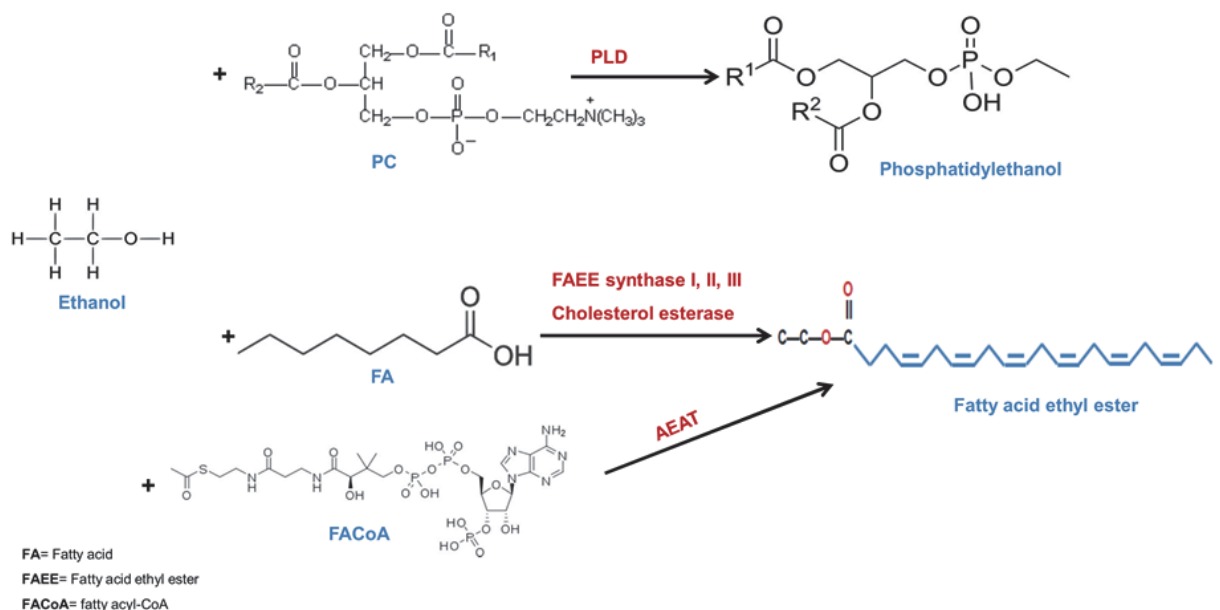

Fatty acid ethyl ester

FACOA $=$ fatty acyl - COA

AEAT= Acylcoenzyme A:ethanol O-acyltransferase

AEAT $=$ Acylcoenzyme A:e
$P C$ sphatidylcholine

PLD= Phospholipase $D$

$R^{1}, R^{2}=$ fatty acid chain

Figure 2.2 Nonoxidative ethanol metabolism. Adapted from Zakhari ${ }^{25}$ and Best el al. ${ }^{72}$.

Ex vivo, inhibition of oxidative ethanol metabolism in the liver and pancreatic homogenates of rats by 4-methyl pyrazole, an ADH inhibitor, by diallyl sulfide, an MEOS inhibitor, and by aminotriazole, a catalase inhibitor, has been shown to result in a shift towards the nonoxidative pathways, resulting in the generation of FAEEs ${ }^{91}$. Thus, a low ADH activity in chronic ethanol abusers may lead to accumulation of FAEEs and, consequently, increased risk for the injurious effects of FAEEs ${ }^{95}$.

\section{Role of microbiota in the endogenous production and oxidation of}

ethanolın addition to being ingested orally, ethanol can be produced endogenously by bacterial fermentation of carbohydrates ${ }^{96}$. The endogenously produced ethanol is absorbed and transferred via the portal vein to the liver, where it is metabolized ${ }^{97}$. Although blood ethanol concentrations are usually very low in sober subjects $(40-45 \mu \mathrm{g} / \mathrm{dl})$, conditions associated with intestinal bacterial overgrowth, such as jejunoileal bypass surgery and tropical sprue, can lead to endogenous ethanol production of up to $1 \mathrm{mM}$ (approximately $4.6 \mathrm{mg} / \mathrm{dl}$ ) and of 2-31 mM (approximately 9.2-142.6 mg/dl) in blood and jejunal aspirates, respectively ${ }^{98,99}$. In addition, 
endogenously produced ethanol has also been found in the cecum of normally fed rats, with concentrations of $0.9 \mathrm{mM}(4.14 \mathrm{mg} / \mathrm{dl})$ reported $^{97}$. Several bacteria and yeasts can ferment sugars to ethanol, including some that can be found in the $\mathrm{Gl}$ tract. For example, gastric overgrowth of Helicobacter pylori $i^{100}$ and small intestinal overgrowth of coliform bacteria such as Klebsiella pneumoniae, Enterobacter cloacae, and Escherichia coli can contribute to endogenous ethanol production ${ }^{98}$. Coliform bacteria and, for example, Clostridium spp., may contribute to ethanol production in the colon as well ${ }^{101}$.

Endogenous and exogenous ethanol can also be further metabolized by the $\mathrm{GI}$ microbiota ${ }^{102,103}$. For instance, oral bacteria and yeasts, including Streptococcus viridans $^{104}$, and Candida strains ${ }^{105}$, and gastric bacteria such as H. pylori $i^{106}$ have been found to possess ADH activity. Intestinal bacteria belonging to the Enterobacteriaceae family, such as E. coli, have also been shown to oxidize ethanol aerobically into acetaldehyde by an $\mathrm{ADH}$-dependent reaction ${ }^{107-109}$. Furthermore, Salaspuro et al. ${ }^{108}$ have demonstrated that $E$. coli is also able to convert ethanol into acetaldehyde under microaerobic, microaerophilic, and anaerobic conditions.

Several bacteria, such as members of the Enterobacteriaceae family, are known to possess catalase activity in addition to ADH activity. Tillonen et al. ${ }^{110}$ demonstrated that human colonic contents could indeed generate acetaldehyde via catalasedependent pathways.

Jokelainen et al. ${ }^{111}$ have shown that in vitro incubation of human colonic contents with ethanol concentrations found in vivo can result in dose-dependent acetaldehyde production. Data on colonic luminal acetaldehyde levels in humans are scarce, most likely due to the volatility of acetaldehyde, but some data from animal studies are available. A marked increase in mucosal acetaldehyde was found in rats with blind loops and concomitant bacterial overgrowth ${ }^{103}$ as well as in the cecum and rectum of rats and the colon of pigs $(271 \mu \mathrm{M}$, approximately $1.2 \mathrm{mg} / \mathrm{dl})$ after administration of $2.5-4.5 \mathrm{~g} / \mathrm{kg}$ ethano $\mathrm{l}^{112-115}$. Furthermore, rectal mucosal acetaldehyde concentrations were found to be higher in conventional than in germ-free rats ${ }^{112}$, and caecal levels of acetaldehyde could be effectively reduced by pretreatment with ciprofloxacin ${ }^{115}$, pointing to a role of the intestinal microbiota in acetaldehyde production ${ }^{112}$.

Besides exhibiting ADH activity, facultative anaerobic bacteria such as Enterobacteriaceae have also been found to exhibit ALDH activity ${ }^{116}$. However, the capacity of the intestinal microbiota to metabolize acetaldehyde by ALDH is rather low $^{117}$. This, combined with the low levels of ALDH in colonic mucosa ${ }^{118}$, results in the accumulation of acetaldehyde in the large intestine ${ }^{65}$. Intracolonic production and accumulation of acetaldehyde is suggested to cause colorectal carcinogenesis ${ }^{119}$, and to be an important determinant for blood acetaldehyde levels and subsequent hepatotoxicity ${ }^{65}$. 
In summary, ethanol as well as its oxidative and nonoxidative metabolites can be found in the contents of both the small and the large intestines, either as a direct consequence of ethanol ingestion or via the systemic circulation, which involves the action of ethanol-metabolizing enzymes in the GI tract and microbiota.

\section{Ethanol-induced changes in the intestinal microbiota}

Besides demonstrating the role of bacteria in ethanol metabolism, mounting evidence has shown that ethanol can also result in quantitative and qualitative changes in the intestinal microbiota. Yan et al. ${ }^{120}$ have demonstrated in a mouse model that intragastric feeding of ethanol $(30.9 \mathrm{~g} / \mathrm{kg} / \mathrm{day})$ for 3 weeks induced small intestinal bacterial overgrowth and caecal dysbiosis. In rats, intragastric administration of ethanol ( $8 \mathrm{~g} / \mathrm{kg} /$ day) for 10 weeks was shown to induce ileal and colonic dysbiosis ${ }^{121}$.

In humans, long-term ethanol consumption was found to be associated not only with small intestinal bacterial overgrowth ${ }^{122,123}$ but also with alterations in the composition of the mucosa-associated microbiota in sigmoid biopsies ${ }^{124}$. Mutlu et al. ${ }^{124}$ found a lower abundance of Bacteroidetes and a higher abundance of Proteobacteria in alcoholics than in healthy controls. In a randomized crossover study performed in healthy volunteers who consumed red wine, dealcoholized red wine, or gin for 20 days, all interventions resulted in changes in the fecal microbiota, as demonstrated by quantitative PCR and denaturing gradient gel electrophoresis, with changes differing between groups ${ }^{125}$. In line with the above, a reduction in the proportion of Bacteroidetes and an increase in the Proteobacteria were also demonstrated by 454 pyrosequencing in a mixed group of patients with hepatitis-B or ethanol-related liver cirrhosis versus healthy individuals. Furthermore, the authors also reported changes on the family level, including, for example, increased numbers of Enterobacteriaceae and Streptococcaceae and reduced numbers of Lachnospiraceae ${ }^{126}$. Moreover, probiotic and synbiotic interventions have been demonstrated to attenuate liver injury in a rat model of alcoholic steatohepatitis ${ }^{127}$ and liver dysfunction in cirrhotic patients ${ }^{128}$, respectively, supporting a role for the gut microbiota in ethanol-induced liver diseases.

In addition to possibly enhanced translocation of endotoxins and direct effects of bacteria on the epithelial barrier, alterations in the composition and activity of gut microbiota can also result in changes in the production or breakdown of ethanol and acetaldehyde. In an in vitro study, for example, Nosova et al. ${ }^{129}$ demonstrated that Bifidobacterium spp. and, to a greater extent, Lactobacillus $G G$, are weak acetaldehyde generators but have a high acetaldehyde-metabolizing capacity, which correlates positively with bacterial concentrations. Nevertheless, additional data on the effects of different dosages and durations of ethanol intake on the intestinal microbiota and subsequent ethanol-related microbial metabolic activity in humans are warranted. 


\section{Epithelial barrier disruption mediated by ethanol and its metabolites}

\section{Intestinal epithelial barrier}

The GI epithelium is composed of a continuous monolayer of intestinal epithelial cells, which facilitate a selective passive entry of luminal nutrients, ions, and water while restricting access of pathogenic substances and microorganisms by means of transcellular and paracellular pathways ${ }^{130}$. The transcellular pathway contains lipophobic and lipophilic pores located in the brush border membrane of enterocytes. ${ }^{131}$ The paracellular pathway is regulated via apical intercellular junctional proteins known as tight junctions (TJs) and via associated proteins known as the adherens junctions (AJs) ${ }^{131}$. The TJs are composed of transmembrane proteins (e.g. claudins), integral membrane proteins (e.g. occludin), junction adhesion molecules, and cytoplasmic zona occludens (ZO) proteins (e.g. ZO-1, ZO-2, and ZO-3), which connect the TJ complex intracellularly with the actin cytoskeleton ${ }^{132}$. The TJs are regulated by both intra- and extracellular signaling molecules. Intracellular signaling molecules that regulate the assembly and disassembly of the TJs include, for example, myosin light chain kinase $(\mathrm{MLCK})^{133}$, Rho GTPases ${ }^{134}$, protein kinase $\mathrm{C}^{135}$, mitogenactivated protein kinases ${ }^{136}$, protein tyrosine kinase ${ }^{137}$, intracellular calcium ${ }^{138}$, and zonulin $^{139,140}$. Extracellular modulators of the TJs include, for example, nutrients, xenobiotics such as nonsteroidal anti-inflammatory drugs, and cytokines (e.g. interferon- $\gamma$, tumor necrosis factor- $\alpha$, and interleukin-1 $\beta)^{141-145}$. Intestinal epithelial barrier function in vivo can be assessed noninvasively by measuring ingested test probes (sugars, polyethylene glycol, radioactively labelled chromium-EDTA), analyzing TJ structures, or measuring the sequelae of barrier dysfunction, such as bacterial translocation and production of serum/plasma endotoxins ${ }^{146-149}$.

\section{Effects of ethanol on small and large intestinal barrier function}

Ethanol and its oxidative and nonoxidative metabolites can be found throughout the GI tract, where they can interfere with several functions, including those of the intestinal barrier. It has been shown that, after oral administration of $0.8 \mathrm{~g} / \mathrm{kg}$ ethanol as a $25 \%$ solution, luminal levels of ethanol can reach more than $400 \mathrm{mg} / \mathrm{dl}$ and can be maintained for $60 \mathrm{~min}$ in the stomach, in the proximal jejunum, and in the duodenum, whereas levels in the ileum were approximately $200 \mathrm{mg} / \mathrm{dl}$, parallel to those in blood $^{24}$. Ethanol concentrations found in the colon are comparable to those in blood $^{24,34,35}$. Hence, the continuous presence of ethanol in the GI tract, which results from equilibration throughout the vascular space, may account for the ethanolinduced epithelial barrier dysfunction in both the upper and the lower GI tract. Few studies have investigated the effects of ethanol intake on Gl tract barrier function in humans (Table 2.3). Most studies are performed in long-term ethanol abusers, 
defined as individuals with a consumption of more than four drinks (>80 g/day) ${ }^{32}$, the majority of whom are also diagnosed with ALD. Overall, an increase in small intestinal

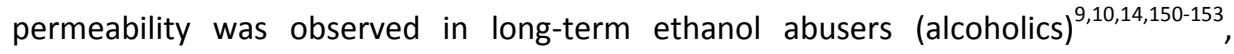
likewise, gastroduodenal permeability increased in nonalcoholics following administration of a single dose of ethanol ${ }^{151,154}$. Millan et al. ${ }^{155}$ reported histological changes in the small intestine following administration of a single dose of ethanol in nonalcoholics, although barrier function was not assessed. Hirsch et al. ${ }^{150}$ did not find changes in the permeability of the small intestine of long-term abusers after 3 days of abstinence. However, in a similar group of patients, the ethanol-induced increase in gastroduodenal permeability was found to persist for at least 7 days in the presence of aspirin ${ }^{152}$. In patients with ALD, an increase in small intestinal permeability has been found to be associated with high levels of endotoxins in blood ${ }^{9,14,156,157}$. Animal studies have demonstrated that both short- and long-term ethanol administration, at dosages ranging from $6 \mathrm{~g} / \mathrm{kg} /$ day to $8 \mathrm{~g} / \mathrm{kg} /$ day, can increase intestinal permeability and induce endotoxemia ${ }^{12,13,15,158}$ subsequently leading to liver injury ${ }^{12,13,15}$, intestinal inflammation $^{159}$ and rectal carcino-genesis ${ }^{12,160,161}$. Moreover, ethanol, when present along with alterations in intestinal permeability and immune status, has been shown to lead to small intestinal bacterial overgrowth, contributing to an increase in endotoxin translocation and an exacerbation of intestinal tissue damage after burn injury in rats ${ }^{162,163}$. Data from studies in humans have confirmed that small intestinal bacterial overgrowth can also occur in patients with ALD, in whom increased numbers of aerobic and anaerobic bacteria were found in jejunal aspirates ${ }^{122,123}$. Data on the effects of ethanol on human colonic barrier function are lacking. In animals, oral administration of ethanol (3-4.5 g/ $\mathrm{kg}$ ) in rats as well as ex vivo exposure of rat colon to acetaldehyde (40-160 $\mu \mathrm{M}$, approximately 176-704 $\mu \mathrm{g} / \mathrm{dl})$ resulted in increased colon permeability $^{164}$. Antibiotics and doxantrazole, a mast cell membrane stabilizer, significantly inhibited these effects, pointing to a mechanistic role for the enteric microbiota and mast cell activation ${ }^{164}$. As for human data, it has recently been shown that moderate red wine consumption can increase small intestine and colon permeability in patients with inflammatory bowel disease ${ }^{154}$. 
Table 2.3 Human studies exploring the effect of ethanol consumption on intestinal barrier function.

\begin{tabular}{|c|c|c|c|c|}
\hline Subjects & $\begin{array}{l}\text { Dose of ethanol } \\
\text { (route of } \\
\text { administration) }\end{array}$ & Parameters assessed & Major findings & Reference \\
\hline $\begin{array}{l}\text { Nonalcoholics } \\
(n=20)\end{array}$ & $\begin{array}{l}45 \mathrm{~g} \text { or } 60 \mathrm{~g} \\
\text { (single } \\
\text { intragastric dose) }\end{array}$ & Histological changes & $\begin{array}{l}\text { Transient damage to the upper } \\
\text { small intestine }\end{array}$ & $\begin{array}{l}\text { Millan } \\
\text { et al. }\end{array}$ \\
\hline $\begin{array}{l}\text { Nonalcoholics } \\
(n=12) \\
\text { Alcoholics } \\
(n=12)\end{array}$ & $\begin{array}{l}20 \mathrm{~g} \text { (single oral } \\
\text { dose) } \\
>80 \mathrm{~g} / \text { day for } \\
>5 \mathrm{yrs}\end{array}$ & $\begin{array}{l}\text { Intestinal } \\
\text { permeability by PEG }\end{array}$ & $\begin{array}{l}\text { Reversible altered } \\
\text { permeability in alcoholics and } \\
\text { nonalcoholics }\end{array}$ & $\begin{array}{l}\text { Robinson } \\
\text { et al. }\end{array}$ \\
\hline $\begin{array}{l}\text { Nonalcoholics (15) } \\
\text { Alcoholics } \\
(n=36)\end{array}$ & $\begin{array}{l}>80-150 \text { g/day } \\
\text { for }>3 \text { yrs } \\
>80-150 \text { g/day } \\
\text { for }>3 \text { yrs }\end{array}$ & $\begin{array}{l}\text { Intestinal } \\
\text { permeability by } \\
\text { chromium-51-EDTA }\end{array}$ & $\begin{array}{l}\text { Increased intestinal } \\
\text { permeability in } \\
\text { alcoholics > nonalcoholics }\end{array}$ & $\begin{array}{l}\text { Bjarnason } \\
\text { et al. }{ }^{9}\end{array}$ \\
\hline $\begin{array}{l}\text { Alcoholics with } \\
\text { cirrhosis ( } n=88) \\
\text { Alcoholic without } \\
\text { cirrhosis }(n=42)\end{array}$ & $\begin{array}{l}>80 \mathrm{~g} / \text { day for } \\
\geq 5 \mathrm{yrs} \\
>80 \mathrm{~g} / \text { day for } \\
\geq 5 \mathrm{yrs}\end{array}$ & $\begin{array}{l}\text { Blood endotoxin } \\
\text { levels }\end{array}$ & $\begin{array}{l}\text { Increased endotoxin levels in } \\
\text { patients with } \\
\text { cirrhosis > patients without } \\
\text { cirrhosis }\end{array}$ & $\begin{array}{l}\text { Bode } \\
\text { et al. }\end{array}$ \\
\hline $\begin{array}{l}\text { Nonalcoholics } \\
(n=20) \\
\text { Alcoholics } \\
(n=18)\end{array}$ & $\begin{array}{l}0.8 \mathrm{~g} / \mathrm{kg} \text { (oral, } \\
\text { i.v.) } \\
100 \mathrm{~g} / \text { day for } \\
\leq 5 \mathrm{yrs}\end{array}$ & $\begin{array}{l}\text { Intestinal } \\
\text { permeability by } \\
\text { morphological } \\
\text { changes }\end{array}$ & $\begin{array}{l}\text { Increased gastroduodenal } \\
\text { permeability in alcoholics } \\
\text { Reversible changes in villous } \\
\text { integrity in alcoholics }\end{array}$ & $\begin{array}{l}\text { Keshavarzian } \\
\text { et al. }{ }^{151}\end{array}$ \\
\hline $\begin{array}{l}\text { Nonalcoholics } \\
(n=10) \\
\text { Alcoholics } \\
(n=18)\end{array}$ & $\begin{array}{l}\text { Nondrinkers } \\
100 \text { g/day for } \\
\leq 5 \text { yrs }\end{array}$ & $\begin{array}{l}\text { Intestinal } \\
\text { permeability by } \\
\text { lactulose-mannitol } \\
\text { test }\end{array}$ & $\begin{array}{l}\text { Increased intestinal } \\
\text { permeability in alcoholics with } \\
\text { chronic liver disease }\end{array}$ & $\begin{array}{l}\text { Keshavarzian } \\
\text { et al. }{ }^{157}\end{array}$ \\
\hline $\begin{array}{l}\text { Nonalcoholics } \\
(n=18) \\
\text { Alcoholics } \\
(n=19)\end{array}$ & $\begin{array}{l}\text { Undefined } \\
\text { Undefined }\end{array}$ & $\begin{array}{l}\text { Intestinal } \\
\text { permeability by } \\
\text { lactulose-mannitol } \\
\text { test on the third day } \\
\text { of abstinence }\end{array}$ & $\begin{array}{l}\text { No changes in intestinal } \\
\text { permeability }\end{array}$ & $\begin{array}{l}\text { Hirsch } \\
\text { et al. }\end{array}$ \\
\hline $\begin{array}{l}\text { Nonalcoholics } \\
(n=30) \\
\text { Alcoholics with } \\
(n=19) \text { or without } \\
\text { cirrhosis }(n=35)\end{array}$ & $\begin{array}{l}\text { Nondrinkers } \\
>60 \mathrm{~g} / \text { day for } \\
>3 \mathrm{yrs} \\
>60 \mathrm{~g} / \text { day for } \\
>3 \mathrm{yrs}\end{array}$ & $\begin{array}{l}\text { Intestinal } \\
\text { permeability by PEG } \\
\text { and blood endotoxin } \\
\text { levels }\end{array}$ & $\begin{array}{l}\text { Increased intestinal } \\
\text { permeability and endotoxin } \\
\text { levels in ALD patients (with or } \\
\text { without cirrhosis) }\end{array}$ & $\begin{array}{l}\text { Parlesak } \\
\text { et al. }{ }^{14}\end{array}$ \\
\hline $\begin{array}{l}\text { Nonalcoholics } \\
(n=26) \\
\text { Alcoholics with } \\
\text { cirrhosis }(n=35)\end{array}$ & $\begin{array}{l}\text { Undefined } \\
\text { Undefined }\end{array}$ & $\begin{array}{l}\text { Intestinal } \\
\text { permeability by PEG } \\
400 \text { and PEG } 3350\end{array}$ & $\begin{array}{l}\text { Increased intestinal } \\
\text { permeability in patients with } \\
\text { cirrhosis and ascites }\end{array}$ & $\begin{array}{l}\text { Lee } \\
\text { et al. }\end{array}$ \\
\hline $\begin{array}{l}\text { Healthy subjects } \\
(n=7) \\
\text { Patients with CD } \\
(n=6) \\
\text { Patients with UC } \\
(n=8)\end{array}$ & $\begin{array}{l}0.4 \mathrm{~g} \text { ethanol } / \mathrm{kg} \\
\text { (oral) } \\
0.4 \mathrm{~g} \text { ethanol } / \mathrm{kg} \\
\text { (oral) } \\
0.4 \mathrm{~g} \text { ethanol } / \mathrm{kg} \\
\text { (oral) }\end{array}$ & $\begin{array}{l}\text { Intestinal } \\
\text { permeability by } \\
\text { lactulose-mannitol- } \\
\text { sucralose test }\end{array}$ & $\begin{array}{l}\text { Increased small intestinal and } \\
\text { colon permeability in patients } \\
\text { with } C D \text { and } U C\end{array}$ & $\begin{array}{l}\text { Swanson } \\
\text { et al. }\end{array}$ \\
\hline
\end{tabular}

ALD; alcoholic liver disease; CD, Crohn's disease; PEG, polyethylene glycol; UC, ulcerative colitis; i.v., intravenous 


\section{In vitro studies on the effects of ethanol and acetaldehyde on epithelial integrity}

The majority of data on ethanol-induced barrier dysfunction results from in vitro studies, all using Caco- 2 cell monolayers. It was found that ethanol in concentrations of $0.1 \%$ up to $10 \%(92-920 \mathrm{mg} / \mathrm{dl})$ significantly decreased transepithelial electrical resistance and increased permeation markers (see Table 2.4). In two studies, ethanol up to a $5 \%(4.6 \mathrm{~g} / \mathrm{dl})$ concentration failed to increase paracellular permeability ${ }^{165,166}$. In contrast, ethanol at concentrations of $2.5 \%(2.3 \mathrm{~g} / \mathrm{dl})$ and above has been shown to increase paracellular permeability by compromising the cell viability ${ }^{167,168}$. Ethanol metabolism into acetaldehyde has been suggested to be required for ethanol-induced barrier disruption.

Table $2.4 \quad$ In vitro studies exploring the effects of ethanol on paracellular permeability using Caco-2 cell monolayers.

\begin{tabular}{|c|c|c|c|}
\hline $\begin{array}{l}\text { Ethanol } \\
\text { concentration }{ }^{\mathrm{a}} / \\
\text { exposure time }\end{array}$ & Significant findings & Possible mechanisms & Reference \\
\hline $\begin{array}{l}1 \%, 2.5 \%, 5 \%, \\
7.5 \%, 10 \%\end{array}$ & $\begin{array}{l}\text { Dose-related drop in TEER } \\
\text { Increase in FSA permeability } \\
\text { Disruption of TJ integrity } \\
\text { Displacement of actin and myosin filaments }\end{array}$ & MLCK activation & $\begin{array}{l}\text { Ma } \\
\text { et al. }\end{array}$ \\
\hline $0-15 \%$ & $\begin{array}{l}\text { Increase in FSA permeability } \\
\text { Disassembly of the microtubules }\end{array}$ & Oxidative stress & $\begin{array}{l}\text { Banan } \\
\text { et al. }\end{array}$ \\
\hline $0-2.5 \% / 24 \mathrm{~h}$ & $\begin{array}{l}\text { Increase in FSA permeability } \\
\text { Disruption of F-actin }\end{array}$ & NF-kappaB activation & $\begin{array}{l}\text { Banan } \\
\text { et al. }\end{array}$ \\
\hline $5 \% / 5 \mathrm{~h}$ & $\begin{array}{l}\text { Drop in TEER } \\
\text { Increase in FSA permeability } \\
\text { Decrease in ZO-1, occludin, } \\
\text { and claudin-1 protein levels }\end{array}$ & Zinc deficiency Oxidative stress & $\begin{array}{l}\text { Zhong } \\
\text { et al. }\end{array}$ \\
\hline $5 \% / 24 \mathrm{~h}$ & $\begin{array}{l}\text { Drop in TEER } \\
\text { Increase in FITC-D4 permeability } \\
\text { Decrease in occludin protein levels }\end{array}$ & $\begin{array}{l}\text { HNF-4 } \alpha \text { inactivation via } \\
\text { oxidative stress and zinc } \\
\text { deficiency }\end{array}$ & $\begin{array}{l}\text { Zhong } \\
\text { et al. }\end{array}$ \\
\hline $0.1 \%$ and $1 \% / 3 \mathrm{~h}$ & $\begin{array}{l}\text { Drop in TEER } \\
\text { Increase in FITC-D4 permeability } \\
\text { Decrease in occludin protein levels }\end{array}$ & $\begin{array}{l}\text { Induction of miR-212 } \\
\text { expression with subsequent } \\
\text { decrease in } \mathrm{ZO}-1 \text { translation }\end{array}$ & $\begin{array}{l}\text { Tang } \\
\text { et al. }\end{array}$ \\
\hline $0.2 \% / 2 \mathrm{~h}$ & $\begin{array}{l}\text { Drop in TEER } \\
\text { Increase in FITC-D4 permeability } \\
\text { Decrease in occludin protein levels }\end{array}$ & $\begin{array}{l}\text { Stimulation of intestinal } \\
\text { circadian clock gene expression }\end{array}$ & $\begin{array}{l}\text { Swanson } \\
\text { et al. }\end{array}$ \\
\hline $0.2 \% / 2 \mathrm{~h}$ & $\begin{array}{l}\text { Drop in TEER } \\
\text { Increase in FSA permeability } \\
\text { Increase in p-Snail protein levels }\end{array}$ & $\begin{array}{l}\text { iNOS- mediated ethanol- } \\
\text { induced Snail activation }\end{array}$ & $\begin{array}{l}\text { Forsyth } \\
\text { et al. }\end{array}$ \\
\hline $0.1-1 \% / 3 \mathrm{~h}$ & $\begin{array}{l}\text { Increase in FITC-D4 permeability } \\
\text { Disruption of ZO-1 and occludin integrity } \\
\text { Increase in acetylated microtubule protein } \\
\text { levels }\end{array}$ & $\begin{array}{l}\text { Hyperacetylation of } \\
\text { microtubules }\end{array}$ & $\begin{array}{l}\text { Elamin } \\
\text { et al. }\end{array}$ \\
\hline
\end{tabular}

${ }^{\mathrm{a}} 1 \%$ equals $1 \mathrm{~g} / \mathrm{dl}$. FITC-D4, fluorescein isothiocyanate-labeled dextran $4 \mathrm{KD} ; \mathrm{FSA}$, fluorescein-5-(and-6)sulfonic acid trisodium salt; HNF- $4 \alpha$, hepatocyte nuclear factor- $4 \alpha$; iNOS, inducible nitric oxide synthase; MLCK, myosin light chain kinase; PER2, period circadian protein homolog 2; TEER, trans-epithelial electrical resistance; ZO-1, zona occludens; TJ, tight junction 
Indeed, acetaldehyde at concentrations ranging from $25 \mu \mathrm{M}$ to $760 \mu \mathrm{M}$ (0.11-3.3 $\mathrm{mg} / \mathrm{dl}$ ) has also been demonstrated to increase permeability (see Table 2.5 ). The concentrations of ethanol tested in vitro were comparable to those found in the human upper $\mathrm{GI}$ tract $^{24}$, whereas concentrations of acetaldehyde were comparable to those found in the rat colon $(0.12-3 \mathrm{mM} \text {, approximately } 0.53-13.2 \mathrm{mg} / \mathrm{dl})^{169}$.

Table 2.5 In vitro studies exploring the effects of acetaldehyde on paracellular permeability using Caco-2 cell monolayers.

\begin{tabular}{|c|c|c|c|}
\hline $\begin{array}{l}\text { Exposure } \\
\text { concentration/time }\end{array}$ & Significant findings & Possible mechanisms & Reference \\
\hline $100-760 \mu \mathrm{M} / 4 \mathrm{~h}$ & $\begin{array}{l}\text { Reduction of TEER } \\
\text { Increase in mannitol permeability }\end{array}$ & - & $\operatorname{Rao}^{165,182}$ \\
\hline $650 \mu \mathrm{M} / 6 \mathrm{~h}$ & $\begin{array}{l}\text { Decrease in TEER } \\
\text { Increase in inulin permeability } \\
\text { Tyrosine phosphorylation of ZO-1, } \\
\text { E-cadherin, and } \beta \text {-catenin }\end{array}$ & $\begin{array}{l}\text { Inhibition of protein } \\
\text { tyrosine phosphatases }\end{array}$ & $\begin{array}{l}\text { Atkinson \& } \\
\text { Rao }^{137}\end{array}$ \\
\hline $100-600 \mu \mathrm{M} / 4 \mathrm{~h}$ & $\begin{array}{l}\text { Decrease in TEER } \\
\text { Increase in inulin and endotoxin } \\
\text { permeability } \\
\text { Dissociation of ZO-1, occludin, } \\
\text { E-cadherin, and } \beta \text {-catenin }\end{array}$ & - & $\begin{array}{l}\text { Seth } \\
\text { et al. }{ }^{183}\end{array}$ \\
\hline $100-600 \mu \mathrm{M} / 4 \mathrm{~h}$ & $\begin{array}{l}\text { Decrease in TEER } \\
\text { Increase in inulin and endotoxin } \\
\text { permeability } \\
\text { Reorganization of occludin, ZO-1, } \\
\text { E-cadherin, and } \beta \text {-catenin } \\
\text { Reorganization of actin cytoskeleton }\end{array}$ & - & $\begin{array}{l}\text { Sheth } \\
\text { et al. }{ }^{184}\end{array}$ \\
\hline $100-600 \mu \mathrm{M} / 3-6 \mathrm{~h}$ & $\begin{array}{l}\text { Redistribution of and reduction in ZO-1, } \\
\text { occludin, E-cadherin, and } \beta \text {-catenin } \\
\text { protein levels } \\
\text { Protein tyrosine phosphorylation }\end{array}$ & $\begin{array}{l}\text { Inhibition of protein } \\
\text { tyrosine phosphatases }\end{array}$ & $\begin{array}{l}\text { Basuroy } \\
\text { et al. }^{186}\end{array}$ \\
\hline $400 \mu \mathrm{M} / 0.5 \mathrm{~h}$ & $\begin{array}{l}\text { Redistribution of E-cadherin and } \beta \text {-catenin } \\
\text { Tyrosine phosphorylation of } \beta \text {-catenin } \\
\text { Abolishment of interaction of } \beta \text {-catenin } \\
\text { with E-cadherin }\end{array}$ & Tyrosine kinase activation & $\begin{array}{l}\text { Sheth } \\
\text { et al. }{ }^{185}\end{array}$ \\
\hline $100-760 \mu \mathrm{M} / 5 \mathrm{~h}$ & $\begin{array}{l}\text { Decrease in TEER } \\
\text { Increase in inulin permeability } \\
\text { Redistribution of ZO-1, occludin, } \\
\text { E-cadherin and } \beta \text {-catenin } \\
\text { Reorganization of actin cytoskeleton } \\
\text { Tyrosine phosphorylation of occludin, } \\
\text { ZO-1, claudin-3, and E-cadherin }\end{array}$ & Tyrosine kinase activation & $\begin{array}{l}\text { Samak } \\
\text { et al. }{ }^{136}\end{array}$ \\
\hline $25-100 \mu \mathrm{M} / 3 \mathrm{~h}$ & $\begin{array}{l}\text { Increase in FITC-D4 permeability } \\
\text { Disruption of ZO-1 and occludin integrity } \\
\text { Increase in acetylated microtubule protein } \\
\text { levels }\end{array}$ & $\begin{array}{l}\text { Hyperacetylation of } \\
\text { microtubules }\end{array}$ & $\begin{array}{l}\text { Elamin } \\
\text { et al. }{ }^{194}\end{array}$ \\
\hline
\end{tabular}

FITC-D4, fluorescein isothiocyanate-labeled dextran 4; TEER, trans-epithelial electrical resistance; ZO-1, zona occludens 


\section{Mechanisms of intestinal barrier dysfunction induced by ethanol and its metabolites}

Several mechanisms underlying the ethanol-induced barrier dysfunction have been proposed, including direct damage to epithelial cells, loss of integrity of TJs and/or AJs, and changes in intestinal microbiota, each of which is discussed below.

\section{Direct damage to epithelial cells}

Ethanol and its metabolites can induce direct cell injury. Long-term ethanol ingestion has been reported to induce ultrastructural and histological changes in duodenal mucosa, including a decrease in the mean total mucosal surface area in chronic alcoholics $^{170}$. Data on the effects of long-term moderate intake are not known. However, oral ingestion of a single dose of ethanol $(1 \mathrm{~g} / \mathrm{kg}$, administered as a $35 \mathrm{~g} / \mathrm{dl}$ solution) has been shown to result in histological changes in the duodenum, including subepithelial bleb formation, hemorrhagic erosions, and inflammatory cell infiltration $^{171}$. In the rectal mucosa of individuals who consumed excessive amounts of ethanol, several ultrastructural changes were found, including inflammatory changes, a decreased number of mucin-secreting goblet cells, and alterations in cell organelles such as distorted mitochondria and dilated endoplasmic reticulum ${ }^{172}$.

Animal studies have demonstrated that acute intragastric administration of ethanol at $5-20 \%(4.6-18.4 \mathrm{~g} / \mathrm{dl})$ for $4 \mathrm{~h}$ can result in hemorrhagic erosions and epithelial cell loss in the proximal small intestine of rats ${ }^{173}$. Similar lesions have also been found in rats gavage fed for 14 days with $18.4 \mathrm{~g} / \mathrm{dl}$ ethanol, including exfoliation and subepithelial oedema of villous tips ${ }^{174}$. Administration of a single dose of ethanol $(6 \mathrm{~g} / \mathrm{kg})$ in mice has also been demonstrated to induce severe injury in ileal mucosa, including formation of submucosal blebbing and ulceration of microvilli ${ }^{15}$.

Long-term (16 weeks) ethanol administration induced various alterations in rat enterocytes, including enlargement, dilatation. and diminishment of the mitochondria, the smooth endoplasmic reticulum, and the rough endoplasmic reticulum, respectively $^{175}$. Interestingly, these alterations were more prominent in the distal ileum than in the proximal jejunum, pointing to the bloodborne route of ethanol in inducing such effects rather than a first-pass effect on the ileal mucosa ${ }^{175}$.

Apart from the histological observations, most data on epithelial cell damage as well as further mechanistic insight comes from in vitro experiments. In vitro studies using Caco-2 cell monolayers have shown that luminal (i.e. apical) exposure to high ethanol concentrations (i.e. 10-15\%, approximately 9.2-13.8 g/dl) can decrease cell viability $^{166,167}$. Ethanol at $13.8 \mathrm{~g} / \mathrm{dl}$ has been found to induce cell apoptosis, an effect that was synergistically enhanced in the presence of estradiol, pointing to a possibly more severe effect of ethanol in females ${ }^{7,176}$. Low concentrations (i.e. $<1 \%,<0.92 \mathrm{~g} / \mathrm{dl}$ ) 
have been shown to promote Caco-2 cell differentiation and to synergize with $E$. coli to induce cell apoptosis ${ }^{177,178}$. Studies investigating effects of acetaldehyde on intestinal cytotoxicity are scarce. However, at concentrations $\leq 1,000 \mu \mathrm{M}(\leq 0.44 \mathrm{~g} / \mathrm{dl})$, acetaldehyde has not been found to compromise intestinal cell viability ${ }^{179}$. Further studies investigating wider ranges of concentrations are warranted.

Nonoxidative ethanol metabolites such as palmitoleic and palmitic acid ethyl esters (10-100 $\mu \mathrm{M})$ have also been demonstrated to induce pancreatic acinar cell necrosis through mechanisms involving intracellular calcium release ${ }^{180}$. It has also been shown that FAEEs at concentrations $(20-40 \mu \mathrm{M})$ reached in blood after moderate ethanol consumption can induce oxidative stress and decrease mitochondrial function in intestinal epithelial cells without compromising cell viability ${ }^{181}$. The discrepancy between recent data and data from earlier studies can be explained by differences in cell type, dosage of ethanol, and duration of exposure to FAEEs. Data on the celldamaging effects of PEth on intestinal epithelial cells are not available. Therefore, further study is required to determine the exact role of PEth and FAEEs in ethanolinduced intestinal epithelial damage.

\section{Effects on tight junction integrity}

\section{Ethanol}

The main mechanisms by which ethanol and its metabolites result in barrier dysfunction are through direct and indirect effects on the integrity of TJs (Table 2.4). Interactions between AJ proteins (E-cadherin and $\beta$-catenin), TJ proteins (ZO-1 and occludin), and cytoskeletal proteins are crucial for the organization of the TJ complex and for subsequent maintenance of the intestinal epithelial barrier ${ }^{137,182-186}$. Several mechanisms involving ethanol-induced disruption of epithelial TJs and AJs have been identified. Ma et al. ${ }^{166}$ have shown that ethanol (1-10\%, approximately 0.92-9.2 g/dl) in Caco-2 monolayers can reversibly disrupt the intestinal epithelial TJ integrity through MLCK activation and subsequent modulation of perijunctional actin and myosin filaments. Furthermore, incubation of Caco-2 cells with ethanol $2.5 \%$, approximately $2.3 \mathrm{~g} / \mathrm{dl}$ ) for $24 \mathrm{~h}$ has been shown to induce nuclear factor- $\mathrm{KB}$ activation, thereby resulting in F-actin cytoskeleton instability and, consequently, intestinal barrier dysfunction ${ }^{187}$. Ethanol has also been found to affect intestinal cells by targeting a number of pre- and post-transcriptional regulators, including circadian clock genes and microRNA (miRNA; short ribonucleic acid molecules of an average of 22 nucleotides that bind to complementary sequences on target messenger RNA transcripts, resulting in translational repression), respectively ${ }^{188,189}$. Swanson et al. ${ }^{190}$ have demonstrated in the rat duodenum and proximal colon as well as in Caco- 2 cells that ethanol-induced intestinal barrier dysfunction occurs through mechanisms involving upregulation of intestinal circadian clock gene expression. In addition, in 
Caco-2 monolayers, ethanol downregulated the target gene ZO-1 of miRNA-212 and, consequently, decreased the mRNA and protein levels of ZO-1 through a mechanism involving hepatocyte nuclear factor- $4 \alpha$ dysfunction ${ }^{191,192}$. In addition, ethanol has been found to induce activation of one of the transcription factors involved in an epithelial-mesenchymal transition program, known as Snail, resulting in upregulation of inducible nitric oxide synthase (iNOS) and, consequently, intestinal epithelial hyperpermeability ${ }^{193}$. Ethanol is also able to induce post-translational modifications in intestinal cell proteins. Very recently, it was demonstrated in a three-dimensional Caco-2 cell culture model that basal exposure to ethanol $(40 \mathrm{mM}$, approximately $184 \mathrm{mg} / \mathrm{dl}$ ) for $3 \mathrm{~h}$ can induce microtubule hyperacetylation, resulting in redistribution of ZO-1 and, consequently, loss of TJ integrity ${ }^{194}$. Such effects were independent of altered TJ-encoding gene expression.

A large number of studies have investigated the role of oxidative stress on the intestinal mucosa as a possible mechanism to explain barrier dysfunction. There is strong evidence to indicate the involvement of cellular oxidative stress in mediating ethanol-induced intestinal barrier dysfunction ${ }^{195}$. Evidence provided by Banan et al. ${ }^{167,196}$ has shown that ethanol $(2.5-15 \%$, approximately $2.3-13.8 \mathrm{~g} / \mathrm{dl}$ ) can increase the paracellular permeability of Caco-2 monolayers via iNOS-mediated generation of reactive oxygen species (ROS), resulting in oxidation of the microtubule cytoskeleton and, consequently, disassembly of the TJs. The involvement of iNOS in ROS-mediated ethanol-induced intestinal hyperpermeability has been confirmed in rats gavage fed with ethanol $(6 \mathrm{~g} / \mathrm{kg} /$ day) for 10 weeks. In that study, inhibition of iNOS attenuated ethanol-induced gut leakiness and the associated endotoxemia ${ }^{197}$. Moreover, decreased intestinal antioxidant capacity has been found to play a crucial role in ethanol-induced intestinal disruption. Zhong et al. ${ }^{198}$ demonstrated in mice that long-term ethanol (4.8\%, approximately $4.4 \mathrm{~g} / \mathrm{dl}$ ) gavage for 4 months can induce ileal oxidative stress mediated by zinc deficiency, thereby sensitizing epithelial cells to ethanol, resulting in loss of $\mathrm{TJ}$ integrity.

\section{Acetaldehyde}

Evidence from in vitro and an ex vivo studies revealed that acetaldehyde has a higher potency than ethanol to induce intestinal barrier dysfunction ${ }^{164,165,182}$, thereby highlighting the relevance of this oxidative metabolite. Mechanistic studies have demonstrated in Caco-2 monolayers that acetaldehyde can induce redistribution of occludin and ZO-1 from the intercellular junctions into the intracellular compartments $^{137,183-185}$ leading to dissociation of these proteins from the actin cytoskeleton, resulting in paracellular hyperpermeability ${ }^{186,199}$. Acetaldehyde not only disrupts the TJs but also induces redistribution of E-cadherin and $\beta$-catenin, thereby disrupting the integrity of the $A J s^{137,185}$. The role of several cell-signaling pathways that regulate barrier function, including protein tyrosine kinases ${ }^{200-204}$ and protein tyrosine phosphatases $^{203}$, in acetaldehyde-induced loss of TJ integrity has been explored. 
Basuroy et al. ${ }^{186}$ have demonstrated that acetaldehyde induces tyrosine phosphorylation and disrupts the integrity of TJs and AJs in human colonic mucosa. Sheth et al. ${ }^{184}$ have shown that acetaldehyde can induce protein tyrosine phosphorylation of E-cadherin and $\beta$-catenin, resulting in loss of interaction between these proteins and, consequently, barrier dysfunction. In addition, acetaldehydeinduced inhibition of protein tyrosine phosphatase was found to disrupt the interactions between the $A J$ proteins and protein tyrosine phosphatase $1 B$ and, consequently, to induce paracellular barrier dysfunction in vitro ${ }^{137}$ and in human colon ex vivo ${ }^{186}$. Not only protein phosphorylation but also hyperacetylation can interfere with barrier dysfunction. Recently, in a three-dimensional Caco-2 cell culture model, it was demonstrated that exposure to acetaldehyde ( $25 \mu \mathrm{M}$, approximately $110 \mu \mathrm{g} / \mathrm{dl})$ for $3 \mathrm{~h}$ can result in increased paracellular permeability through mechanisms involving hyperacetylation of microtubular protein ( $\alpha$-tubulin) ${ }^{194}$.

\section{Nonoxidative metabolites}

Data on the effects of the nonoxidative metabolites, i.e. PEth and FAEEs, on the intestinal epithelial barrier function are limited. In one study, incubation of Caco-2 cells for $48 \mathrm{~h}$ with ethanol $(0.05 \%, 46 \mathrm{mg} / \mathrm{dl})$ was found to increase intracellular accumulation of PEth, resulting in claudin-1 endocytosis, disruption of claudin-1/ZO-1 TJs, and activation of ZO-1-associated nucleic acid binding proteins (ZONABs), which, consequently, promoted cell proliferation ${ }^{74}$. Similarly, high levels of accumulated PEth in colonic polyp sections obtained from long-term ethanol abusers were associated with remarkable ZO-1 mislocalization. ${ }^{74}$ These data have been confirmed in vivo and ex vivo; for example, incorporation of PEth in membranes and disruption of ZO-1 and ZONAB localization was found to be correlated with increased cell proliferation in the colonic epithelium of mice (consuming $9.2 \mathrm{~g} / \mathrm{dl}$ for 4 months) and in the adenomas of long-term ethanol consumers ( $30 \mathrm{~g} /$ day), respectively ${ }^{74}$. Although FAEEs have been found to possess cytotoxic activity in pancreatic cells ${ }^{205,206}$ and liver cells ${ }^{207}$, research on their role in ethanol-induced barrier dysfunction has received little attention. However, it was recently shown in a Caco-2 three-dimensional cell culture model that exposure to ethyl ester oleate and ethyl ester palmitate at $20 \mu \mathrm{M}$ or $40 \mu \mathrm{M}$ concentrations can dose-dependently induce ZO-1 and occludin redistribution and, consequently, a decrease in the paracellular barrier function ${ }^{181}$. Interestingly, these changes were partially attenuated by preincubation with the nutritional antioxidant resveratrol, pointing to the involvement of ROS generation in FAEE-induced intestinal barrier dysfunction ${ }^{181}$.

\section{Modulation of tight junctions by microbiota}

In addition to converting ethanol into acetaldehyde metabolically ${ }^{65}$, the intestinal microbiota can also modulate the TJs directly or indirectly via increased levels of 
lipopolysaccharide (LPS), an endotoxin derived from gram-negative bacteria ${ }^{208}$. As discussed previously, ethanol has been shown to alter the composition of the intestinal microbiota, which can result in increased levels of endotoxin ${ }^{124}$. Bode et al. ${ }^{122}$ showed that ethanol can induce overgrowth of gram-negative anaerobic bacteria in the jejunum of alcoholics, predisposing them to increased levels of luminal LPS. Furthermore, short-term ethanol administration has been shown to increase plasma LPS levels approximately five folds within 30-90 min in rats ${ }^{209}$ and in mice ${ }^{210}$, whereas 4 weeks of ethanol feeding increases the plasma LPS levels 15 folds in rats ${ }^{211}$.

In humans, long- and short-term ethanol consumption has been found to induce excessive and transient increases in blood LPS levels, respectively ${ }^{212-214}$. LPS has been shown to induce epithelial hyperpermeability via a poly (ADP-ribose) synthetase (PARS)-dependent mechanism ${ }^{216}$ and MLCK activation ${ }^{217}$. Since increased levels of circulating LPS can potentiate an increase in intestinal permeability ${ }^{215}$, ethanol and LPS in combination may represent a two-hit insult on intestinal epithelial barrier integrity.Intestinal bacteria can also modulate intestinal barrier integrity directly via mechanisms involving changes in TJ protein expression and distribution. The effects differ between bacterial strains. For example, enteropathogenic E. coli has been demonstrated to disrupt TJs in vitro ${ }^{216}$ and to increase intestinal epithelial permeability in vivo ${ }^{217}$. In contrast, several probiotic bacteria, including $E$. coli strain Nissle $1917^{218,219}$, Bifidobacterium infantis ${ }^{220}$, and Lactobacillus plantarum MB452 ${ }^{221}$, have been shown to promote intestinal barrier integrity in vitro by increasing expression of the ZO-2 and occludin proteins, by reducing expression of the claudin-2 protein, and by increasing transcription of the occludin genes. Furthermore, Karczewski et al. ${ }^{222}$ have recently shown that administration of Lactobacillus plantarum WCFS1 into the duodenum of healthy human volunteers increases expression of ZO-1 and occludin in duodenal biopsies and protects against phorbol ester-induced dislocation of ZO-1 and occludin in vitro.

Studies investigating the role of the intestinal microbiota in ethanol-induced intestinal barrier dysfunction have been performed in rats and have reported that pretreatment with antibiotics can ameliorate ethanol-induced intestinal barrier dysfunction and the associated endotoxemia ${ }^{164,223}$. Modulation of gut microbiota by probiotics or prebiotics $^{13,224}$ in animals ${ }^{127,225}$ and in humans ${ }^{226}$ has been demonstrated to improve the intestinal barrier function. Therefore, the effects of probiotic or prebiotic treatment on intestinal barrier function after moderate and long-term ethanol consumption merit further investigation. 


\section{Conclusion}

On the basis of currently existing knowledge, ethanol and its metabolites, including acetaldehyde, PEth, and FAEEs, are considered to reach the entire GI tract, including the large intestine. The effects of ethanol and its metabolites on the intestine depend on various factors such as the food consumption pattern, host factors, e.g. sex, and the presence of gene polymorphisms for the enzymes involved in ethanol metabolism. Although ethanol by itself can be injurious, scientific evidence strongly points towards a very important role of its oxidative metabolite acetaldehyde, especially in intestinal barrier disruption and induction of colorectal cancers associated with ethanol consumption. In addition, ethanol has been shown to act synergistically with acetaldehyde, E. coli, and burn injury, resulting in more pronounced intestinal barrier dysfunction.

In vitro studies have led to exciting new information on the mechanisms of ethanoland acetaldehyde-induced TJ disruption. However, detailed information about the precise mode of interaction between the TJ proteins complex and the mechanisms by which this TJ disruption can be (therapeutically) modulated or prevented is still lacking. So far, information on the effects of the nonoxidative metabolites, i.e. PEth and FAEEs, on intestinal epithelial barrier function is limited and has received little attention. The evidence so far, however, indicates that nonoxidative metabolites could be major modulators of epithelial permeability. Moreover, information on the effects of ethanol and acetaldehyde on other components of intestinal epithelium, such as mucin and mucin-secreting cells (i.e. goblet cells), is largely lacking. Since the intestinal microbiota plays a crucial role in the generation and accumulation of intracolonic acetaldehyde and since ethanol and its metabolites can reach the colon via blood, mechanistic research on ethanol-induced colonic barrier dysfunction, taking into account the role of the gut microbiota, is warranted. Understanding the cellular and molecular mechanisms that mediate the effects of ethanol and its metabolites on intestinal barrier dysfunction may provide leads for therapeutic targets that can prevent or reverse ethanol-induced intestinal failure and the subsequent liver injury. 


\section{References}

1. WHO Global Status Report on Alcohol 2004. Geneva: Department of Mental Health and Substance Abuse: World Health Organisation, 2004.

2. Mann RE, Smart RG, Govoni R. The epidemiology of alcoholic liver disease. Alcohol Res Health 2003;27:209-19.

3. Saunders JB, Latt N. Epidemiology of alcoholic liver disease. Baillieres Clin Gastroenterol 1993;7: 555-79.

4. Deltenre P, Mathurin P. Epidemiology of alcoholic liver disease and new challenges. Gastroenterol Clin Biol 2009;33:1147-50.

5. Salaspuro MP. Alcohol consumption and cancer of the gastrointestinal tract. Best Pract Res Clin Gastroenterol 2003;17:679-94.

6. Robles EA, Mezey E, Halsted $\mathrm{CH}$, et al. Effect of ethanol on motility of the small intestine. Johns Hopkins Med J 1974;135:17-24.

7. Asai $\mathrm{K}$, Buurman WA, Reutelingsperger $\mathrm{CP}$, et al. Low concentrations of ethanol induce apoptosis in human intestinal cells. Scand J Gastroenterol 2003;38:1154-61.

8. Rao R. Endotoxemia and gut barrier dysfunction in alcoholic liver disease. Hepatology 2009;50: 638-44.

9. Bjarnason I, Peters TJ, Wise RJ. The leaky gut of alcoholism: possible route of entry for toxic compounds. Lancet 1984;1:179-82.

10. Robinson GM, Orrego $\mathrm{H}$, Israel $\mathrm{Y}$, et al. Low-molecular-weight polyethylene glycol as a probe of gastrointestinal permeability after alcohol ingestion. Dig Dis Sci 1981;26:971-7.

11. Mathurin P, Deng QG, Keshavarzian A, et al. Exacerbation of alcoholic liver injury by enteral endotoxin in rats. Hepatology 2000;32:1008-17.

12. Keshavarzian A, Farhadi A, Forsyth $\mathrm{CB}$, et al. Evidence that chronic alcohol exposure promotes intestinal oxidative stress, intestinal hyperpermeability and endotoxemia prior to development of alcoholic steatohepatitis in rats. J Hepatol 2009;50:538-547.

13. Keshavarzian A, Choudhary S, Holmes EW, et al. Preventing gut leakiness by oats supplementation ameliorates alcohol-induced liver damage in rats. J Pharmacol Exp Ther 2001;299:442-8.

14. Parlesak A, Schafer C, Schutz T, et al. Increased intestinal permeability to macromolecules and endotoxemia in patients with chronic alcohol abuse in different stages of alcohol-induced liver disease. J Hepatol 2000;32:742-7.

15. Lambert JC, Zhou Z, Wang L, et al. Prevention of alterations in intestinal permeability is involved in zinc inhibition of acute ethanol-induced liver damage in mice. J Pharmacol Exp Ther 2003;305:880-6.

16. Adachi Y, Bradford BU, Gao W, et al. Inactivation of Kupffer cells prevents early alcohol-induced liver injury. Hepatology 1994;20:453-60.

17. Nanji AA, Khettry U, Sadrzadeh SM. Lactobacillus feeding reduces endotoxemia and severity of experimental alcoholic liver (disease). Proc Soc Exp Biol Med 1994;205:243-7.

18. Djamali A, Reese S, Yracheta J, et al. Epithelial-to-mesenchymal transition and oxidative stress in chronic allograft nephropathy. Am J Transplant 2005;5:500-9.

19. Welcker K, Martin A, Kolle $\mathrm{P}$, et al. Increased intestinal permeability in patients with inflammatory bowel disease. Eur J Med Res 2004;9:456-60.

20. Squier CA, Cox $P$, Hall BK. Enhanced penetration of nitrosonornicotine across oral mucosa in the presence of ethanol. J Oral Pathol 1986;15:276-9.

21. Howie NM, Trigkas TK, Cruchley AT, et al. Short-term exposure to alcohol increases the permeability of human oral mucosa. Oral Dis 2001;7:349-54.

22. Squier CA, Kremer MJ, Wertz PW. Effect of ethanol on lipid metabolism and epithelial permeability barrier of skin and oral mucosa in the rat. J Oral Pathol Med 2003;32:595-9.

23. Wight AJ, Ogden GR. Possible mechanisms by which alcohol may influence the development of oral cancer--a review. Oral Oncol 1998;34:441-7.

24. Halsted CH, Robles EA, Mezey E. Distribution of ethanol in the human gastrointestinal tract. Am J Clin Nutr 1973;26:831-4.

25. Zakhari S. Overview: how is alcohol metabolized by the body? Alcohol Res Health 2006;29:245-54. 
26. Hachet-Haas M, Converset N, Marchal O, et al. FRET and colocalization analyzer--a method to validate measurements of sensitized emission FRET acquired by confocal microscopy and available as an ImageJ Plug-in. Microsc Res Tech 2006;69:941-56.

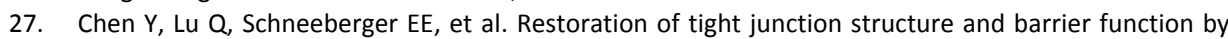
down-regulation of the mitogen-activated protein kinase pathway in ras-transformed Madin-Darby canine kidney cells. Mol Biol Cell 2000;11:849-62.

28. Crabb DW, Bosron WF, Li TK. Ethanol metabolism. Pharmacol Ther 1987;34:59-73.

29. Levitt MD, Li R, DeMaster EG, et al. Use of measurements of ethanol absorption from stomach and intestine to assess human ethanol metabolism. Am J Physiol 1997;273:G951-7.

30. Norberg A, Jones AW, Hahn RG, et al. Role of variability in explaining ethanol pharmacokinetics: research and forensic applications. Clin Pharmacokinet 2003;42:1-31.

31. Holford NH. Clinical pharmacokinetics of ethanol. Clin Pharmacokinet 1987;13:273-92.

32. Eckardt MJ, File SE, Gessa GL, et al. Effects of moderate alcohol consumption on the central nervous system. Alcohol Clin Exp Res 1998;22:998-1040.

33. Oneta $\mathrm{CM}$, Simanowski UA, Martinez $\mathrm{M}$, et al. First pass metabolism of ethanol is strikingly influenced by the speed of gastric emptying. Gut 1998;43:612-9.

34. Levitt MD, Doizaki W, Levine AS. Hypothesis: metabolic activity of the colonic bacteria influences organ injury from ethanol. Hepatology 1982;2:598-600.

35. Jones AW. Distribution of ethanol between saliva and blood in man. Clin Exp Pharmacol Physiol 1979;6:53-9.

36. Goist KC, Jr., Sutker PB. Acute alcohol intoxication and body composition in women and men. Pharmacol Biochem Behav 1985;22:811-4.

37. Lammers SM, Mainzer DE, Breteler MH. Do alcohol pharmacokinetics in women vary due to the menstrual cycle? Addiction 1995;90:23-30.

38. Agarwal DP, Goedde HW. Pharmacogenetics of alcohol dehydrogenase (ADH). Pharmacol Ther 1990;45:69-83.

39. Seitz HK, Oneta CM. Gastrointestinal alcohol dehydrogenase. Nutr Rev 1998;56:52-60.

40. Seitz HK, Egerer G, Oneta C, et al. Alcohol dehydrogenase in the human colon and rectum. Digestion 1996;57:105-8.

41. Vaglenova J, Martinez SE, Porte S, et al. Expression, localization and potential physiological significance of alcohol dehydrogenase in the gastrointestinal tract. Eur J Biochem 2003;270:2652-62.

42. Jornvall H, Danielsson O, Hjelmqvist L, et al. The alcohol dehydrogenase system. Adv Exp Med Biol 1995;372:281-94.

43. Jornvall H, Hoog JO. Nomenclature of alcohol dehydrogenases. Alcohol Alcohol 1995;30:153-61.

44. Jelski W, Szmitkowski M. Alcohol dehydrogenase (ADH) and aldehyde dehydrogenase (ALDH) in the cancer diseases. Clin Chim Acta 2008;395:1-5.

45. Fisher OZ, Peppas NA. Quantifying tight junction disruption caused by biomimetic pH-sensitive hydrogel drug carriers. J Drug Deliv Sci Technol 2008;18:47-50.

46. Dong YJ, Peng TK, Yin SJ. Expression and activities of class IV alcohol dehydrogenase and class III aldehyde dehydrogenase in human mouth. Alcohol 1996;13:257-62.

47. Yin SJ, Chou FJ, Chao SF, et al. Alcohol and aldehyde dehydrogenases in human esophagus: comparison with the stomach enzyme activities. Alcohol Clin Exp Res 1993;17:376-81.

48. Pares X, Cederlund E, Moreno A, et al. Class IV alcohol dehydrogenase (the gastric enzyme). Structural analysis of human sigma sigma-ADH reveals class IV to be variable and confirms the presence of a fifth mammalian alcohol dehydrogenase class. FEBS Lett 1992;303:69-72.

49. Woods A, Cheung PC, Smith FC, et al. Characterization of AMP-activated protein kinase beta and gamma subunits. Assembly of the heterotrimeric complex in vitro. J Biol Chem 1996;271:10282-90.

50. Caballeria J, Frezza M, Hernandez-Munoz R, et al. Gastric origin of the first-pass metabolism of ethanol in humans: effect of gastrectomy. Gastroenterology 1989;97:1205-9.

51. Julkunen RJ, Tannenbaum L, Baraona E, et al. First pass metabolism of ethanol: an important determinant of blood levels after alcohol consumption. Alcohol 1985;2:437-41.

52. Lim RT, Jr., Gentry RT, Ito D, et al. First-pass metabolism of ethanol is predominantly gastric. Alcohol Clin Exp Res 1993;17:1337-44.

53. Lieber CS. Ethanol metabolism, cirrhosis and alcoholism. Clin Chim Acta 1997;257:59-84. 
54. Frezza M, di Padova C, Pozzato G, et al. High blood alcohol levels in women. The role of decreased gastric alcohol dehydrogenase activity and first-pass metabolism. N Engl J Med 1990;322:95-9.

55. Seitz HK, Egerer G, Simanowski UA, et al. Human gastric alcohol dehydrogenase activity: effect of age, sex, and alcoholism. Gut 1993;34:1433-7.

56. Dohmen $\mathrm{K}$, Baraona $\mathrm{E}$, Ishibashi $\mathrm{H}$, et al. Ethnic differences in gastric sigma-alcohol dehydrogenase activity and ethanol first-pass metabolism. Alcohol Clin Exp Res 1996;20:1569-76.

57. Lieber CS. Cytochrome P-4502E1: its physiological and pathological role. Physiol Rev 1997;77:517-44.

58. Sedghi S, Keshavarzian A, Klamut M, et al. Elevated breath ethane levels in active ulcerative colitis: evidence for excessive lipid peroxidation. Am J Gastroenterol 1994;89:2217-21.

59. Ingelman-Sundberg M, Ronis MJ, Lindros KO, et al. Ethanol-inducible cytochrome P4502E1: regulation, enzymology and molecular biology. Alcohol Alcohol Suppl 1994;2:131-9.

60. Beno I, Volkovova K, Staruchova M, et al. The activity of $\mathrm{Cu} / \mathrm{Zn}$-superoxide dismutase and catalase of gastric mucosa in chronic gastritis, and the effect of alpha-tocopherol. Bratisl Lek Listy 1994;95:9-14.

61. Lieber CS. Metabolism of alcohol. Clin Liver Dis 2005;9:1-35.

62. Agarwal DP. Molecular genetic aspects of alcohol metabolism and alcoholism. Pharmacopsychiatry 1997;30:79-84.

63. Bosron WF, Li TK. Genetic polymorphism of human liver alcohol and aldehyde dehydrogenases, and their relationship to alcohol metabolism and alcoholism. Hepatology 1986;6:502-10.

64. Li TK, Bosron WF. Genetic variability of enzymes of alcohol metabolism in human beings. Ann Emerg Med 1986;15:997-1004.

65. Salaspuro M. Bacteriocolonic pathway for ethanol oxidation: characteristics and implications. Ann Med 1996;28:195-200.

66. Li TK, Yin SJ, Crabb DW, et al. Genetic and environmental influences on alcohol metabolism in humans. Alcohol Clin Exp Res 2001;25:136-44.

67. Freudenheim JL, Ambrosone CB, Moysich KB, et al. Alcohol dehydrogenase 3 genotype modification of the association of alcohol consumption with breast cancer risk. Cancer Causes Control 1999;10:369-77.

68. Crabb DW, Edenberg HJ, Bosron WF, et al. Genotypes for aldehyde dehydrogenase deficiency and alcohol sensitivity. The inactive ALDH2(2) allele is dominant. J Clin Invest 1989;83:314-6.

69. Baan R, Straif K, Grosse Y, et al. Carcinogenicity of alcoholic beverages. Lancet Oncol 2007;8:292-3.

70. Seitz HK, Stickel F. Molecular mechanisms of alcohol-mediated carcinogenesis. Nat Rev Cancer 2007;7:599-612.

71. Moreira MT, Smith LA, Foxcroft D. Social norms interventions to reduce alcohol misuse in university or college students. Cochrane Database Syst Rev 2009:CD006748.

72. Best CA, Laposata M. Fatty acid ethyl esters: toxic non-oxidative metabolites of ethanol and markers of ethanol intake. Front Biosci 2003;8:e202-17.

73. Pannequin J, Delaunay N, Darido C, et al. Phosphatidylethanol accumulation promotes intestinal hyperplasia by inducing ZONAB-mediated cell density increase in response to chronic ethanol exposure. Mol Cancer Res 2007;5:1147-57.

74. Aradottir S, Asanovska G, Gjerss S, et al. PHosphatidylethanol (PEth) concentrations in blood are correlated to reported alcohol intake in alcohol-dependent patients. Alcohol Alcohol 2006;41:431-7.

75. Varga A, Hansson P, Lundqvist $C$, et al. Phosphatidylethanol in blood as a marker of ethanol consumption in healthy volunteers: comparison with other markers. Alcohol Clin Exp Res 1998;22:1832-7.

76. Gnann H, Weinmann W, Thierauf A. Formation of Phosphatidylethanol and Its Subsequent Elimination During an Extensive Drinking Experiment Over 5 Days. Alcohol Clin Exp Res 2012.

77. Gunnarsson T, Karlsson A, Hansson P, et al. Determination of phosphatidylethanol in blood from alcoholic males using high-performance liquid chromatography and evaporative light scattering or electrospray mass spectrometric detection. J Chromatogr B Biomed Sci Appl 1998;705:243-9.

78. Varga A, Hansson P, Johnson G, et al. Normalization rate and cellular localization of phosphatidylethanol in whole blood from chronic alcoholics. Clin Chim Acta 2000;299:141-50.

79. Chen $\mathrm{Q}$, Barros $\mathrm{H}$, Floren $\mathrm{CH}$, et al. Absorption and incorporation into tissue lipids of $3 \mathrm{H}$-arachidonicand 14C-linoleic acid: effects of ethanol in jejunal tissue cultures and in vivo. Scand J Clin Lab Invest 1994;54:495-504 
80. Pannequin J, Delaunay N, Darido C, et al. Phosphatidylethanol accumulation promotes intestinal hyperplasia by inducing ZONAB-mediated cell density increase in response to chronic ethanol exposure. Mol Cancer Res 2007;5:1147-57.

81. Lange LG. Nonoxidative ethanol metabolism: formation of fatty acid ethyl esters by cholesterol esterase. Proc Natl Acad Sci U S A 1982;79:3954-7.

82. Keshavarzian A, Zorub $\mathrm{O}$, Sayeed $\mathrm{M}$, et al. Acute ethanol inhibits calcium influxes into esophageal smooth but not striated muscle: a possible mechanism for ethanol-induced inhibition of esophageal contractility. J Pharmacol Exp Ther 1994;270:1057-62.

83. Diczfalusy MA, Bjorkhem I, Einarsson C, et al. Characterization of enzymes involved in formation of ethyl esters of long-chain fatty acids in humans. J Lipid Res 2001;42:1025-32.

84. Kulaga V, Pragst $F$, Fulga $N$, et al. Hair analysis of fatty acid ethyl esters in the detection of excessive drinking in the context of fetal alcohol spectrum disorders. Ther Drug Monit 2009;31:261-6.

85. Lange LG, Sobel BE. Mitochondrial dysfunction induced by fatty acid ethyl esters, myocardial metabolites of ethanol. J Clin Invest 1983;72:724-31.

86. Wright M, Bieser KJ, Kinnunen PM, et al. Nonoxidative ethanol metabolism in human leukocytes: detection of fatty acid ethyl ester synthase activity. Biochem Biophys Res Commun 1987;142:979-85.

87. Laposata EA, Scherrer DE, Mazow C, et al. Metabolism of ethanol by human brain to fatty acid ethyl esters. J Biol Chem 1987;262:4653-7.

88. Laposata EA, Scherrer DE, Lange LG. Fatty acid ethyl esters in adipose tissue. A laboratory marker for alcohol-related death. Arch Pathol Lab Med 1989;113:762-6.

89. Hutson JR, Aleksa K, Pragst F, et al. Detection and quantification of fatty acid ethyl esters in meconium by headspace-solid-phase microextraction and gas chromatography-mass spectrometry. J Chromatogr B Analyt Technol Biomed Life Sci 2009;877:8-12.

90. Bakdash A, Burger P, Goecke TW, et al. Quantification of fatty acid ethyl esters (FAEE) and ethyl glucuronide (EtG) in meconium from newborns for detection of alcohol abuse in a maternal health evaluation study. Anal Bioanal Chem 2010;396:2469-77.

91. Werner J, Saghir M, Fernandez-del Castillo C, et al. Linkage of oxidative and nonoxidative ethanol metabolism in the pancreas and toxicity of nonoxidative ethanol metabolites for pancreatic acinar cells. Surgery 2001;129:736-44.

92. Refaai MA, Nguyen PN, Steffensen TS, et al. Liver and adipose tissue fatty acid ethyl esters obtained at autopsy are postmortem markers for premortem ethanol intake. Clin Chem 2002;48:77-83.

93. Borucki K, Kunstmann S, Dierkes J, et al. In heavy drinkers fatty acid ethyl esters in the serum are increased for $44 \mathrm{hr}$ after ethanol consumption. Alcohol Clin Exp Res 2004;28:1102-6.

94. Borucki K, Dierkes J, Wartberg J, et al. In heavy drinkers, fatty acid ethyl esters remain elevated for up to 99 hours. Alcohol Clin Exp Res 2007;31:423-7.

95. $\mathrm{Wu} \mathrm{H}, \mathrm{Cai} \mathrm{P}, \mathrm{Clemens} \mathrm{DL}$, et al. Metabolic basis of ethanol-induced cytotoxicity in recombinant HepG2 cells: role of nonoxidative metabolism. Toxicol Appl Pharmacol 2006;216:238-47.

96. Blomstrand R. Observations of the formation of ethanol in the intestinal tract in man. Life Sci II 1971; 10:575-82.

97. Krebs HA, Perkins JR. The physiological role of liver alcohol dehydrogenase. Biochem J 1970;118: 635-44.

98. Klipstein FA, Engert RF. Enterotoxigenic intestinal bacteria in tropical sprue. III. Preliminary characterization of Klebsiella pneumoniae enterotoxin. J Infect Dis 1975;132:200-3.

99. Mezey E, Imbembo AL, Potter JJ, et al. Endogenous ethanol production and hepatic disease following jejunoileal bypass for morbid obesity. Am J Clin Nutr 1975;28:1277-83.

100. Roine RP, Salmela KS, Salaspuro M. Alcohol metabolism in Helicobacter pylori-infected stomach. Ann Med 1995;27:583-8.

101. Lin Y, Tanaka S. Ethanol fermentation from biomass resources: current state and prospects. Appl Microbiol Biotechnol 2006;69:627-42.

102. Still JL. Alcohol enzyme of Bact. coli. Biochem J 1940;34:1177-82.

103. Baraona E, Julkunen R, Tannenbaum L, et al. Role of intestinal bacterial overgrowth in ethanol production and metabolism in rats. Gastroenterology 1986;90:103-10.

104. Kurkivuori J, Salaspuro V, Kaihovaara P, et al. Acetaldehyde production from ethanol by oral streptococci. Oral Oncol 2007;43:181-6 
105. Tillonen J, Homann N, Rautio M, et al. Role of yeasts in the salivary acetaldehyde production from ethanol among risk groups for ethanol-associated oral cavity cancer. Alcohol Clin Exp Res 1999; 23:1409-15.

106. Roine RP, Salmela KS, Hook-Nikanne J, et al. Alcohol dehydrogenase mediated acetaldehyde production by Helicobacter pylori--a possible mechanism behind gastric injury. Life Sci 1992;51: 1333-7.

107. Jokelainen $K$, Siitonen A, Jousimies-Somer $H$, et al. In vitro alcohol dehydrogenase-mediated acetaldehyde production by aerobic bacteria representing the normal colonic flora in man. Alcohol Clin Exp Res 1996;20:967-72.

108. Salaspuro V, Nyfors S, Heine R, et al. Ethanol oxidation and acetaldehyde production in vitro by human intestinal strains of Escherichia coli under aerobic, microaerobic, and anaerobic conditions. Scand J Gastroenterol 1999;34:967-73.

109. Kishore R, Hill JR, McMullen MR, et al. ERK1/2 and Egr-1 contribute to increased TNF-alpha production in rat Kupffer cells after chronic ethanol feeding. Am J Physiol Gastrointest Liver Physiol 2002;282:G6-15.

110. Tillonen J, Kaihovaara $\mathrm{P}$, Jousimies-Somer $\mathrm{H}$, et al. Role of catalase in in vitro acetaldehyde formation by human colonic contents. Alcohol Clin Exp Res 1998;22:1113-9.

111. Jokelainen $\mathrm{K}$, Roine $\mathrm{RP}$, Vaananen $\mathrm{H}$, et al. In vitro acetaldehyde formation by human colonic bacteria. Gut 1994;35:1271-4.

112. Seitz HK, Simanowski UA, Garzon FT, et al. Possible role of acetaldehyde in ethanol-related rectal cocarcinogenesis in the rat. Gastroenterology 1990;98:406-13.

113. Tillonen J, Vakevainen S, Salaspuro V, et al. Metronidazole increases intracolonic but not peripheral blood acetaldehyde in chronic ethanol-treated rats. Alcohol Clin Exp Res 2000;24:570-5.

114. Jokelainen $\mathrm{K}$, Matysiak-Budnik T, Makisalo H, et al. High intracolonic acetaldehyde values produced by a bacteriocolonic pathway for ethanol oxidation in piglets. Gut 1996;39:100-4.

115. Visapaa JP, Jokelainen K, Nosova T, et al. Inhibition of intracolonic acetaldehyde production and alcoholic fermentation in rats by ciprofloxacin. Alcohol Clin Exp Res 1998;22:1161-4.

116. Nosova $\mathrm{T}$, Jokelainen $\mathrm{K}$, Kaihovaara $\mathrm{P}$, et al. Aldehyde dehydrogenase activity and acetate production by aerobic bacteria representing the normal flora of human large intestine. Alcohol Alcohol 1996;31:555-64.

117. Nosova $\mathrm{T}$, Jokelainen $\mathrm{K}$, Kaihovaara $\mathrm{P}$, et al. Characteristics of aldehyde dehydrogenases of certain aerobic bacteria representing human colonic flora. Alcohol Alcohol 1998;33:273-80.

118. Koivisto T, Salaspuro M. Aldehyde dehydrogenases of the rat colon: comparison with other tissues of the alimentary tract and the liver. Alcohol Clin Exp Res 1996;20:551-5.

119. Seitz HK, Homann N. The role of acetaldehyde in alcohol-associated cancer of the gastrointestinal tract. Novartis Found Symp 2007;285:110-9; discussion 119-4, 198-9.

120. Kevil CG, Oshima T, Alexander B, et al. H(2)O(2)-mediated permeability: role of MAPK and occludin. Am J Physiol Cell Physiol 2000;279:C21-30.

121. Mutlu E, Keshavarzian A, Engen $P$, et al. Intestinal dysbiosis: a possible mechanism of alcohol-induced endotoxemia and alcoholic steatohepatitis in rats. Alcohol Clin Exp Res 2009;33:1836-46.

122. Bode JC, Bode C, Heidelbach R, et al. Jejunal microflora in patients with chronic alcohol abuse. Hepatogastroenterology 1984;31:30-4.

123. Casafont Morencos F, de las Heras Castano G, Martin Ramos L, et al. Small bowel bacterial overgrowth in patients with alcoholic cirrhosis. Dig Dis Sci 1996;41:552-6.

124. Mutlu EA, Gillevet PM, Rangwala $\mathrm{H}$, et al. Colonic microbiome is altered in alcoholism. Am J Physiol Gastrointest Liver Physiol 2012;302:G966-78.

125. Queipo-Ortuno MI, Boto-Ordonez M, Murri M, et al. Influence of red wine polyphenols and ethanol on the gut microbiota ecology and biochemical biomarkers. Am J Clin Nutr 2012;95:1323-34.

126. Chen $\mathrm{Y}$, Yang $\mathrm{F}$, Lu $\mathrm{H}$, et al. Characterization of fecal microbial communities in patients with liver cirrhosis. Hepatology 2011;54:562-72.

127. Forsyth $\mathrm{CB}$, Farhadi A, Jakate $\mathrm{SM}$, et al. Lactobacillus GG treatment ameliorates alcohol-induced intestinal oxidative stress, gut leakiness, and liver injury in a rat model of alcoholic steatohepatitis. Alcohol 2009;43:163-72.

128. Amano M, Nakayama M, Kaibuchi K. Rho-kinase/ROCK: A key regulator of the cytoskeleton and cell polarity. Cytoskeleton (Hoboken) 2010;67:545-54. 
129. Nosova $\mathrm{T}$, Jousimies-Somer $\mathrm{H}$, Jokelainen $\mathrm{K}$, et al. Acetaldehyde production and metabolism by human indigenous and probiotic Lactobacillus and Bifidobacterium strains. Alcohol Acohol 2000;35:561-8.

130. Baumgart DC, Dignass AU. Intestinal barrier function. Curr Opin Clin Nutr Metab Care 2002;5:685-94.

131. Turner JR. Intestinal mucosal barrier function in health and disease. Nat Rev Immunol 2009;9: 799-809.

132. Van Itallie CM, Anderson JM. The molecular physiology of tight junction pores. Physiology (Bethesda) 2004;19:331-8.

133. Blair SA, Kane SV, Clayburgh DR, et al. Epithelial myosin light chain kinase expression and activity are upregulated in inflammatory bowel disease. Lab Invest 2006;86:191-201.

134. Gopalakrishnan S, Raman N, Atkinson SJ, et al. Rho GTPase signaling regulates tight junction assembly and protects tight junctions during ATP depletion. Am J Physiol 1998;275:C798-809.

135. Jain S, Suzuki T, Seth A, et al. Protein kinase Czeta phosphorylates occludin and promotes assembly of epithelial tight junctions. Biochem J 2011;437:289-99.

136. Samak G, Aggarwal S, Rao RK. ERK is involved in EGF-mediated protection of tight junctions, but not adherens junctions, in acetaldehyde-treated Caco-2 cell monolayers. Am J Physiol Gastrointest Liver Physiol 2011;301:G50-9.

137. Atkinson KJ, Rao RK. Role of protein tyrosine phosphorylation in acetaldehyde-induced disruption of epithelial tight junctions. Am J Physiol Gastrointest Liver Physiol 2001;280:G1280-8.

138. Samak G, Narayanan D, Jaggar JH, et al. CaV1.3 channels and intracellular calcium mediate osmotic stress-induced $\mathrm{N}$-terminal c-Jun kinase activation and disruption of tight junctions in Caco-2 CELL MONOLAYERS. J Biol Chem 2011;286:30232-43.

139. Fasano $A$. Zonulin and its regulation of intestinal barrier function: the biological door to inflammation, Molecular biology of the cell 2000;11:849-62autoimmunity, and cancer. Physiol Rev 2011;91:151-75.

140. Gonzalez-Mariscal L, Tapia R, Chamorro D. Crosstalk of tight junction components with signaling pathways. Biochim Biophys Acta 2008;1778:729-56.

141. Lichtenberger LM, Zhou Y, Dial EJ, et al. NSAID injury to the gastrointestinal tract: evidence that NSAIDs interact with phospholipids to weaken the hydrophobic surface barrier and induce the formation of unstable pores in membranes. J Pharm Pharmacol 2006;58:1421-8.

142. Watson CJ, Hoare CJ, Garrod DR, et al. Interferon-gamma selectively increases epithelial permeability to large molecules by activating different populations of paracellular pores. J Cell Sci 2005;118: 5221-30.

143. Wang F, Graham WV, Wang Y, et al. Interferon-gamma and tumor necrosis factor-alpha synergize to induce intestinal epithelial barrier dysfunction by up-regulating myosin light chain kinase expression. Am J Pathol 2005;166:409-19.

144. Al-Sadi R, Ye D, Said HM, et al. Cellular and molecular mechanism of interleukin-1beta modulation of Caco-2 intestinal epithelial tight junction barrier. J Cell Mol Med 2011;15:970-82.

145. Nusrat A, Turner JR, Madara JL. Molecular physiology and pathophysiology of tight junctions. IV. Regulation of tight junctions by extracellular stimuli: nutrients, cytokines, and immune cells. Am J Physiol Gastrointest Liver Physiol 2000;279:G851-7.

146. Menzies IS. Intestinal permeability in coeliac disease. Gut 1972;13:847.

147. Menzies IS, Laker MF, Pounder R, et al. Abnormal intestinal permeability to sugars in villous atrophy. Lancet 1979;2:1107-9.

148. Grootjans J, Thuijls G, Verdam F, et al. Non-invasive assessment of barrier integrity and function of the human gut. World J Gastrointest Surg 2010;2:61-9.

149. Bjarnason I, MacPherson A, Hollander D. Intestinal permeability: an overview. Gastroenterology 1995;108:1566-81.

150. Hirsch S, Chaves G, Gotteland M, et al. [Intestinal permeability in alcoholic patients without liver damage]. Rev Med Chil 1997;125:653-8.

151. Keshavarzian A, Fields JZ, Vaeth J, et al. The differing effects of acute and chronic alcohol on gastric and intestinal permeability. Am J Gastroenterol 1994;89:2205-11.

152. Farhadi A, Keshavarzian A, Kwasny MJ, et al. Effects of aspirin on gastroduodenal permeability in alcoholics and controls. Alcohol 2010;44:447-56.

153. Lee S, Son SC, Han MJ, et al. Increased intestinal macromolecular permeability and urine nitrite excretion associated with liver cirrhosis with ascites. World J Gastroenterol 2008;14:3884-90. 
154. Swanson GR, Tieu V, Shaikh M, et al. Is moderate red wine consumption safe in inactive inflammatory bowel disease? Digestion 2011;84:238-44

155. Millan MS, Morris GP, Beck IT, et al. Villous damage induced by suction biopsy and by acute ethanol intake in normal human small intestine. Dig Dis Sci 1980;25:513-25.

156. Bode C, Kugler V, Bode JC. Endotoxemia in patients with alcoholic and non-alcoholic cirrhosis and in subjects with no evidence of chronic liver disease following acute alcohol excess. J Hepatol 1987;4: 8-14.

157. Keshavarzian A, Holmes EW, Patel M, et al. Leaky gut in alcoholic cirrhosis: a possible mechanism for alcohol-induced liver damage. Am J Gastroenterol 1999;94:200-7.

158. Bode C, Vollmer E, Hug J, et al. Increased permeability of the gut to polyethylene glycol and dextran in rats fed alcohol. Ann N Y Acad Sci 1991;625:837-40.

159. Dinda PK, Kossev P, Beck IT, et al. Role of xanthine oxidase-derived oxidants and leukocytes in ethanol-induced jejunal mucosal injury. Dig Dis Sci 1996;41:2461-70.

160. Simanowski UA, Seitz HK, Baier B, et al. Chronic ethanol consumption selectively stimulates rectal cell proliferation in the rat. Gut 1986;27:278-82.

161. McGarrity TJ, Peiffer LP, Colony PC, et al. The effects of chronic ethanol administration on polyamine content during dimethylhydrazine-induced colorectal carcinogenesis in the rat. Carcinogenesis 1988;9:2093-8.

162. Kavanaugh MJ, Clark C, Goto $M$, et al. Effect of acute alcohol ingestion prior to burn injury on intestinal bacterial growth and barrier function. Burns 2005;31:290-6.

163. Choudhry MA, Fazal N, Goto M, et al. Gut-associated lymphoid T cell suppression enhances bacterial translocation in alcohol and burn injury. Am J Physiol Gastrointest Liver Physiol 2002;282:G937-47.

164. Ferrier L, Berard F, Debrauwer L, et al. Impairment of the intestinal barrier by ethanol involves enteric microflora and mast cell activation in rodents. Am J Pathol 2006;168:1148-54.

165. Rao RK. Acetaldehyde-induced increase in paracellular permeability in Caco-2 cell monolayer. Alcohol Clin Exp Res 1998;22:1724-30.

166. Ma TY, Nguyen D, Bui V, et al. Ethanol modulation of intestinal epithelial tight junction barrier. Am J Physiol 1999;276:G965-74.

167. Banan A, Choudhary S, Zhang Y, et al. Ethanol-induced barrier dysfunction and its prevention by growth factors in human intestinal monolayers: evidence for oxidative and cytoskeletal mechanisms. J Pharmacol Exp Ther 1999;291:1075-85.

168. Banan A, Smith GS, Kokoska ER, et al. Role of actin cytoskeleton in prostaglandin-induced protection against ethanol in an intestinal epithelial cell line. J Surg Res 2000;88:104-13.

169. Rao RK, Seth A, Sheth P. Recent Advances in Alcoholic Liver Disease I. Role of intestinal permeability and endotoxemia in alcoholic liver disease. Am J Physiol Gastrointest Liver Physiol 2004;286:G881-4.

170. Bode JC, Knuppel H, Schwerk W, et al. Quantitative histomorphometric study of the jejunal mucosa in chronic alcoholics. Digestion 1982;23:265-70.

171. Gottfried EB, Korsten MA, Lieber CS. Alcohol-induced gastric and duodenal lesions in man. Am J Gastroenterol 1978;70:587-92.

172. Brozinsky S, Fani K, Grosberg SJ, et al. Alcohol ingestion-induced changes in the human rectal mucosa: light and electron microscopic studies. Dis Colon Rectum 1978;21:329-35.

173. Tamai $\mathrm{H}$, Kato $\mathrm{S}$, Horie $\mathrm{Y}$, et al. Effect of acute ethanol administration on the intestinal absorption of endotoxin in rats. Alcohol Clin Exp Res 2000;24:390-4.

174. Napolitano LM, Koruda MJ, Zimmerman K, et al. Chronic ethanol intake and burn injury: evidence for synergistic alteration in gut and immune integrity. J Trauma 1995;38:198-207.

175. Rossi MA, Zucoloto S. Effect of chronic ethanol ingestion on the small intestinal ultrastructure in rats. Beitr Pathol 1977;161:50-61.

176. Asai K, Buurman WA, Reutelingsperger CP, et al. Modular effects of estradiol on ethanol-induced apoptosis in human intestinal epithelial cells. Scand J Gastroenterol 2005;40:326-35.

177. Laurent C, Besancon P, Caporiccio B. Ethanol and polyphenolic free wine matrix stimulate the differentiation of human intestinal Caco-2 cells. Influence of their association with a procyanidin-rich grape seed extract. J Agric Food Chem 2005;53:5541-8.

178. Amin PB, Diebel LN, Liberati DM. Dose-dependent effects of ethanol and E. coli on gut permeability and cytokine production. J Surg Res 2009;157:187-92. 
179. Desjeux JF, Heyman M, Grasset E. Systems of membrane transport, genetics and nutrition; the example of congenital anomalies of intestinal transport in children. Reprod Nutr Dev 1984;24:785-92.

180. Criddle DN, Raraty MG, Neoptolemos JP, et al. Ethanol toxicity in pancreatic acinar cells: mediation by nonoxidative fatty acid metabolites. Proc Natl Acad Sci U S A 2004;101:10738-43.

181. Elhaseen Elamin DJ KJ-U, Sven C. van IJzendoorn, Freddy Troost, Jos L. Broers, Jan Dekker, Ad Masclee. Modulation of Intestinal Epithelial Barrier Function by Fatty Acid Ethyl Esters in a Three Dimensional (3D) Epithelial cell culture model: Role of nonoxidative ethanol metabolism. Gastroenterology 2011;140:S-502.

182. Rao RK. Acetaldehyde-induced barrier disruption and paracellular permeability in Caco-2 cell monolayer. Methods Mol Biol 2008;447:171-83.

183. Seth A, Basuroy S, Sheth P, et al. L-Glutamine ameliorates acetaldehyde-induced increase in paracellular permeability in Caco-2 cell monolayer. Am J Physiol Gastrointest Liver Physiol 2004;287: G510-7.

184. Sheth $\mathrm{P}$, Seth $\mathrm{A}$, Thangavel $\mathrm{M}$, et al. Epidermal growth factor prevents acetaldehyde-induced paracellular permeability in Caco-2 cell monolayer. Alcohol Clin Exp Res 2004;28:797-804.

185. Sheth $\mathrm{P}$, Seth A, Atkinson KJ, et al. Acetaldehyde dissociates the PTP1B-E-cadherin-beta-catenin complex in Caco-2 cell monolayers by a phosphorylation-dependent mechanism. Biochem J 2007;402: 291-300.

186. Basuroy S, Sheth P, Mansbach CM, et al. Acetaldehyde disrupts tight junctions and adherens junctions in human colonic mucosa: protection by EGF and L-glutamine. Am J Physiol Gastrointest Liver Physiol 2005;289:G367-75.

187. Banan A, Keshavarzian A, Zhang L, et al. NF-kappaB activation as a key mechanism in ethanol-induced disruption of the F-actin cytoskeleton and monolayer barrier integrity in intestinal epithelium. Alcohol 2007;41:447-60.

188. Bartel DP. MicroRNAs: target recognition and regulatory functions. Cell 2009;136:215-33.

189. Shukla GC, Singh J, Barik S. MicroRNAs: Processing, maturation, target recognition and regulatory functions. Mol Cell Pharmacol 2011;3:83-92.

190. Swanson G, Forsyth CB, Tang Y, et al. Role of intestinal circadian genes in alcohol-induced gut leakiness. Alcohol Clin Exp Res 2011;35:1305-14.

191. Zhong W, Zhao Y, McClain CJ, et al. Inactivation of hepatocyte nuclear factor-4\{alpha\} mediates alcohol-induced downregulation of intestinal tight junction proteins. Am J Physiol Gastrointest Liver Physiol 2010;299:G643-51.

192. Tang $Y$, Banan A, Forsyth CB, et al. Effect of alcohol on miR-212 expression in intestinal epithelial cells and its potential role in alcoholic liver disease. Alcohol Clin Exp Res 2008;32:355-64.

193. Forsyth CB, Tang Y, Shaikh M, et al. Role of snail activation in alcohol-induced iNOS-mediated disruption of intestinal epithelial cell permeability. Alcohol Clin Exp Res 2011;35:1635-43.

194. Elamin E, Jonkers D, Juuti-Uusitalo K, et al. Effects of ethanol and acetaldehyde on tight junction integrity: in vitro study in a three dimensional intestinal epithelial cell culture model. PLoS One 2012;7:e35008.

195. Varella Morandi Junqueira-Franco M, Ernesto Troncon L, Garcia Chiarello P, et al. Intestinal permeability and oxidative stress in patients with alcoholic pellagra. Clin Nutr 2006;25:977-83.

196. Banan A, Fields JZ, Decker $\mathrm{H}$, et al. Nitric oxide and its metabolites mediate ethanol-induced microtubule disruption and intestinal barrier dysfunction. J Pharmacol Exp Ther 2000;294:997-1008.

197. Tang Y, Forsyth CB, Farhadi A, et al. Nitric oxide-mediated intestinal injury is required for alcoholinduced gut leakiness and liver damage. Alcohol Clin Exp Res 2009.

198. Zhong W, McClain CJ, Cave M, et al. The role of zinc deficiency in alcohol-induced intestinal barrier dysfunction. Am J Physiol Gastrointest Liver Physiol 2010;298:G625-33.

199. Suzuki T, Seth A, Rao R. Role of phospholipase Cgamma-induced activation of protein kinase Cepsilon (PKCepsilon) and PKCbetal in epidermal growth factor-mediated protection of tight junctions from acetaldehyde in Caco-2 cell monolayers. J Biol Chem 2008;283:3574-83.

200. Basuroy S, Sheth P, Kuppuswamy D, et al. Expression of kinase-inactive c-Src delays oxidative stressinduced disassembly and accelerates calcium-mediated reassembly of tight junctions in the Caco-2 cell monolayer. J Biol Chem 2003;278:11916-24. 
201. Rao RK, Basuroy S, Rao VU, et al. Tyrosine phosphorylation and dissociation of occludin-ZO-1 and Ecadherin-beta-catenin complexes from the cytoskeleton by oxidative stress. Biochem J 2002;368:47181.

202. Rao RK, Li L, Baker RD, et al. Glutathione oxidation and PTPase inhibition by hydrogen peroxide in Caco-2 cell monolayer. Am J Physiol Gastrointest Liver Physiol 2000;279:G332-40.

203. Seth $A$, Sheth $P$, Elias $B C$, et al. Protein phosphatases $2 A$ and 1 interact with occludin and negatively regulate the assembly of tight junctions in the CACO-2 cell monolayer. J Biol Chem 2007;282:1148798.

204. Sheth P, Basuroy S, Li C, et al. Role of phosphatidylinositol 3-kinase in oxidative stress-induced disruption of tight junctions. J Biol Chem 2003;278:49239-45.

205. Petersen $\mathrm{OH}$, Tepikin AV, Gerasimenko JV, et al. Fatty acids, alcohol and fatty acid ethyl esters: toxic Ca2+ signal generation and pancreatitis. Cell Calcium 2009;45:634-42.

206. Wu H, Bhopale KK, Ansari GA, et al. Ethanol-induced cytotoxicity in rat pancreatic acinar AR42J cells: role of fatty acid ethyl esters. Alcohol Alcohol 2008;43:1-8.

207. Aydin HH, Celik HA, Deveci R, et al. Induction of apoptosis by fatty acid ethyl esters in HepG2 cells. Food Chem Toxicol 2005;43:139-45.

208. Hietbrink F, Besselink MG, Renooij W, et al. Systemic inflammation increases intestinal permeability during experimental human endotoxemia. Shock 2009;32:374-8.

209. Rivera CA, Bradford BU, Seabra V, et al. Role of endotoxin in the hypermetabolic state after acute ethanol exposure. Am J Physiol Gastrointest Liver Physiol 1998;275:G1252-G1258.

210. Zhou Z, Wang L, Song Z, et al. A critical involvement of oxidative stress in acute alcohol-induced hepatic TNF-alpha production. Am J Pathol 2003;163:1137-46.

211. Guntaka SR, Samak G, Seth A, et al. Epidermal growth factor protects the apical junctional complexes from hydrogen peroxide in bile duct epithelium. Lab Invest 2011;91:1396-409.

212. Tsukita S, Furuse M. Occludin and claudins in tight-junction strands: leading or supporting players? Trends Cell Biol 1999;9:268-73.

213. Bode JC, Bode C, Heidelbach R, et al. Jejunal microflora in patients with chronic alcohol abuse. Hepatogastroenterology 1984;31:30-4.

214. Fukui H, Brauner B, Bode JC, et al. Plasma endotoxin concentrations in patients with alcoholic and non-alcoholic liver disease: reevaluation with an improved chromogenic assay. J Hepatol 1991;12:162-9.

215. Hietbrink F, Besselink MGH, Renooij W, et al. Systemic Inflammation Increases Intestinal Permeability during Experimental Human Endotoxemia. Shock 2009;32:374-378.

216. Simonovic I, Arpin M, Koutsouris A, et al. Enteropathogenic Escherichia coli activates ezrin, which participates in disruption of tight junction barrier function. Infect Immun 2001;69:5679-88.

217. Shifflett $D E$, Clayburgh DR, Koutsouris A, et al. Enteropathogenic E. coli disrupts tight junction barrier function and structure in vivo. Lab Invest 2005;85:1308-24.

218. Zyrek AA, Cichon $C$, Helms $S$, et al. Molecular mechanisms underlying the probiotic effects of Escherichia coli Nissle 1917 involve ZO-2 and PKCzeta redistribution resulting in tight junction and epithelial barrier repair. Cell Microbiol 2007;9:804-16.

219. Ukena SN, Singh A, Dringenberg U, et al. Probiotic Escherichia coli Nissle 1917 inhibits leaky gut by enhancing mucosal integrity. PLoS One 2007;2:e1308.

220. Ewaschuk JB, Diaz $H$, Meddings $L$, et al. Secreted bioactive factors from Bifidobacterium infantis enhance epithelial cell barrier function. Am J Physiol Gastrointest Liver Physiol 2008;295:G1025-34.

221. Anderson RC, Cookson AL, McNabb WC, et al. Lactobacillus plantarum MB452 enhances the function of the intestinal barrier by increasing the expression levels of genes involved in tight junction formation. BMC Microbiol 2010;10:316.

222. Karczewski J, Troost FJ, Konings I, et al. Regulation of human epithelial tight junction proteins by Lactobacillus plantarum in vivo and protective effects on the epithelial barrier. Am J Physiol Gastrointest Liver Physiol 2010;298:G851-G859.

223. Adachi $\mathrm{Y}$, Moore LE, Bradford BU, et al. Antibiotics prevent liver injury in rats following long-term exposure to ethanol. Gastroenterology 1995;108:218-24.

224. Tang $Y$, Forsyth $C B$, Banan $A$, et al. Oats supplementation prevents alcohol-induced gut leakiness in rats by preventing alcohol-induced oxidative tissue damage. J Pharmacol Exp Ther 2009. 
225. Wang Y, Kirpich I, Liu Y, et al. Lactobacillus rhamnosus GG treatment potentiates intestinal hypoxiainducible factor, promotes intestinal integrity and ameliorates alcohol-induced liver injury. Am J Pathol 2011;179:2866-75.

226. Terry S, Nie M, Matter K, et al. Rho signaling and tight junction functions. Physiology (Bethesda) 2010;25:16-26. 
50 


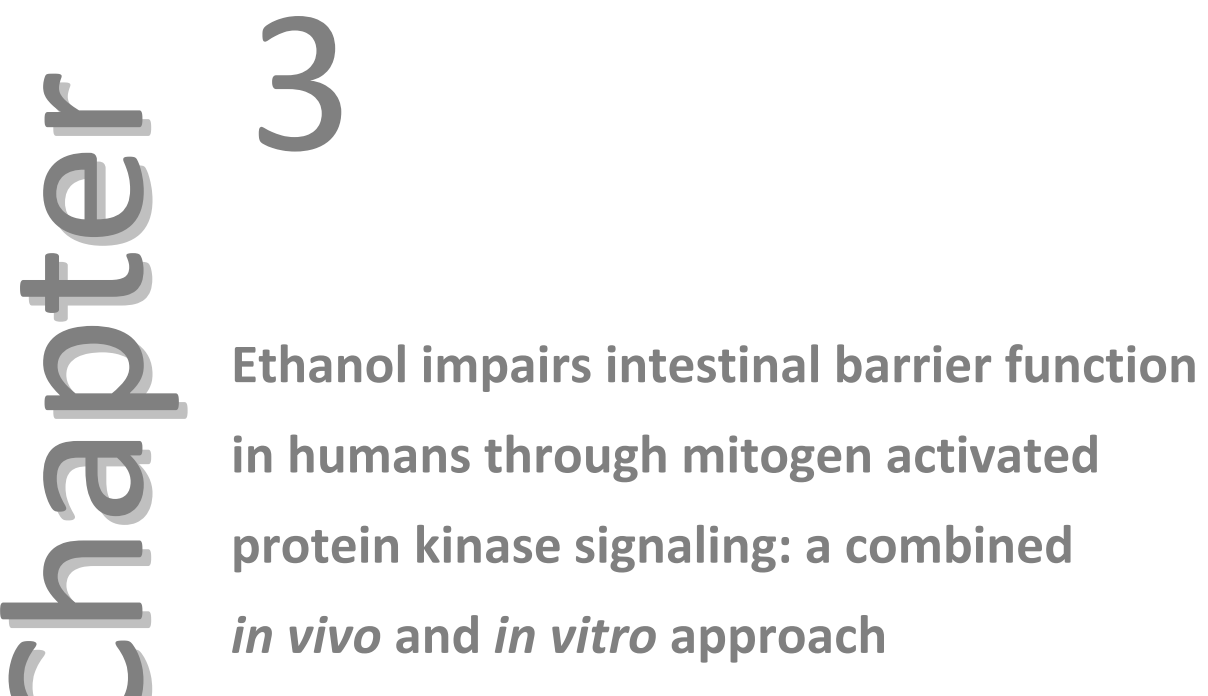

Elhaseen Elamin, Ad Masclee, Freddy Troost, Harm-Jan Pieters, Daniel Keszthelyi, Katarina Aleksa, Jan Dekker, Daisy Jonkers

Submitted 


\section{Abstract}

\section{Objective}

Ethanol-induced gut barrier disruption is associated with several gastrointestinal and liver disorders. Human data on effects of moderate ethanol consumption on both intestinal barrier integrity and related mechanisms are lacking. We examined effects of a single moderate ethanol dose on small and large intestinal permeability, and we explored the role of mitogen activated protein kinase (MAPK) pathway as a primary signaling mechanism.

\section{Design}

Intestinal permeability was assessed in 12 healthy volunteers after intraduodenal administration of $20 \mathrm{~g}$ ethanol by a multi-sugar test, and localization of the tight junction (TJ) and gene expression, phosphorylation of the MAPK isoforms p38, ERK and JNK as indicative of activation were analyzed in duodenal biopsies. The role of MAPK activation was further examined in vitro using Caco-2 monolayers.

\section{Results}

Ethanol increased small and large intestinal permeability, paralleled by redistribution of ZO-1 and occludin, down-regulation of ZO-1 and up-regulation of myosin light chain kinase (MLCK) mRNA expression, and increased MAPK isoforms phosphorylation. In Caco-2 monolayers, ethanol increased permeability, induced redistribution of the junctional proteins and F-actin, and MAPK and MLCK activation, which could be reversed by pretreatment with either MAPK isoforms inhibitors or the anti-oxidant Lcysteine.

\section{Conclusions}

Intraduodenal administration of ethanol increases small and large intestinal permeability and induces changes in localization of TJ protein and gene expression. The data indicate a pivotal role for MAPK and its crosstalk with MLCK in ethanol induced intestinal barrier disruption. 


\section{Introduction}

Ethanol (ethyl alcohol) consumption is associated with several gastrointestinal (GI) and liver disorders, especially alcoholic liver disease (ALD) ${ }^{1}$. ALD is a progressive disease initiated by steatosis and inflammation, followed by liver fibrosis and cirrhosis $^{2}$. Only $30 \%$ of chronic alcoholics eventually develop cirrhosis, indicating that additional factors are required to cause liver injury ${ }^{3}$. Recent evidence points to a role for the gut-liver axis in the pathogenesis of ALD. Ethanol is known to disrupt GI epithelial barrier integrity ${ }^{4}$, with subsequent translocation of potentially harmful bacteria and their products such as endotoxins ${ }^{5}$ and peptidoglycans ${ }^{6}$ into the portal circulation resulting in liver injury, thereby contributing to ALD. Dysfunction of GI mucosal barrier may result in increased susceptibility not only to infections ${ }^{7}$ but also to development of ethanol-related GI cancers ${ }^{8}$.

Human studies investigating effects of ethanol on intestinal barrier function have focused mainly on chronic heavy drinkers $(>80 \mathrm{~g} / \mathrm{day})^{9}$, demonstrating that ethanol increases small intestinal permeability ${ }^{10}$. The effects of moderate ethanol consumption on GI barrier function are less well known but are especially relevant since daily moderate alcohol consumption (daily intake of 1-2 alcoholic drinks or 12-24 g ethanol) is widespread ${ }^{11}$. Ethanol and its metabolites reach the distal GI tract through the vascular space ${ }^{12}$. Therefore, ethanol and its metabolites may be injurious not only to the small intestinal but also to the large intestinal barrier. Intestinal barrier integrity is maintained by the tight junctions (TJs), a complex meshwork of transmembrane and cytoplasmic proteins including occludin, claudins and zona occludens family $(Z O-1,2,3)$, linked to the cytoskeletal protein F-actin ${ }^{13}$. The TJs are supported by the adherens junctions proteins (AJs) E-cadherin and $\beta$-catenin, which are also required for TJ assembly and sealing of the paracellular space ${ }^{14}$.

Data obtained in vitro using intestinal epithelial cells (Caco-2 cell monolayers) indicate that ethanol disrupts TJs integrity via mechanisms involving oxidative stress ${ }^{10}$, modulation of microtubules ${ }^{15}$ and activation of the cell signaling pathway myosin light chain kinase $(\mathrm{MLCK})^{16}$. Mitogen activated protein kinase (MAPK) isoforms including P38, extracellular signal-regulated kinase (ERK) and stress-activated protein kinase/CJun N-terminal kinase (SAPK/JNK) have been linked to formation and integrity of the $\mathrm{TJS}^{17}$. Prior in vitro studies have demonstrated that activation of MAPK mediates intestinal epithelial barrier dysfunction ${ }^{18}$.

Data on mechanims of ethanol-induced barrier dysfunction are mainly derived from in vitro studies ${ }^{19}$. In addition, insight into effects of moderate doses of ethanol on human intestinal barrier function and potential mechanisms involved is still lacking. The aims of this study were to determine effects of a single moderate dose of ethanol, administered intraduodenally, on 1) small intestinal and colonic permeability and 
2) localization and expression of TJ in duodenal biopsies. In addition, the role of MAPK pathway as a primary signaling mechanism involved in ethanol-induced barrier disruption was investigated both in vivo in duodenal biopsies and in vitro in Caco-2 cell monolayers.

\section{Subjects and methods}

\section{Subjects and study design}

The study was performed according to a randomized placebo-controlled crossover design, in 12 healthy subjects. Participants were healthy men from Caucasian ethnicity, between 18 and 45 years of age to avoid genome-related differences in ethanol metabolism ${ }^{20}$. Exclusion criteria included $\mathrm{BMl}>35 \mathrm{~kg} / \mathrm{m}^{2}$, history of gastrointestinal disorders, abdominal surgery, excessive alcohol consumption (>20 g/day) and smoking. The study protocol was approved by the Ethics Committee of Maastricht University Medical Center (MUMC), conducted in accordance with the Declaration of Helsinki and registered at the Clinical Trial Registry (www.clinicaltrials.gov). All participants provided written informed consent.

An overview of the experimental procedures is given in Figure 3.1. The study consisted of two test days in a random order, with a washout period of one week. Participants arrived at the MUMC at 08:00 AM after an overnight fast. An intravenous cannula was placed in an antecubital vein for blood sampling. Then, the tube was placed intraduodenally, and optimal positioning was confirmed by X-ray. Via the tube, either $20 \mathrm{~g}$ ethanol in $100 \mathrm{ml}$ water $(5 \% \mathrm{v} / \mathrm{v})$ or water (placebo) was infused at a rate $7 \mathrm{ml} / \mathrm{min}$ for $15 \mathrm{~min}$. Earlier observations indicate that ethanol reaches concentrations of $2-10 \%$ in small intestinal lumen after consumption of $50 \mathrm{ml}$ ethanol in $20 \%$ solution $^{21}$. Ethanol was introduced directly into the duodenum to overcome interindividual variations in its upper $\mathrm{Gl}$ metabolism after oral consumption ${ }^{22}$. Thereafter, participants received an oral multi-sugar drink to assess intestinal permeability, consisting of $1 \mathrm{~g}$ lactulose (Centrafarm, Etten-Leur, the Netherlands), $1 \mathrm{~g}$ sucralose (Brenntag, Sittard, the Netherlands), 1 g erythritol (Danisco, Copenhagen, Denmark), 1 g sucrose (Van Gilse, Dinteloord, the Netherlands), and $0.5 \mathrm{~g}$ L-rhamnose (Danisco) dissolved in $150 \mathrm{ml}$ tap water. At $\mathrm{t}=30 \mathrm{~min}$ after start of placebo or ethanol perfusion, participants underwent a gastroduodenoscopy, mucosal biopsies were obtained from the second part of the duodenum (forceps diameter: $2.8 \mathrm{~mm}$ ), frozen immediately in liquid nitrogen and stored at $-80^{\circ} \mathrm{C}$ until further analyses. Blood samples were collected before and 15, 30, 45, 60, 90, 120, 150 and 180 min after onset of ethanol perfusion. Urine was collected in plastic containers before, and in three fractions after ethanol perfusion, i.e. 0-2 h, 2-5 $\mathrm{h}$ and 5-24 h. All biosamples were stored at $-80^{\circ} \mathrm{C}$ within 4 hours after collection. For safety, participants were not 
allowed to leave the hospital unless their breath ethanol concentration was $<0.05 \%$, the legal limit in the Netherlands.

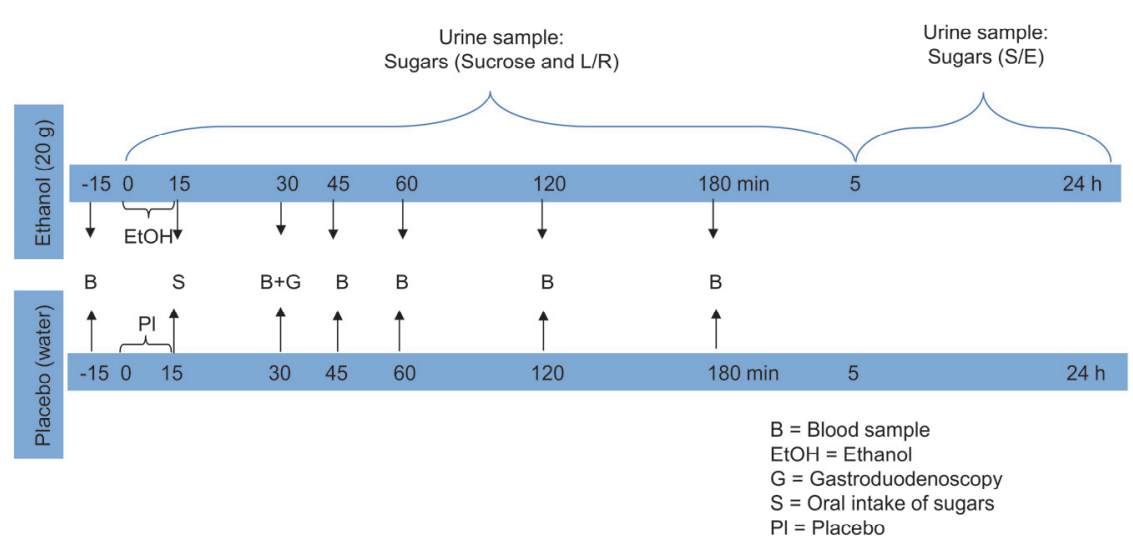

Figure 3.1 Timeline of the test day. B, Blood sample; EtOH, Ethanol; G, Gastroduodenoscopy; S, Oral intake of sugars; $\mathrm{PI}$, Placebo

\section{Measurements}

Liver function, blood ethanol and fatty acid ethyl esters (FAEES) levels

Plasma alanine aminotransferase (ALT) and $\gamma$-glutamyltransferas ( $\gamma \mathrm{GT}$ ) were determined before and $60 \mathrm{~min}$ after ethanol perfusion. Blood ethanol concentrations were determined by headspace gas chromatography aided with Flame Ionization Detection System with a detection limit of $10 \mathrm{mg} / \mathrm{dl}$. Plasma concentrations were converted to blood alcohol concentration (BAC) using the conversion factor 0.809 . Plasma levels of fatty acid ethyl esters (FAEEs) including ethyl oleate and ethyl palmitate were analyzed by gas chromatograph with a mass selective detector GC-MS QP-2010 PLUS equipped with GCMS solutions Software (Shimadzu, Maryland, U.S.A) ${ }^{23}$.

\section{Assessment of intestinal barrier function}

Intestinal barrier function was assessed using a multi-sugar recovery test. Urinary sugar recovery was quantified by combined HPLC (Model PU-1980 pump, Jasco Benelux, Maarsen, the Netherlands) and mass spectrometry (Model LTQXL, Thermo Electron, Breda, the Netherlands) as described by van Wijck et al. ${ }^{24}$. Sucrose in $0-2 \mathrm{~h}$ urine, Lactulose/rhamnose (L/R) ratio in 0-5 $\mathrm{h}$ urine and sucralose/ erythritol (S/E) ratios in the 5-24 $\mathrm{h}$ urine fraction were determined as indicators for gastroduodenal, small and large intestinal permeability, respectively. 


\section{Localization and gene expression of ZO-1 and occludin in duodenal mucosa}

Immunofluorescence staining was performed as described previously ${ }^{25}$ with minor modifications ${ }^{25}$. Tissue sections were examined under Leica TCS SPE confocal laser scanning microscope (Leica Micro systems $\mathrm{GmbH}$, Mannheim, Germany), images were acquired at $512 \times 512$ pixel resolutions and z-stacks were obtained using Leica Application Suite Advanced Fluorescence software (Leica Microsystems GmbH). Images were processed and quantified as described by Fisher et al. ${ }^{26}$ with minor modifications. Briefly, staining of ZO-1 and occludin in the TJ region from uniform Z sections perpendicular to the apical cell surface of the epithelium were subjected to projection and passed through a Gaussian smoothing filter. Plot profiles of the staining intensity along the perpendicular lines were generated using Image J software ${ }^{27}$. Next, grey scale values of each image were calculated and normalized against a summed maximum intensity matrix $(512 \times 512 \times 256)^{26}$.

Gene expression of occludin, claudin 3, and claudin 4, myosin light chain kinase (MLCK) and ZO-1 in duodenal mucosal biopsies was evaluated by qPCR as described previously ${ }^{28}$. Primer sequences are given in Table 3.1.

Table 3.1 Primer sequence of RT-PCR.

\begin{tabular}{llll}
\hline Gene & Sequence ID & Forward primer & Reverse primer \\
\hline GAPDH & NM_002046.3 & TGCACCACCAACTGCTTAGC & GGCATGGACTGTGGTCATGAG \\
CLDN 2 & NM_016675.4 & ATGGCCTCTCTTGGCCTCCAA & TCACACATACCCTGTCAGGCT \\
CLDN 4 & NM_001305.3 & ACAGACAAGCCTTACTCC & GGAAGAACAAAGCAGAG \\
MLCK & NM_053025.3 & GCCTGACCACGAATATAA & GCTCCTTCTCATCATCATC \\
OCLN & NM_002538.2 & TCAGGGAATATCCACCTATCACTTCAG & CATCAGCAGCAGCCATGTACTCTTCAC \\
ZO-1 & NM_003257.3 & AGGGGCAGTGGTGGTTTCTGTTCTTTC & GCAGAGGTCAAAGTTCAAGGCTCAAGAGG \\
\hline
\end{tabular}

GAPDH= Glyceraldehyde 3-phosphate dehydrogenase; OCCL= Occludin; CLAU4= Claudin 4; MLCK= Myosin light chain kinase; ZO-1= Zona occludens 1.

\section{Assessment of MAPK isoforms phosphorylation in duodenal biopsies}

Frozen tissue samples were homogenized in ice-cold PBS containing protease and phosphatase inhibitor cocktail (10 $\mu \mathrm{l} / \mathrm{ml}$ PBS; Sigma-Aldrich). Concentrations of soluble proteins were quantified in tissue supernatants using the bicinchoninic acid assay (BCA; Bio-Rad). Lysates of Hela cells treated with Anisomycin were used as positive controls for phosphorylated P38 and JNK, whereas A431 cells treated with recombinant human epidermal growth factor were used for ERK1/2. Phosphorylated forms of P38, ERK1/2 and JNK in tissue and cell lysates were analysed using semiquantitative sandwich ELISA according to manufacturer's instructions (Ray Biotech), and data are expressed as optical density (OD) at $450 \mathrm{~nm}$. 
Colon adenocarcinoma cell line (Caco-2) from ATCC (Rockville, USA; passage 30-40) were maintained in Dulbecco's Modified Eagle Medium (DMEM; Lonza Benelux BV, Breda, the Netherlands) and barrier permeability was determined using Caco-2 monolayers grown on collagen-coated permeable polycarbonate transwell filters (Costar, Cambridge, MA, USA) as described previously ${ }^{15}$.

Briefly, monolayers were exposed to $40 \mathrm{mM}$ ethanol for $3 \mathrm{~h}$, either alone or after pretreatment for $1 \mathrm{~h}$ with $100 \mu \mathrm{M}$ SB2035809 (P38 inhibitor; Cell Signaling Technology, MA, USA), PD98059 (ERK 1/2 inhibitor; Cell Signaling Technology, MA, USA) or SP600125 (JNK inhibitor; Selleckchem, TX, USA) in medium. Thereafter, barrier function was assessed by measuring transepithelial electrical resistance (TEER) and apical to basolateral permeation of the fluorescent marker fluorescein isothiocyanatelabeled dextran $4 \mathrm{KDa}$ (1 mg/ml FITC-D4; Sigma-Aldrich) using an EVOM Epithelial Voltohmmeter (World Precision Instruments, Berlin, Germany) and spectrophotometer at an excitation and emission wavelengths of $498 \mathrm{~nm}$ and $540 \mathrm{~nm}$, respectively, and permeability was quantified as percentage of TEER and FITC-D4 permeating to the basal compartment.

Following subjection to the aforementioned treatments, Caco-2 monolayers were fixed on the inserts for $10 \mathrm{~min}$ with $4 \%(\mathrm{w} / \mathrm{v})$ paraformaldehyde and permeabilized with $0.1 \%(\mathrm{v} / \mathrm{v})$ Triton X-100 in PBS at RT for 40 min. Next, monolayers were processed for immunofluorescence staining of the TJ proteins ZO-1 and occludin, AJ proteins $\mathrm{E}$-cadherin and $\beta$-catenin, and F-actin as we described previously ${ }^{15}$.

\section{Determination of MAPK isoforms and MLC protein phosphorylation in Caco-2 cells}

Activation of MAPKs and MLCK was determined by assessment of MAPK isoforms and MLC phosphorylation using cell-based ELISA kits (Ray Biotech Inc, Norcross, GA, USA.) according to manufacturer's instructions. Briefly, Caco-2 cells $\left(20 \times 10^{3}\right)$ were seeded in 96 well-plates (Corning BV) and incubated overnight at $37^{\circ} \mathrm{C}, 5 \% \mathrm{CO}_{2}$. Then, monolayers were treated as described previously, fixed and blocked. Thereafter, monolayers were incubated with rabbit anti: total and phosphorylated P38 (p-P38), ERK1/2 (p-ERK1/2) and JNK ( $p$-JNK, 1:100 dilution in the blocking solution; Ray Biotech), and phosphorylated MLC (p-MLC1:100 dilution in the blocking solution; Cell Signaling Technology), followed by HRP-conjugated mouse anti-rabbit IgG (Dako, Glostrup, Denmark). Finally, 3, 3', 5, 5'-Tetramethylbenzidine (TMB) was added, followed by stop solution and optical density was read at $450 \mathrm{~nm}$ by SpectraMax M2 spectrophotometer (Molecular Devices).

\section{Power calculation and statistical analyses}

The primary outcome was intestinal permeability. In a study by Troost et al. ${ }^{29}$, small intestinal permeability increased in 15 healthy volunteers after intake of indomethacin $(L / R$ ratio $=0.036)$ versus placebo $(P<0.05)$. To detect similar differences 
in small intestinal permeability between interventions, a sample size of 12 healthy volunteers was needed with $\alpha=0.05, \beta=0.8$ and $P<0.05$. Statistical analyses were performed using GraphPad Prism software (version 5, Windows, San Diego, CA, USA). Data were tested for normality by the Kolmogorov-Smirnoff test. Normally distributed data were analyzed by independent Student's t test. Wilcoxon's and Mann-Whitney $U$ tests were used for abnormally distributed data. In vitro data, each conducted in triplicate, are presented as means \pm SDs of at least three experiments. One-way analysis of variance (ANOVA) followed by Tukey's Multiple Comparison post-hoc test were used, and $P$ value $<0.05$ was considered statistically significant.

\section{Results}

\section{Subjects}

Twelve male healthy volunteers [age $30.8 \pm 3.1$ years; BMI $23.0 \pm 0.07 \mathrm{~kg} / \mathrm{m}^{2}$ ] participated in this study. None of the subjects experienced any gastrointestinal discomfort during the test days. No side effects occurred and no changes in plasma ALT and $\gamma$ GT levels after ethanol administration were observed (data not shown).

\section{Ethanol and FAEE}

Blood samples collected prior to the intervention were negative for ethanol (i.e. $<10 \mathrm{mg} / \mathrm{dl}$ plasma) and FAEEs. Following intraduodenal ethanol, plasma ethanol concentration peaked at $15 \mathrm{~min}(62 \mathrm{mg} / \mathrm{dl})$ and gradually declined to $11 \mathrm{mg} / \mathrm{dl}$ at 180 min (Figure 3.2A). Mean plasma concentrations of the FAEEs, ethyl oleate and ethyl palmitate were significantly increased $30 \mathrm{~min}$ after ethanol administration versus to baseline, and decreased towards basal levels at $180 \mathrm{~min}$ (Figure 3.2B).

\section{Gastroduodenal, small and large intestinal permeability}

There was no significant difference in mean urinary sucrose recovery between placebo (2.309 \pm 0.85$)$ and ethanol $(3.087 \pm 1.51)$, $(P>0.5$; Figure 3.3A). However, the $L / R$ ratio, representing small intestinal permeability, was significantly higher after ethanol $(0.089 \pm 0.04)$ compared to placebo $(0.047 \pm 0.02),(P<0.1$; Figure $3.3 \mathrm{~B})$. Furthermore, ethanol significantly increased the S/E ratio in 5-24 $\mathrm{h}$ urine as indicator for large intestinal permeability versus placebo $(0.317 \pm 0.18$ vs. $0.026 \pm 0.03$, respectively), $(P<0.01$; Figure $3.3 C)$. 
A

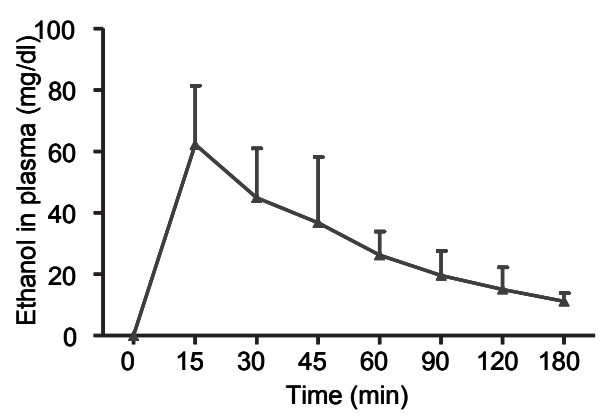

B
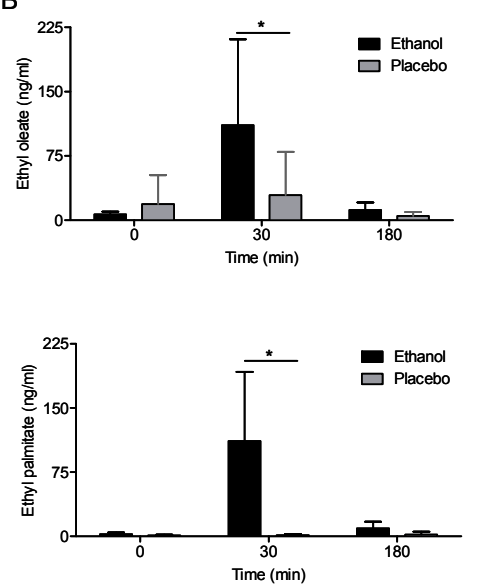

Figure 3.2 Effect of placebo or single dose of $20 \mathrm{~g}$ of ethanol administration on blood ethanol and FAEE levels. [A] Ethanol was analyzed in plasma of the individual volunteers after ethanol administration at the following time points: $0,15,30,45,60,90,120$, and $180 \mathrm{~min}$, and presented as mean \pm SDs. [B] Ethyl oleate and Ethyl palmitate were determined in plasma at 0,30 , and $180 \mathrm{~min}$, and presented as mean \pm SD $(n=12)$.

\section{Localization and expression of TJ proteins in duodenal mucosa}

After placebo administration, ZO-1 and occludin showed strong staining in duodenal biopsies at the apical part of epithelial cells, being continuous without disruption and showed colocalization along the villous epithelium. In contrast, after ethanol, ZO-1 and occludin showed less immune reactivity, disruption and complete absence of colocalization at the apical membrane compared with placebo (Figure 3.3D).

These features were confirmed by measurement of normalized image intensity of immunolabeled ZO-1 and occludin in duodenal biopsies. The normalized intensity of both ZO-1 and occludin decreased significantly after ethanol versus placebo (Figure 3.3E).

In addition, ethanol significantly down-regulated ZO-1 and up-regulated MLCK mRNA expression compared to placebo $(P<0.05$; Figure $3.3 \mathrm{~F})$. No differences were found in gene expression of occludin, claudin 3 and claudin 4 ( $P>0.05$; Figure 3.3F). 


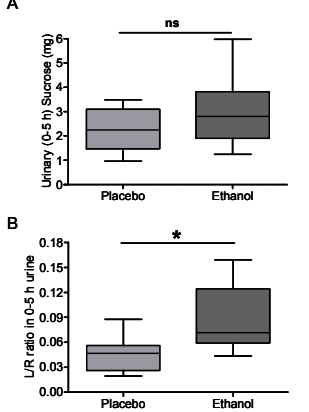

C

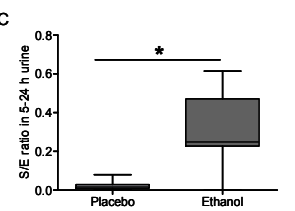

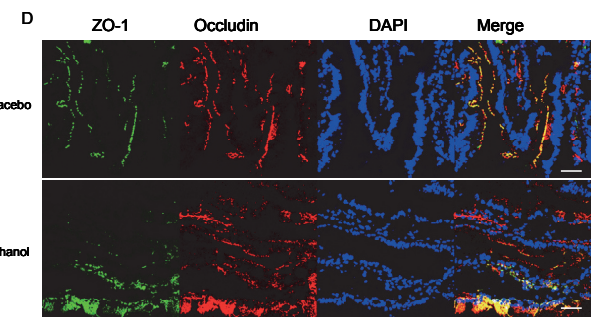

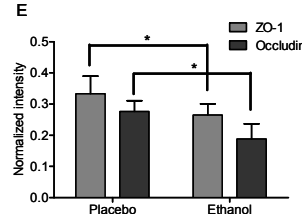

Figure 3.3 Effects of placebo and single dose of $20 \mathrm{~g}$ of ethanol on intestinal permeability, TJs protein and gene expression in the duodenum. [A] Effects on gastroduodenal permeability (sucrose, 0-5 $\mathrm{h}$ urinary recovery). Data presented as boxplots displaying minimum, maximum, and the 25th, 50th and 75th percentiles $(n=12) ; P>0.05$ vs. placebo. [B] Effects on small intestinal permeability (lactulose/rhamnose; L/R ratio, 0-5 $\mathrm{h}$ urine). Data presented as boxplots displaying minimum, maximum, and the 25 th, 50th and 75 th percentiles $(n=12) ;{ }^{*} P<0.01$ vs. placebo. [C] Effects on large intestinal permeability (sucralose/erythritol; S/E ratio, 5-24 h urine). Data presented as boxplots displaying minimum, maximum, and the 25th, 50th and 75th percentiles $(n=11) ;{ }^{*} P<0.01$ vs. placebo. [D] Representative images of immunelocalization of ZO-1 (green), occludin (red), and nuclei (blue) at a 400x magnification are shown. Scale bar represents $10 \mu \mathrm{m}$. [E] Normalized intensity of immunofluorescent-labelled ZO-1 and occludin in duodenal mucosa. Z-stack images were at $40 \times$ objective power. Data are mean \pm SD ( $\mathrm{n}=12) .{ }^{*} P<0.05$ for ZO-1, ${ }^{\#} P<0.05$ for occludin. [F] Normalized mRNAs expression of occludin (occl), claudin 4 (clau4), and claudin 3 (clau3), MLCK and ZO-1 in duodenal biopsy specimens determined by $\mathrm{qPCR}$. Each bar represents the mean \pm SD; ${ }^{*} P<0.05$ comparing ethanol with placebo.

\section{Phosphorylation of MAPK isoforms}

The phosphorylation of MAPK isoforms in duodenal tissue after ethanol and placebo administration was checked quantitatively by ELISA. Results showed that ethanol significantly increased levels of phosphorylated P38 (p-P38), ERK1/2 (p-ERK) and JNK (p-JNK) compared to the placebo $(P<0.05$; Figure $3.4 \mathrm{~A}, \mathrm{~B}$ and $C$, respectively.after 30 min of ethanol administration.

\section{Activation of MAPK in Caco-2 cells}

Next, we used Caco-2 cell monolayers to further elucidate the role of activation of MAPK in ethanol-induced barrier disruption in vitro by assessment of their protein phosphorylation. Compared with control, $40 \mathrm{mM}$ ethanol significantly induced activation of MAPK in Caco-2 cells, indicated by increased p-P38/total P38 (Figure 
3.5A), p-ERK1/2/total ERK1/2 (Figure 3.5B), and p-JNK/total JNK ratio (Figure 3.5C). Activation of MAPK was completely prevented by pretreatment with the P38 kinase inhibitor SB2035809 (Figure 3.5A), ERK1/2 inhibitor PD98059 (Figure 3.5B), and JNK inhibitor SP600125 (Figure 3.5C). To determine whether ethanol exposure causes MAPK activation via oxidative stress, Caco-2 cells were exposed to ethanol with or without L-cysteine, because L-cysteine is the rate limiting substrate for glutathione synthesis. Pretreatment of Caco-2 cells with L-cysteine $(100 \mu \mathrm{M})$ significantly attenuated ethanol-induced increased activation of P38 (Figure 5D), ERK1/2 (Figure 3.5E), and JNK (Figure 3.5F).

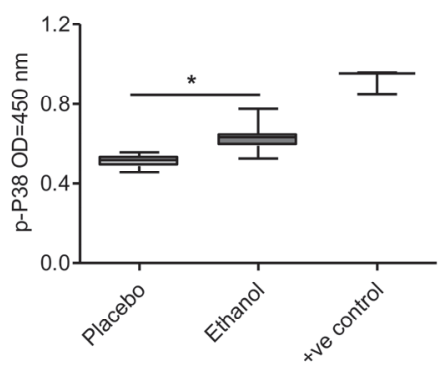

C

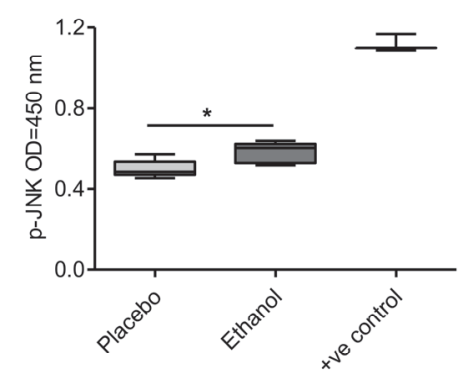

B

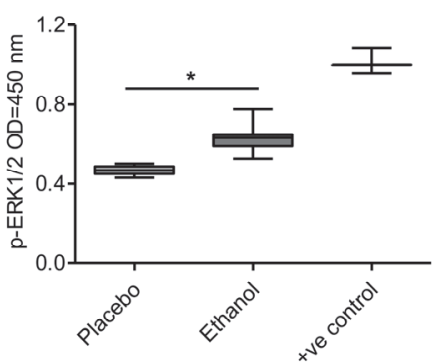

Figure 3.4 Effect of placebo and single dose of $20 \mathrm{~g}$ of ethanol on phosphorylation of MAPK isoforms in intestinal epithelium. Mucosal protein was isolated from tissue lysates, and the levels of phosphorylated MAPK were determined by ELISA using anti-phosphospecific antibodies against p-P38 [A], p-ERK1/2 [B], and [C] and p-JNK. Lysates of Hela cells treated with Anisomycin were used as positive control (+ve control) for phosphorylated P38 and JNK, whereas A431 cells treated with recombinant human epidermal growth factor were used for phosphorylated ERK1/2. ( $\mathrm{n}=12$ separate sample preparations; ${ }^{*} P<0.05$ vs. placebo).

\section{MAPK activation in ethanol-induced barrier disruption in Caco-2 monolayers}

In ethanol-treated monolayers, TEER values declined significantly (Figure 3.6A, C and E), and FITC-D4 permeation increased significantly (Figure 3.6B, D, and F) compared to controls. In contrast, monolayers pretreated with the MAPK isoforms inhibitors SB2035809, PD98059, and SP600125 showed no significant drop in TEER (Figure 3.6A, 
$\mathrm{C}$ and $\mathrm{E}$ ) or increase in FITC-D4 permeation (Figure 3.6B, D, and F) after subsequent ethanol treatment.

A

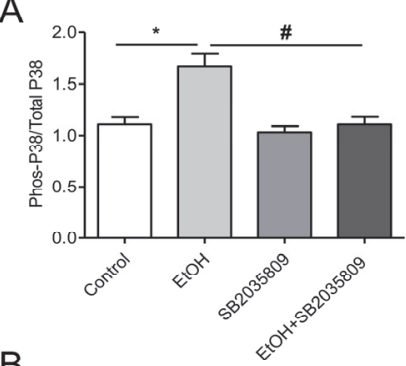

B

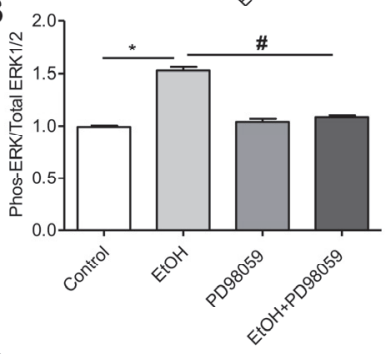

C

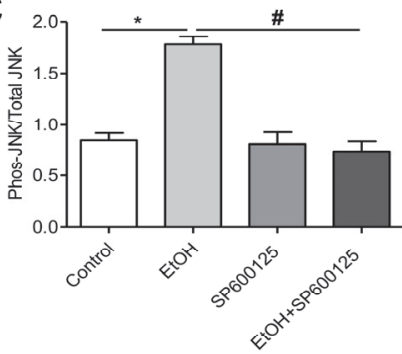

D

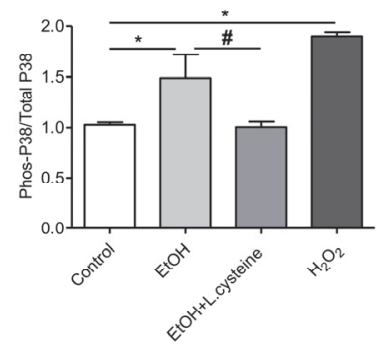

$\mathrm{E}$

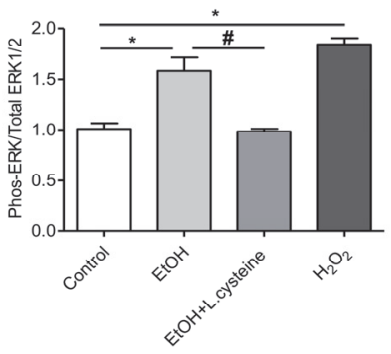

$\mathrm{F}$

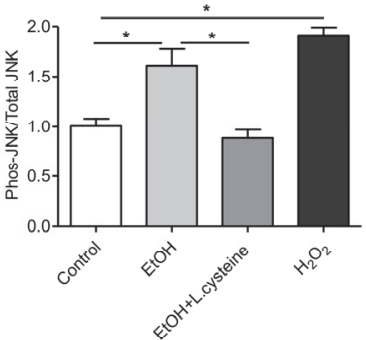

Figure 3.5 Effect of ethanol on phosphorylation of MAPK isoforms in Caco-2 cells. [A] Phosphorylation of P38, [B] ERK1/2, and [C] JNK was determined by cell-based ELISA and expressed as the ratio of the phosphorylated to the total form of each protein. $n=3$ and $* P<0.0001$ vs. control and ${ }^{\#} P<0.0001$ vs. ethanol in the presence of SB2035809, PD98055, or SP600125, respectively. Effect of L-cysteine on ethanol-induced phosphorylation of P38 [D], ERK1/2 [E], and JNK [F], determined by cell-based ELISA, and expressed as the ratio of the phosphorylated to the total amount of each protein. $\mathrm{H}_{2} \mathrm{O}_{2}$ used as positive control. $\mathrm{n}=3$ and ${ }^{*} P<0.0001$ vs. control and ${ }^{\#} P<0.0001$ vs. ethanol after pretreatment with L-cysteine. 

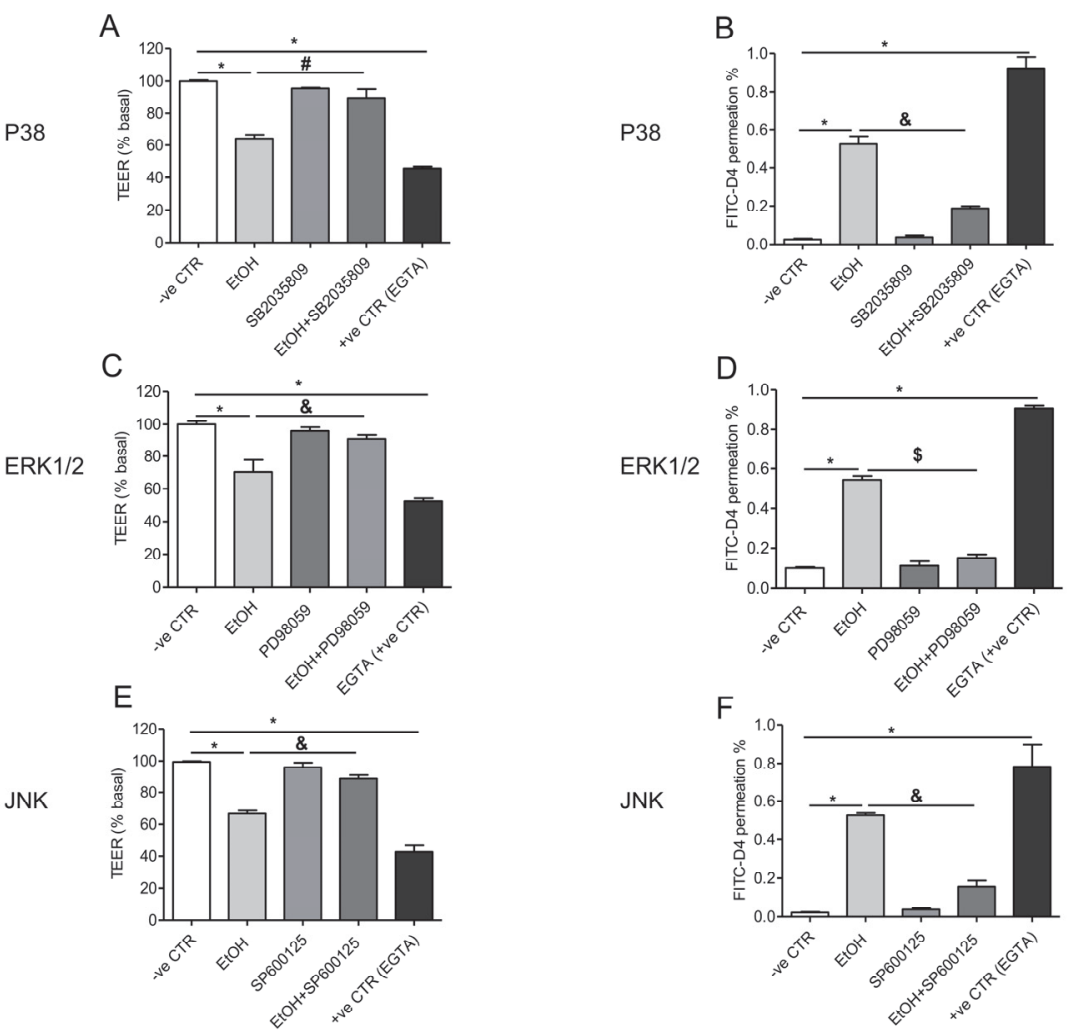

Figure 3.6 Effects of MAPK inhibition on ethanol-induced barrier dysfunction in Caco-2 monolayers. Confluent human intestinal epithelial cells (Caco-2) grown on inserts were assessed for transepithelial electrical resistance (TEER) and permeability to FITC-D4 after $3 \mathrm{~h}$ after treatment with P38 inhibitor [A] and [B], ERK1/2 inhibitor [C] and [D] and JNK inhibitor [E] and [F], respectively. Permeability is expressed as percentage of basal TEER and FITC-D4 permeation from apical to basal chamber. Some cells were treated only with medium or ethylene glycol tetra acetic acid (EGTA) as negative (-ve CTR) and positive control (+ve CTR), respectively. In addition, some monolayers were pretreated for $1 \mathrm{~h}$ with $100 \mu \mathrm{M}$ of the P38-specific kinase inhibitor SB2035809, ERK1/2 PD98055 and JNK SP600125. Data are means \pm SDs of triplicate wells from three separate experiments. ${ }^{*} P<0.0001$ vs. control, ${ }^{\sharp} P<0.001,{ }^{\&} P<0.0001$ and ${ }^{\$} P<0.05$ vs. ethanol after pretreatment with each MAPK inhibitor.

Compared to control, treatment of Caco-2 monolayers with $40 \mathrm{mM}$ ethanol induced delocalization and internalization of ZO-1 and occludin (Figure 3.7A), and of $\mathrm{E}$-cadherin and $\beta$-catenin from apical membranes to intracellular compartments (Figure 3.7B). However, pretreatment of Caco-2 monolayers with SB2035809, PD98059, or SP600125 attenuated ethanol-induced changes in localization of the TJ (Figure 3.7A), and AJ (Figure 3.7B).

Ethanol-induced intestinal barrier dysfunction may involve MLCK activation, as indicated by MLC phosphorylation ${ }^{16}$. As shown in Figure 3.7C, ethanol significantly increased MLC phosphorylation in Caco-2 monolayers compared to controls. 
However, inhibition of MAPK isoforms with SB2035809, PD98059 and SP600125 prvented ethanol-induced induced increase in MLC phosphorylation, comparable to the effect of pretreatment with $50 \mu \mathrm{M}$ of 1-(5-iodonaphthalene-1-sulfonyl)-1Hhexahydro-1,4-diazepine (ML-7), a specific MLCK inhibitor ${ }^{16}$. Since MLCK activation induces contraction of the peri-junctional actomyosin ring resulting in loss of TJ integrity $^{30}$, our experiments were extended further to elucidate effects of MAPK inhibition on ethanol-induced actin cytoskeleton rearrangement by immunofluorescence microscopy. As shown in figure 7D, in control condition, basal F-actin is uniformly distributed and organized in ring-like structures around the cellular periphery. However, in ethanol-treated monolayers, F-actin appears disorganized with thickened stress fibers (Figure 3.7D, arrowhead). Inhibition of MAPK isoforms by SB2035809, PD98059, or SP600125 attenuated ethanol-induced remodeling of actin cytoskeleton (Figure 3.7D).
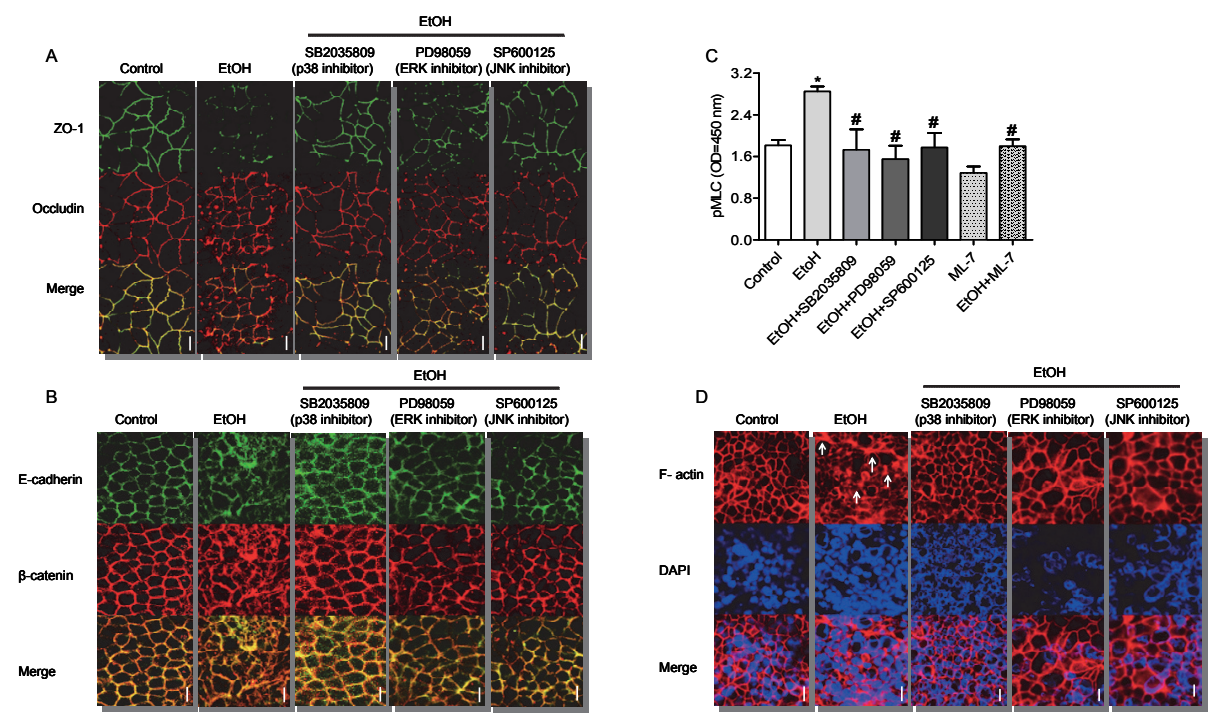

Figure 3.7 Effects of MAPK inhibition on ethanol-induced redistribution of TJ and AJ proteins; activation of MLCK and reorganization of F-actin cytoskeleton in Caco-2 monolayers. Monolayers subjected to aforementioned treatments (see Figure 5) were washed, fixed, permeabilized, and double-stained for ZO-1, occludin and E-cadherin, and ß-catenin. [A] Representative images of immunostaining of ZO-1 (green) and occludin (red) of three independent experiments. Scale bar $=10 \mu \mathrm{m}$. [B] Representative images of immunostaining of E-cadherin (green) and $\beta$-catenin (red). Scale bar=10 $\mu \mathrm{m}$. [C] Effects of MAPK inhibition on ethanol (EtOH)-induced myosin light chain (MLC) phosphorylation. Caco-2 cell monolayers were incubated with $40 \mathrm{mM}$ ethanol (EtOH) for $3 \mathrm{~h}$ with or without MAPK inhibitors (as in Figure 3.5) or MLCK inhibitor (ML-7) pretreatment for $1 \mathrm{~h}$, and analyzed by cell-based ELISA, using phosphospecific MLC antibodies $(n=3)$. Each bar represents the mean \pm SD; ${ }^{*} P<0.0001$ vs. control and ${ }^{\#} P<0.0001$ vs. ethanol. [D] Effects of MAPK inhibition on ethanol (EtOH)-induced F-actin reorganization. Caco-2 cell monolayers incubated with $40 \mathrm{mM}$ ethanol for $3 \mathrm{~h}$ with or without MAPK inhibitors pretreatment for $1 \mathrm{~h}$ were fixed and stained for F-actin with Texas red-X phalloidin Scale bar $=10 \mu \mathrm{m}$. 


\section{Discussion}

This study demonstrates that administration of a single moderate ethanol dose increases both small and large intestinal permeability in healthy volunteers. The impairment of intestinal barrier function was paralleled by redistribution of ZO-1 and occludin, down-regulation of ZO-1 and up-regulation of MLCK gene expression, and activation of MAPK isoforms (i.e.p38, ERK1/2 and JNK) in duodenal mucosa. In vitro data further confirmed that ethanol induces MAPK isoforms phosphorylation, together with changes in permeability, redistribution of ZO-1 and occludin, disruption of F-actin ring and a significant increase in phosphorylation of MLC. These changes were reversed by the anti-oxidant L-cysteine and by MAPK inhibitors.

Previous studies reporting on effect of ethanol on barrier function have mainly been performed in alcoholics ${ }^{19}$. We are the first to report on effects of a moderate dose of ethanol on intestinal epithelial barrier combining data at functional level with data of epithelial TJs at transcriptional and posttranscriptional level, focusing on potential mechanisms.

At functional level, our results are in line with those of Robinson et al. ${ }^{31}$ showing that a single moderate dose of ethanol increases excretion of urinary PEG 400 indicating increased small intestinal permeability. We did not observe any effect on gastroduodenal permeability in the present study, in contrast to previous reports ${ }^{4,32}$. This is not surprising given the fact that ethanol was administered via a tube directly into the distal duodenum, bypassing the stomach and proximal duodenum.

Interestingly, we found not only increase in small intestinal permeability but also in colon. While an increase in colon permeability by ethanol has been reported in animal studies, so far no data are available with respect to the human condition. In rats, oral ethanol (3-4.5 g/ $/ \mathrm{kg}$ ) for 12 days was found to increase colon permeability. This could be prevented by antibiotics and also by mast cell membrane stabilizers, indicating involvement of colon microbiota and mast cell activation ${ }^{33}$.

After ingestion, ethanol can reach the colon mucosa by diffusion from the blood ${ }^{12}$. Intestinal bacteria exhibit alcohol dehydrogenase (ALD) and to a lesser extent aldehyde dehydrogenase (ALDH) activity $^{34}$ with a lower capacity to metabolize acetaldehyde $^{35}$. Together with less active ALDH in colon mucosa ${ }^{36}$ this will result in intracolonic accumulation of acetaldehyde. Increased intracolonic accumulation of acetaldehyde is considered an important factor contributing to colorectal carcinogenesis $^{37}$ and hepatotoxicity ${ }^{38}$.

Little is known about duration of the increments in small and large intestinal permeability by ethanol. Robinson et $a l^{31}$ found the increase in small intestinal permeability after a single ethanol dose to be transient. This does not exclude that prolonged changes may occur after repeated, chronic ethanol exposure. Ethanol 
consumption has been associated with elevation of plasma endotoxins ${ }^{39}$ and increased drug absorption ${ }^{40}$, possibly through changes in intestinal barrier function. Recent data indicate that in patients with inflammatory bowel diseases (IBD) in remission, in whom intestinal permeability already is increased, moderate red wine consumption (i.e. $20 \mathrm{~g}$ ethanol per day) even further increased both small and large intestinal permeability and is potentially more injurious ${ }^{32}$.

We found that ethanol-induced increase in small intestinal permeability was associated with disruption of the key TJ proteins ZO-1 and occludin, and modulated mRNA expression of ZO-1 and MLCK in duodenal biopsies. Timing of biopsy sampling, i.e. $30 \mathrm{~min}$ after ethanol perfusion, was based on plasma ethanol levels. So far, no mechanistic studies in humans are available on effects of moderate ethanol intake. However, in chronic alcoholics, Tang et al. ${ }^{30}$ have reported an increased microRNA 212 expression with subsequent posttranscriptional suppression of ZO-1 synthesis in colon mucosa of chronic alcoholics.

In vitro, down-regulation of ZO-1 and activation of MLCK have been shown to mediate ethanol-induced TJ disruption and actin cytoskeleton rearrangement, and consequently, increased intestinal epithelial permeability ${ }^{16}$. Other cell signaling pathways including, mitogen activated protein kinase (MAPK) have also been proposed as mechanism for ethanol-induced barrier dysfunction ${ }^{41}$. MAPK isoforms including $\mathrm{p} 38$, extracellular signal-regulated kinase (ERK) and stress-activated protein kinase/C-Jun N-terminal kinase (SAPK/JNK) represent a converging point for many signaling pathways and have been linked to broad spectrum of cellular responses to extracellular stimuli such as growth factors and stress ${ }^{42}$. In the present study, we observed that ethanol induced phosphorylation of p38, ERK1/2 and JNK in duodenal mucosa, indicating their activation. These observations led us to further explore their role in Caco- 2 cell monolayers. Our in vitro results confirmed that ethanol exposure, at a concentration that can be achieved in blood after moderate consumption, can induce MAPK activation akin to $\mathrm{H}_{2} \mathrm{O}_{2}$, a potent oxidative stress inducer. In addition, ethanol increased permeability and induced abnormal distribution of TJ proteins and AJ proteins which could be attenuated by MAPK inhibition. No such effects were found after pretreatment with the anti-oxidant L-cysteine, indicating that ethanol activates MAPK, at least partly, through an oxidative stress-dependent mechanism. This finding is in line with reports by others and by our group, identifying oxidative stress as a key factor in the mechanisms by which ethanol and its metabolites disrupt intestinal barrier function ${ }^{43,44}$. Furthermore, oxidative stress has been found to activate MAPK in intestinal epithelial cells ${ }^{45}$. Therefore, our findings have relevance for ethanol-induced gut leakiness and indicate that these effects may partly be reduced by pretreatment with antioxidants.

The inability of ethanol to induce changes in Caco-2 monolayers after pretreatment with MAPK inhibitors suggests that ethanol requires MAPK activation to disrupt TJ, highlighting a pivotal role for MAPK in ethanol-induced barrier disruption. Previously, it has been found that p38-dependent MLCK activation is required for burn-induced 
intestinal permeability ${ }^{46}$. Our study provides evidence that ethanol leads to MAPKdependent MLC phosphorylation, F-actin rearrangement and stress fiber formation in Caco-2 cells. Disruption of actin cytoskeleton and interaction with TJ and AJ are implicated in ethanol and acetaldehyde-induced loss of TJ integrity in Caco-2 cell monolayers ${ }^{47}$. Therefore, our in vitro data support the in vivo observations that ethanol increases intestinal permeability in association with up-regulation of MLCK gene expression and activation of MAPKs in duodenal mucosa.

Ethanol and FAEEs including ethyl oleate and ethyl palmitate were measured in plasma, showing that ethanol can reach high levels within the first 30 min after administration, accompanied by increased concentrations of the FAEEs ethyl oleate and ethyl palmitate. Acetaldehyde concentrations have not been measured due to its volatile character.

Duodenal biopsies obtained at the same time point (i.e. 30 min post-administration) have shown major changes on TJ at both posttranscriptional and transcriptional levels. Prior in vitro data have shown that ethanol ${ }^{43}$, acetaldehyde ${ }^{48}$ and FAEEs ${ }^{44}$ are able to increase paracellular permeability. Intestinal mucosa is considered a major site for FAEE synthesis ${ }^{49}$. Together with a shift of ethanol metabolism into nonoxidative pathways resulting from low ALD activity in chronic alcoholics, additive or even synergistic deleterious effects of ethanol and its oxidative and nonoxidative metabolites are expected in vivo ${ }^{50}$.

Limitations of our study include the lack of assessment of TJ integrity at the colon mucosal level. In addition, being a proof of concept study, ethanol was administered directly into the duodenum to overcome interindividual variations in its upper $\mathrm{GI}$ metabolism. Our data allow future studies to include more physiological approaches with a major focus on the colon.

In conclusion, a moderate dose of ethanol increases small and large intestinal permeability. Oxidative stress-mediated activation of MAPK is involved in ethanolinduced TJ and AJ disruption, actin cytoskeleton reorganization and consequently, intestinal epithelial barrier dysfunction. Our findings have potential implications for pathogenesis of alcoholic-related liver and GI disorders. A better understanding of molecular mechanisms involved in ethanol-induced gut leakiness may provide clues for the development of preventive strategies. 


\section{References}

1. Mann RE, Smart RG, Govoni R. The epidemiology of alcoholic liver disease. Alcohol Res Health 2003;27:209-19.

2. Sawada T, Kita J, Nagata H, et al. Hepatectomy for metastatic liver tumor in patients with liver dysfunction. Hepatogastroenterology 2007;54:2306-9.

3. Rao RK, Seth A, Sheth P. Recent Advances in Alcoholic Liver Disease I. Role of intestinal permeability and endotoxemia in alcoholic liver disease. Am J Physiol Gastrointest Liver Physiol 2004;286:G881-4.

4. Keshavarzian A, Fields JZ, Vaeth J, et al. The differing effects of acute and chronic alcohol on gastric and intestinal permeability. Am J Gastroenterol 1994;89:2205-11.

5. Bode JC, Bode C, Heidelbach R, et al. Jejunal microflora in patients with chronic alcohol abuse. Hepatogastroenterology 1984;31:30-4.

6. Tabata $\mathrm{T}$, Tani $\mathrm{T}$, Endo $\mathrm{Y}$, et al. Bacterial translocation and peptidoglycan translocation by acute ethanol administration. J Gastroenterol 2002;37:726-31.

7. Mandrekar P, Catalano D, Szabo G. Inhibition of lipopolysaccharide-mediated NFkappaB activation by ethanol in human monocytes. Int Immunol 1999;11:1781-90.

8. Squier CA, Cox P, Hall BK. Enhanced penetration of nitrosonornicotine across oral mucosa in the presence of ethanol. J Oral Pathol 1986;15:276-9.

9. Eckardt MJ, File SE, Gessa GL, et al. Effects of moderate alcohol consumption on the central nervous system. Alcohol Clin Exp Res 1998;22:998-1040.

10. Bode C, Kugler V, Bode JC. Endotoxemia in patients with alcoholic and non-alcoholic cirrhosis and in subjects with no evidence of chronic liver disease following acute alcohol excess. J Hepatol 1987;4: 8-14.

11. Dufour MC. What is moderate drinking? Defining "drinks" and drinking levels. Alcohol Res Health 1999;23:5-14.

12. Halsted $\mathrm{CH}$, Robles EA, Mezey E. Distribution of ethanol in the human gastrointestinal tract. Am J Clin Nutr 1973;26:831-4.

13. Shen $L$, Weber CR, Raleigh DR, et al. Tight junction pore and leak pathways: a dynamic duo. Annu Rev Physiol 2011;73:283-309.

14. Guo X, Rao JN, Liu L, et al. Regulation of adherens junctions and epithelial paracellular permeability: a novel function for polyamines. Am J Physiol Cell Physiol. 2003;285:C1174-87.

15. Elamin E, Jonkers D, Juuti-Uusitalo K, et al. Effects of ethanol and acetaldehyde on tight junction integrity: in vitro study in a three dimensional intestinal epithelial cell culture model. PLoS One 2012;7:e35008

16. Ma TY, Nguyen D, Bui V, et al. Ethanol modulation of intestinal epithelial tight junction barrier. Am J Physiol 1999;276:G965-74.

17. Usatyuk PV, Natarajan V. Role of mitogen-activated protein kinases in 4-hydroxy-2-nonenal-induced actin remodeling and barrier function in endothelial cells. J Biol Chem 2004;279:11789-97.

18. Samak G, Narayanan D, Jaggar JH, et al. CaV1.3 channels and intracellular calcium mediate osmotic stress-induced $\mathrm{N}$-terminal c-Jun kinase activation and disruption of tight junctions in Caco-2 Cell monolayers. J Biol Chem 2011;286:30232-43.

19. Elamin EE, Masclee AA, Dekker J, et al. Ethanol metabolism and its effects on the intestinal epithelial barrier. Nutr Rev 2013;71:483-99.

20. Seitz HK, Egerer G, Simanowski UA, et al. Human gastric alcohol dehydrogenase activity: effect of age, sex, and alcoholism. Gut 1993;34:1433-7.

21. Millan MS, Morris GP, Beck IT, et al. Villous damage induced by suction biopsy and by acute ethanol intake in normal human small intestine. Dig Dis Sci 1980;25:513-25.

22. Chen $\mathrm{Y}, \mathrm{Lu} \mathrm{Q}$, Schneeberger EE, et al. Restoration of tight junction structure and barrier function by down-regulation of the mitogen-activated protein kinase pathway in ras-transformed Madin-Darby canine kidney cells. Mol Biol Cell 2000;11:849-62.

23. Hutson JR, Rao C, Fulga N, et al. An improved method for rapidly quantifying fatty acid ethyl esters in meconium suitable for prenatal alcohol screening. Alcohol 2011;45:193-9.

24. Bhoopathi P, Gondi CS, Gujrati M, et al. SPARC mediates Src-induced disruption of actin cytoskeleton via inactivation of small GTPases Rho-Rac-Cdc42. Cell Signal 2011;23:1978-87. 
25. Zhou Y, Wang Q, Mark Evers B, et al. Oxidative stress-induced intestinal epithelial cell apoptosis is mediated by p38 MAPK. Biochem Biophys Res Commun 2006;350:860-5.

26. Fisher OZ, Peppas NA. Quantifying Tight Junction Disruption Caused by Biomimetic pH-Sensitive Hydrogel Drug Carriers. J Drug Deliv Sci Technol 2008;18:47-50.

27. Abramoff MD, Magelhaes, P.J., Ram, S.J. Image Processing with ImageJ. Biophotonics International 2004; 11:36-42.

28. Keszthelyi D, Troost FJ, Jonkers DM, et al. Does acute tryptophan depletion affect peripheral serotonin metabolism in the intestine? Am J Clin Nutr 2012;95:603-8.

29. Troost FJ, Saris WH, Brummer RJ. Recombinant human lactoferrin ingestion attenuates indomethacininduced enteropathy in vivo in healthy volunteers. Eur J Clin Nutr 2003;57:1579-85.

30. Tang $Y$, Banan A, Forsyth CB, et al. Effect of alcohol on miR-212 expression in intestinal epithelial cells and its potential role in alcoholic liver disease. Alcohol Clin Exp Res 2008;32:355-64.

31. Robinson GM, Orrego $\mathrm{H}$, Israel $\mathrm{Y}$, et al. Low-molecular-weight polyethylene glycol as a probe of gastrointestinal permeability after alcohol ingestion. Dig Dis Sci 1981;26:971-7.

32. Swanson GR, Tieu V, Shaikh M, et al. Is moderate red wine consumption safe in inactive inflammatory bowel disease? Digestion 2011;84:238-44.

33. Ferrier $L$, Berard F, Debrauwer $L$, et al. Impairment of the intestinal barrier by ethanol involves enteric microflora and mast cell activation in rodents. Am J Pathol 2006;168:1148-54.

34. Nosova $\mathrm{T}$, Jokelainen $\mathrm{K}$, Kaihovaara $\mathrm{P}$, et al. Aldehyde dehydrogenase activity and acetate production by aerobic bacteria representing the normal flora of human large intestine. Alcohol Alcohol 1996;31: 555-64.

35. Nosova $\mathrm{T}$, Jokelainen $\mathrm{K}$, Kaihovaara $\mathrm{P}$, et al. Characteristics of aldehyde dehydrogenases of certain aerobic bacteria representing human colonic flora. Alcohol Alcohol 1998;33:273-80.

36. Koivisto $T$, Salaspuro M. Aldehyde dehydrogenases of the rat colon: comparison with other tissues of the alimentary tract and the liver. Alcohol Clin Exp Res 1996;20:551-5.

37. Seitz HK, Homann N. The role of acetaldehyde in alcohol-associated cancer of the gastrointestinal tract. Novartis Found Symp 2007;285:110-9; discussion 119-4, 198-9.

38. Salaspuro M. Bacteriocolonic pathway for ethanol oxidation: characteristics and implications. Ann Med 1996;28:195-200.

39. Shibayama Y, Asaka S, Nakata K. Endotoxin hepatotoxicity augmented by ethanol. Exp Mol Pathol 1991;55:196-202.

40. Weathermon R, Crabb DW. Alcohol and medication interactions. Alcohol Res Health 1999;23:40-54.

41. Leve F, de Souza W, Morgado-Diaz JA. A cross-link between protein kinase A and Rho-family GTPases signaling mediates cell-cell adhesion and actin cytoskeleton organization in epithelial cancer cells. J Pharmacol Exp Ther 2008;327:777-88.

42. Ye J, Tsukamoto $T$, Sun A, et al. A role for intracellular calcium in tight junction reassembly after ATP depletion-repletion. Am J Physiol 1999;277:F524-32.

43. Forsyth $C B$, Tang $Y$, Shaikh $M$, et al. Role of snail activation in alcohol-induced iNOS-mediated disruption of intestinal epithelial cell permeability. Alcohol Clin Exp Res 2011;35:1635-43.

44. Borbiev T, Birukova A, Liu F, et al. p38 MAP kinase-dependent regulation of endothelial cell permeability. Am J Physiol Lung Cell Mol Physiol 2004;287:L911-8.

45. Mehta D, Rahman A, Malik AB. Protein kinase C-alpha signals rho-guanine nucleotide dissociation inhibitor phosphorylation and rho activation and regulates the endothelial cell barrier function. J Biol Chem 2001;276:22614-20.

46. Aepfelbacher M, Zumbihl R, Heesemann J. Modulation of Rho GTPases and the actin cytoskeleton by YopT of Yersinia. Curr Top Microbiol Immunol 2005;291:167-75.

47. Sheth $\mathrm{P}$, Seth $\mathrm{A}$, Thangavel $\mathrm{M}$, et al. Epidermal growth factor prevents acetaldehyde-induced paracellular permeability in Caco-2 cell monolayer. Alcohol Clin Exp Res 2004;28:797-804.

48. Rao RK. Acetaldehyde-induced barrier disruption and paracellular permeability in Caco-2 cell monolayer. Methods Mol Biol 2008;447:171-83.

49. Diczfalusy MA, Bjorkhem I, Einarsson C, et al. Characterization of enzymes involved in formation of ethyl esters of long-chain fatty acids in humans. J Lipid Res 2001;42:1025-32.

50. Wu H, Cai P, Clemens DL, et al. Metabolic basis of ethanol-induced cytotoxicity in recombinant HepG2 cells: role of nonoxidative metabolism. Toxicol Appl Pharmacol 2006;216:238-47. 
70 


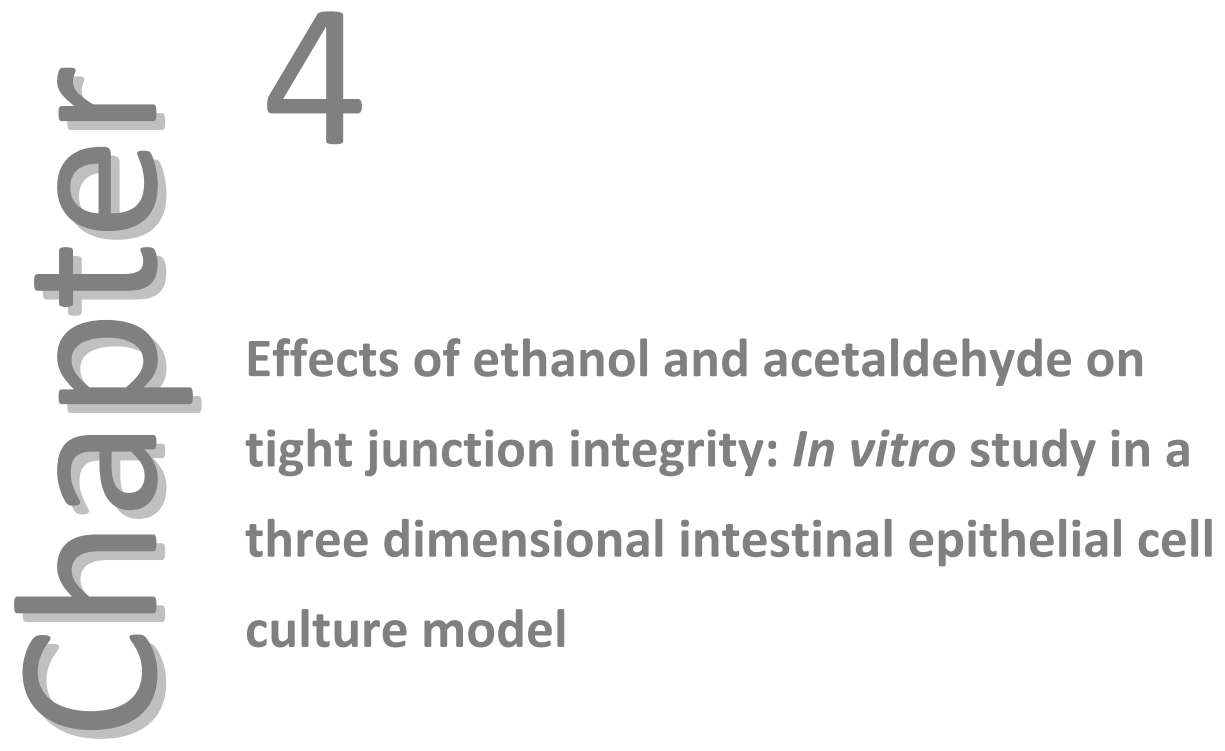

Elhaseen Elamin, Daisy Jonkers, Kati Juuti-Uusitalo, Sven van IJzendoorn, Freddy Troost, Hans Duimel, Jos Broers, Fons Verheyen, Jan Dekker, Ad Masclee PloS One 2012; 7:e35008 


\section{Abstract}

\section{Background}

Intestinal barrier dysfunction and translocation of endotoxins are involved in the pathogenesis of alcoholic liver disease. Exposure to ethanol and its metabolite, acetaldehyde at relatively high concentrations have been shown to disrupt intestinal epithelial tight junctions in the conventional two dimensional cell culture models. The present study investigated quantitatively and qualitatively the effects of ethanol at concentrations detected in the blood after moderate ethanol consumption, of its metabolite acetaldehyde and of the combination of both compounds on intestinal barrier function in a three-dimensional cell culture model.

\section{Methods and Findings}

Caco-2 cells were grown in a basement membrane matrix (Matrigel ${ }^{\mathrm{TM}}$ ) to induce spheroid formation and were then exposed to the compounds at the basolateral side. Morphological differentiation of the spheroids was assessed by immunocytochemistry and transmission electron microscopy. The barrier function was assessed by the flux of FITC-labeled dextran from the basal side into the spheroids' luminal compartment using confocal microscopy. Caco-2 cells grown on Matrigel assembled into fully differentiated and polarized spheroids with a central lumen, closely resembling enterocytes in vivo and provide an excellent model to study epithelial barrier functionality. Exposure to ethanol (10-40 mM) or acetaldehyde (25-200 $\mu \mathrm{M})$ for $3 \mathrm{~h}$, dose-dependently and additively increased the paracellular permeability and induced redistribution of ZO-1 and occludin without affecting cell viability or tight junction-encoding gene expression. Furthermore, ethanol and acetaldehyde induced lysine residue and microtubules hyperacetylation.

\section{Conclusions}

These results indicate that ethanol at concentrations found in the blood after moderate drinking and acetaldehyde, alone and in combination, can increase the intestinal epithelial permeability. The data also point to the involvement of protein hyperacetylation in ethanoland acetaldehyde-induced loss of tight junctions integrity. 


\section{Introduction}

It is well known that consumption of ethanol may result in a variety of noxious effects in the human body, especially in the liver ${ }^{1}$. Previous studies in humans and in animal models have demonstrated that ethanol causes intestinal mucosa damage, which may give rise to an increase in intestinal permeability ${ }^{2-7}$. This allows harmful and potentially toxic luminal compounds, such as endotoxins to enter the systemic circulation and to contribute to alcoholic liver disease or alcohol related diseases in other organs ${ }^{4,8-11}$. Intestinal mucosal barrier function and integrity depend on an intact paracellular pathway, which is largely regulated by intercellular junctions, i.e. tight junctions (TJs), adherens junctions (AJs) and desmosomes ${ }^{12}$. The TJs are multiprotein complexes composed of transmembrane proteins (occludin, the claudin family, tricellulin, junction adhesion molecule, and others) that interact with the cytoplasmic plaque proteins (e.g., ZO-1, ZO-2, ZO-3, AF6, cingulin), which in turn interact with F-actin to anchor occludin and the other transmembrane proteins to the cytoskeleton perijunctional ring of actomyosin ${ }^{12-20}$. In vitro studies using the conventional two dimensional (2D) cell culture model of intestinal cell monolayers grown on filters have shown that ethanol as well as its main metabolite, acetaldehyde disrupt epithelial TJs integrity and thereby increase paracellular permeability ${ }^{21-29}$. Recently, it has been reported that ethanol synergizes acetaldehyde-induced TJs disruption $^{30}$. The in vitro data published so far have shown that the disruption of intestinal barrier function occurs after apical exposure to ethanol in concentrations at $1 \% \mathrm{v} / \mathrm{v}\left(\sim 217 \mathrm{mM}\right.$ ) and higher ${ }^{21,22,26-29}$. Such concentrations can only be found in the lumen of the small intestine, immediately after "binge drinking", which is defined as consumption of least $160 \mathrm{~g} / \mathrm{day}^{31}$. Although variations have been reported worldwide in the definition of moderate ethanol consumption, consumption of (12-24 g/day) on a regular base is more widespread ${ }^{32}$. This amount of up to $20 \mathrm{~g} /$ day can result in ethanol serum concentrations of about $10-40 \mathrm{mM}$; one magnitude lower than previously tested ${ }^{33}$. Data on effects of ethanol at these concentrations on intestinal permeability and TJs complex are scarce. Current in vitro approaches to study the integrity and permeability of intestinal epithelial monolayers predominantly employ cell culture systems in which epithelial cells are grown on flat Transwell filter membranes. Although such 2D cell cultures may produce tight epithelial cell monolayers, important microenvironmental conditions that in a coordinated manner promote key signaling pathways and enable cell proliferation, differentiation and monolayer permeability, are lost. As a consequence, 2D cell culture systems fail to capture physiologically-significant and three-dimensional aspects of tissue biology ${ }^{34,35}$. Many of these aspects can be secured when cells are cultured in 3D matrices. This has been demonstrated for epithelial cells of various origins, including intestinal epithelial cells $^{35-42}$. Thus, unlike conventional 2D intestinal cell monolayers, intestinal epithelial cells cultured in a 3D matrix maintain specific morphological and biochemical properties of the in vivo tissue, including formation of microvilli and expression of 
brush border enzymes and remain in a differentiated and functionally active state for longer periods ${ }^{43}$. Three dimensional intestinal epithelial cultures thus provide an excellent model system to study intestinal epithelial integrity ${ }^{43}$.

Aim of the present study was to investigate in the 3D intestinal epithelial cell culture model of Caco-2 cells, the effects of ethanol at concentrations that are found in the blood after moderate drinking, and of the main ethanol metabolite acetaldehyde, on a) intestinal epithelial barrier function b) TJ proteins and c) TJ encoding gene expression.

\section{Materials and Methods}

\section{Cell line and culture conditions}

Colonic adenocarcinoma cell line (Caco-2) from the American Type Culture Collection, (ATCC, Rockville, USA) were cultured in Dulbecco's Modified Eagle Medium (DMEM; Lonza Benelux BV, Breda, NL) containing $4.5 \mathrm{~g} / \mathrm{l}$ glucose and L-glutamine, 10\% (v/v) fetal calf serum (Invitrogen, Breda, the Netherlands), 1\% (v/v) solution of nonessential amino acids (Invitrogen) and $1 \%(\mathrm{v} / \mathrm{v})$ solution of antibiotic/antimycotic mixture $(10,000$ units of penicillin, $10,000 \mu \mathrm{g}$ of streptomycin, and $25 \mu \mathrm{g}$ of amphotericin $\mathrm{B}$ per $\mathrm{ml}$; Invitrogen) at $37^{\circ} \mathrm{C}$ and in air plus $5 \% \mathrm{CO}_{2}$ atmosphere.

\section{Three dimensional epithelial cell culture and exposure to ethanol and acetaldehyde}

Caco- 2 cells were initially grown as standard monolayers on plastic support until they reached approximately $70-80 \%$ confluency. Twenty $\mu$ growth factor-reduced Matrigel ( $8 \mathrm{mg} / \mathrm{ml}$; BD Biosciences, San Jose, California USA) was allowed to solidify at $37^{\circ} \mathrm{C}$ for 30 minutes in glass bottom culture dishes (MatTek Corporation, Ashland, USA) for barrier function and immunofluorescence analysis, and in 96 well-plates (Corning BV, Amsterdam, the Netherlands) for redox state, mitochondrial function and cell viability assays. The Caco- 2 cells $\left(50 \times 10^{3}\right.$ cells/well; passage $\left.39-48\right)$ were resuspended in serum-free medium, mixed with $40 \%(\mathrm{v} / \mathrm{v})$ Matrigel and plated on the solidified Matrigel. Thereafter, the complete growth medium was added and spheroids were allowed to form over $5-7$ days at $37^{\circ} \mathrm{C}$. The quality of cultures was checked by counting the number of spheroids from four different quadrants and by classifying them according to the number of lumens formed. Only cultures consisting of more than $70 \%$ spheroids with a single lumen were used for further experiments. Spheroids were exposed to ethanol $(10 \mathrm{mM}, 20 \mathrm{mM}$ and $40 \mathrm{mM})$, acetaldehyde $(25 \mu \mathrm{M}, 50 \mu \mathrm{M}, 100 \mu \mathrm{M}, 200 \mu \mathrm{M})$ and the combination of both for $3 \mathrm{~h}$. These concentrations of ethanol are in the range found in the blood after moderate drinking ${ }^{44}$. To prevent evaporation, cultures were kept in small boxes and sealed with 
a plastic tape. Two $\mathrm{mM}$ ethylene glycol tetra acetic acid (EGTA) to induce maximum TJs disruption and growth medium only were used as positive and negative controls, respectively. In separate experiments, spheroids were exposed to Trichostatin A $(300 \mathrm{ng} / \mathrm{ml})$, an acetylating agent, for immunofluorescence analysis of protein acetylation.

\section{Assessment of intestinal epithelial barrier function}

To assess epithelial paracellular barrier function, spheroids were incubated under the above mentioned experimental conditions in the presence of $1 \mathrm{mg} / \mathrm{ml}$ fluorescein isothothiocyanate (FITC)-labeled dextran of 4 kDa (FITC-D4; Sigma Chemical Co, Amsterdam, the Netherlands) for $3 \mathrm{~h}$. Although less physiological and being a limitation of the current model, the intestinal barrier function was assessed from the basal to the luminal side, due to difficulties in exposing the luminal side of the model to a test substrate. The flux of FITC-D4 from the basolateral compartment into the lumen was monitored using a Leica TCS SPE confocal laser scanning microscope, equipped with a $63 \times$ oil immersion objective (Leica Microsystems $\mathrm{GmbH}$, Mannheim, Germany). The mean fluorescence intensity of the FITC-D4 from 8 spheroids was measured using Image $J$ software and expressed as the ratio of the luminal over the basal compartment, as previously described ${ }^{43}$.

\section{Fluorescent assessment of cell viability}

In this test a single-reagent fluorescence assay measures the relative number of living cells in the cell population, based on a single marker for cell viability (CellTiterApotox $^{\mathrm{TM}}$ Cell Viability Assay, Promega, Amsterdam, the Netherlands). Briefly, when the fluorogenic cell-permeant peptide substrate, glycyl-phenylalanyl-aminofluorocoumarin (GF-AFC), is cleaved by the live-cell protease activity it releases AFC generating a fluorescent signal proportional to the number of living cells. This live-cell protease activity marker becomes inactive upon loss of cell membrane integrity and leakage to the surrounding culture medium. After culturing the Caco-2 cells in 3D in 96-well plates, the wells were washed twice with HBSS $(\mathrm{pH} 7.4)$ and then incubated with $100 \mu \mathrm{l}$ of either $(10-40 \mathrm{mM})$ ethanol or $(25-200 \mu \mathrm{M})$ acetaldehyde at $37^{\circ} \mathrm{C}$ for $3 \mathrm{~h}$. Thereafter, $100 \mu \mathrm{l}$ of the reagent assay (GF-AFC) was added to each well and incubated for $60 \mathrm{~min}$. Positive ( $9 \%$ Triton X-100 solution) and negative (plain medium) control wells were also used for comparison of maximal and minimal membrane disruption, respectively. The fluorescence was measured at an excitation and emission wavelength of 400 and $505 \mathrm{~nm}$, respectively, by Varioskan Flash (Thermo Fisher Scientific Inc., Waltham, MA, USA). The cell viability was calculated from the fluorescent values and expressed as percentage of the negative control (plain medium only). 


\section{Immunofluorescence labeling}

At the end of the experimental period, Caco-2 spheroids in culture dishes were fixed in $4 \%(\mathrm{w} / \mathrm{v})$ paraformaldehyde in Hank's Buffered Salt Solution (HBSS; Invitrogen) at $37^{\circ} \mathrm{C}$ for $40 \mathrm{~min}$. Then, spheroids were washed thrice with HBSS and permeabilized with $0.1 \%(\mathrm{v} / \mathrm{v})$ Triton X-100 in PBS at room temperature for $40 \mathrm{~min}$. Next, spheroids were incubated with a blocking buffer containing $3 \%(\mathrm{w} / \mathrm{v})$ bovine serum albumin (BSA) in PBS, $\mathrm{pH} 7.4$, at $37^{\circ} \mathrm{C}$ for $2 \mathrm{~h}$ and washed with HBSS. Thereafter, spheroids were incubated with the following primary antibodies at 1:100 dilution in $3 \%(\mathrm{w} / \mathrm{v})$ BSA in PBS, pH 7.4 at $4^{\circ} \mathrm{C}$ overnight: mouse anti-ZO-1 (Zymed Laboratories, San Francisco, USA), rabbit anti-occludin (Zymed Laboratories), rabbit anti- $\beta$-catenin (Abcam, Cambridge, UK), mouse anti-E-cadherin (Abcam), mouse anti-acetylated $\alpha$-tubulin (Abcam) or rabbit anti-acetylated lysine (Enzo life sciences, Antwerp, Belgium). The next morning, spheroids were warmed at room temperature for $20 \mathrm{~min}$, washed thrice with HBSS and incubated with either Cy3-conjugated goat anti rabbit immunoglobulin (Jackson Laboratories, Suffolk, UK) or Alexa-488 conjugated goat anti mouse immunoglobulin (Invitrogen) secondary antibodies (1:100 dilution in 3\% $(\mathrm{w} / \mathrm{v})$ $\mathrm{BSA}$ in PBS, $\mathrm{pH} 7.4$ ) at $37^{\circ} \mathrm{C}$ for $1.5 \mathrm{~h}$. Actin filaments were stained using phalloidin (1:500 in PBS; Sigma Chemical Co). After another washing in HBSS, spheroids were stained for 5 min with diamidino-2-phenylindole (DAPI; 1:10,000 dilution in PBS; Sigma Chemical Co). Finally, spheroids were mounted in dishes using VectaShield mounting medium (Vector Laboratories, Burlingame, USA). Confocal images were obtained using a Leica TCS SPE confocal laser scanning microscope (Leica Microsystems GmbH). Image J software was used to process and analyze the images.

\section{Transmission electron microscopy (TEM)}

To assess the ultrastructural morphology of TJ and other cell-cell junctions in control spheroids and those exposed to ethanol (10 mM, $20 \mathrm{mM}$ and $40 \mathrm{mM})$ and acetaldehyde $(25 \mu \mathrm{M}, 50 \mu \mathrm{M}, 100 \mu \mathrm{M}, 200 \mu \mathrm{M})$ for $3 \mathrm{~h}$, the 3D spheroids were fixed in either $2.5 \%$ or Karnovsky's fixative in $0.1 \mathrm{M}$ phosphate buffer $(\mathrm{pH} 7.4)$ for 24 hours. After a short rinse in PBS, the samples were postfixed in $1 \%$ osmium tetroxide in $0.1 \mathrm{M}$ sodium cacodylate buffer containing $1.5 \%$ ferricyanide $\left(\mathrm{pH} 7.4,4^{\circ} \mathrm{C}\right)$ for $1 \mathrm{~h}$. Next, the spheroids were rinsed in PBS for $45 \mathrm{~min}$, dehydrated in a graded series of ethanol (70-100\%) and routinely embedded in epon (Ladd Research Industries Williston, USA). For light microscopy, $1 \mu \mathrm{m}$ thin sections were prepared and stained with toluidine blue (TB; Merck, Darmstadt, Germany). Finally, ultrathin sections were cut, stained with uranyl acetate (TED PELLA, Redding, CA) and lead citrate (Acros organics, Geel, Belgium), and examined in a Philips CM100 electron microscope (Philips CM100, Eindhoven, the Netherlands). 


\section{RNA isolation and reverse transcription}

Spheroids for RNA isolation were incubated with Matrisperse (BD Biosciences) to digest the Matrigel at $4^{\circ} \mathrm{C}$ for $2 \mathrm{~h}$. Thereafter, cultures were transferred to Eppendorf tubes and incubated with $1 \mathrm{ml}$ Trizol (Invitrogen), $10 \mu \mathrm{l} \beta$-mercaptoethanol and $200 \mu \mathrm{l}$ chloroform for $3 \mathrm{~min}$ at room temperature. Next, samples were centrifuged at $12,000 \mathrm{rpm}$ for $15 \mathrm{~min}$ at $4^{\circ} \mathrm{C}$. About $600 \mu \mathrm{l}$ from the upper, colorless phase was mixed with an equal volume of isopropanol and glycogen $(20 \mathrm{mg} / \mathrm{ml})$. Then, samples were incubated for $1 \mathrm{~h}$ at $-20^{\circ} \mathrm{C}$ and centrifuged at $12,000 \mathrm{rpm}$ at $4^{\circ} \mathrm{C}$ for $30 \mathrm{~min}$, after which a cell pellet could be seen. The pellets were washed thrice with $75 \%(\mathrm{v} / \mathrm{v})$ ethanol and dissolved in $20 \mu \mathrm{l}$ RNase-free water. Quantity and purity of the RNA samples was determined using a Nanodrop spectrophotometer (NanoDrop Technologies, Wilmington, USA).

\section{Quantification of gene expression using real-time PCR}

The mRNA levels of claudin-2, claudin-4, ZO-1, occludin, and myosin light chain kinase (MLCK) were assessed by real-time PCR. Briefly, $0.1 \mu \mathrm{g} / \mu \mathrm{l}$ total RNA was used as a template for the cDNA synthesis using the iScript cDNA synthesis kits (Bio-Rad, Veenendaal, the Netherlands). The cDNA was diluted 40x with RNAse free water. Each reaction contained $12.5 \mu \mathrm{l}$ iQ Sybr Green Supermix, $1 \mu \mathrm{l}$ of $10 \mu \mathrm{M}$ gene-specific forward and reverse primers, $4 \mu$ ldiluted cDNA template and $5.5 \mu$ sterile $\mathrm{H}_{2} \mathrm{O}$. As 'housekeeping' gene, glyceraldehyde 3-phosphate dehydrogenase (GAPDH) was used. Primer sequences were designed using Beacon designer software and are listed in Table 4.1. Reactions were run on My IQ Single Color Real Time PCR Detection System (Bio-Rad). RT-PCR conditions used were $3 \mathrm{~min}$ at $95^{\circ} \mathrm{C}$, followed by 40 amplification cycles of 10 seconds at $95^{\circ} \mathrm{C}$ and 45 seconds at $60^{\circ} \mathrm{C}$. Expression of the TJ-coding mRNA was normalized with GAPDH mRNA expression.

Table 4.1 Primer sequences for real-time PCR.

\begin{tabular}{|c|c|c|c|}
\hline Gene & Sequence ID & Forward primer & Reverse primer \\
\hline GAPDH & NM_002046.3 & TGCACCACCAACTGCTTAGC & GGCATGGACTGTGGTCATGAG \\
\hline CLDN 2 & NM_016675.4 & ATGGCCTCTCTTGGCCTCCAA & TCACACATACCCTGTCAGGCT \\
\hline CLDN 4 & NM_001305.3 & ACAGACAAGCCTTACTCC & GGAAGAACAAAGCAGAG \\
\hline MLCK & NM_053025.3 & GCCTGACCACGAATATAA & GСTССTTCTCATCATCATC \\
\hline \multirow[t]{2}{*}{ OCLN } & NM_002538.2 & TCAGGGAATATCCACCTATCA & CATCAGCAGCAGCCATGTACTCTTCA \\
\hline & & CTTCAG & $\mathrm{C}$ \\
\hline \multirow[t]{2}{*}{ ZO-1/TJP-1 } & NM_003257.3 & AGGGGCAGTGGTGGTTTTCTG & GCAGAGGTCAAAGTTCAAGGCTCAA \\
\hline & & TTCTTTC & GAGG \\
\hline
\end{tabular}

GADPH: glyceraldehyde-3-phosphate dehydrogenase; CLDN 2: claudin 2; CLDN 4: claudin 4; MLCK: myosin light chain kinase; OCLN: occludin; ZO-11/TJP-1: zonula occludens 1 / tight junction protein 1 


\section{Statistical analysis}

All experiments were performed in triplicate and results were reported as mean $\pm S D$ of at least 8 spheroids per experiments. A one-way analysis of variance (ANOVA) and Tukey's post hoc test were performed to determine significant differences between experimental conditions. Differences were considered statistically significant when $P<0.05$.

\section{Results}

\section{Intestinal epithelial caco-2 cells in 3D culture}

After 7 days in culture, Caco-2 cells embedded in 40\% Matrigel formed hollow multicellular spheroids consisting of a single layer of 40-50 cells and expressed the TJ proteins ZO-1 and occludin at the intercellular junctions surrounding the lumen (Figure 4.1A). The adherence junction (AJ) proteins, ß-catenin and E-cadherin were expressed basolaterally at the regions of cell-cell contact and the basal side (Figure 4.1B). The luminal side of the cytoplasm of the cells in the spheroids was filled by actin filaments stained with the TRITC-conjugated phalloidin (Figure 4.1C). By TEM, well developed bundles of microvilli facing the lumen and the junctional complex (TJs, AJs, desmosomes) between cells could be distinguished (Figure 4.2A); the Golgi apparatus was localized at the supranuclear region of the Caco-2 cells (Figure 4.2B).

\section{Effects of ethanol and acetaldehyde on paracellular permeability}

In unexposed spheroids, FITC-D4 was exclusively observed in the culture medium/matrigel matrix at the basolateral side of spheroids (Figure $4.3 \mathrm{~A}$ ) resulting in a very low luminal to basolateral (L/BL) fluorescent ratio (Figure 4.3D). Exposure to EGTA (2 mM), which is well-known to disrupt tight junctions, resulted in a rapid FITCD4 flux (Figure 4.3A) and the L/BL ratio in this condition was set to 1 (Figure 4.3D4.3F). Exposure of Caco-2 spheroids to ethanol (10-40 $\mathrm{mM}$ ) increased the intraluminal FITC-D4 fluorescent signals (Figure 4.3A) and significantly increased the L/BL fluorescent ratio, when compared to the unexposed spheroids, in a dose-dependent manner (Figure 4.3D). Similarly, exposure to acetaldehyde $(25-200 \mu \mathrm{M})$ for $3 \mathrm{~h}$ increased the intraluminal FITC-D4 fluorescent signals (Figure 4.3B) and significantly increased the $\mathrm{L} / \mathrm{BL}$ fluorescent ratio when compared to the unexposed spheroids, in a dose-dependent manner (Figure 4.3E). Next, the effects of combined exposure to ethanol and acetaldehyde on barrier function were examined. As shown in Figure 4.3C, exposure to $25 \mu \mathrm{M}$ or $50 \mu \mathrm{M}$ acetaldehyde in the presence of $10 \mathrm{mM}$ ethanol significantly increased the L/BL FITC-D4 ratio versus exposure to ( $25 \mu \mathrm{M}$ or $50 \mu \mathrm{M})$ acetaldehyde alone (Figure 4.3F). 
A

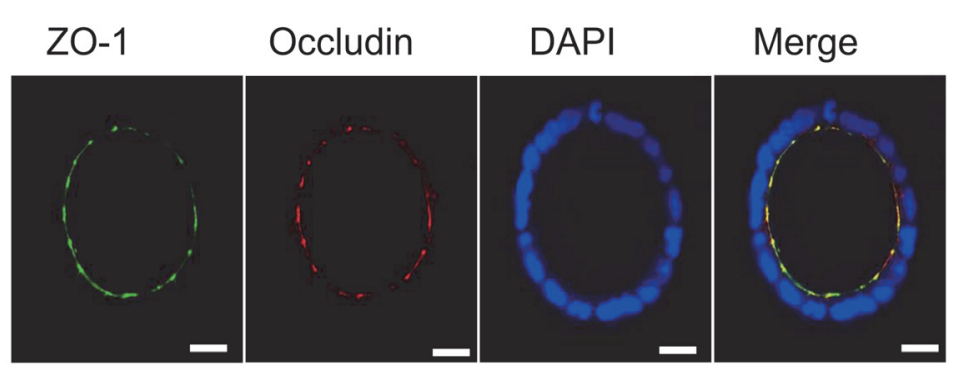

B

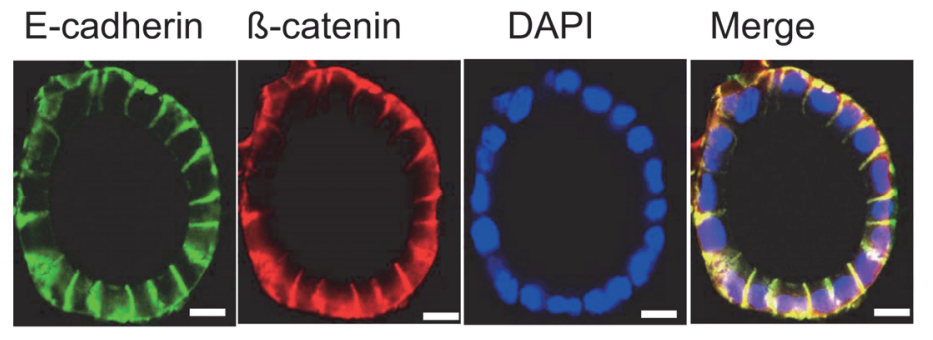

C

F-actin

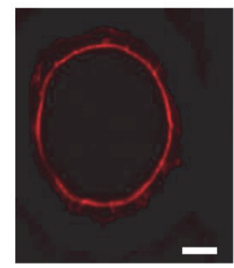

DAPI

Merge

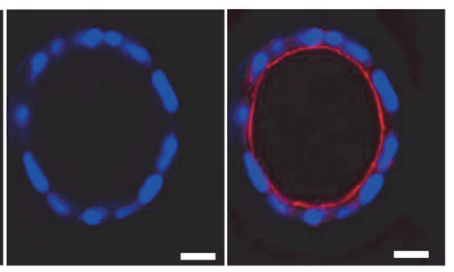

Figure 4.1 Three-dimensional Caco-2 spheroids express the TJ, the AJ proteins and the peri-junctional actin ring. [A] Protein expression of ZO-1 and occludin was detected using immunofluorescence microscopy (original magnification, $\times 63$ ) with mouse anti- ZO-1 (green), rabbit anti-occludin (red) followed by DAPI nuclear stain (blue). [B] Protein expression of E-cadherin and $B$-catenin was detected using immunofluorescence microscopy (original magnification, $\times 63$ ) with mouse anti-E-cadherin (green), rabbit anti-ß-catenin (red); and nuclei were counterstained with DAPI. [C] Actin filaments were detected using fluorescence microscopy (original magnification, $\times 63$ ) with phalloidin (red) and nuclei were counterstained with DAPI (blue). Representative images captured from cross-section of the spheroids are shown. The bars indicate $10 \mu \mathrm{m}$. 
A

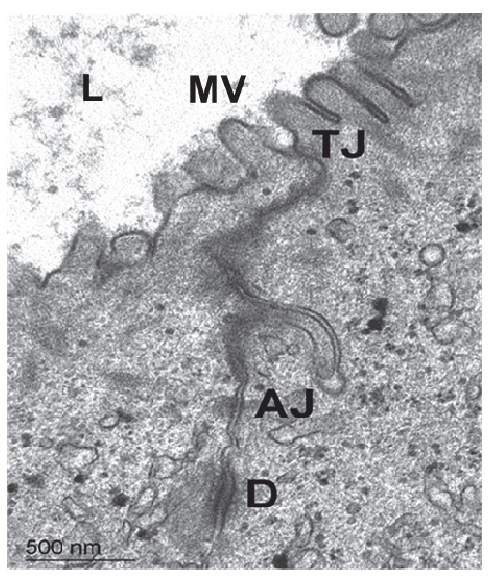

B

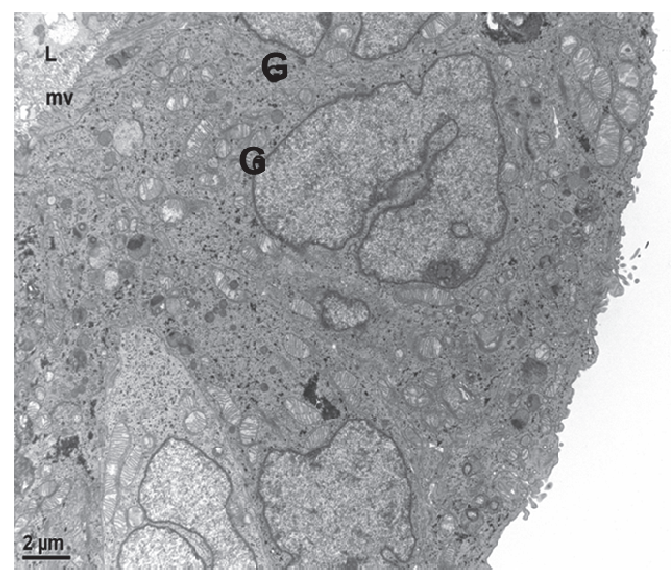

Figure 4.2 Transmission electron microscopy analysis of Caco-2 cells spheroids. A junctional complex (tight junction; TJ, adherens junction; AJ, D; desmosome) between adjacent cells is evident, apically $[A]$. The 3-D culture resulted in a luminal space $(L)$ with formation of microvilli $(\mathrm{mv})$ at the apical side and polarization of cells located in the cortical region of spheroid is indicated by supranuclear localization of Golgi (G) apparatuses [B].

\section{Effects of ethanol and acetaldehyde on cell viability}

Exposure of Caco-2 spheroids to ethanol (10, 20 and $40 \mathrm{mM})$ and acetaldehyde $(25,50,100$ and $200 \mu \mathrm{M})$ did not significantly reduce cell viability $(96.2 \pm 5.5,99.0 \pm 5.4$, 108.8 \pm 4.5 ; ethanol) and $(90.4 \pm 1.7,99.3 \pm 1.3,99.1 \pm 1.5,99.5 \pm 2$; acetaldehyde), whereas exposure to $9 \%$ Triton X-100 solution significantly reduced cell viability towards $24.7 \pm 3.9 \%$ (compared to negative control; $P<.0001$ ), (data not shown).

\section{Effects of ethanol and acetaldehyde on tight junction integrity and morphology}

As tight junctions are crucial for the paracellular barrier function, the effects of ethanol and acetaldehyde on the TJs integrity were determined. The $3 \mathrm{~h}$ exposure to ethanol $(40 \mathrm{mM})$ and acetaldehyde $(200 \mu \mathrm{M})$ resulted in loss of ZO-1 and occludin at the intercellular junctions as compared to the negative control (Figure 4.4A). Other concentrations of ethanol $(10,20 \mathrm{mM})$ and acetaldehyde $(100 \mu \mathrm{M})$ had similar effects (data not shown). At the ultrastructural level, cell-cell junctions displayed no visible differences between control and ethanol- or acetaldehyde-treated spheroids (Figure 4.4B). A reduction or change in the appearance of microvilli was noted in acetaldehyde-treated cells (Figure 4.4B). 
A

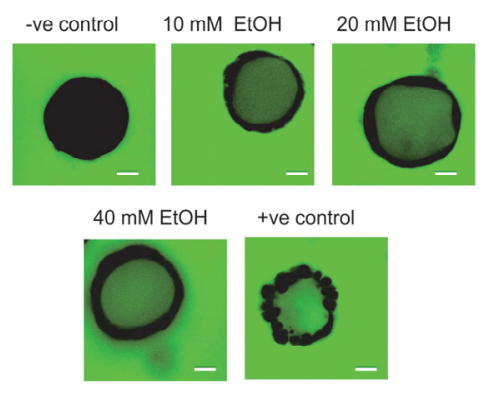

B

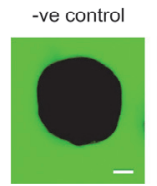

$100 \mu \mathrm{M} \mathrm{AcH}$
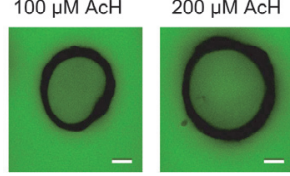

$25 \mu \mathrm{M} \mathrm{AcH}$

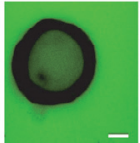

$200 \mu \mathrm{M} \mathrm{AcH}$

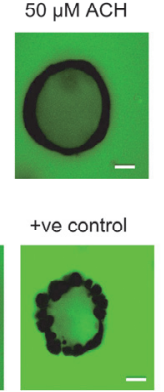

C
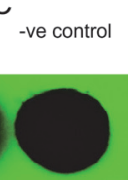

$50 \mu \mathrm{M} \mathrm{AcH}$

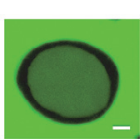

$25 \mu \mathrm{M} \mathrm{AcH}$

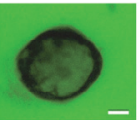

$50 \mu \mathrm{M} \mathrm{ACH}$ $10 \mathrm{mM} \mathrm{EtOH}$

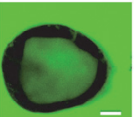

D

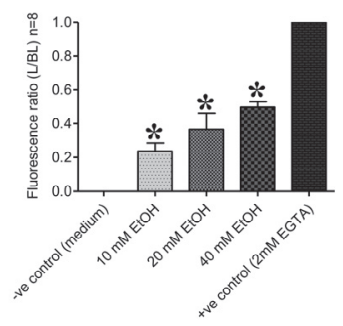

E

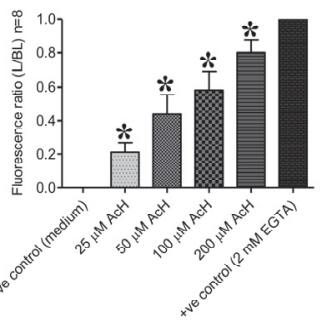

$\mathrm{F}$

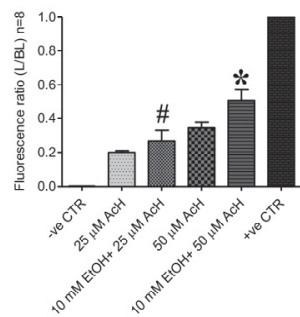

Figure 4.3 Ethanol and acetaldehyde and in combination increase permeation of the fluorescent marker FITC-D4 from the basolateral to the luminal side of Caco-2 spheroids. [A-C] Spheroids were exposed at the basal side, in the presence of FITC-D4, to medium only (-ve control), $2 \mathrm{mM}$ EGTA (+ve control) and either $10 \mathrm{mM}, 20 \mathrm{mM}, 40 \mathrm{mM}$ ethanol (panel A), $25 \mu \mathrm{M}, 50 \mu \mathrm{M}, 100$ $\mu \mathrm{M}$ or $200 \mu \mathrm{M}$ acetaldehyde (panel B) or in combination (panel C). Intraluminal accumulation of FITC-D4 (green) was measured using confocal microscopy (original magnification, $\times 63$ ) and representative images captured from the middle transsection of spheroids are shown and the bars indicate $10 \mu \mathrm{m}$. Ethanol, acetaldehyde and in combination increase FITC-D4 permeation dose-dependently in Caco-2 spheroids. [D-F] The mean fluorescence intensity of FITC-D4 from 8 spheroids was measured and expressed as the ratio of the luminal (L) over the basal (BL) compartment. The L/BL ratio of EGTA exposure (maximal TJ disruption) was set to 1 . All graphs indicate the results of three replicate experiments. Data were expressed as means $\pm S D$, for ethanol (D), for acetaldehyde (E) and for combination (F), ${ }^{*} P<0.0001$. 


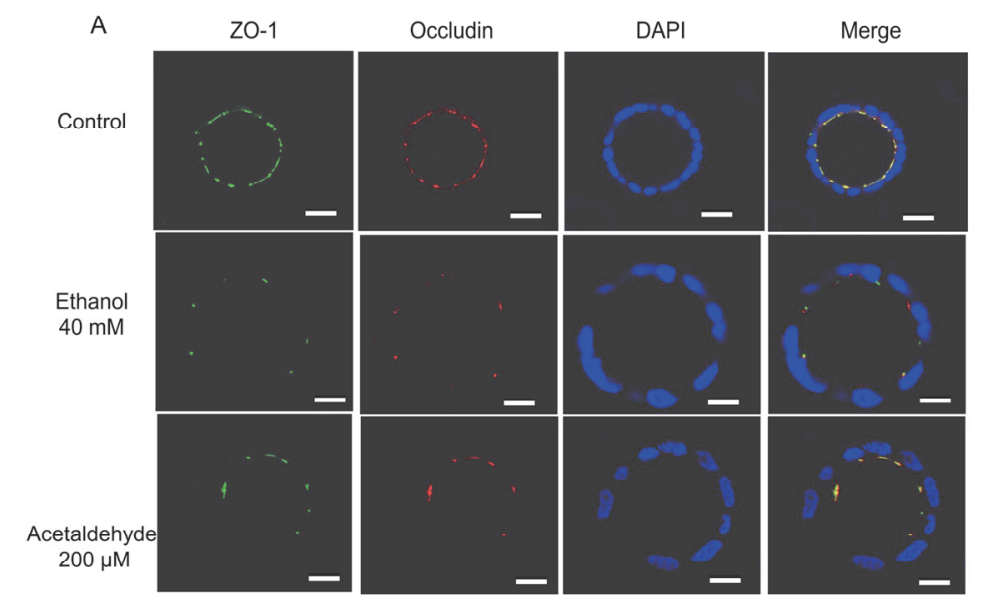

B
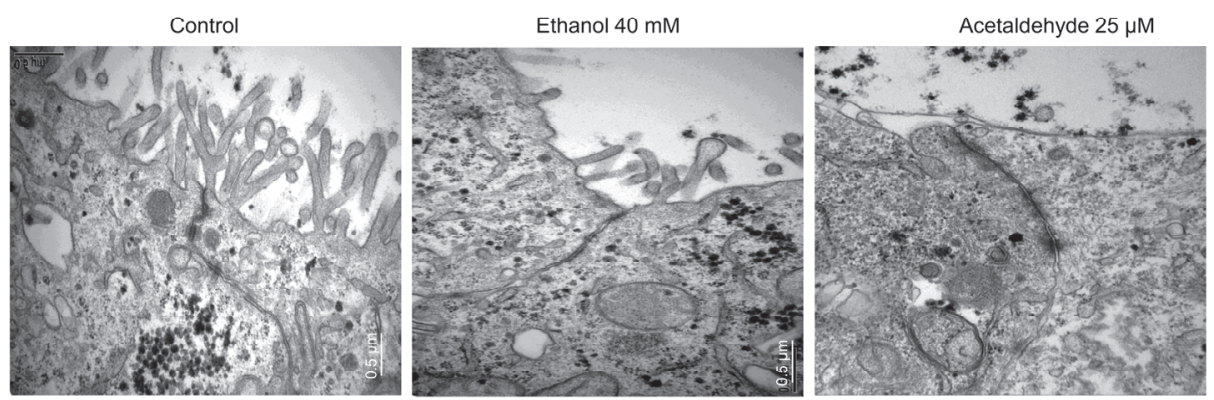

Figure 4.4 Ethanol and acetaldehyde exposure alters ZO-1 and occludin distribution at tight junctions of the Caco-2 spheroids. [A] Spheroids were exposed to medium only as control, $40 \mathrm{mM}$ ethanol or $200 \mu \mathrm{M}$ acetaldehyde for $3 \mathrm{~h}$ and labeled for ZO-1 (green), occludin (red) and nuclei (blue) by confocal immunofluorescence staining (original magnification, $\times 63$ ) and representative images captured from the middle transection of spheroids are shown. Bars indicate $10 \mu \mathrm{m}$. Effects of ethanol and acetaldehyde on TJ morphology. [B] Caco-2 spheroids were exposed to medium only, either ethanol or acetaldehyde for $3 \mathrm{~h}$, fixed and processed for Transmission electron microscopy. The lateral surface is indicated by arrows. Bars indicate $0.5 \mu \mathrm{m}$.

\section{Effects of ethanol and acetaldehyde on protein acetylation}

Since acetylation of microtubules and other proteins at lysine residues can affect different cell structures, possibly including the TJs, non-treated (negative control), ethanol, acetaldehyde and Trichostatin A (TSA; positive control)-treated spheroids were stained for acetylated $\alpha$-tubulin, acetylated lysine residues, DAPI, and ZO-1. Ethanol, acetaldehyde, and TSA-treated spheroids showed an increased staining of acetylated $\alpha$-tubulin and lysine residues compared to the control spheroids (Figure 4.5). Given the important role of the microtubules in TJ assembly, we investigated 
whether ethanol and acetaldehyde induced- $\alpha$-tubulin hyperacetylation correlated with a disrupted ZO-1 localization pattern. Ethanol, acetaldehyde and TSA-treated spheroids showed a marked $\alpha$-tubulin hyperacetylation associated with ZO-1 mislocalization when compared to the control spheroids (Figure 4.5).

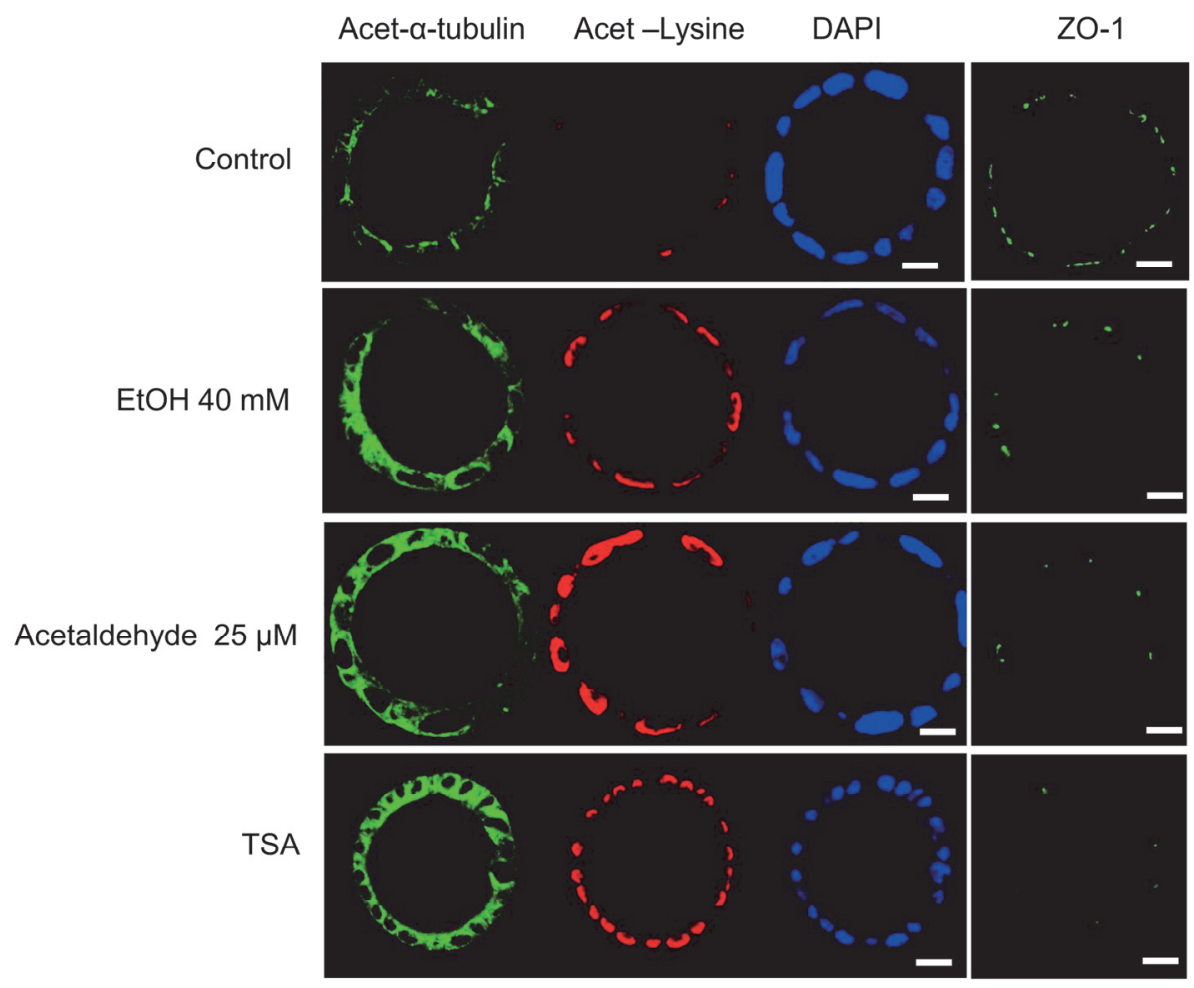

Figure 4.5 Hyperacetylation of $\alpha$-tubulin and lysine residues, and localization of ZO-1 in Caco-2 spheroids. Protein expression of acetylated- $\alpha$-tubulin, acetylated-lysine residues and ZO-1 detected using immunofluorescence microscopy (original magnification, $\times 63$ ) with mouse anti- $\alpha$-tubulin (green), rabbit anti-acetylated-lysine (bred), and nuclei were counterstained with DAPI (blue) and mouse anti-ZO-1 (green). Representative images captured from crosssections of the spheroids are shown. The bars indicate $10 \mu \mathrm{m}$.

\section{Effects of ethanol and acetaldehyde on tight junction gene expression}

The mRNA expression of claudin 2, claudin 4, MLCK, ZO-1 and occludin did not reveal any differences in expression patterns between either ethanol or acetaldehydeexposed and non-exposed Caco-2 spheroids (all $P>0.05$ versus control, Figure 4.6). 


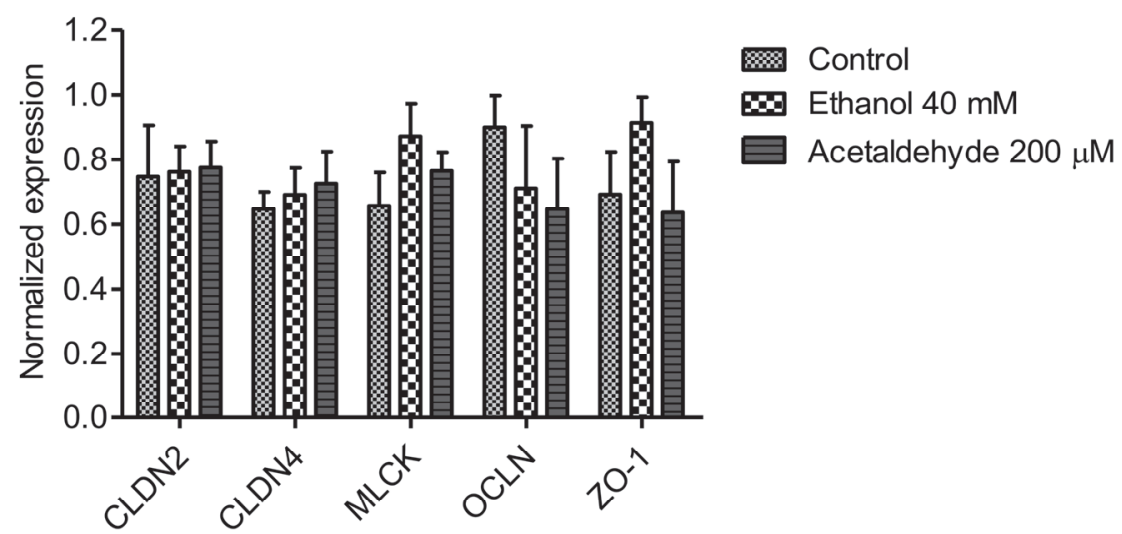

Figure 4.6 Ethanol and acetaldehyde did not alter expression of the tight junction-coding genes in Caco-2 spheroids. Spheroids were incubated with medium only (control), $40 \mathrm{mM}$ ethanol and $200 \mu \mathrm{M}$ acetaldehyde. Data were expressed as means of three replicates \pm SDs; all $P$ values $>0.05$ comparing ethanol or acetaldehyde vs. control.

\section{Discussion}

In the present study, using a 3D Caco-2 cell culture model, ethanol as well as acetaldehyde at concentrations as seen after moderate ethanol ingestion dosedependently increased paracellular permeability. The combined exposure resulted in an additive but not a synergistic effect. Furthermore, ethanol and acetaldehyde caused a redistribution and intracellular mislocalization of ZO-1 and occludin, and induced lysine residue and microtubule hyperacetylation. These changes were detected without a significant loss of cell viability or altered TJs-encoding gene expression.

Three-dimensional cell culture models are increasingly used to investigate epithelial pathophysiology. Since cell-stromal interaction is crucial in epithelial cell biology, a more realistic microenvironment is established to elicit an in vivo like response to stressors $^{45}$. Therefore, the 3D cultures provide more physiological cellular interactions which are important for cell behavior, stability and gene expression. In contrast, epithelial cells grown as 2D monolayers on artificial membranes, polyethylene terephathalate membranes for example, may partially lose their original characteristics as the monolayer growth being largely influenced by different factors including the physicochemical properties of the membrane ${ }^{46}$. We and others have shown that Caco-2 cells are capable of differentiating into 3D spheroids with a central lumen that exhibit numerous features of intestinal epithelium in vivo ${ }^{43,47,48}$. This 
includes full polarization of the cells, development of tight and adherens junctions, and formation of microvilli ${ }^{36,42,49}$.

In this study, the effects of ethanol and acetaldehyde at concentrations found in the blood after moderate ethanol consumption on barrier function using a 3D cell culture model were investigated. In moderate drinking the ethanol concentration in the blood can reach concentrations ranging from 5 to $6 \mathrm{mg} / \mathrm{dl}$, to levels of over $90 \mathrm{mg} / \mathrm{dl}$ $(\sim 20 \mathrm{mM})^{50}$. Furthermore, concentrations at $0.1 \%(\sim 20)$ and $0.2 \%(\sim 0 \mathrm{mM})$ ethanol have been used by others to gain mechanistic insight into ethanol-induced intestinal barrier dysfunction ${ }^{51-53}$. Therefore, the ethanol concentrations used in the present study are within the range of the blood concentrations, providing view of the changes caused by basal exposure of the intestinal epithelium to ethanol. Moderate ethanol consumption is defined as one standard drink (i.e. 12 grams of ethanol) a day for women, and two standard drinks a day for men ${ }^{33,54}$. Exposure of the 3D Caco-2 spheroids at the basal side, mimicking in vivo basolateral exposure of the intestinal epithelium to concentrations of $10-40 \mathrm{mM}$ ethanol, in the range of those found in the blood after moderate ethanol consumption, dose-dependently increased the paracellular permeability ${ }^{44}$. These observations indicate that ethanol at concentrations in the blood observed in moderate drinkers already may give rise to intestinal barrier dysfunction. Therefore, further studies investigating the mechanisms of moderate ethanol consumption-induced intestinal injury are warranted. Despite the morphological differences between $2 \mathrm{D}$ and $3 \mathrm{D}$ models, these results of the $3 \mathrm{D}$ model are in line with those obtained with the $2 \mathrm{D}$ model $^{21,22}$. However, most ethanol concentrations used in the 2D model were 20-80 fold higher ( 0.217-3.255 M) than those found in the distal small and large intestines after moderate ethanol consumption. The current data support recent observations that exposure to ethanol, at concentrations which can reach the distal small intestine as well as the colon, is able to disrupt the epithelial integrity in vitro ${ }^{53,55}$. It is known that Caco-2 monolayers have tighter cell junctions and thereby are more resistant to noxious agents than the human small intestinal epithelium ${ }^{56,57}$. This may explain why only luminal ethanol concentrations greater than $1 \% \sim 217 \mathrm{mM}$ were able to decrease the paracellular barrier function in Caco-2 monolayers. In this study, exposure of Caco-2 spheroids to (25-200 $\mu \mathrm{M})$ acetaldehyde resulted in a dose-dependent increase in the paracellular permeability. Caco-2 spheroids were exposed at the basolateral side mimicking the exposure to acetaldehyde found in the blood. Serum concentrations of acetaldehyde depend on the amount of ethanol consumed and the presence of different alcohol dehydrogenases and aldehyde dehydrogenase isozymes ${ }^{44}$. In other studies, luminal exposure of Caco-2 monolayers to higher concentrations $(100-600 \mu \mathrm{M})$ of acetaldehyde increased the paracellular permeability by disrupting the TJs integrity $^{23-28}$. Acetaldehyde was found more potent than ethanol in disrupting the barrier function, that is similar effects on permeability were reached at much lower concentrations. Based on these observations, combined exposure of the intestinal 
mucosa to these two barrier stressors in vivo will lead to more deleterious effects on the barrier function. Recently, Geetha et al., have shown that exposure to ethanol at $100 \mathrm{mM}$ did not increase the paracellular permeability in 2D Caco-2 monolayers, but in combination with 100 and $200 \mu \mathrm{M}$ acetaldehyde synergistically increased the paracellular permeability through a Src kinase and MLCK-dependent mechanisms ${ }^{30}$. The differences between results may be related to the differences in the cell culture models and the permeability markers used.

Data from the present study revealed that neither ethanol nor acetaldehyde at the indicated concentrations compromised cell viability. Inspection of TJ and other cellcell junctions at the ultrastructural level with electron microscopy revealed no apparent differences between control and ethanol- or acetaldehyde-exposed Caco-2 spheroids. However, in ethanol- or acetaldehyde-exposed Caco-2 spheroids, a reorganization of ZO-1 and occludin at the intercellular junctions and mislocalization of these proteins was found in conjunction with the observed enhancement in paracellular permeability. These data suggest that ethanol and acetaldehyde alter the molecular composition of TJ which likely affects TJ integrity. Our data contribute to the mounting evidence that loss of TJs integrity in response to both, ethanol and acetaldehyde is responsible for barrier dysfunction ${ }^{21-24}$. It has been shown that luminal exposure of Caco-2 monolayers to ethanol (2.5 to $15 \%=0.543-3.255 \mathrm{M}$ ) increased nitration of tubulin and disruption of barrier function by inducible nitric oxide synthase-dependent mechanism ${ }^{22,58}$. Furthermore, ethanol $(5-10 \%=1.085$ $2.170 \mathrm{M}$ ) reduced TEER of Caco-2 cell monolayers and increased paracellular permeability by a myosin light chain kinase-dependent mechanism ${ }^{21}$. Very recently, it has been shown that ethanol-induced intestinal hyperpermeability may require Snail activation via inducible nitric oxide synthase (iNOS) and p21-activated kinase (PAK1) ${ }^{58}$. Interestingly, Swanson and colleagues have shown that ethanol can induce intestinal hyperpermeability through stimulation of intestinal circadian clock gene expression ${ }^{53}$. Mechanisms of acetaldehyde-induced barrier dysfunction have largely been attributed to protein phosphatase and tyrosine kinase activation. Such increase in their activities can ultimately inhibit regulation of the phosphorylationdephosphorylation balance of the TJ and AJ proteins and consequently, disruption of the barrier function ${ }^{24,27}$. Ethanol has been shown to alter microtubule morphology in Caco-2 monolayers and consequently, barrier dysfunction ${ }^{59}$. Here, we have shown that Caco-2 spheroids basolaterally exposed to ethanol or acetaldehyde exhibit intense immunreactivity to antibodies against acetylated $\alpha$-tubulin and lysine residues. Interestingly, simultaneous immunostaining revealed a concomitant $\alpha$ tubulin hyperacetylation and ZO-1 mislocalization, suggesting that microtubule stabilization resulting from acetylation may lead to TJs disruption with subsequent increase in paracellular permeability. Trichostatin A mimicked the effect, suggesting that ethanol- and acetaldehyde-induced barrier dysfunction may be due to modulation of the TJs by histone acetylation. In line with this data, induction of 
histone acetylation has been shown to be associated with loss of TJs integrity ${ }^{60}$. In hepatocytes has revealed that $\alpha$-tubulin is a major target for ethanol and acetaldehyde-induced acetylation and impaired microtubule polymerization ${ }^{61-63}$. Since microtubule acetylation is regulated by coordinated activities of acetyltransferases and the microtubule-specific deacetylases, sirtuin T2 (SirT2) and histone deacetylases 6 (HDAC6), it is suggested that ethanol and acetaldehyde treatment inhibits these deacetylases activity especially SirT2 due to its $\mathrm{NAD}^{+}$dependency, leading to microtubule hyperacetylation ${ }^{62,64-67}$. The data show that hyperacetylation of microtubules is associated with ethanol-induced TJ disruption may further explain the molecular mechanism of ethanol-induced intestinal barrier dysfunction. In the present study, 3 hour exposure to either ethanol or acetaldehyde did not affect the TJs genes at the transcription level. However, Yueming Tang et al. demonstrated that $24 \mathrm{~h}$ exposure to ethanol (at $1 \%=217 \mathrm{mM}$ ) upregulated microRNA (miR-212) expression, thereby down-regulating the translation of ZO-1 and increased the paracellular permeability of Caco-2 monolayers ${ }^{51}$. In a combined in vivo and in vitro study, ethanol exposure $(5 \% \mathrm{vol} / \mathrm{vol}=1.085 \mathrm{M})$ for $5 \mathrm{~h}$ decreased the mRNA levels of Ts proteins through dysfunction of hepatocytes nuclear factor- $4 \alpha(H N F-4 \alpha)^{68}$. Since these studies have shown indirect effects of ethanol on TJ genes expression, further investigations are necessary to delineate the potential effects of ethanol and acetaldehyde on the expression of the TJ and AJ-encoding genes.

In summary, the results of the present study indicate that basolateral exposure of Caco-2 cells cultured in 3D to ethanol at concentrations found in the blood after moderate ethanol consumption, acetaldehyde and in combination, dose-dependently and additively increase paracellular permeability. Furthermore, ethanol and acetaldehyde induced lysine residue and microtubule hyperacetylation. This suggests that the changes on intestinal epithelial permeability may be induced, at least in part, by direct effects on the TJ and hyperacetylation of microtubules rather than loss of cell viability or altered TJ-encoding gene expression.

The 3D Caco-2 spheroids described in this study may represent a suitable cell culture model to study the intestinal epithelium under both, physiological and pathological conditions. Understanding the cellular mechanisms that regulate the intestinal epithelial barrier dysfunction induced by ethanol and its metabolites may lead to the development of therapeutic and/or nutritional strategies that are able to restore or prevent ethanol-induced intestinal epithelial damage during moderate ethanol consumption. 


\section{References}

1. Willner IR, Reuben A. Alcohol and the liver. Curr Opin Gastroenterol 2005;21:323-30

2. Keshavarzian A, Farhadi A, Forsyth $C B$, et al. Evidence that chronic alcohol exposure promotes intestinal oxidative stress, intestinal hyperpermeability and endotoxemia prior to development of alcoholic steatohepatitis in rats. J Hepatol 2009;50:538-547.

3. Soufi FG, Sheervalilou R, Vardiani M, et al. Chronic resveratrol administration has beneficial effects in experimental model of type 2 diabetic rats. Endocr Regul 2012;46:83-90.

4. Parlesak A, Schafer C, Schutz T, et al. Increased intestinal permeability to macromolecules and endotoxemia in patients with chronic alcohol abuse in different stages of alcohol-induced liver disease. J Hepatol 2000;32:742-7.

5. Keshavarzian A, Fields JZ, Vaeth J, et al. The differing effects of acute and chronic alcohol on gastric and intestinal permeability. Am J Gastroenterol 1994;89:2205-11.

6. Millan MS, Morris GP, Beck IT, et al. Villous damage induced by suction biopsy and by acute ethanol intake in normal human small intestine. Dig Dis Sci 1980;25:513-25.

7. Worthington BS, Meserole L, Syrotuck JA. Effect of daily ethanol ingestion on intestinal permeability to macromolecules. Am J Dig Dis 1978;23:23-32.

8. Bode C, Kugler V, Bode JC. Endotoxemia in patients with alcoholic and non-alcoholic cirrhosis and in subjects with no evidence of chronic liver disease following acute alcohol excess. J Hepatol 1987;4: 8-14.

9. Robinson $\mathrm{GM}$, Orrego $\mathrm{H}$, Israel $\mathrm{Y}$, et al. Low-molecular-weight polyethylene glycol as a probe of gastrointestinal permeability after alcohol ingestion. Dig Dis Sci 1981;26:971-7.

10. Keshavarzian A, Holmes EW, Patel M, et al. Leaky gut in alcoholic cirrhosis: a possible mechanism for alcohol-induced liver damage. Am J Gastroenterol 1999;94:200-7.

11. Bjarnason I, Peters TJ, Wise RJ. The leaky gut of alcoholism: possible route of entry for toxic compounds. Lancet 1984;1:179-82.

12. Tsukita S, Furuse M, Itoh M. Multifunctional strands in tight junctions. Nat Rev Mol Cell Biol 2001;2:285-93.

13. Laukoetter MG, Bruewer M, Nusrat A. Regulation of the intestinal epithelial barrier by the apical junctional complex. Curr Opin Gastroenterol 2006;22:85-9.

14. Turner JR. Molecular basis of epithelial barrier regulation: from basic mechanisms to clinical application. Am J Pathol 2006;169:1901-9.

15. Ivanov Al, Hunt D, Utech M, et al. Differential roles for actin polymerization and a myosin II motor in assembly of the epithelial apical junctional complex. Mol Biol Cell 2005;16:2636-50.

16. Anderson JM, Van Itallie CM. Tight junctions and the molecular basis for regulation of paracellular permeability. Am J Physiol 1995;269:G467-75.

17. Van Itallie CM, Anderson JM. The molecular physiology of tight junction pores. Physiology (Bethesda) 2004;19:331-8.

18. Itoh M, Furuse M, Morita K, et al. Direct binding of three tight junction-associated MAGUKs, ZO-1, ZO2, and ZO-3, with the COOH termini of claudins. J Cell Biol 1999;147:1351-63.

19. Furuse $\mathrm{M}$, Hirase $\mathrm{T}$, Itoh $\mathrm{M}$, et al. Occludin: a novel integral membrane protein localizing at tight junctions. J Cell Biol 1993;123:1777-88.

20. Schulzke JD, Fromm M. Tight junctions: molecular structure meets function. Ann N Y Acad Sci 2009;1165:1-6.

21. Ma TY, Nguyen D, Bui V, et al. Ethanol modulation of intestinal epithelial tight junction barrier. Am J Physiol 1999;276:G965-74.

22. Banan A, Choudhary S, Zhang $Y$, et al. Ethanol-induced barrier dysfunction and its prevention by growth factors in human intestinal monolayers: evidence for oxidative and cytoskeletal mechanisms. J Pharmacol Exp Ther 1999;291:1075-85.

23. Rao RK. Acetaldehyde-induced barrier disruption and paracellular permeability in Caco-2 cell monolayer. Methods Mol Biol 2008;447:171-83.

24. Sheth $\mathrm{P}$, Seth A, Atkinson KJ, et al. Acetaldehyde dissociates the PTP1B-E-cadherin-beta-catenin complex in Caco-2 cell monolayers by a phosphorylation-dependent mechanism. Biochem J 2007;402: 291-300. 
25. Sheth $\mathrm{P}$, Seth $\mathrm{A}$, Thangavel $\mathrm{M}$, et al. Epidermal growth factor prevents acetaldehyde-induced paracellular permeability in Caco-2 cell monolayer. Alcohol Clin Exp Res 2004;28:797-804.

26. Seth A, Basuroy S, Sheth $P$, et al. L-Glutamine ameliorates acetaldehyde-induced increase in paracellular permeability in Caco-2 cell monolayer. Am J Physiol Gastrointest Liver Physiol 2004;287: G510-7.

27. Atkinson KJ, Rao RK. Role of protein tyrosine phosphorylation in acetaldehyde-induced disruption of epithelial tight junctions. Am J Physiol Gastrointest Liver Physiol 2001;280:G1280-8.

28. Rao RK. Acetaldehyde-induced increase in paracellular permeability in Caco-2 cell monolayer. Alcohol Clin Exp Res 1998;22:1724-30.

29. Lee H, Zhang P, Herrmann A, et al. Acetylated STAT3 is crucial for methylation of tumor-suppressor gene promoters and inhibition by resveratrol results in demethylation. Proc Natl Acad Sci U S A 2012; 109:7765-9.

30. Geetha S, Rao RK. M1687 Ethanol synergizes acetaldehyde-induced tight junction (TJ) disruption in CACO-2 cell monolayers by SRC kinase and myosin light chain kinase (MLCK)-dependent mechanism. Gastroenterology 2009;136 Suppl 1:A-410.

31. Malyutina $S$, Bobak $M$, Kurilovitch $S$, et al. Relation between heavy and binge drinking and all-cause and cardiovascular mortality in Novosibirsk, Russia: a prospective cohort study. Lancet 2002;360: 1448-54.

32. Dufour MC. What is moderate drinking? Defining "drinks" and drinking levels. Alcohol Res Health 1999;23:5-14.

33. Werch CE, Gorman DR, Marty PJ. Relationship between alcohol consumption and alcohol problems in young adults. J Drug Educ 1987;17:261-76.

34. Griffith LG, Swartz MA. Capturing complex 3D tissue physiology in vitro. Nat Rev Mol Cell Biol 2006;7: 211-24.

35. Pampaloni F, Reynaud EG, Stelzer EH. The third dimension bridges the gap between cell culture and live tissue. Nat Rev Mol Cell Biol 2007;8:839-45.

36. O'Brien LE, Zegers MM, Mostov KE. Opinion: Building epithelial architecture: insights from threedimensional culture models. Nat Rev Mol Cell Biol 2002;3:531-7.

37. Bissell MJ, Rizki A, Mian IS. Tissue architecture: the ultimate regulator of breast epithelial function. Curr Opin Cell Biol 2003;15:753-62.

38. Schmeichel KL, Bissell MJ. Modeling tissue-specific signaling and organ function in three dimensions. J Cell Sci 2003;116:2377-88.

39. Nickerson CA, Goodwin TJ, Terlonge J, et al. Three-dimensional tissue assemblies: novel models for the study of Salmonella enterica serovar Typhimurium pathogenesis. Infect Immun 2001;69:7106-20.

40. Honer zu Bentrup K, Ramamurthy R, Ott CM, et al. Three-dimensional organotypic models of human colonic epithelium to study the early stages of enteric salmonellosis. Microbes Infect 2006;8:1813-25.

41. Lindfors $K$, Halttunen $T$, Huotari $P$, et al. Identification of novel transcription factor-like gene from human intestinal cells. Biochem Biophys Res Commun 2000;276:660-6.

42. Halttunen T, Marttinen A, Rantala I, et al. Fibroblasts and transforming growth factor beta induce organization and differentiation of T84 human epithelial cells. Gastroenterology 1996;111:1252-62.

43. Juuti-Uusitalo K, Klunder L, Sjollema KA, et al. Differential effects of TNF (TNFSF2) and IFN-gamma on intestinal epithelial cell morphogenesis and barrier function in three-dimensional culture. PLoS One 2011;6:e22967.

44. Zakhari S. Overview: how is alcohol metabolized by the body? Alcohol Res Health 2006;29:245-54.

45. Ohmori T, Yang JL, Price JO, et al. Blockade of tumor cell transforming growth factor-betas enhances cell cycle progression and sensitizes human breast carcinoma cells to cytotoxic chemotherapy. Exp Cell Res 1998;245:350-9.

46. Kim JB. Three-dimensional tissue culture models in cancer biology. Semin Cancer Biol 2005;15:365-77.

47. Jaffe $A B, K a j i ~ N$, Durgan J, et al. Cdc42 controls spindle orientation to position the apical surface during epithelial morphogenesis. J Cell Biol 2008;183:625-33.

48. Kim JB, Stein R, O'Hare MJ. Three-dimensional in vitro tissue culture models of breast cancer-- a review. Breast Cancer Res Treat 2004;85:281-91.

49. Ivanov Al, Hopkins AM, Brown GT, et al. Myosin II regulates the shape of three-dimensional intestinal epithelial cysts. J Cell Sci 2008;121:1803-14. 
50. Eckardt MJ, File SE, Gessa GL, et al. Effects of moderate alcohol consumption on the central nervous system. Alcohol Clin Exp Res 1998;22:998-1040.

51. Tang $Y$, Banan A, Forsyth CB, et al. Effect of alcohol on miR-212 expression in intestinal epithelial cells and its potential role in alcoholic liver disease. Alcohol Clin Exp Res 2008;32:355-64.

52. Forsyth CB, Tang $\mathrm{Y}$, Shaikh M, et al. Alcohol stimulates activation of Snail, epidermal growth factor receptor signaling, and biomarkers of epithelial-mesenchymal transition in colon and breast cancer cells. Alcohol Clin Exp Res 2010;34:19-31.

53. Swanson G, Forsyth $\mathrm{CB}$, Tang $\mathrm{Y}$, et al. Role of intestinal circadian genes in alcohol-induced gut leakiness. Alcohol Clin Exp Res 2011;35:1305-14.

54. Services USDoAUSDoHaH. Home and Garden Bulletin No. 232. Nutrition and Your Health: Dietary Guidelines for Americans. 1990.

55. Forsyth $C B$, Tang $Y$, Shaikh $M$, et al. Role of snail activation in alcohol-induced iNOS-mediated disruption of intestinal epithelial cell permeability. Alcohol Clin Exp Res 2011;35:1635-43.

56. Korsten MA, Matsuzaki S, Feinman L, et al. High Blood Acetaldehyde Levels after Ethanol Administration. New Engl J Med 1975;292:386-389.

57. Harada S, Agarwal DP, Werner Goedde H, et al. Blood ethanol and acetaldehyde levels in Japanese alcoholics and controls. Pharmacol Biochem Behav 1983;18:139-40.

58. Forsyth $C B$, Tang $Y$, Shaikh $M$, et al. Role of snail activation in alcoholilnduced iNOS-mediated disruption of intestinal epithelial cell permeability. Alcohol Clin Exp Res 2011;35:1635-43.

59. Banan A, Smith GS, Rieckenberg CL, et al. Protection against ethanol injury by prostaglandin in a human intestinal cell line: role of microtubules. Am J Physiol 1998;274:G111-21.

60. Ohata A, Usami M, Miyoshi M. Short-chain fatty acids alter tight junction permeability in intestinal monolayer cells via lipoxygenase activation. Nutrition 2005;21:838-47.

61. Tuma DJ, Smith SL, Sorrell MF. Acetaldehyde and microtubules. Ann N Y Acad Sci 1991;625:786-92.

62. Kannarkat GT, Tuma DJ, Tuma PL. Microtubules are more stable and more highly acetylated in ethanol-treated hepatic cells. J Hepatol 2006;44:963-70.

63. Shepard BD, Tuma DJ, Tuma PL. Chronic ethanol consumption induces global hepatic protein hyperacetylation. Alcohol Clin Exp Res 2010;34:280-91.

64. Kouzarides T. Acetylation: a regulatory modification to rival phosphorylation? EMBO J 2000;19: 1176-9.

65. Polevoda B, Sherman F. The diversity of acetylated proteins. Genome Biol 2002;3:reviews0006.

66. Yu BJ, Kim JA, Moon JH, et al. The diversity of lysine-acetylated proteins in Escherichia coli. J Microbiol Biotechnol 2008;18:1529-36.

67. North BJ, Marshall BL, Borra MT, et al. The human Sir2 ortholog, SIRT2, is an NAD+-dependent tubulin deacetylase. Mol Cell 2003;11:437-44.

68. Zhong $\mathrm{W}$, Zhao $\mathrm{Y}, \mathrm{McClain} \mathrm{CJ}$, et al. Inactivation of hepatocyte nuclear factor-4\{alpha\} mediates alcohol-induced downregulation of intestinal tight junction proteins. Am J Physiol Gastrointest Liver Physiol;299:G643-51. 


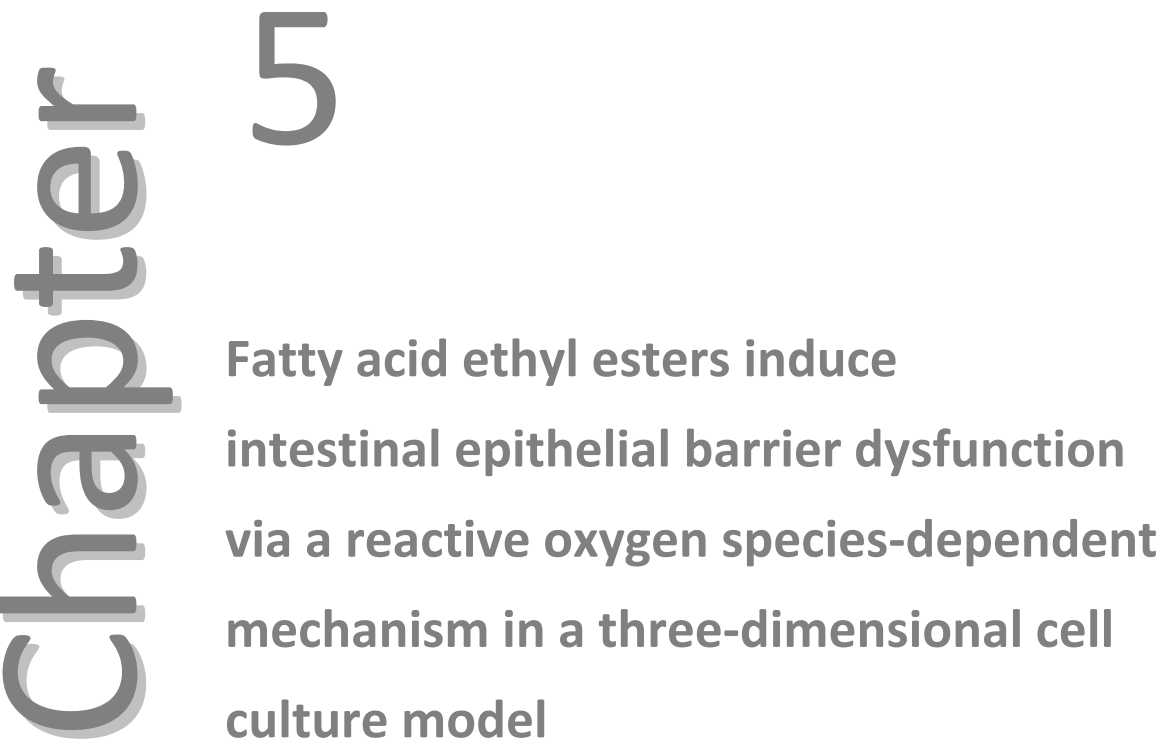

Elhaseen Elamin, Ad Masclee, Kati Juuti-Uusitalo, Sven van IJzendoorn, Freddy Troost, Jan Dekker, Daisy Jonkers

PloS One; 8: e58561 


\section{Abstract}

\section{Background \& Aims}

Evidence is accumulating that ethanol and its oxidative metabolite, acetaldehyde, can disrupt intestinal epithelial integrity, an important factor contributing to ethanolinduced liver injury. However, ethanol can also be metabolized non-oxidatively generating phosphatidylethanol and fatty acid ethyl esters (FAEEs). This study aims to investigate the effects of FAEEs on barrier function, and to explore the role of oxidative stress as possible mechanism.

\section{Methods}

Epithelial permeability was assessed by paracellular flux of fluorescein isothiocyanateconjugated dextran using live cell imaging. Cell integrity was evaluated by lactate dehydrogenase release. Localization and protein levels of ZO-1 and occludin were analyzed by immunofluorescence and cell-based ELISA, respectively. Intracellular oxidative stress and cellular ATP levels were measured by dichlorofluorescein and luciferase driven bioluminescence, respectively.

\section{Results}

In vitro, ethyl oleate and ethyl palmitate dose dependently increased permeability associated with disruption and decreased ZO-1 and occludin protein levels, respectively, and increased intracellular oxidative stress without compromising cell viability. These effects could partially be attenuated by pretreatment with the antioxidant, resveratrol, pointing to the role of oxidative stress in the FAEEs-induced intestinal barrier dysfunction.

\section{Conclusions}

These findings show that FAEEs can induce intestinal barrier dysfunction by disrupting the tight junctions, most likely via reactive oxygen species-dependent mechanism. 


\section{Introduction}

Ethanol is widely consumed worldwide and associated with the development of alcoholic liver diseases (ALD). Disruption of tight junctions (TJs) between intestinal epithelial cells may lead to an increased intestinal permeability resulting in an enhanced permeation of toxins and pathogens into the circulation with subsequent endotoxaemia ${ }^{1}$. This process is considered to play a key role in the pathogenesis of $\mathrm{ALD}^{2,3}$. There is increasing evidence that ethanol ${ }^{4-6}$ and to a greater extent, its oxidative metabolite, acetaldehyde ${ }^{7,8}$ can disrupt the TJs and increase paracellular permeability in Caco-2 cell monolayers by mechanisms involving e.g. inducible nitric oxide synthase (iNOS)-mediated reactive oxygen species (ROS) generation ${ }^{5,6}$, and protein tyrosine phosphorylation ${ }^{9}$. A part from oxidative metabolism, ethanol can be metabolized non-oxidatively by the enzyme phospholipase $D$ and fatty acid ethyl ester synthases, generating phosphatidylethanol and fatty acid ethyl esters (FAEEs), respectively ${ }^{10,11}$. FAEEs including ethyl oleate and ethyl palmitate, have been detected in blood at concentrations ranging between $10 \mu \mathrm{M}$ and $50 \mu \mathrm{M}$ with half-life of 24 and 44-99 $\mathrm{h}$ following moderate and heavy ethanol consumption, respectively, and have been proposed as biomarkers for both recent and long-term ethanol intake $\mathrm{e}^{12-14}$. Increased levels of FAEEs have also been found in the liver, pancreas, heart and adipose tissue following death of intoxicated subjects ${ }^{15}$. Since fatty acids and ethanol are absorbed by enterocytes, the intestine is also considered a major site for FAEEs synthesis ${ }^{16}$. Moreover, duodenal mucosa has been found to possess high FAEE synthase activity with subsequent FAEEs production ${ }^{16}$. However, little is known about concentrations present in the intestine after ethanol ingestion.

FAEEs have been shown to accumulate in the hydrophobic membranes resulting in uncoupling oxidative phosphorylation and fragility of the mitochondria and lysosomes, respectively ${ }^{17,18}$. Moreover, FAEEs can decrease protein synthesis and induce apoptosis ${ }^{19-21}$. Collectively, these studies strongly suggest that FAEEs may induce cell injury. Although evidence indicates that FAEEs exert cytotoxic activity in pancreatic $^{18,22}$ and liver cells ${ }^{21}$, potential effects on intestinal epithelial cells are unknown.

The present study aimed to investigate the effects of FAEEs on intestinal paracellular barrier function by using a three-dimensional (3D) cell culture model of Caco-2 cells ${ }^{23}$. Since metabolic stress can affect the TJs integrity and FAAEs have been demonstrated to inhibit mitochondrial function by uncoupling oxidative phosphorylation ${ }^{17}$, the effects of FAEEs on cellular oxidative stress and intracellular ATP levels were also investigated. 


\section{Materials and methods}

\section{Cell line and culture conditions}

Caco-2 cells from the American Type Culture Collection, (ATCC, Rockville, USA) were maintained in Dulbecco's Modified Eagle Medium (DMEM; Lonza Benelux BV, Breda, $\mathrm{NL}$ ) containing $4.5 \mathrm{~g} / \mathrm{l}$ glucose and L-glutamine, $10 \%(\mathrm{v} / \mathrm{v})$ fetal calf serum (Invitrogen, Breda, the Netherlands), 1\% ( $v / v)$ solution of non-essential amino acids (Invitrogen) and $1 \%(\mathrm{v} / \mathrm{v})$ solution of antibiotic/antimycotic mixture $(10,000$ units of penicillin, $10,000 \mu \mathrm{g}$ of Streptomycin, and $25 \mu \mathrm{g}$ of Amphotericin B per ml; Invitrogen) in an atmosphere of $5 \% \mathrm{CO}_{2}$ at $37^{\circ} \mathrm{C}$.

\section{Three dimensional epithelial cell culture}

Caco-2 cells were initially grown in growth factor-reduced Matrigel $(8 \mathrm{mg} / \mathrm{ml}$; BD Biosciences, San Jose, California USA) in $10 \mathrm{~mm}$ glass bottom culture dishes of $35 \mathrm{~mm}$ diameter (MatTek Corporation, Ashland, USA) for barrier function and immunofluorescence analysis, and in 96 well-plates (Corning BV, Amsterdam, the Netherlands) for redox state, cell viability, ELISA cell-based and ATP assays, as described previously ${ }^{24}$. Briefly, The Caco- 2 cells $\left(50 \times 10^{3}\right.$ cells/well; passage $\left.30-38\right)$ were resuspended in serum-free medium, mixed with $40 \%(\mathrm{v} / \mathrm{v})$ Matrigel and plated on the solidified Matrigel. Thereafter, the complete growth medium was added and spheroids were allowed to form at $37^{\circ} \mathrm{C}$ for $5-7$ days. The quality of cultures was checked by counting the number of spheroids and classifying them according to the number of lumens formed. Only cultures containing $>70 \%$ of spheroids with a single lumen were used for further experiments.

\section{Exposure to FAEEs and determination of intestinal epithelial barrier function}

FAEEs were dissolved in $0.1 \%$ dimethyl sulfoxide (DMSO) and spheroids were exposed to either $20 \mu \mathrm{M}$ or $40 \mu \mathrm{M}$ of ethyl oleate (EO) or ethyl palmitate (EP) for $24 \mathrm{~h}^{25}$. Two mM ethylene glycol tetra acetic acid (EGTA) to induce maximum TJs disruption and growth medium only were used as positive and negative control, respectively. To determine paracellular barrier function, spheroids were incubated with the above indicated concentrations in the presence of $1 \mathrm{mg} / \mathrm{ml}$ fluorescein isothothiocyanatelabeled dextran of 4 KDa (FITC-D4; Sigma Chemical Co, Amsterdam, NL) for $24 \mathrm{~h}$. Barrier function was assessed by the flux of FITC-D4 from the basal to the luminal compartment (i.e., L/B ratio) using confocal microscopy. Confocal images were taken with Leica TCS SPE confocal laser scanning microscope (Leica Microsystems GmbH, Mannheim, Germany) and processed using TCS SPE browser and Image J software ${ }^{26}$. 


\section{Lactate dehydrogenase assay}

Cell plasma membrane integrity was evaluated by measuring lactate dehydrogenase (LDH) release. The assay (CytoTox-ONE ${ }^{\mathrm{TM}}$ Homogeneous Membrane Integrity Assay; Promega, the Netherlands) was performed according to the manufacture's instruction. Briefly, Caco-2 cells were cultured in 96 well-plates in 3D and incubated with 20 or $40 \mu \mathrm{M}$ EO or EP. Then, plates were incubated at $37^{\circ} \mathrm{C}$ for $24 \mathrm{~h}$ and equilibrated at room temperature (RT) for $20 \mathrm{~min}$. Next, $100 \mu \mathrm{l}$ of the reconstituted substrate mix was added. The plate was incubated at RT, protected from light, for 30 min and thereafter, $20 \mu \mathrm{l}$ of stop solution was added. Maximum LDH release was induced by using lysis solution. The fluorescence was measured at an excitation and an emission wavelength of $560 \mathrm{~nm}$ and $590 \mathrm{~nm}$. The percentage of LDH activity was calculated as percentage of maximum LDH release (i.e. fully lysed cells).

\section{Assessment of ZO-1 and occludin localization}

At the end of FAEEs exposure, Caco-2 spheroids in culture dishes were fixed in $4 \%$ $(w / v)$ paraformaldehyde in Hank's Buffered Salt Solution (HBSS; Invitrogen) at $37^{\circ} \mathrm{C}$ for $40 \mathrm{~min}$ and processed for immunocytochemistry as described previously ${ }^{24}$. Briefly, spheroids were permeabilized with $0.1 \%(\mathrm{v} / \mathrm{v})$ Triton X-100 in PBS at RT for 40 min and were incubated with a blocking buffer containing $3 \%(\mathrm{w} / \mathrm{v})$ bovine serum albumin (BSA) in PBS, $\mathrm{pH} 7.4$, at $37^{\circ} \mathrm{C}$ for $2 \mathrm{~h}$. Spheroids were then incubated overnight with mouse anti-ZO-1 (Zymed Laboratories, San Francisco, USA) and rabbit anti-occludin (Zymed Laboratories) at 1:100 dilution in 3\% (w/v) BSA in PBS, pH 7.4 at $4^{\circ} \mathrm{C}$. Next, spheroids were incubated with Alexa-488 conjugated goat anti-mouse (Invitrogen) and or Cy3-conjugated goat anti-rabbit (Jackson Laboratories, Suffolk, UK) secondary antibodies (1:100 dilution) at $37^{\circ} \mathrm{C}$ for $1.5 \mathrm{~h}$. After that spheroids were stained for 5 min with diamidino-2-phenylindole (DAPI; 1:10,000 dilution in PBS; Sigma Chemical Co) and mounted in dishes using VectaShield mounting medium (Vector Laboratories, Burlingame, USA). Confocal images were obtained using a Leica TCS SPE confocal laser scanning microscope. Image J software was used to process and analyze the images ${ }^{27}$.

\section{Assessment of ZO-1 and occludin protein levels}

ZO-1 and occludin protein levels were assessed using a cell-based ELISA kits (Ray Biotech, Inc. Norcross, GA, USA) with minor modifications. Briefly, Caco-2 spheroids grown on 96 well-plates (Corning BV, Amsterdam, the Netherlands) were exposed to medium only as control and either $40 \mu \mathrm{M}$ EO or EP alone for $24 \mathrm{~h}$, or after pretreatment for $1 \mathrm{~h}$ with $10 \mu \mathrm{M}$ of the antioxidant resveratrol (trans-3,4', 5-trihydroxy stilbene) ${ }^{28}$. The cultures were washed with PBS and then $100 \mu \mathrm{l}$ of fixative solution (provided in the kit) was added to each well, and incubated with shaking at RT for 20 min. After another washing, a quenching buffer was added at RT for $20 \mathrm{~min}$, followed by a blocking solution for $1 \mathrm{~h}$ at $37^{\circ} \mathrm{C}$. After washing thrice, either 
mouse anti-ZO-1 or rabbit anti-occludin (1:100 dilution in the blocking solution; Cell Signaling Technology, Inc, MA, USA) was added, and the plate was incubated with shaking at RT for $1 \mathrm{~h}$. Next, $25 \mu \mathrm{l}$ of HRP-conjugated mouse anti-rabbit IgG (1:100 dilution in the blocking solution; Dako Netherlands BV, Heverlee, Belgium) was added to each well and incubated at RT for $1 \mathrm{~h}$. Then, the plate was washed three times and $100 \mu \mathrm{l}$ of 3, 3', 5, 5'-tetramethylbenzidine (TMB) was added to each well and incubated with shaking in the dark at RT for $30 \mathrm{~min}$. Finally, $25 \mu \mathrm{l}$ of stop solution was added to each well and the optical density was read at $450 \mathrm{~nm}$ with a spectrophotometer.

\section{Detection of reactive oxygen species (ROS)}

The generation of $\mathrm{H}_{2} \mathrm{O}_{2}$ was monitored by using 2', 7'- dichlorodihydrofluorescein diacetate (DCF-DA, Sigma Chemical Co, Amsterdam, NL), which is non-fluorescent unless oxidized by intracellular reactive oxygen species (ROS). Caco-2 cells were cultured in 96 well plates in 3D and were preloaded with $100 \mu \mathrm{M}$ DCF-DA for $1 \mathrm{~h}$ at $37^{\circ} \mathrm{C}$. Dose dependent measurement of the generation of ROS was done by incubating the cells with FAEEs for $24 \mathrm{~h} . \mathrm{H}_{2} \mathrm{O}_{2}(30 \mu \mathrm{M})$ treated spheroids were used as positive control. Spheroids were then washed twice in HBSS buffer and the fluorescence was measured at an excitation and an emission wavelength of $485 \mathrm{~nm}$ and $540 \mathrm{~nm}$, respectively.

\section{Luminescent ATP assay}

The number of viable cells in culture was quantified based on the amount of ATP produced by metabolically active cells using luminescent assay kits (CellTiter-Glo ${ }^{\circledR}$ Luminescent Cell Viability Assay, Promega, the Netherlands) according to the manufacturer's instructions. Briefly, Caco-2 cells were cultured in 96 well-plates in 3D and were incubated with medium only ('negative' control), 20 or $40 \mu \mathrm{M}$ of either EO or $\mathrm{EP}$, and $30 \mu \mathrm{M} \mathrm{H}_{2} \mathrm{O}_{2}$ ('positive' control). Then, plates were incubated at $37^{\circ} \mathrm{C}$ for $24 \mathrm{~h}$ and equilibrated at RT for $30 \mathrm{~min}$. Thereafter, $100 \mu \mathrm{l}$ of the reagent assay was added to each well. The contents were mixed on an orbital shaker for $2 \mathrm{~min}$ to induce cell lysis and incubated at RT for $10 \mathrm{~min}$ to stabilize the luminescent signal. The luminescence was measured using SpectraMax M2 (Molecular Devices, Sunnyvale, CA, USA). ATP level was calculated from the luminescent values and presented as a percentage of the medium only-treated 'negative' control.

\section{Statistical analysis}

All experiments were performed in triplicate and results were reported as means $\pm S D$ of at least 8 spheroids per experiment. A one-way analysis of variance (ANOVA) and Tukey's post hoc test were performed to determine significant differences between experimental conditions. The correlation between intracellular ROS and barrier 
dysfunction was analyzed by using Spearman test. Differences were considered statistically significant when $P<0.05$. All data analyses were conducted with GraphPad Prism software package (GraphPad Software Incorporated, CA, USA).

\section{Results}

\section{Effects of FAEEs on paracellular permeability}

To determine the effect of FAEEs exposure on intestinal epithelium permeability, Caco-2 spheroids were treated with EO and EP for $24 \mathrm{~h}$. In medium-only treated spheroids, FITC-D4 was exclusively observed in the culture medium at the basolateral side of spheroids (Figure 5.1A) resulting in a very low L/BL fluorescence ratio (Figure 5.1B). As a 'positive' control, exposure to EGTA ( $2 \mathrm{mM}$ ) resulted in a rapid FITC-D4 flux from the basolateral side to the lumen, and the $L / B L$ ratio was set to 1 (Figure 5.1B). Exposure of Caco-2 spheroids to both EO and EP (20 and $40 \mathrm{mM}$ ) increased the intraluminal FITC-D4 fluorescence signals (Figure 5.1A and 5.1C) and significantly increased the L/BL fluorescence ratio versus the medium only control, in a dose dependent manner $(P<0.0001$; Figure 5.1B and 5.1D). Interestingly, the magnitude of the effects differed between EO- and EP-treated spheroids. The mean FITC-D4 fluorescence ratio was significantly higher in response to $20 \mu \mathrm{M}$ EO compared to $20 \mu \mathrm{M}$ EP $(0.34 \pm 0.02$ vs. $0.21 \pm 0.03$, respectively; $P<0.0001)$ as well as in response to $40 \mu \mathrm{M}$ EO compared to $40 \mu \mathrm{M}$ EP $(0.45 \pm 0.06$ vs. $0.38 \pm 0.10$, respectively; $P<0.001)$ (Figure 5.1B, 5.1D).

\section{Effects of FAEEs on cell membrane integrity (LDH leakage)}

To investigate whether exposure to EO or EP can reduce cell viability of Caco-2 cells, cell membrane integrity was examined by measuring LDH release. No significant increase in LDH activity was detected after incubation with neither $20 \mu \mathrm{M}$ nor $40 \mu \mathrm{M}$ of EO or EP compared to medium only control ( $P>0.05$, Figure 5.2$)$. 
A

$$
\mathrm{EO} 0 \mu \mathrm{M}
$$

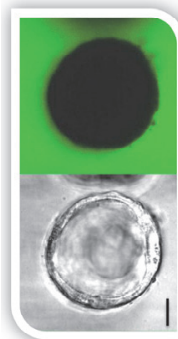

$$
\mathrm{EO} 20 \mu \mathrm{M}
$$

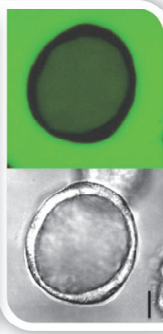

EO $40 \mu \mathrm{M}$

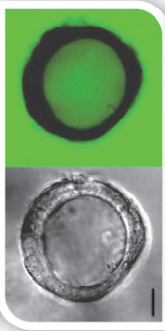

C

$\mathrm{EP} 0 \mu \mathrm{M}$

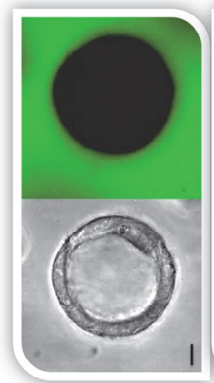

EP $20 \mu \mathrm{M}$

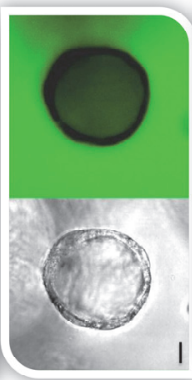

EP $40 \mu \mathrm{M}$

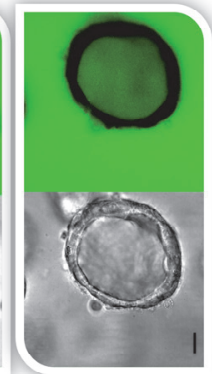

EGTA 2mM
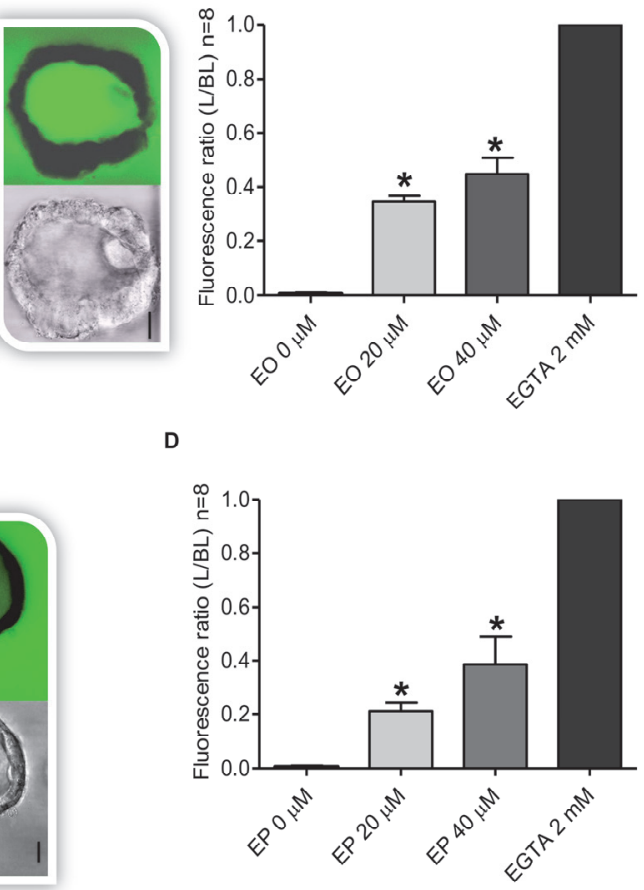

Figure 5.1 Effect of ethyl oleate (EO) and ethyl palmitate (EP) on paracellular permeability in 3D Caco-2 spheroids. [A] Spheroids were treated or not treated with either EO $(20,40 \mu \mathrm{M})$, EGTA (positive control) or [C] EP $(20,40 \mu \mathrm{M})$ in the presence of FITC-D4 at $37^{\circ} \mathrm{C}$ for $24 \mathrm{~h}$. Intraluminal accumulation of FITC-D4 (green) was observed using confocal microscopy and representative images captured from the middle of spheroids are shown. The bar indicates 10 $\mu \mathrm{m}$. The mean fluorescence intensity of FITC-D4 after exposure to [B] EO and [D] EP was measured and expressed as the ratio of the luminal $(L)$ over the basal (BL) compartment. The $\mathrm{L} / \mathrm{BL}$ ratio as determined following EGTA exposure was set to 1 . All graphs indicate the results of three replicate experiments. Data expressed as means $\pm \mathrm{SD},{ }^{*} P<0.0001$, compared to medium only-treated control. 


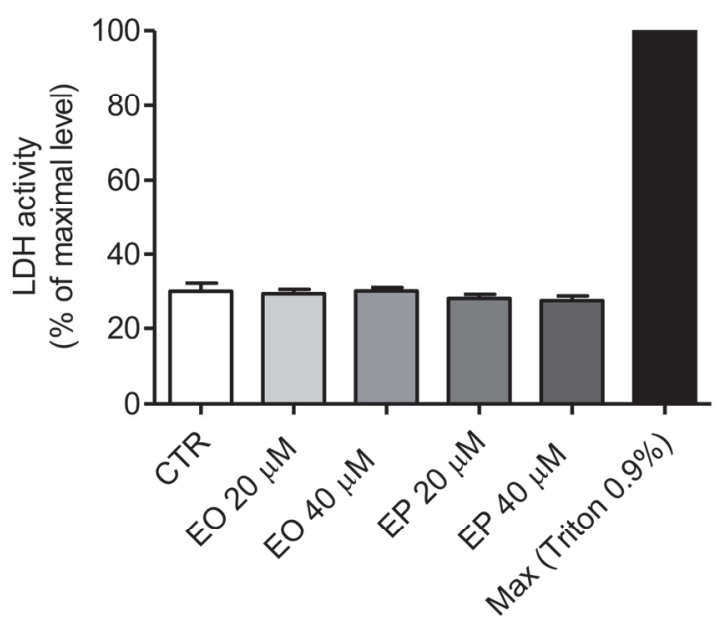

Figure 5.2. Effect of ethyl oleate (EO) and ethyl palmitate (EP) on LDH release in Caco-2 spheroids.

Caco-2 spheroids were treated with a cell lysis buffer to induce maximum LDH leakage (Max), medium only as control (CTR), EO 20 and $40 \mu \mathrm{M}$ or EP 20 and $40 \mu \mathrm{M}$ at $37^{\circ} \mathrm{C}$ for $24 \mathrm{~h}$. LDH activity was determined by a fluorescent assay $(n=3)$. Data are reported as percentage of maximum $L D H$ release and values are presented as means $\pm S D, P>0.05$ vs. medium onlytreated control.

\section{Effects of FAEEs on localization and protein levels of ZO-1 and occludin}

Since TJs are dynamic structures and respond quickly to pathophysiological stimuli, modulation of barrier function is often associated with changes in TJ integrity. Therefore, we used confocal immunofluorescence microscopy imaging to determine the effect of EO and EP on the intercellular protein localization of ZO-1 and occludin in Caco-2 spheroids. No changes occurred in localization of either ZO-1 or occludin in medium-only treated control spheroids (Figure 5.3A). By 24 hours, exposure to EO or EP resulted in loss of ZO-1 and occludin at the intercellular junctions and caused mislocalization of both proteins at the plasma membrane (Figure 5.3A). To evaluate whether the FAEEs-mediated changes in ZO-1 and occludin localization are accompanied by reduced levels of their proteins, a cell-based ELISA was used. In this assay, proteins levels are measured in fixed cells, eliminating the need for lysate preparation. Compared with medium only-treated control spheroids, significant reduction of ZO-1 and occludin levels were observed in EO-treated spheroids $(P<0.0001$; Figure $5.3 \mathrm{~B}$ and $5.3 \mathrm{C}$, respectively). Similarly, treatment with EP significantly reduce ZO-1 and occludin protein levels compared to that observed in medium only-treated controls ( $P<0.0001$; Figure 5.3B and 5.3C, respectively). In line with the higher fluorescence ratio, EO $40 \mu \mathrm{M}$ was also more potent in decreasing ZO-1 and occludin protein levels than EP $40 \mu \mathrm{M}(P<0.01$ and $P<0.05$, respectively; Figure 5.3B and 5.3C). 


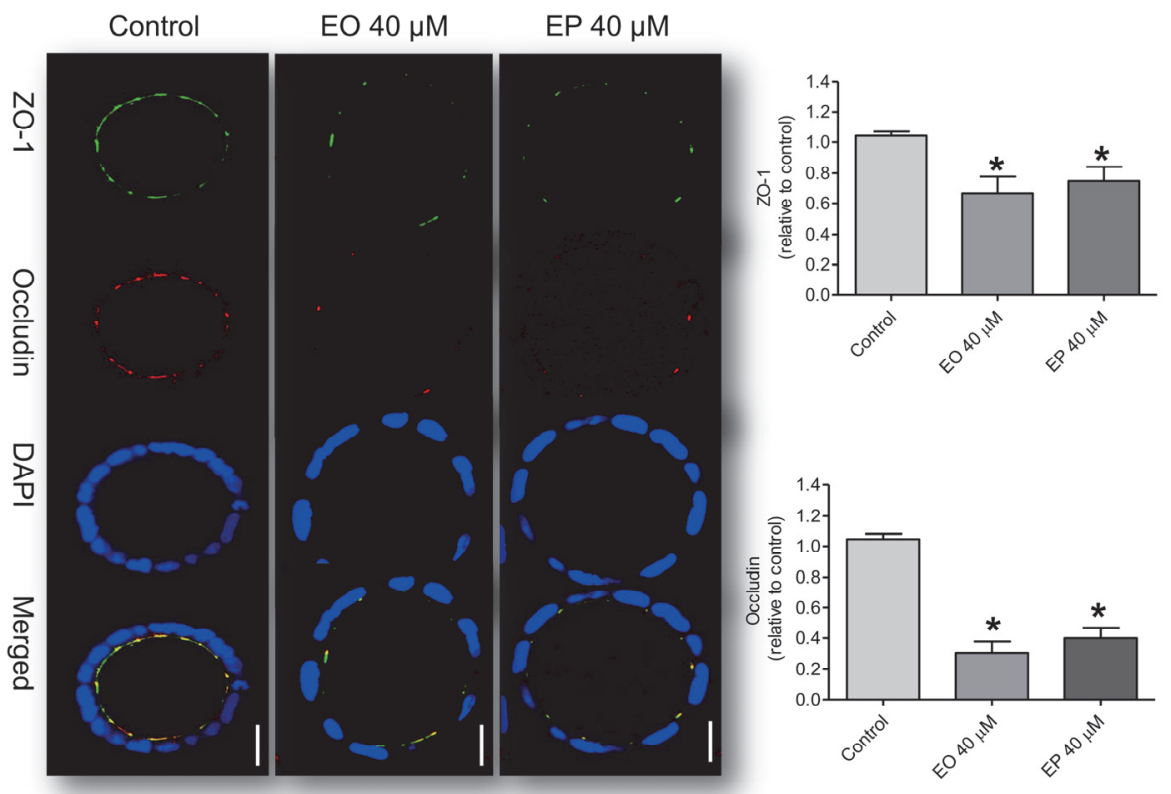

Figure 5.3 Effect of ethyl oleate (EO) or ethyl palmitate (EP) on ZO-1 and occludin localization in 3D Caco2 spheroids. [A] Spheroids were exposed to medium only (control), EO $40 \mu \mathrm{M}$ or $40 \mu \mathrm{M}$ EP for $24 \mathrm{~h}$, and immunostained for ZO-1 (green), occludin (red) and nuclei (blue) by confocal immunofluorescence staining, and representative images captured from the middle of spheroids are shown. The bar indicates $10 \mu \mathrm{m}$. Exposure to ethyl oleate (EO) and ethyl palmitate (EP) decreases ZO-1 and occludin protein levels. ZO-1 [B] and occludin [C] protein levels relative to control after exposure to medium only (control), EO $40 \mu \mathrm{M}$, or $40 \mu \mathrm{M}$ EP for $24 \mathrm{~h} .{ }^{*} P<0.0001$. ZO-1 and occludin protein levels were lower after EO $40 \mu \mathrm{M}$ vs. EP $40 \mu \mathrm{M}$; $(P<0.01$ and $P<0.05$, respectively).

\section{Effects of FAEEs on cellular oxidative stress}

DCF-DA was used to test whether FAEEs can induce ROS generation in Caco-2 spheroids. Exposure to $20 \mu \mathrm{M}$ or $40 \mu \mathrm{M}$ EO or EP for $24 \mathrm{~h}$, dose-dependently increased the intracellular ROS contents of 3D spheroids compared to medium-only treated controls ( ${ }^{*} P<0.0001$; Figure 5.4$)$. ROS generation was higher in response to EO $20 \mu \mathrm{M}$ and $40 \mu \mathrm{M}$ compared to EP $20 \mu \mathrm{M}$ and $40 \mu \mathrm{M}$, respectively. However, these differences did not reach statistical significance (both $P>0.05$; Figure 5.4). 


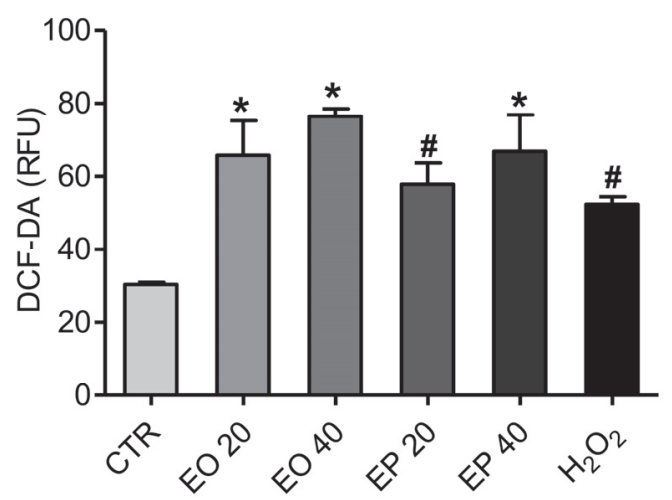

Figure 5.4 Effects of ethyl oleate (EO) or ethyl palmitate (EP) on ROS generation in the 3D Caco-2 spheroids. The spheroids were pretreated with $100 \mu \mathrm{M}$ DCF-DA for $1 \mathrm{~h}$ at $37^{\circ} \mathrm{C}$ and subsequently with either medium only as negative control (CTR), EO 20 or $40 \mu \mathrm{M}$ ), EP 20 or $40 \mu \mathrm{M}$ or $\mathrm{H}_{2} \mathrm{O}_{2}(30 \mu \mathrm{M})$ as positive control for $24 \mathrm{~h}$. Cellular ROS production was measured by DCF fluorescence, and reported as relative fluorescent units (RFU). Data expressed as means \pm SD, ${ }^{*} P<0.0001$ and ${ }^{\#} P<0.001$ vs. CTR.

\section{Effects of resveratrol on FAEEs-induced oxidative stress}

Resveratrol (3, 4', 5 tri-hydroxystilbene), a polyphenol found in grape skin and red wine, has been shown to possess a wide range of biological and pharmacological properties including potent antioxidant activity by scavenging free radicals and inhibiting lipid peroxidation ${ }^{29-32}$. Pretreatment of spheroids with $10 \mu \mathrm{M}$ resveratrol prior to challenge with either $40 \mathrm{mM}$ EO or EP, significantly attenuated the EO- and EP-induced increase in intracellular ROS levels $(P<0.05$; Figure $5.5 \mathrm{~A})$. This increase in ROS was higher in response to EO $40 \mu \mathrm{M}$ compared to EP $40 \mu \mathrm{M}$, respectively $(P<0.05$; Figure 5.5A). Furthermore, a linear correlation was found between the increase in ROS generation and the decrease in paracellular barrier function after FAEEs exposure ( $r=0.9$ and $P<0.01$; Figure 5.5B). 
A

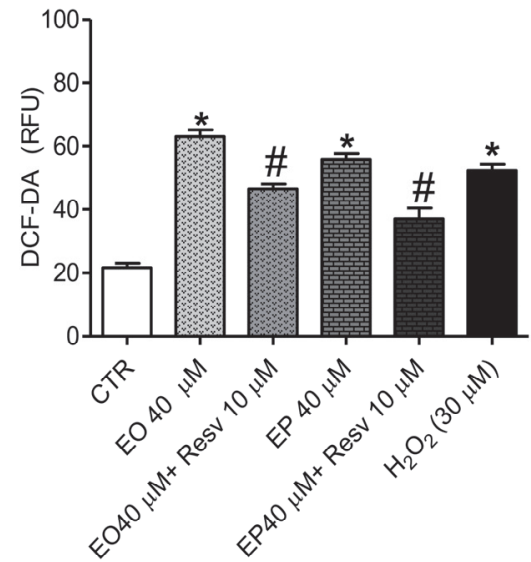

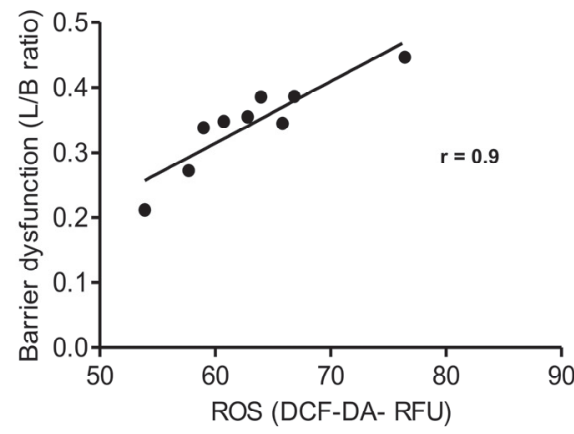

Figure 5.5 Effects of Resveratrol (Resv) on ethyl oleate (EO)- and ethyl palmitate (EP)-induced oxidative stress. [A] Spheroids were exposed to medium only as control (CTR) or $40 \mu \mathrm{M}$ of either EO or EP for $24 \mathrm{~h}$, or first treated with $10 \mu \mathrm{M}$ resveratrol for $1 \mathrm{~h}$ prior to treatment with either EO or EP for $24 \mathrm{~h}$. Values are means $\pm S D,{ }^{*} P<0.0001$ vs. CTR, \#P<0.0001 vs. treated only with EO or EP. [B] The association between the increase in ROS generation and paracellular permeability was analyzed by Spearman test $(r=0.9$ and $P<0.01)$.

\section{Involvement of ROS in FAEEs-induced changes in paracellular permeability}

To investigate the role of oxidative stress and increased $\mathrm{H}_{2} \mathrm{O}_{2}$ as mediator of the FAEEs-induced increase in epithelial permeability, Caco-2 spheroids were pretreated with $10 \mu \mathrm{M}$ resveratrol at $37^{\circ} \mathrm{C}$ for $1 \mathrm{~h}$, followed by incubation with $40 \mu \mathrm{M}$ EO or EP for $24 \mathrm{hrs}$. Exposure of Caco-2 spheroids to EO increased the intraluminal FITC-D4 flux (Figure 5.6A), and significantly increased the L/BL fluorescence ratio compared with the medium-only treated controls $(P<0.0001$; Figure 5.6B). Resveratrol attenuated EOinduced FITC-D4 flux (Figures 5.6A), and significantly decreased L/BL fluorescence ratio compared to EO alone ( $P<0.0001$; Figure $5.6 \mathrm{~B})$. A similar attenuating effect of resveratrol was observed for EP-induced barrier dysfunction $(P<0.0001$; Figures 5.6A and 5.6B). 

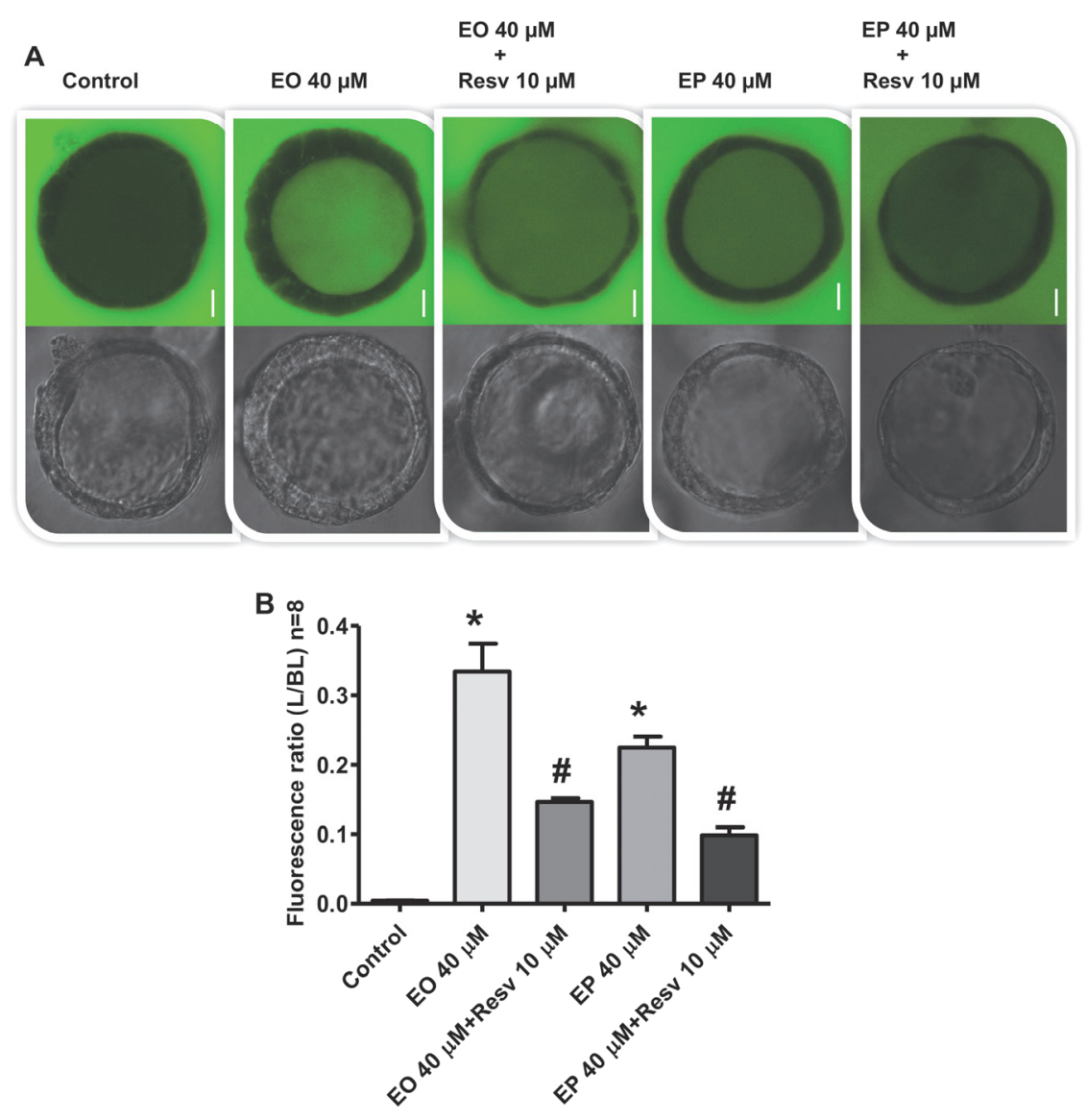

Figure 5.6 Effects of Resveratrol (Resv) on the ethyl oleate (EO)- and ethyl palmitate (EP)-induced barrier dysfunction in Caco-2 spheroids. Spheroids were exposed to medium (control) or treated with EO or EP for $24 \mathrm{~h}$, or first treated with $10 \mu \mathrm{M}$ resveratrol for $1 \mathrm{~h}$ prior to treatment with $40 \mu \mathrm{M}$ of either EO or EP for $24 \mathrm{~h}$. [A] Intraluminal accumulation of FITC-D4 (green) was observed using confocal microscopy and representative images captured from the middle of spheroids are shown. The bar indicates $10 \mu \mathrm{m}$. [B] The mean fluorescence intensity of FITC-D4 after exposure was measured and expressed as the ratio of the luminal $(L)$ over the basal $(B L)$ compartment. Values are Means $\pm S D, * P<0.0001$ vs. medium only-treated control, $\# P<0.0001$ vs. treated only with EO or EP. FITC-D4 fluorescence ratio, EO 40 vs. EP $40 \mu \mathrm{M} ;(P<0.0001$, Figure 5.6A and 5.6B).

\section{Role of ROS in FAEEs-induced changes in localization and protein levels of ZO-1 and occludin}

The effects of EO and EP on ZO-1 and occludin localization in Caco-2 cell spheroids were analyzed in either presence or absence of resveratrol pretreatment. Control spheroids showed apical intercellular localization of ZO-1 and occludin with strong co- 
localization of both proteins in the tight junctions (Figure 5.7A). EO and EP treatment resulted in reduced staining for both ZO-1 and occludin with miscolocalization of both proteins. The disruption of ZO-1 and occludin induced by FAEEs was partially prevented by resveratrol (Figure 5.7A). Pretreatment of the spheroids with $10 \mu \mathrm{M}$ resveratrol for $1 \mathrm{~h}$ was able to significantly preserve ZO-1 and occludin proteins levels, compared to EO alone ( $P<0.0001$; Figure $5.7 \mathrm{~B}$ and $5.7 \mathrm{C}$, respectively). Similarly, pretreatment of the spheroids with resveratrol significantly preserved the ZO-1 and occludin protein levels compared to EP ( $P<0.0001$; Figure 5.7B and 5.7C, respectively). No differences could be observed in ZO-1 and occludin protein levels between $\mathrm{EO}$ and EP after pretreatment with resveratrol ( $P>0.05$; Figure 5.7B and 5.7C, respectively).
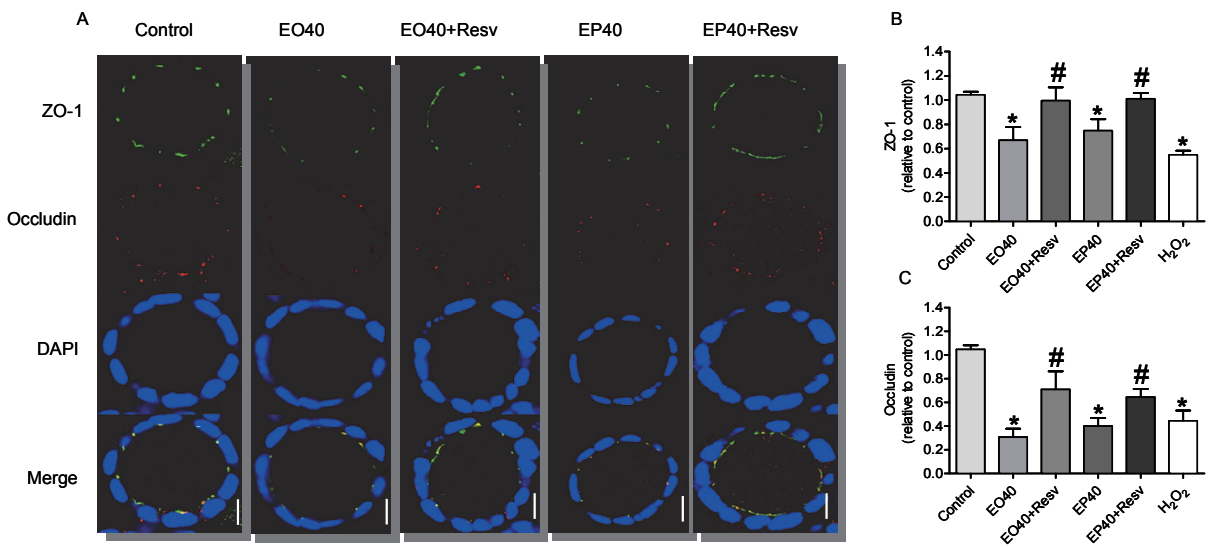

Figure 5.7 Effects of Resveratrol (Resv) on the ethyl oleate (EO)- and ethyl palmitate (EP)-inducedinduced changes in ZO-1 and occludin localization, and protein levels. [A] Spheroids were exposed to medium (control) or treated with $40 \mu \mathrm{M}$ of either EO or EP for $24 \mathrm{~h}$, or first treated with $10 \mu \mathrm{M}$ resveratrol for $1 \mathrm{~h}$ prior to treatment with either EO or EP for $24 \mathrm{~h}$, and immunostained for ZO-1 (green), occludin (red) and nuclei (blue) by confocal immunofluorescence staining, and representative images captured from the middle of spheroids are shown. The bar indicates $10 \mu \mathrm{m}$. [B] ZO-1 and [C] occludin protein levels relative to control after exposure to the indicated concentrations of EO, EP and $\mathrm{H}_{2} \mathrm{O}_{2}$. Values are Means $\pm S D,{ }^{*} P<0.0001$ vs. medium only-treated control, $\# P<0.0001$ vs. treated only with $E O$ or EP. ZO-1 and occludin protein levels, EO $40 \mu \mathrm{M}$ vs. EP $40 \mu \mathrm{M}$; both $(P<0.05)$.

\section{Effects of FAEEs on intracellular ATP levels}

As TJs stability is influenced by a number of intracellular events including energy depletion $^{33}$, we assessed whether FAEEs can reduce intracellular ATP levels in Caco-2 spheroids. As shown in Figure 5.8, exposure to $20 \mu \mathrm{M}$ or $40 \mu \mathrm{M}$ of either EO or EP for $24 \mathrm{~h}$ did not decrease the intracellular ATP levels compared to control $(100.9 \pm 9.4 \%$ and $102.1 \pm 6.4 \%, 104.9 \pm 3.6$ and $98.5 \pm 9.8$, respectively vs. $102.2 \pm 4.0 \%, P>0.05)$. There 
were also no differences in the intracellular ATP levels between EO and EP treatments.

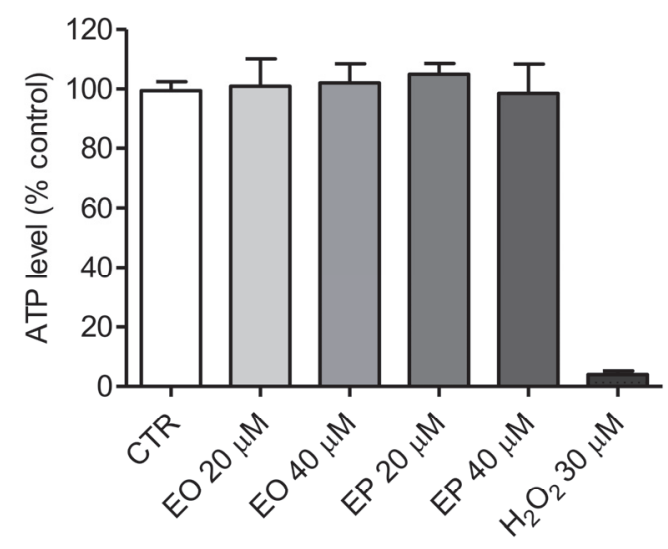

Figure 5.8 Effects of ethyl oleate (EO) and ethyl palmitate (EP) on intracellular ATP levels. Caco-2 spheroids were treated with medium only as negative control (CTR), EO 20 or $40 \mu \mathrm{M}$ ), EP 20 or $40 \mu \mathrm{M}$ or $\mathrm{H}_{2} \mathrm{O}_{2}(30 \mu \mathrm{M})$ as positive control for $24 \mathrm{~h}$. Intracellular ATP levels were determined by a bioluminescence assay $(n=3)$. Data are reported as percentage of untreated controls and values are presented as means $\pm S D, P>0.05$ vs. CTR.

\section{Discussion}

This study is the first to show that the non-oxidative ethanol metabolites ethyl oleate (EO) and ethyl palmitate (EP) cause a dose-dependent disruption of the intestinal epithelial TJs, resulting in increased paracellular permeability without compromising cell viability. Furthermore, EO and EP increased cellular oxidative stress, which was found to correlate with barrier dysfunction. Preincubation with the antioxidant resveratrol ameliorated the FAEEs-induced TJ disruption and barrier dysfunction.

The interaction between FAEEs and intestinal epithelial cells has been examined using a Caco-2 cell 3D culture model, which presents a physiological in vitro model to study (patho) physiological functions of intestinal epithelial cells, including morphogenesis ${ }^{23}$ and TJs integrity ${ }^{24}$. Our data showed that treatment of epithelial cells with 20 or $40 \mu \mathrm{M}$ of either EO or EP results in enhanced paracellular permeability in a dosedependent manner. The concentrations we used are within the biologically relevant, physiological range attained in serum (20-40 $\mu \mathrm{M})$ after ingestion of a drink equivalent to $10 \mathrm{~g}$ ethanol ${ }^{34}$. 
An increase in paracellular permeability can be caused by different events including epithelial cell death ${ }^{35}$. However, cellular viability was not compromised in the present study, indicating that the FAEEs-induced barrier dysfunction was independent of loss of cell viability. Cytotoxic effects of FAEEs have been reported on pancreatic ${ }^{36}$ and liver cells ${ }^{37}$, but in those experiments much higher concentrations of FAEEs $(100-800 \mu \mathrm{M})$ have been used.

As disruption of the TJs will contribute to changes in permeability, we examined whether the FAEEs-induced barrier dysfunction could be due to changes in localization an expression of TJ proteins. Exposure to FAEEs did alter ZO-1 and occludin localization and decrease their protein levels, indicating that changes in paracellular permeability observed by FAEEs treatment were due to disruption of TJs integrity. Our data confirm previous findings by our group ${ }^{24}$, and by others on ethanol and the

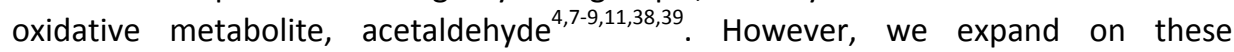
observations by showing for the first time that these changes can also be induced by the non-oxidative metabolites FAEEs, and thus may contribute to barrier dysfunction after ethanol ingestion.

Mislocalization and/or internalization of the TJ proteins can result in rapid changes in the composition and structure of the TJ proteins ${ }^{40,41}$. Intracellular interaction between occludin and actin filaments through ZO-1 plays an important role in organization of the $\mathrm{TJs}^{42}$. In this study, no intracellular staining of ZO-1 or occludin was observed, suggesting involvement of a process of disassembly rather than active remodelling through internalization. Moreover, our cell-based ELISA revealed reduced ZO-1 and occludin protein levels, most likely due to inhibition of protein synthesis. In line with these data, FAEEs have also been shown to inhibit protein synthesis in acinar cells ${ }^{43}$ and hepatocytes ${ }^{21}$.

Although FAEEs have been shown to induce ROS generation in hepatocytes ${ }^{44}$ and blood cells ${ }^{45}$, no such data were available with respect to intestinal cells. In this study, exposure to EO and EP dose-dependently increased ROS generation in Caco-2 spheroids. Furthermore, ROS production was found to correlate with the FAEEsinduced barrier dysfunction. Previously, an increase in oxidative stress has been shown to disrupt mucosal barrier function of intestinal epithelial cells through mechanisms involving oxidation, nitration, disassembly, and instability of the actin cytoskeleton $^{46,47}$, and cellular microtubules ${ }^{24}$. In addition, increased ROS production has been implicated in membrane damage and the subsequent amino acid transport reduction that is necessary for protein core synthesis ${ }^{48}$, which may also contribute to the observed decrease in ZO-1 and occludin protein levels.

Oxidative stress-mediated intestinal barrier disruption may offer opportunities for intervention strategies with antioxidants. Therefore, we tested whether resveratrol at nutritionally relevant concentrations can attenuate FAEEs-induced barrier function. The main reason for reduction of oxidative stress by resveratrol is its ability to scavenge intracellular $\operatorname{ROS}^{49}$. Since resveratrol is effectively metabolized by Caco- 2 
cells, enterocytes are considered a major target site for this dietary antioxidant ${ }^{50}$. Pretreatment with resveratrol attenuated the FAEEs-induced ROS generation, barrier dysfunction and changes in ZO-1 and occludin. Taken together, these findings suggest that the FAEEs-induced barrier dysfunction is oxidative stress-dependent. These observations are in line with previous data demonstrating that antioxidants can inhibit ROS $\left(\mathrm{H}_{2} \mathrm{O}_{2}\right)$-induced paracellular hyperpermeability ${ }^{51}$. In the present study, FAEEs increased $\mathrm{H}_{2} \mathrm{O}_{2}$ production, which has previously been found to increase paracellular permeability in Caco-2 monolayers via protein kinase $\mathrm{C}^{52}$, mitogen activated protein kinase $^{52}$ and protein tyrosine-dependent mechanisms ${ }^{53}$. Involvement of these signaling pathways in the FAEEs-induced ROS and modulation of barrier dysfunction cannot be ruled out, and merits further investigation.

Oxidants have been shown to deplete ATP in different cells and such changes in intracellular ATP levels are known to affect epithelial permeability ${ }^{54,55}$. However, in this study EO and EP failed to influence the intracellular ATP levels. In contrast, Criddle et al. have demonstrated that FAEEs, namely palmitoleic acid ethyl ester $(100 \mu \mathrm{M})$, can inhibit ATP synthesis in pancreatic acinar cells ${ }^{22}$. The discrepancy between these results and our observations may in part be explained by the difference in the type of the FAEEs and the concentrations employed.

In this study, EO showed a stronger effect than EP in increasing the FITC-D4 flux in Caco-2 spheroids. EO was also found to induce a more pronounced decrease in ZO-1 and occludin protein levels and a higher increase of ROS compared to EP. Given the higher concentrations of serum EO in long-term alcoholics and binge drinkers (9865 and $557 \mathrm{pmol} / \mathrm{ml}$, respectively) ${ }^{56}$, these observations indicate that EO generated after ethanol consumption is the main contributor of FAEEs induced barrier dysfunction in vivo. Since EP can also be detected in plasma and lead to barrier disruption, the presence of both metabolites may have additive or even synergetic injurious effects on intestinal epithelial integrity.

It is noteworthy that Caco-2 cells are transformed cells, raising the possibility that the effect of ROS in a nontransformed cell may be different. However, the transformed cells are known to be resistant to ROS-induced injury ${ }^{53}$, and therefore, ROS may be more injurious to the intestinal epithelial than the observations in this study. Ex vivo, inhibition of the oxidative ethanol metabolism has been shown to result in shifting ethanol metabolism towards the non-oxidative pathways resulting in FAEEs generation ${ }^{57}$. Therefore the damaging effects of FAEEs are expected to be particularly important in chronic alcohol users with low ADH activity. In heavy drinkers, FAEEs have been found to remain elevated for up to 99 hours $^{14}$. Based on the present data, it can be speculated that accumulation of FAEEs in alcoholics may contribute to the pathogenesis of alcoholic liver disease by inducing intestinal barrier disruption and consequently liver injury. Therefore, our study provides a scientific rationale to further investigate the role of FAEEs in ethanol-induced gut ad liver diseases in humans. 
In summary, our study shows for the first time that FAEEs are able to induce intestinal barrier dysfunction partly by ROS-induced TJs modulation and thereby may contribute to the pathogenesis of ALD. Furthermore, our results demonstrate that resveratrol in intestinal epithelial cells can combat the damaging effects of FAEEs-induced oxidative stress on mucosal barrier function. Our findings a) provide new insights into understanding the role of the non-oxidative metabolism in ethanol-induced intestinal injury, which may be especially relevant in chronic alcoholics and b) indicate the involvement of oxidative stress which might have the potential to test antioxidants as therapeutic target to reduce the noxious effects of ethanol on the small and large intestine. 


\section{References}

1. Purohit V, Bode JC, Bode C, Brenner DA, Choudhry MA, et al. Alcohol, intestinal bacterial growth, intestinal permeability to endotoxin, and medical consequences: Summary of a symposium. Alcohol 2008;42:349-61.

2. Keshavarzian A, Holmes EW, Patel M, Iber F, Fields JZ, et al. Leaky gut in alcoholic cirrhosis: a possible mechanism for alcohol-induced liver damage. Am J Gastroenterol 1999;94:200-7.

3. Rao R. Endotoxemia and gut barrier dysfunction in alcoholic liver disease. Hepatology 2009;50: 638-44.

4. Ma TY, Nguyen D, Bui V, Nguyen $\mathrm{H}$, Hoa N. Ethanol modulation of intestinal epithelial tight junction barrier. Am J Physiol 1999;276: G965-74.

5. Banan A, Choudhary S, Zhang Y, Fields JZ, Keshavarzian A. Ethanol-induced barrier dysfunction and its prevention by growth factors in human intestinal monolayers: evidence for oxidative and cytoskeletal mechanisms. J Pharmacol Exp Ther 1999;291: 1075-85.

6. Banan A, Fields JZ, Decker H, Zhang Y, Keshavarzian A. Nitric oxide and its metabolites mediate ethanol-induced microtubule disruption and intestinal barrier dysfunction. J Pharmacol Exp Ther 2000;294:997-1008.

7. Rao RK. Acetaldehyde-induced increase in paracellular permeability in Caco-2 cell monolayer. Alcohol Clin Exp Res 1998;22:1724-30.

8. Atkinson KJ, Rao RK. Role of protein tyrosine phosphorylation in acetaldehyde-induced disruption of epithelial tight junctions. Am J Physiol Gastrointest Liver Physiol 2001;280:G1280-8.

9. Basuroy S, Sheth P, Mansbach CM, Rao RK. Acetaldehyde disrupts tight junctions and adherens junctions in human colonic mucosa: protection by EGF and L-glutamine. Am J Physiol Gastrointest Liver Physiol 2005;289:G367-75.

10. Lieber CS. Ethanol metabolism, cirrhosis and alcoholism. Clin Chim Acta 1997;257:59-84.

11. Rao RK (2008) Acetaldehyde-induced barrier disruption and paracellular permeability in Caco-2 cell monolayer. Methods Mol Biol 2008;447:171-83.

12. Doyle KM, Cluette-Brown JE, Dube DM, Bernhardt TG, Morse CR, et al. Fatty acid ethyl esters in the blood as markers for ethanol intake. JAMA 1996;276:1152-6.

13. Borucki K, Kunstmann S, Dierkes J, Westphal S, Diekmann S, et al. In heavy drinkers fatty acid ethyl esters in the serum are increased for $44 \mathrm{hr}$ after ethanol consumption. Alcohol Clin Exp Res 2004;28: 1102-6.

14. Borucki K, Dierkes J, Wartberg J, Westphal S, Genz A, et al. In heavy drinkers, fatty acid ethyl esters remain elevated for up to 99 hours. Alcohol Clin Exp Res 2007;31:423-427.

15. Laposata EA, Lange LG. Presence of nonoxidative ethanol metabolism in human organs commonly damaged by ethanol abuse. Science 1986;231:497-9.

16. Diczfalusy MA, Bjorkhem I, Einarsson C, Hillebrant CG, Alexson SE. Characterization of enzymes involved in formation of ethyl esters of long-chain fatty acids in humans. J Lipid Res 2001;42:1025-32.

17. Lange LG, Sobel BE. Mitochondrial dysfunction induced by fatty acid ethyl esters, myocardial metabolites of ethanol. J Clin Invest 1983;72:724-31.

18. Haber PS, Wilson JS, Apte MV, Pirola RC. Fatty acid ethyl esters increase rat pancreatic lysosomal fragility. J Lab Clin Med 1993;121:759-64.

19. Kaphalia BS, Ansari GA. Fatty acid ethyl esters and ethanol-induced pancreatitis. Cell Mol Biol (Noisyle-grand). 2001; 47 Online Pub:OL173-9.

20. Aydin HH, Celik HA, Deveci R, Karacali S, Saydam G, et al. Induction of apoptosis by fatty acid ethyl esters in HepG2 cells. Food Chem Toxicol 2005;43:139-45.

21. Szczepiorkowski ZM, Dickersin GR, Laposata M. Fatty acid ethyl esters decrease human hepatoblastoma cell proliferation and protein synthesis. Gastroenterology 1995;108:515-22.

22. Criddle DN, Murphy J, Fistetto G, Barrow S, Tepikin AV, et al. Fatty acid ethyl esters cause pancreatic calcium toxicity via inositol trisphosphate receptors and loss of ATP synthesis. Gastroenterology 2006;130:781-93.

23. Vespa A, Darmon AJ, Turner CE, D'Souza SJ, Dagnino L. Ca2+-dependent localization of integrin-linked kinase to cell junctions in differentiating keratinocytes. J Biol Chem 2003;278:11528-35. 
24. Elamin E, Jonkers D, Juuti-Uusitalo $K$, van ljzendoorn S, Troost $F$, et al. Effects of ethanol and acetaldehyde on tight junction integrity: in vitro study in a three dimensional intestinal epithelial cell culture model. PloS one 2012;7:e35008.

25. Gubitosi-Klug RA, Gross RW. Fatty acid ethyl esters, nonoxidative metabolites of ethanol, accelerate the kinetics of activation of the human brain delayed rectifier K+ channel, Kv1.1. J Biol Chem 1996; 271:32519-22.

26. Collins TJ. ImageJ for microscopy. Biotechniques 2007;43:25-30.

27. Abramoff MD, Magelhaes PJ, Ram S.J. Image Processing with ImageJ. Biophotonics International 2004;11:36-42.

28. Murias M, Jager W, Handler N, Erker T, Horvath Z, et al. Antioxidant, prooxidant and cytotoxic activity of hydroxylated resveratrol analogues: structure-activity relationship. Biochem Pharmacol 2005;69: 903-12.

29. Carrasco-Pozo C, Mizgier ML, Speisky H, Gotteland M. Differential protective effects of quercetin, resveratrol, rutin and epigallocatechin gallate against mitochondrial dysfunction induced by indomethacin in Caco-2 cells. Chem Biol Interact 2012;195: 199-205.

30. Panaro MA, Carofiglio V, Acquafredda A, Cavallo P, Cianciulli A. Anti-inflammatory effects of resveratrol occur via inhibition of lipopolysaccharide-induced NF-kappaB activation in Caco-2 and SW480 human colon cancer cells. Br J Nutr 2012;108:1623-32.

31. Martin AR, Villegas I, La Casa C, de la Lastra CA. Resveratrol, a polyphenol found in grapes, suppresses oxidative damage and stimulates apoptosis during early colonic inflammation in rats. Biochem Pharmacol 2004;67:1399-410.

32. Belguendouz L, Fremont L, Gozzelino MT. Interaction of transresveratrol with plasma lipoproteins. Biochem Pharmacol 1998;55:811-6

33. Tsukamoto T, Nigam SK. Role of tyrosine phosphorylation in the reassembly of occludin and other tight junction proteins. Am J Physiol 1999;276:F737-50.

34. Doyle KM, Bird DA, al-Salihi S, Hallaq Y, Cluette-Brown JE, et al. Fatty acid ethyl esters are present in human serum after ethanol ingestion. J Lipid Res 1994;35:428-37.

35. Noren NK, Liu BP, Burridge K, Kreft B. p120 catenin regulates the actin cytoskeleton via Rho family GTPases. J Cell Biol 2000;150:567-80.

36. Criddle DN, Raraty MG, Neoptolemos JP, Tepikin AV, Petersen $\mathrm{OH}$, et al. Ethanol toxicity in pancreatic acinar cells: mediation by nonoxidative fatty acid metabolites. Proc Natl Acad Sci U S A 2004;101: 10738-43.

37. Laposata M, Szczepiorkowski ZM, Brown JE. Fatty-Acid Ethyl-Esters - Nonoxidative Metabolites of Ethanol. Prostaglandins Leukotrienes and Essential Fatty Acids 1995;52:87-91.

38. Seth A, Basuroy S, Sheth P, Rao RK. L-Glutamine ameliorates acetaldehyde-induced increase in paracellular permeability in Caco-2 cell monolayer. Am J Physiol Gastrointest Liver Physiol 2004;287: G510-7.

39. Sheth P, Seth A, Atkinson KJ, Gheyi T, Kale G, et al. Acetaldehyde dissociates the PTP1B-E-cadherinbeta-catenin complex in Caco-2 cell monolayers by a phosphorylation-dependent mechanism. Biochem J 2007;402:291-300.

40. Poritz LS, Garver KI, Tilberg AF, Koltun WA. Tumor necrosis factor alpha disrupts tight junction assembly. J Surg Res 2004;116:14-8.

41. Bruewer $M$, Utech $M$, Ivanov $A l$, Hopkins $A M$, Parkos $C A$, et al. Interferon-gamma induces internalization of epithelial tight junction proteins via a macropinocytosis-like process. FASEB J 2005;19:923-33.

42. Liu Y, Nusrat A, Schnell FJ, Reaves TA, Walsh S, et al. Human junction adhesion molecule regulates tight junction resealing in epithelia. J Cell Sci 2000;113 ( Pt 13): 2363-74.

43. Waszkiewicz N, Szajda SD, Zalewska A, Szulc A, Kepka A, et al. Alcohol abuse and glycoconjugate metabolism. Folia Histochem Cytobiol 2012;50:1-11.

44. Wu H, Cai P, Clemens DL, Jerrells TR, Ansari GA, et al. Metabolic basis of ethanol-induced cytotoxicity in recombinant HepG2 cells: role of nonoxidative metabolism. Toxicol Appl Pharmacol 2006;216: 238-47.

45. Tyulina OV, Prokopieva VD, Dodd RD, Hawkins JR, Clay SW, et al. In vitro effects of ethanol, acetaldehyde and fatty acid ethyl esters on human erythrocytes. Alcohol Alcohol 2002;37:179-86. 
46. Banan A, Zhang $\mathrm{Y}$, Losurdo J, Keshavarzian A. Carbonylation and disassembly of the F-actin cytoskeleton in oxidant induced barrier dysfunction and its prevention by epidermal growth factor and transforming growth factor alpha in a human colonic cell line. Gut 2000;46:830-7.

47. Banan A, Zhang L, Shaikh M, Fields JZ, Farhadi A, et al. Novel effect of NF-kappaB activation: carbonylation and nitration injury to cytoskeleton and disruption of monolayer barrier in intestinal epithelium. Am J Physiol Cell Physiol 2004;287:C1139-51.

48. Reilly ME, Patel VB, Peters TJ, Preedy VR. In vivo rates of skeletal muscle protein synthesis in rats are decreased by acute ethanol treatment but are not ameliorated by supplemental alpha-tocopherol. J Nutr 2000;130:3045-9.

49. Panaro MA, Carofiglio V, Acquafredda A, Cavallo P, Cianciulli A (2012) Anti-inflammatory effects of resveratrol occur via inhibition of lipopolysaccharide-induced NF-kappaB activation in Caco-2 and SW480 human colon cancer cells. Br J Nutr. 2012;108:1623-32.

50. Kaldas MI, Walle UK, Walle T. Resveratrol transport and metabolism by human intestinal Caco-2 cells. J Pharm Pharmacol 2003;55:307-12.

51. Rao RK, Li L, Baker RD, Baker SS, Gupta A. Glutathione oxidation and PTPase inhibition by hydrogen peroxide in Caco-2 cell monolayer. Am J Physiol Gastrointest Liver Physiol 2000;279:G332-40.

52. Seth A, Yan F, Polk DB, Rao RK. Probiotics ameliorate the hydrogen peroxide-induced epithelial barrier disruption by a PKC- and MAP kinase-dependent mechanism. Am J Physiol Gastrointest Liver Physiol 2008;294:G1060-9.

53. Rao RK, Baker RD, Baker SS, Gupta A, Holycross M. Oxidant-induced disruption of intestinal epithelial barrier function: role of protein tyrosine phosphorylation. Am J Physiol 1997;273:G812-23.

54. Lewis K, McKay DM. Metabolic stress evokes decreases in epithelial barrier function. Ann N Y Acad Sci 2009;1165:327-37.

55. Unno N, Menconi MJ, Salzman AL, Smith M, Hagen S, et al. Hyperpermeability and ATP depletion induced by chronic hypoxia or glycolytic inhibition in Caco-2BBe monolayers. Am J Physiol 1996;270: G1010-21.

56. Soderberg BL, Salem RO, Best CA, Cluette-Brown JE, Laposata M. Fatty acid ethyl esters. Ethanol metabolites that reflect ethanol intake. Am J Clin Pathol 2003;119 Suppl:S94-9.

57. Werner J, Saghir M, Fernandez-del Castillo C, Warshaw AL, Laposata M. Linkage of oxidative and nonoxidative ethanol metabolism in the pancreas and toxicity of nonoxidative ethanol metabolites for pancreatic acinar cells. Surgery 2001;129:736-44. 
112 C 


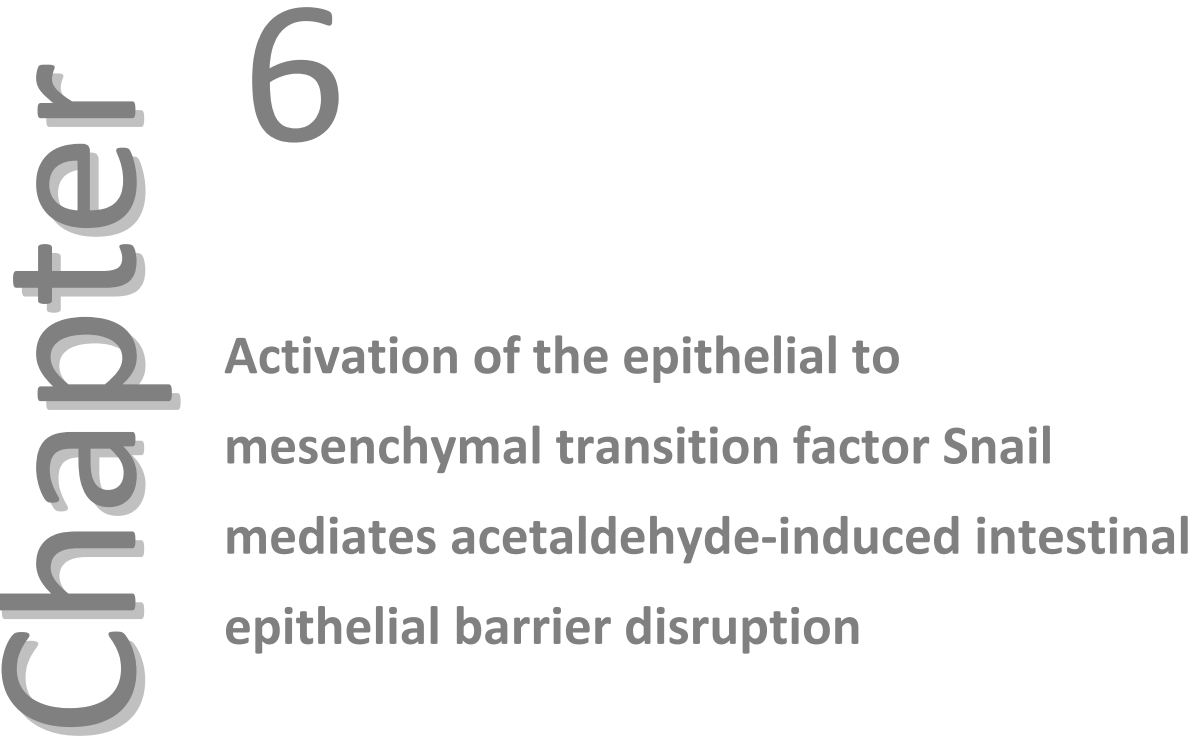

Elhaseen Elamin, Ad Masclee, Freddy Troost, Jan Dekker, Daisy Jonkers Alcohol Clin Exp Res 2013 


\section{Abstract \\ Background \\ Acetaldehyde is mutagenic and can reach high concentrations in colonic lumen after ethanol consumption, and is associated with intestinal barrier dysfunction and an increased risk of progressive cancers, including colorectal carcinoma. Snail, the transcription factor of epithelial-mesenchymal transition is known to downregulate expression of tight junction (TJ) and adherens junction (AJ) proteins, resulting in loss of epithelial integrity, cancer progression, and metastases. Since acetaldehyde is mutagenic, the role of Snail in the acetaldehyde-induced disruption of intestinal epithelial TJs deserves further investigation. Aims: To investigate the role of oxidative stress and Snail activation in acetaldehyde-induced barrier disruption in Caco-2 monolayers.}

\section{Methods}

The monolayers were exposed from the apical side to acetaldehyde +/- L-cysteine. Reactive oxygen species (ROS) generation and Snail activation were assessed by ELISA and immunofluorescence. Paracellular permeability, localization and expression of ZO-1, occludin, E-cadherin, $\beta$-catenin were examined using transepithelial electrical resistance (TEER), fluorescein isothiocyanate-labeled dextran 4 KD (FITC-D4), immunofluorescence and ELISA, respectively. Involvement of Snail was further addressed by inhibiting Snail using small interfering RNA (siRNA).

\section{Results}

Exposure to $25 \mu \mathrm{M}$ acetaldehyde increased ROS generation and ROS-dependently induced Snail phosphorylation. In addition, acetaldehyde increased paracellular permeability (decrease in TEER and increase in FITC-D4 permeation) in association with redistribution and decrease of $\mathrm{TJ}$ and $\mathrm{AJ}$ protein levels, which could be attenuated by L-cysteine. Knockdown of Snail by siRNA attenuated the acetaldehydeinduced redistribution and decrease in the TJ and AJ proteins, in association with improvement of the barrier function.

\section{Conclusions}

Our data demonstrate that oxidative stress-mediated Snail phosphorylation is likely a novel mechanism contributing to the deleterious effects of acetaldehyde on the TJ and $\mathrm{AJ}$, and intestinal barrier function. 


\section{Introduction}

There is a large body of evidence to indicate that ethanol and its metabolites can disrupt intestinal epithelial barrier function ${ }^{1}$. This can ultimately lead to enhanced translocation of endotoxins and endotoxemia, which has been implicated in the pathogenesis of alcoholic liver disease $(A L D)^{2,3}$. The paracellular epithelial barrier is maintained by tight junctions (TJ), which is a complex of transmembrane proteins including claudins and occludin and scaffolding proteins such as zona occludens family, including ZO-1, connected intracellularly with the actin cytoskeleton ${ }^{4-6}$. In addition, the assembly of TJ between epithelial cells requires prior formation of adherens junctions (AJ) including the proteins E-cadherin and $\beta$-catenin ${ }^{7}$.

The deleterious effects of ethanol have mainly been attributed to acetaldehyde ${ }^{8,9}$, an oxidative ethanol metabolite generated, e.g., by human alcohol dehydrogenase ${ }^{10}$, and intestinal microbiota ${ }^{11,12}$. Since colonic mucosa and microbiota are less metabolically capable to oxidize acetaldehyde to acetate compared to upper $\mathrm{Gl} \operatorname{tract}^{13}$, high levels of acetaldehyde can be accumulated in the colon mucosa after ethanol consumption. Others and we have shown that acetaldehyde can disrupt intestinal epithelial TJs and thereby increases paracellular permeability ${ }^{1,8,9,14}$. Although the precise mechanism is ill defined, roles for reactive oxygen species $(\mathrm{ROS})^{15,16}$, protein tyrosine kinase $(\mathrm{PTK})^{14,17}$, and protein phosphatase $2 \mathrm{~A}$ (PP2A) have been reported ${ }^{18}$. In addition to barrier dysfunction, accumulation of acetaldehyde and subsequent ROS generation in colonic mucosa of alcoholics is suggested to play a key role in the pathogenesis of colorectal hyperproliferation and carcinogenesis ${ }^{19,20}$, and to be an important determinant for blood acetaldehyde levels and subsequent liver injury ${ }^{21}$.

Recently, Forsyth et al. have demonstrated in vitro and in mice that ethanol-mediated inducible nitric oxide synthase (iNOS) upregulation can directly induce activation of the epithelial-to-mesenchymal transition (EMT) transcription factor Snail, resulting in increased intestinal permeability ${ }^{22}$. EMT is characterized by decreased expression of junctional proteins including $\mathrm{AJ}$ and $\mathrm{TJ}^{23}$, and is shown to play a role in loss of epithelial integrity, cancer progression, and metastases ${ }^{24}$. Although Snail expression has been found to be increased in the colon of long-term ethanol abusers, where high luminal concentrations of acetaldehyde can be present ${ }^{25}$, the role of Snail on intestinal barrier integrity after acetaldehyde stimulation has not been explored.

Therefore, the aim of this study was to determine if activation of Snail is involved in acetaldehyde-induced alterations of intestinal barrier function and/or TJ and AJ organization. We hypothesized that acetaldehyde-induced oxidative stress results in activation of Snail, which will lead to disruption of TJ and AJ proteins resulting in increased paracellular permeability. 


\section{Materials and Methods}

\section{Reagents}

Cell culture reagents were purchased from Invitrogen and Lonza Benelux BV (Breda, the Netherlands). Fluorescein isothiocyanate (FITC-D4), dichlorodihydrofluorescein diacetate (DCF-DA) and Triton X-100 were purchased from Sigma-Aldrich (Amsterdam, the Netherlands). Cell-based ELISA assay kits were purchased from RayBiotech (Norcross, GA, USA). Snail siRNA and Accell siRNA delivery medium were purchased from Thermo Scientific Dharmacon (Lafayette, CO, USA). Control RNA was purchased from Santa Cruz Biotechnology (Dallas, TX, USA). Mouse polyclonal anti-ZO-1 and rabbit-anti occludin antibodies were purchased from Zymed Laboratories (San Francisco, USA). Rabbit-anti E-cadherin, rabbit-anti $\beta$-catenin and rabbit-anti Snail, and rabbit-anti phosphorylated Snail (s246) antibodies were purchased from Abcam (Cambridge, UK). Alexa-fluor 488-conjugated anti-mouse IgG and Cy3-conjugated antirabbit IgG antibodies were from Jackson Laboratories (Suffolk, UK). HRP-conjugated anti-mouse and anti-rabbit antibodies were purchased from Dako BV (Heverlee, Belgium). Diamidino-2-phenylindole (DAPI) was purchased from Sigma-Aldrich (Amsterdam, the Netherlands).

\section{Cell line and culture conditions}

Human colorectal adenocarcinoma cells, Caco-2, purchased from the European Collection of Cell Cultures (ECACC; Salisbury, UK) were grown under standard culture conditions as described previously ${ }^{1}$. Although Caco- 2 cells express many enzymes (e.g. alkaline phosphatase, sucrose, isomaltase and aminopeptidase) present in the small intestine ${ }^{26}$, the high TEER and poor paracellular permeability properties ${ }^{27,28}$ in later passages of cells ${ }^{29}$ often resemble colonic epithelium.

\section{Measurement of reactive oxygen species (ROS)}

The generation of ROS was monitored by using 2', 7'- dichlorodihydrofluorescein diacetate (DCF-DA, Sigma Chemical Co, Amsterdam, NL), which is non-fluorescent unless oxidized by intracellular ROS. Caco-2 cells $\left(20 \times 10^{3}\right)$ were cultured in 96 well plates and were preloaded with $100 \mu \mathrm{M}$ DCF-DA for $1 \mathrm{~h}$ at $37^{\circ} \mathrm{C}$. Measurement of intracellular ROS in Caco-2 cells was performed after $3 \mathrm{~h}$ luminal incubation with either medium only as control or $25 \mu \mathrm{M}$ of acetaldehyde in the presence or absence of $1 \mathrm{~h}$ pretreatment with $100 \mu \mathrm{M}$ of the antioxidant L-cysteine. Since acetaldehyde is highly volatile, acetaldehyde solutions were prepared at $4^{\circ} \mathrm{C}$. Caco- 2 monolayers were exposed in partly plastic tape-sealed plates and acetaldehyde was replaced each hour to compensate for evaporation. The monolayers were then washed twice in Hank's Balanced Salt Solution buffer (HBSS) and the fluorescence (485Ex/530Em) was measured by SpectraMax M2 spectrofluorometer (Molecular Devices, Sunnyvale, CA, 
USA). DCF oxidation (as percentage over of basal value) was estimated as: $\left.\mathrm{RFU}_{\text {Experimental }} \mathrm{X} 100\right) / \mathrm{RFU}_{\text {basal }}$.

\section{Intestinal epithelial cell monolayer barrier function}

Both transepithelial electrical resistance (TEER) and fluorescein isothiocyanatelabeled-dextran 4 KDa (FITC-D4) permeation were assessed as parameters of barrier function. For TEER measurement, Caco-2 cells (passage 40-48) were seeded at a density of $10^{5}$ cells on collagen-coated polycarbonate membrane Transwell inserts with a surface area of $0.33 \mathrm{~cm}^{2}$ and $0.4 \mu \mathrm{m}$ pore size (Costar, Cambridge, MA, USA). The integrity of the monolayer was evaluated by measuring the TEER, using an EVOM Epithelial Volt-ohm-meter with an STX2 electrode (World Precision Instruments, Berlin, Germany). Monolayers with TEER $>600 \mathrm{Ohm} . \mathrm{cm}^{2}$ were exposed for $3 \mathrm{~h}$ at the apical side to either medium only as control or $25 \mu \mathrm{M}$ acetaldehyde, in the presence or absence of $1 \mathrm{~h}$ luminal pretreatment with $100 \mu \mathrm{M}$ L-cysteine. To obtain monolayer resistance, total TEER (cell monolayer + insert) calculated as $\Omega \bullet \mathrm{cm}^{2}$ by multiplying the meter readings by the effective surface area of the filter membrane was subtracted from background TEER (approximately $30 \Omega \bullet \mathrm{cm}^{2}$ ). Data are reported as TEER percentage of medium-only treated controls. By the end of the TEER measurements, FITC-D4 (1 mg/ml; Sigma-Aldrich, Amsterdam, the Netherlands) was added to the apical compartment and incubated for $1 \mathrm{~h}$ at $37^{\circ} \mathrm{C}$. Then, $100 \mu \mathrm{l}$ of medium from the apical and basal compartments were collected in 96 well plates and FITC-D4 was measured spectrophotometrically using SpectraMax M2 spectrofluorometer (Molecular Devices, Sunnyvale, CA, USA) at excitation and emission spectra of $485 \mathrm{~nm}$ and $540 \mathrm{~nm}$, respectively, and data reported as relative fluorescent unit (RFU).

\section{Immunofluorescent staining of TJ, AJ and phosphorylated Snail}

Caco- 2 cells $\left(50 \times 10^{3}\right)$ grown on eight-well chamber slides for 21 days were treated with $25 \mu \mathrm{M}$ acetaldehyde for $3 \mathrm{~h}$. Cells were then washed with PBS, fixed and permeabilized with ethanol/ acetone $1: 1$ and $0.4 \%$ Triton $\mathrm{x}-100$ for $40 \mathrm{~min}$, respectively. After blocking with $3 \%(\mathrm{w} / \mathrm{v})$ bovine serum albumin (BSA), cells were stained with primary antibodies: mouse anti-ZO-1, rabbit anti-occludin, mouse anti-Ecadherin, rabbit anti- $\beta$-catenin, rabbit anti-Snail and rabbit phosphorylated Snail (P-Snail; Abcam, Cambridge, UK, 1:100 dilution in 3\% (w/v) BSA in PBS, pH 7.4). Then, cells were washed with PBS, and incubated for $1 \mathrm{~h}$ with either Alexa-488 conjugated goat anti-mouse (Invitrogen, Breda, the Netherlands) or Cy3-conjugated goat antirabbit (Jackson Laboratories, Suffolk, UK) secondary antibodies (1:100 dilution in 3\% $(\mathrm{w} / \mathrm{v}) \mathrm{BSA}$ in PBS, $\mathrm{pH} 7.4)$ at $37^{\circ} \mathrm{C}$ for $1.5 \mathrm{~h}$. The cells were washed again and were counterstained with diamidino-2-phenylindole (DAPI; 1:10,000 dilution in PBS; SigmaAldrich) for $5 \mathrm{~min}$. The cells were washed again before examination with a Leica TCS SPE confocal laser scanning microscope (Leica Microsystems GmbH, Mannheim, 
Germany). Representative images were processed and analyzed by Image J software ${ }^{30}$

\section{Transfection of cells with Snail small interfering RNA}

Caco-2 ( $10^{5}$ cells) about $50 \%$ confluency were transfected with Snail siRNA (Thermo Scientific Dharmacon, Lafayette, CO, USA), or control nonspecific siRNA (Santa Cruz Biotechnology, CA) using Accell siRNA reagents (Thermo Scientific Dharmacon), according to manufacturer's protocol. Briefly, cells grown on either 96 well-plate, 8 well chambers, or transwell inserts (Costar, Cambridge, MA, USA) were incubated in serum- and antibiotic-free medium for $24 \mathrm{~h}$. Then, cells were transfected with $5 \mathrm{nM}$ of either siRNA or control nonspecific siRNA in $100 \mu \mathrm{l}$ Accell siRNA delivery medium (Thermo Scientific Dharmacon), gently shaken and incubated at $37^{\circ} \mathrm{C}$ for $48 \mathrm{~h}$. Next, a cell-based ELISA assay with rabbit anti-Snail (Abcam) was performed to monitor the efficiency of Snail knockdown. Thereafter, the transfection mixture was replaced with Accell delivery media and permeability experiments were conducted.

\section{Assessment of total and phosphorylated Snail, TJs and AJs protein expression}

Total Snail, P-Snail, ZO-1, occludin, E-cadherin, and $\beta$-catenin protein levels were assessed by cell-based ELISA kits (RayBiotech, Inc. Norcross, GA, USA) according to manufacturer's instructions with minor modifications. Briefly, Caco-2 cells $\left(20 \times 10^{3}\right)$ were seeded in 96 well-plates (Corning BV, Amsterdam, The Netherlands) and incubated overnight at $37 \stackrel{\circ}{\circ} \mathrm{C}, 5 \% \mathrm{CO}_{2}$. Then, monolayers were treated as described previously and washed thoroughly with PBS and fixed using fixative solution (acetic acid) for $20 \mathrm{~min}$ at room temperature with shaking. After washing, a quenching buffer was added and the plate was incubated for $20 \mathrm{~min}$ at room temperature (RT). Thereafter, a blocking solution was added and incubated for $1 \mathrm{~h}$ at $37^{\circ} \mathrm{C}$. After triple washings, either rabbit anti-Snail or anti- P-Snail (pS246, 1:100 dilution in the blocking solution; Abcam) was added, and incubated for $1 \mathrm{~h}$ at RT with shaking. In other experiments, monolayers in were incubated for $1 \mathrm{~h}$ with mouse anti-ZO-1, rabbit antioccludin, mouse anti-E-cadherin, and rabbit anti- $\beta$-catenin (1:100 dilution in the blocking solution; Abcam) at RT. Next, HRP-conjugated mouse anti-rabbit IgG (1:100 dilution in the blocking solution; Dako Netherlands BV, Heverlee, Belgium) was added to each well and incubated for $1 \mathrm{~h}$ at RT. Then, the plate was washed thrice and 3, 3', 5, 5'-tetramethylbenzidine (TMB) was added to each well and incubated for $30 \mathrm{~min}$ with shaking at $\mathrm{RT}$ in the dark. Finally, stop solution $\left(2 \mathrm{NH}_{2} \mathrm{SO}_{4}\right)$ was added to each well and the optical density was read at $450 \mathrm{~nm}$ by SpectraMax M2 spectrophotometer (Molecular Devices). 


\section{Dot blotting phosphorylated Snail}

Caco-2 cell lysates were prepared with radioimmunoprecipitation assay (RIPA) buffer containing ( $150 \mathrm{mM} \mathrm{NaCl}, 1.0 \%$ Triton $\mathrm{X}-100,0.5 \%$ sodium deoxycholate, $0.1 \%$ sodium dodecyl sulphate, and $50 \mathrm{mM}$ Tris, protease and phosphates inhibitors cocktail), and protein levels were determined using bicinchoninic acid protein assay (BCA) protein assay (Bio-Rad Laboratories). Using a narrow-mouth pipette tip, $2 \mu \mathrm{l}$ of samples were spotted onto a nitrocellulose membrane at the center of pencil-drawn grids and was let dry to the air. Next, nonspecific sites were blocked by soaking the membrane in $5 \%$ (w/v) BSA in Tris-buffered saline and Tween 20 buffer (TBS-T) $(20 \mathrm{mM}$ Tris- $\mathrm{HCl}, 150$ $\mathrm{mM} \mathrm{NaCl}$ and $0.05 \%$, Tween20 $\mathrm{pH}$ 7.5) for $1 \mathrm{~h}$ at RT. Then, the membrane was incubated with rabbit anti-phosphorylated Snail $(10 \mu \mathrm{g} / \mathrm{ml}$ dissolved in BSA/TBS, Abcam) for $30 \mathrm{~min}$ at RT. Thereafter, membrane was washed in TBS ( $3 \times 5 \mathrm{~min})$ and incubated with swine anti-rabbit horseradish peroxidase (HRP)-conjugated secondary antibody (1:1000 dilution; Dako, Glostrup, Denmark) for 30 min at RT, followed by washing in TBST (15 $\mathrm{min} \times 1.5 \mathrm{~min} \times 2)$, then once with TBS (5 min). Finally, the membrane was incubated using a chemiluminescence kit (GE Healthcare Europe $\mathrm{GmbH}$, Diegem, Belgium) for 1 min, covered with Saran wrap, and visualized by chemidoc XRS (Bio-Rad, Hercules, CA). Quantification of the dots was done using Image J software ${ }^{30}$.

\section{Statistical analysis}

Obtained data of at least three independent experiments, each conducted in triplicate, are presented as means \pm SD. Statistics were performed using GraphPad Prism 4 (GraphPad Software Incorporated, La Jolla, CA, USA). One-way analysis of variance (ANOVA) was used followed by Tukey's Multiple Comparison Test. $P$ values < 0.05 were considered statistically significant.

\section{Results}

\section{Intracellular ROS generation}

The pro-oxidant effects of acetaldehyde were evaluated by measuring intracellular oxidation of DCF-DA. Exposure of cells to $25 \mu \mathrm{M}$ acetaldehyde led to a $40 \%$ increase in DCF oxidation compared to medium only-treated controls $(p<0.0001$; Figure $6.1 \mathrm{~A})$. Pretreatment of cells with L-cysteine significantly attenuated this increase $(P<0.05$; Figure 6.1A). 


\section{Role of ROS generation in barrier dysfunction}

To investigate the role of ROS in acetaldehyde-induced barrier dysfunction, we compared the effects of $3 \mathrm{~h}$ exposure of $25 \mu \mathrm{M}$ acetaldehyde, the minimum concentration we found to disrupt epithelial barrier integrity without decreasing cell viability $^{1}$, on TEER and FITC-D4 permeation in Caco- 2 monolayers versus L-cysteine pretreated monolayers. As expected, exposure to $25 \mu \mathrm{M}$ acetaldehyde for $3 \mathrm{~h}$ caused marked disruption of intestinal barrier function in Caco- 2 monolayers as indicated by a $60 \%$ decrease in TEER ( $P<0.0001$ vs. medium only-treated controls, Figure $6.1 \mathrm{~B}$ ) and significant increase in FITC-D4 permeation $(P<0.0001$ vs. medium only-treated controls, Figure 6.1C). However, pretreatment with $100 \mu \mathrm{M}$ L-cysteine for $1 \mathrm{~h}$ significantly attenuated the acetaldehyde-induced TEER decrease $(P<0.0001$, Figure 6.1B), and decreased FITCD-4 permeation compared to acetaldehyde alone $(P<0.0001$, Figure $6.1 \mathrm{C}$ ). In addition, a negative correlation between ROS generation and the TEER, and a positive correlation between ROS and FITC-D4 permeation were found after acetaldehyde exposure $(r=-0.8$ and $r=0.7$, respectively; both $P<0.0001$; Figure 6.1D, 6.1E).

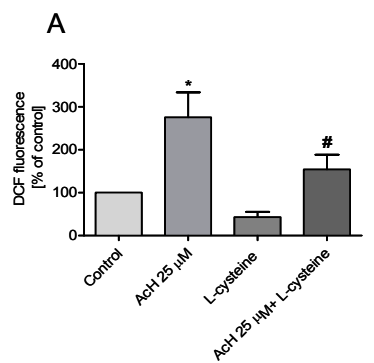

D

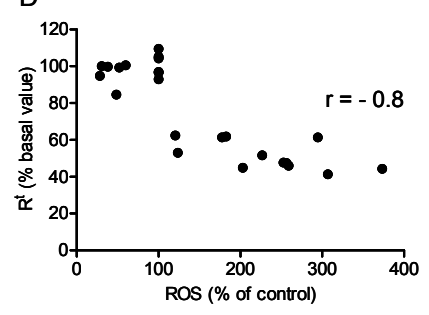

B

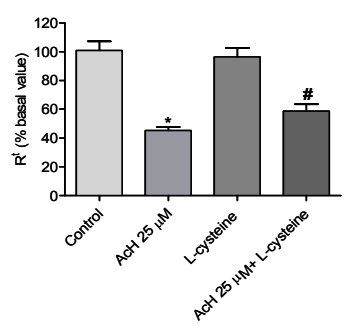

C

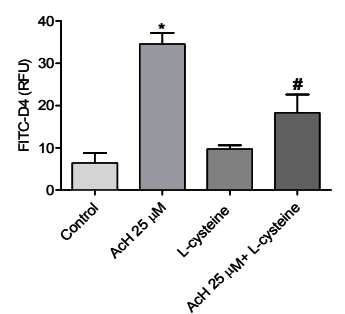

$\mathrm{E}$

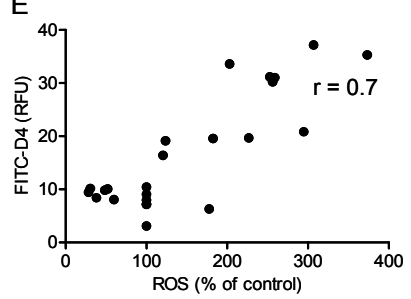

Figure 6.1 Acetaldehyde elevates intracellular reactive oxygen species (ROS) levels and Inhibition of ROS with L-cysteine attenuates acetaldehyde-induced TEER decrease and FD4 permeation. [A] Caco-2 cell monolayers pretreated with or without L-cysteine were exposed to $25 \mu \mathrm{M}$ acetaldehyde $(\mathrm{AcH})$ for 3 h. ROS generation was assayed using 2', 7'dichlorodihydrofluorescein diacetate (DCF-DA) and expressed as percentage of medium onlytreated control. Data are presented as means $\pm S D$ of three independent experiments. ${ }^{*} P<0.0001$ vs. control, and ${ }^{\#} P<0.001$ vs. monolayers treated with $\mathrm{AcH}$. [B] Caco-2 cell monolayers were pretreated with $100 \mu \mathrm{M}$ L-cysteine $1 \mathrm{~h}$ prior to $25 \mu \mathrm{M}$ acetaldehyde (AcH) administration. TEER was measured by using an epithelial Volt-ohm-meter and compared with the medium only-treated control. Values are means $\pm S D, n=6 .{ }^{*} P<0.0001$ vs. control and 
${ }^{\#} P<0.0001$ vs. acetaldehyde-treated cell monolayers in the absence of L-cysteine. [C] FITC-D4 permeation to the basal compartment was measured fluorometrically and compared to the control. Values are means $\pm S D$ of, $n=18$. ${ }^{*} P<0.0001$ versus control and ${ }^{\#} P<0.0001$ vs. acetaldehyde-treated cell monolayers in the absence of L-cysteine. [D] Correlations between the increase in ROS and decrease in TEER, and [E] increase in FITC-D4 permeation. Data points indicate ROS and TEER production under the aforementioned conditions/treatments.

\section{Role of ROS in acetaldehyde-induced TJs and AJs disruption}

Microscopic analysis of immunofluorescence-labeled ZO-1 and occludin in the medium only-treated control, showed that the distribution of ZO-1 in Caco-2 monolayers was localized mainly in cell boundaries and was tightly arranged with sharp, continuous smooth edges, and showing a typical 'chicken wire' shape without abnormalities. Similarly, occludin was sharply localized around cell borders colocalizing with ZO-1 (Figure 6.2A). In contrast, exposure to $25 \mu \mathrm{M}$ acetaldehyde resulted in disruption of these networks, lower levels of staining, and redistribution of ZO-1 and occludin from intercellular junctions into intracellular compartments with loss of co-localization and apparent gap formation between the cells (Figure 6.2A, arrowheads). Pretreatment with L-cysteine attenuated acetaldehyde-induced redistribution of ZO-1 and occludin, in particular the apparent gaps between cells seem not to form in these conditions (Figure 6.2A).

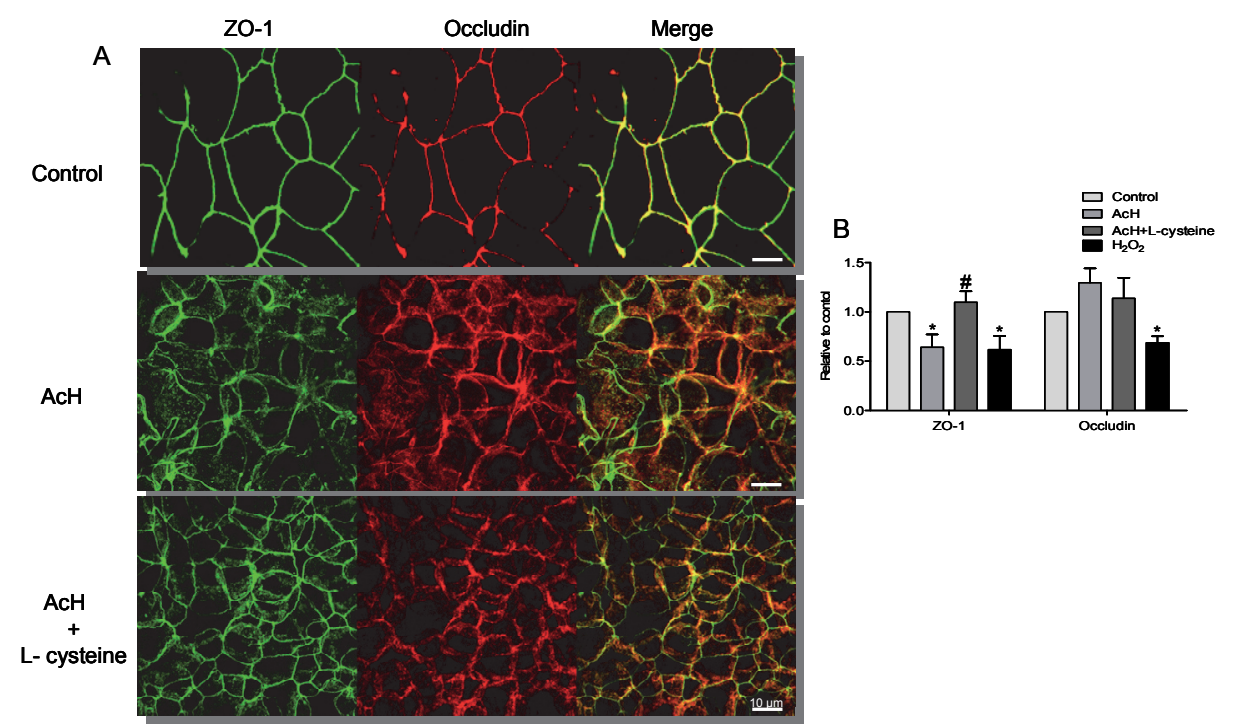

Figure 6.2 L-cysteine attenuates acetaldehyde-induced disruption and reduction in ZO-1 and occludin protein levels in Caco-2 cell monolayers. [A] Caco-2 cell monolayers incubated with $25 \mu \mathrm{M}$ acetaldehyde $(\mathrm{AcH})$ for $3 \mathrm{~h}$ with or without L-cysteine pretreatment were fixed and doublestained for ZO-1 and occludin. [B] Cell-based ELISA assay of ZO-1 and occludin protein levels. $\mathrm{H}_{2} \mathrm{O}_{2}$ (30 mM) was added as a positive control to induce decrease in TJ protein levels. ${ }^{*} P<0.0001$ versus control and ${ }^{\#} P<0.0001$ versus acetaldehyde-treated cell monolayers in the absence of L-cysteine. 
In addition, treatment with acetaldehyde significantly reduced ZO-1 $(P<0.0001)$, but not occludin $(P>0.05)$ protein levels compared with medium-treated controls (Figure 6.2B). Previously, $\mathrm{H}_{2} \mathrm{O}_{2}$ has been shown to induce intestinal barrier disruption ${ }^{31}$. In this study, exposure to $30 \mathrm{mM} \mathrm{H}_{2} \mathrm{O}_{2}$ (positive control) resulted in reduction of both ZO-1 and occludin protein levels compared with medium-treated controls $(P<0.0001$; Figure 6.2B). Pretreatment of the Caco-2 cells with L-cysteine for $1 \mathrm{~h}$ significantly preserved ZO-1 proteins levels, compared to acetaldehyde alone ( $P<0.0001$; Figure 6.2B).

Acetaldehyde exposure also resulted in redistribution of AJ proteins, E-cadherin and $\beta$-catenin, which was prevented by L-cysteine treatment (Figure 6.3A). Furthermore, treatment with acetaldehyde significantly reduced E-cadherin $(P<0.0001)$, but not $\beta$-catenin $(P>0.05)$ protein levels compared with medium-treated control (Figure 6.3B). Pretreatment with L-cysteine significantly and totally preserved E-cadherin protein levels, compared to acetaldehyde alone $(P<0.0001$; Figure 6.3B).

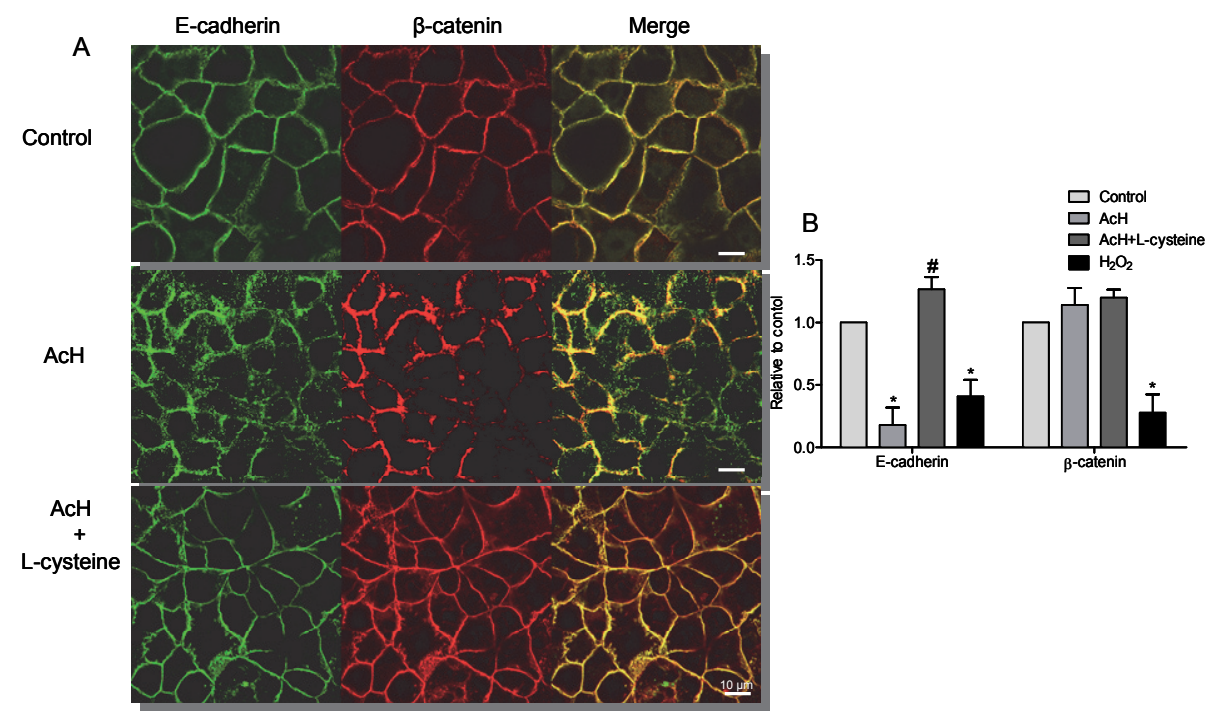

Figure 6.3 L-cysteine attenuates acetaldehyde-induced disruption of E-cadherin and $\beta$-catenin in Caco-2 cell monolayers. [A] Caco-2 cell monolayers incubated with $25 \mu \mathrm{M}$ acetaldehyde (AcH) for $3 \mathrm{~h}$ with or without L-cysteine pretreatment were fixed and double-stained for E-cadherin and $\beta$-catenin. [B] Cell-based ELISA assay of E-cadherin and $\beta$-catenin protein levels. $\mathrm{H}_{2} \mathrm{O}_{2}(30 \mathrm{mM})$ was added as a positive control to induce decrease in AJ proteins levels. ${ }^{*} P<0.0001$ versus control and ${ }^{\#} P<0.0001$ versus acetaldehyde-treated cell monolayers in the absence of L-cysteine. 


\section{ROS generation and acetaldehyde-induced Snail phosphorylation}

To establish whether acetaldehyde can induce Snail activation (i.e. phosphorylation at Ser246: Snail ${ }^{\text {pS246}}$ ) via oxidative stress, Caco-2 monolayers were exposed to acetaldehyde with or without pretreatment by L-cysteine and nuclear localization as well as protein levels of Snail ${ }^{\text {pS246 }}$ were assessed by immunocytochemistry and cell based-ELISA, respectively. As shown in Figure $6.4 \mathrm{~A}$, hardly any Snail ${ }^{\mathrm{p} 246}$ nuclear staining is visible in untreated cells, whereas treatment with acetaldehyde $(\mathrm{AcH})$ for $3 \mathrm{~h}$ resulted in massive increased of nuclear Snail ${ }^{\mathrm{pS} 246}$ accumulation. Pretreatment with L-cysteine completely prevented the acetaldehyde-induced nuclear Snail ${ }^{\text {ps246 }}$ accumulation.

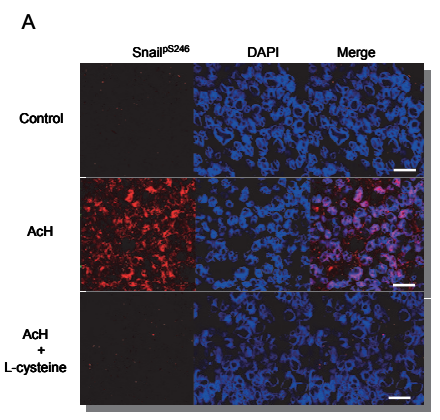

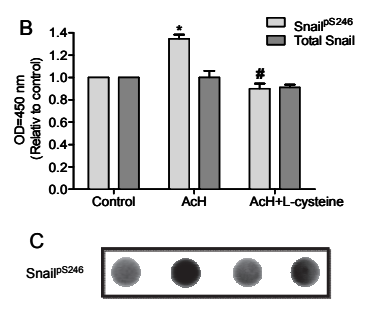

$\mathrm{D}$

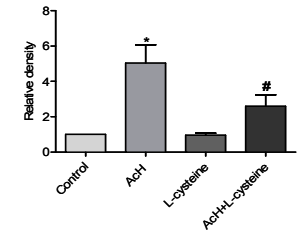

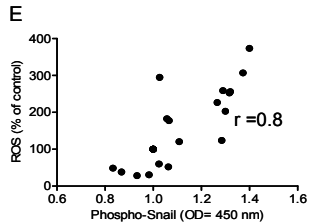

Figure 6.4 Acetaldehyde induces phosphorylation of Snail on serine residues (Snail ${ }^{\text {pS246 }}$ ) by a ROSdependent mechanism. [A] Caco-2 cells grown on glass bottom dishes were treated with 25 $\mu \mathrm{M}$ acetaldehyde $(\mathrm{ACH})$ for $3 \mathrm{~h}$ and then fixed and stained with rabbit anti- Snail ${ }^{\mathrm{pS} 246}$. Nuclei were stained with DAPI. Cells indicated by $\mathrm{AcH}+\mathrm{L}$-cysteine were pretreated with $100 \mu \mathrm{M}$ L-cysteine for $1 \mathrm{~h}$. Images are representative from 3 separate experiments $(n=9)$. Scale bar = $10 \mu \mathrm{m}$. [B] Cell-based ELISA analysis of total and Snail ${ }^{\mathrm{pS2} 26}{ }^{*} P<0.0001$ versus control and ${ }^{\#} P<0.0001$ versus acetaldehyde-treated cell monolayers in the absence of L-cysteine. Snail phosphorylation (Snail ${ }^{\mathrm{pS} 246}$ ) by acetaldehyde $(\mathrm{AcH})$ is mediated by oxidative stress. [C] Representative dot blot analysis of Snail ${ }^{\mathrm{pS} 246}$ expression in Caco-2 cells incubated with (AcH) in the absence or presence of pretreatment with L-cysteine. [D] Densitometric analysis of three different experiments. Values are means \pm SD of, $n=3$. ${ }^{*} P<0.001$ versus control and ${ }^{\#} P<0.001$ versus acetaldehyde-treated cell monolayers in the absence of L-cysteine. [E] Correlations between the increase in ROS generation and Snail phosphorylation. Data points indicate production of ROS and induction Snail phosphorylation under the aforementioned conditions/treatments. 
Protein levels of Snail ${ }^{\mathrm{pS} 246}$ were significantly increased after exposure to acetaldehyde as compared to the total Snail levels untreated controls $(P<0.001)$. Pretreatment with L-cysteine significantly attenuated the acetaldehyde-induced increase in Snail ${ }^{\text {p2246 }}$ protein levels $(P<0.05$; Figure 6.4B). To complement this data, dot blotting was performed showing that expression of Snail ${ }^{\text {pS246 }}$ increased in Caco-2 cells incubated with acetaldehyde and decreased after pretreatment with L-cysteine (Figure 6.4C). Densitometric analysis of the dots showed acetaldehyde to significantly enhance Snail ${ }^{\text {pS246 }}$ expression compared to control cells $(P<0.01)$, which could be attenuated by L-cysteine ( $P 0.01$ vs. acetaldehyde alone; Figure 6.4D). Furthermore, a linear correlation was found between the increase in ROS generation and Snail phosphorylation under the aforementioned treatments $(r=0.8$ and $P<0.0001$, Figure 6.4E).

\section{SiRNA inhibition of Snail and acetaldehyde-induced barrier disruption}

To further assess the involvement of Snail activation in acetaldehyde-induced barrier dysfunction and TJ disruption, we knocked down Snail using specific siRNA. As shown in Figure $6.5 \mathrm{~A}$, total Snail protein levels were significantly reduced $(80 \%)$ by specific siRNA transfection $(P<0.01)$. In acetaldehyde-treated cells that were either untransfected or transfected with a non-specific siRNA, the TEER declined significantly compared to medium only-treated controls $(P<0.05$ : Figure 6.5B). In contrast, transfection with Snail-specific siRNA significantly attenuated the acetaldehydeinduced TEER drop compared to non-specific siRNA transfected monolayers $(P<0.001$; Figure 6.5B). In addition, acetaldehyde significantly increased FITC-D4 permeability in non-specific siRNA transfected monolayers $(P<0.05$; Figure 6.5C). However, in Snailspecific siRNA transfected monolayers, acetaldehyde-induced FITC-D4 permeability was significantly lower compared to non-specific siRNA transfected monolayers $(P<0.05$; Figure 6.5C). 


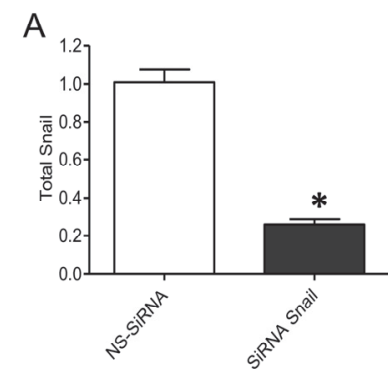

B
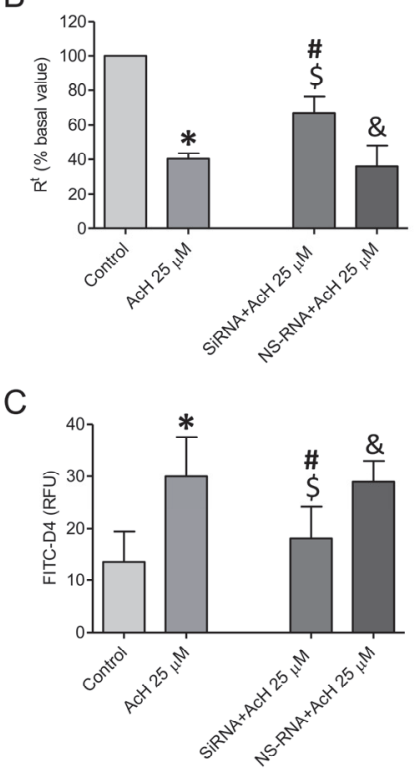

Figure 6.5 Knockdown of Snail attenuates acetaldehyde-induced barrier dysfunction. [A] Caco-2 monolayers were transfected with siRNA specific for Snail or non-specific RNA (NS-RNA). Values are means $\pm S D(n=3) .{ }^{*} P<0.01$ is significantly different from the value for NS-RNA. [B] Monolayers were treated with $25 \mu \mathrm{M}$ acetaldehyde $(\mathrm{AcH})$ and TEER was measured by using an epithelial Volt-ohm-meter and values are presented as means $\pm \mathrm{SD}, \mathrm{n}=6 .{ }^{*} P<0.0001$ and ${ }^{\&} P<0.0001$ vs. control. ${ }^{\#} P<0.05$ vs. AcH $25 \mu \mathrm{M}$ and ${ }^{\$} P<0.001$ vs. NS-siRNA+ AcH $25 \mu \mathrm{M}$. [C] FITC-D4 permeation to the basal compartment was measured fluorometrically and compared with the control. Values are means \pm SD of, $n=18$. ${ }^{*} P<0.0001$ and ${ }^{\circledR} P<0.001$ vs. control. ${ }^{\#} P<0.05$ vs. AcH $25 \mu \mathrm{M}$ and ${ }^{\$} P<0.005$ vs. control siRNA+ AcH $25 \mu \mathrm{M}$.

To determine whether Snail is involved in acetaldehyde-induced modulation TJ and AJ, protein expression of ZO-1, occludin, $\beta$-catenin and E-cadherin was assessed. In nonspecific siRNA transfected monolayers, acetaldehyde induced redistribution of ZO-1 (Figure 6.6A), and a decrease in ZO-1 protein levels ( $P<0.05$; Figure 6.6B). However, knocking down Snail by Snail-specific siRNA transfection attenuated the acetaldehydeinduced ZO-1 and occludin redistribution (Figure 6.6A), and significantly prevented the decrease in ZO-1 protein levels $(P<0.05$; Figure 6.6B). 

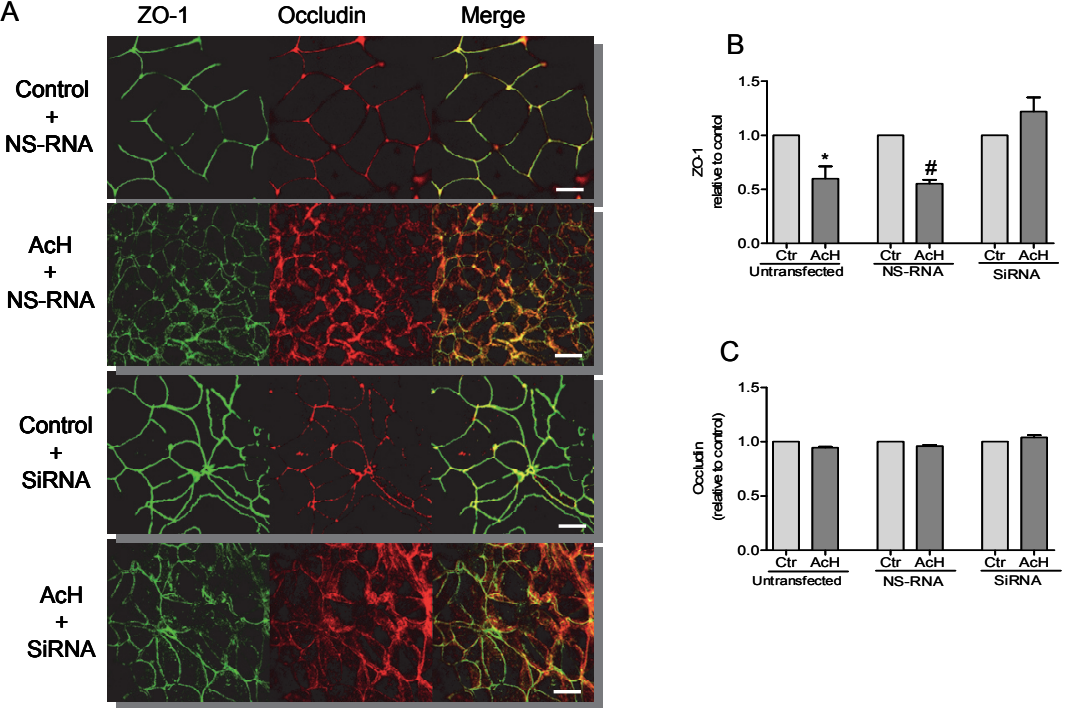

C

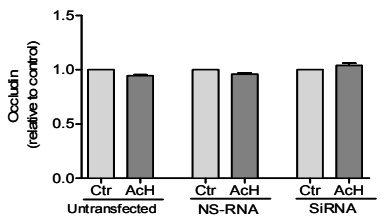

Figure 6.6 Knockdown of Snail dampens acetaldehyde-induced disruption and reduction in ZO-1 and occludin protein levels in Caco-2 cell monolayers. [A] Caco-2 cells were left untransfected or transfected with either siRNA specific for Snail (siRNA) or non-specific RNA (NS-RNA) and then were incubated with $25 \mu \mathrm{M}$ acetaldehyde $(\mathrm{AcH})$ for $3 \mathrm{~h}$, fixed and double-stained for $\mathrm{ZO}-1$ and occludin. [B] Cell-based ELISA assay of ZO-1 and occludin protein levels. ${ }^{*} P<0.0001$ versus control (medium only-treated) and ${ }^{\#} P<0.0001$ versus acetaldehyde-treated cell monolayers in presence of non-specific RNA.

In addition, exposure of non-specific siRNA transfected monolayers to acetaldehyde also resulted in redistribution of E-cadherin and $\beta$-catenin (Figure 6.7A), and a decrease in $\mathrm{E}$-cadherin protein levels $(P<0.05$; Figure 6.7B). In contrast, knocking down Snail significantly attenuated the acetaldehyde-induced redistribution of E-cadherin and $\beta$-catenin (Figure 6.7A), and the decrease in E-cadherin protein levels $(P<0.05$; Figure 6.7B). 

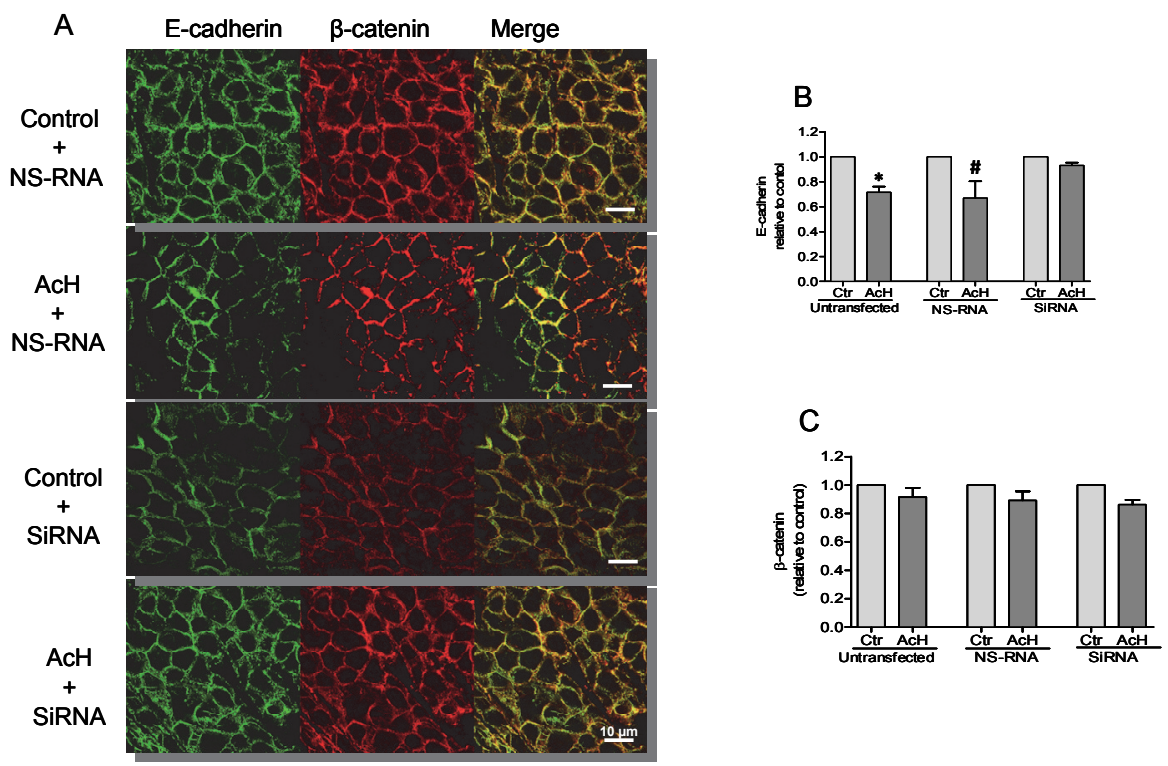

Figure 6.7 Knockdown of Snail dampens acetaldehyde-induced disruption and reduction in E-Cadherin and $\beta$-Catenin protein levels in Caco-2 cell monolayers. [A] Caco-2 cells were left untransfected or transfected with either siRNA specific for Snail (siRNA) or non-specific RNA (NS-RNA) and then were incubated with $25 \mu \mathrm{M}$ acetaldehyde $(\mathrm{AcH})$ for $3 \mathrm{~h}$, fixed and doublestained for ZO-1 and occludin. [B] Cell-based ELISA assay of ZO-1 and occludin protein levels. ${ }^{*} P<0.0001$ versus control (medium only-treated) and ${ }^{\#} P<0.0001$ versus acetaldehyde-treated cell monolayers in the presence of non-specific RNA.

\section{Discussion}

In the present study, the effects of acetaldehyde on cellular redox status, Snail activation, and barrier dysfunction were investigated using Caco-2 cell monolayers. The results show that acetaldehyde: (i) increases ROS production; (ii) ROSdependently decreases TEER, increases FITC-D4 paracellular permeability, and induces redistribution of the TJ proteins ZO-1 and occludin and the AJ proteins E-cadherin and $\beta$-catenin; and (iii) induces Snail phosphorylation and nuclear translocation. All findings were abolished or significantly attenuated by Snail specific siRNA.

Since acetaldehyde is highly volatile, its measurement in tissues is therefore rather difficult. However, incubation of human colonic contents with ethanol at concentrations achievable in vivo after moderate ethanol consumption (i.e. $22 \mathrm{mM}$ and $44 \mathrm{mM}$ ) has been shown to generate $58 \mu \mathrm{M}$ and $238 \mu \mathrm{M}$ acetaldehyde, respectively ${ }^{32}$. In a previous study, we found that acetaldehyde at concentrations 
ranging between 25 and $200 \mu \mathrm{M}$ can increase intestinal epithelial paracellular permeability $^{1}$. In line with the above observations, the concentration of $25 \mu \mathrm{M}$ used in the present study is considered physiologically relevant.

Recently, our group has shown that acetaldehyde induces an increase in paracellular permeability via induction of microtubule hyperacetylation and simultaneous loss of $\mathrm{TJ}$ integrity ${ }^{1}$. In the present study, we further supported these findings and found that the acetaldehyde-induced intestinal barrier dysfunction is ROS-dependent by demonstrating that L-cysteine could attenuate the acetaldehyde-induced TJ and AJ disruption. In line with this data, inhibition of ROS has been shown to mediate the protective effects of L-cysteine on ethanol-induced disassembly of TJ proteins ${ }^{33}$. One possible mechanism of acetaldehyde-induced ROS in disruption of intestinal epithelial integrity is ROS-induced Snail activation ${ }^{22}$. Studies have shown that Snail activation can repress expression of the AJ protein E-cadherin in epithelial cells ${ }^{34}$. In this study, using the Caco-2 cell monolayer model of intestinal permeability, the role of Snail in acetaldehyde-induced loss of TJ and AJ integrity was delineated by knocking down Snail expression using specific siRNA. We show that siRNA-mediated snail inhibition attenuates acetaldehyde-induced intestinal barrier dysfunction. In addition, we show that L-cysteine-mediated inhibition of ROS prevents acetaldehyde-induced Snail phosphorylation, i.e. activation of the protein and translocation to the nucleus. No further data are available on the role of Snail on acetaldehyde-induced intestinal injury, but our findings are in line with prior data showing that ethanol is capable of activating Snail, and inducing its nuclear localization resulting in loss of TJs integrity in Caco-2 monolayers ${ }^{25,35}$. In Madin-Darby Canine Kidney (MDCK) cell monolayers, Snail has been shown to induce TEER decrease without increasing mannitol permeation ${ }^{36}$. In contrast, we did find both a decrease in TEER as well as an increase in FITC-D4 permeation across intestinal epithelial cell monolayers. Nevertheless, the data obtained from MDCK cells clearly support a role for Snail in regulation of epithelial permeability, as does our data. The differences between both studies can be attributed to the different cell types and different permeability markers used.

In our study, acetaldehyde-induced Snail activation was associated with redistribution of ZO-1 and occludin as well as E-cadherin and $\beta$-catenin. In addition, there was a decrease in ZO-1 and E-cadherin protein expression, pointing further to the role of Snail activation in acetaldehyde-induced paracellular hyperpermeability. These results are comparable to previously reported studies indicating that redistribution of E-cadherin and $\beta$-catenin plays a crucial role in acetaldehyde-induced barrier dysfunction in Caco-2 cell monolayers ${ }^{18,37}$. In addition, our data have also shown that acetaldehyde-induced ROS generation is responsible for acetaldehyde-induced Snail activation. In line with these findings, upregulation of iNOS with subsequent cellular oxidative stress has been shown to activate Snail-mediated EMT in different cell types including breast epithelium ${ }^{38}$, renal epithelial cells ${ }^{39,40}$, and in Caco-2 cells with subsequent intestinal barrier dysfunction ${ }^{35}$. Since acetaldehyde is a potent ROS 
generator, highly mutagenic and Snail-mediated EMT has a hallmark in carcinogenesis $^{41}$ and cancer progression ${ }^{42}$, our study is the first demonstration for a key role of Snail in acetaldehyde-induced oxidative stress and subsequent intestinal hyperpermeability. Increased intestinal permeability is involved in the pathogenesis of various GIT and liver disorders including inflammatory bowel disease ${ }^{43}$ and liver cirrhosis $^{3,44}$.

In summary, our data demonstrate that acetaldehyde-induced intestinal epithelial hyperpermeability is ROS dependent. In addition, the data provide new evidence that ROS-mediated Snail activation is one of the key mechanisms involved in acetaldehydeinduced intestinal barrier disruption. Further delineation of these mechanisms may provide new therapeutic targets for prevention of acetaldehyde-induced intestinal barrier disruption and its subsequent liver injury. 


\section{References}

1. Elamin E, Jonkers D, Juuti-Uusitalo K, van ljzendoorn S, Troost $F$, et al. Effects of ethanol and acetaldehyde on tight junction integrity: in vitro study in a three dimensional intestinal epithelial cell culture model. PLoS One 2012;7:e35008.

2. Bode C, Kugler V, Bode JC. Endotoxemia in patients with alcoholic and non-alcoholic cirrhosis and in subjects with no evidence of chronic liver disease following acute alcohol excess. J Hepatol 1987;4: 8-14.

3. Keshavarzian A, Holmes EW, Patel M, Iber F, Fields JZ, et al. Leaky gut in alcoholic cirrhosis: a possible mechanism for alcohol-induced liver damage. Am J Gastroenterol 1999;94:200-7.

4. Van Itallie CM, Anderson JM. The molecular physiology of tight junction pores. Physiology (Bethesda) 2004;19:331-8.

5. Fanning AS, Jameson BJ, Jesaitis LA, Anderson JM. The tight junction protein ZO-1 establishes a link between the transmembrane protein occludin and the actin cytoskeleton. J Biol Chem 1998;273: 29745-53.

6. Turner JR, Rill BK, Carlson SL, Carnes D, Kerner R, et al. Physiological regulation of epithelial tight junctions is associated with myosin light-chain phosphorylation. Am J Physiol 1997;273:C1378-85.

7. Harris TJ, Tepass U. Adherens junctions: from molecules to morphogenesis. Nature reviews Molecular cell biology 2010;11:502-14.

8. Rao RK. Acetaldehyde-induced increase in paracellular permeability in Caco-2 cell monolayer. Alcohol Clin Exp Res 1998;22:1724-30.

9. Rao RK. Acetaldehyde-induced barrier disruption and paracellular permeability in Caco-2 cell monolayer. Methods Mol Biol 2008;447:171-83.

10. Crabb DW, Bosron WF, Li TK. Ethanol metabolism. Pharmacol Ther 1987;34:59-73.

11. Jokelainen K, Siitonen A, Jousimies-Somer H, Nosova T, Heine R, et al. In vitro alcohol dehydrogenasemediated acetaldehyde production by aerobic bacteria representing the normal colonic flora in man. Alcohol Clin Exp Res 1996;20:967-72.

12. Salaspuro V, Nyfors S, Heine R, Siitonen A, Salaspuro M, et al. Ethanol oxidation and acetaldehyde production in vitro by human intestinal strains of Escherichia coli under aerobic, microaerobic, and anaerobic conditions. Scand J Gastroenterol 1999;34:967-73.

13. Nosova $\mathrm{T}$, Jokelainen $\mathrm{K}$, Kaihovaara $\mathrm{P}$, Heine $\mathrm{R}$, Jousimies-Somer $\mathrm{H}$, et al. Characteristics of aldehyde dehydrogenases of certain aerobic bacteria representing human colonic flora. Alcohol Alcohol 1998;33:273-80.

14. Atkinson KJ, Rao RK. Role of protein tyrosine phosphorylation in acetaldehyde-induced disruption of epithelial tight junctions. Am J Physiol Gastrointest Liver Physiol 2001;280:G1280-8.

15. Banan A, Farhadi A, Fields JZ, Mutlu E, Zhang L, et al. Evidence that nuclear factor-kappa B activation is critical in oxidant-induced disruption of the microtubule cytoskeleton and barrier integrity and that its inactivation is essential in epidermal growth factor-mediated protection of the monolayers of intestinal epithelia. J Pharmacol Exp Ther 2003;306:13-28.

16. Banan A, Fields JZ, Decker H, Zhang Y, Keshavarzian A. Nitric oxide and its metabolites mediate ethanol-induced microtubule disruption and intestinal barrier dysfunction. J Pharmacol Exp Ther 2000;294:997-1008.

17. Sheth P, Basuroy S, Li C, Naren AP, Rao RK. Role of phosphatidylinositol 3-kinase in oxidative stressinduced disruption of tight junctions. J Biol Chem 2003;278:49239-45.

18. Dunagan M, Chaudhry K, Samak G, Rao RK. Acetaldehyde disrupts tight junctions in Caco-2 cell monolayers by a protein phosphatase 2A-dependent mechanism. Am J Physiol Gastrointest Liver Physiol 2012;303:G1356-64.

19. Seitz HK, Homann N. The role of acetaldehyde in alcohol-associated cancer of the gastrointestinal tract. Novartis Found Symp 2007;285:110-9; discussion 119-4, 198-9.

20. Seitz HK, Stickel F. Molecular mechanisms of alcohol-mediated carcinogenesis. Nat Rev Cancer 2007; 7:599-612.

21. Salaspuro M. Bacteriocolonic pathway for ethanol oxidation: characteristics and implications. Ann Med 1996;28:195-200. 
22. Forsyth $\mathrm{CB}$, Tang $\mathrm{Y}$, Shaikh M, Zhang L, Keshavarzian A. Role of snail activation in alcohol-induced iNOS-mediated disruption of intestinal epithelial cell permeability. Alcohol Clin Exp Res 2011;35: 1635-43.

23. Thiery JP, Sleeman JP. Complex networks orchestrate epithelial-mesenchymal transitions. Nat Rev Mol Cell Biol 2006;7:131-42.

24. Moreno-Bueno G, Portillo F, Cano A. Transcriptional regulation of cell polarity in EMT and cancer. Oncogene 2008;27: 6958-69.

25. Forsyth CB, Tang Y, Shaikh M, Zhang L, Keshavarzian A. Alcohol stimulates activation of Snail, epidermal growth factor receptor signaling, and biomarkers of epithelial-mesenchymal transition in colon and breast cancer cells. Alcohol Clin Exp Res 2010;34:19-31.

26. Chantret I, Barbat A, Dussaulx E, Brattain MG, Zweibaum A. Epithelial polarity, villin expression, and enterocytic differentiation of cultured human colon carcinoma cells: a survey of twenty cell lines. Cancer Res 1988;48:1936-42.

27. Grasset E, Pinto M, Dussaulx E, Zweibaum A, Desjeux JF. Epithelial properties of human colonic carcinoma cell line Caco-2: electrical parameters. Am J Physiol 1984;247:C260-7.

28. Artursson $\mathrm{P}$, Ungell $\mathrm{AL}$, Lofroth JE. Selective paracellular permeability in two models of intestinal absorption: cultured monolayers of human intestinal epithelial cells and rat intestinal segments. Pharm Res 1993;10:1123-9.

29. Briske-Anderson MJ, Finley JW, Newman SM. The influence of culture time and passage number on the morphological and physiological development of Caco-2 cells. Proc Soc Exp Biol Med 1997;214: 248-57.

30. Carmona R, Macias D, Guadix JA, Portillo V, Perez-Pomares JM, et al. A simple technique of image analysis for specific nuclear immunolocalization of proteins. J Microsc 2007;225:96-9.

31. Rao RK, Baker RD, Baker SS, Gupta A, Holycross M. Oxidant-induced disruption of intestinal epithelial barrier function: role of protein tyrosine phosphorylation. Am J Physiol 1997;273:G812-23.

32. Jokelainen K, Roine RP, Vaananen H, Farkkila M, Salaspuro M. In vitro acetaldehyde formation by human colonic bacteria. Gut 1994;35:1271-4.

33. Banan A, Choudhary S, Zhang Y, Fields JZ, Keshavarzian A. Ethanol-induced barrier dysfunction and its prevention by growth factors in human intestinal monolayers: evidence for oxidative and cytoskeletal mechanisms. J Pharmacol Exp Ther 1999;291:1075-85.

34. Cano A, Perez-Moreno MA, Rodrigo I, Locascio A, Blanco MJ, et al. The transcription factor snail controls epithelial-mesenchymal transitions by repressing E-cadherin expression. Nat Cell Biol 2000; 2:76-83.

35. Forsyth CB, Tang Y, Shaikh M, Zhang L, Keshavarzian A. Role of Snail Activation in Alcohol-Induced iNOS-Mediated Disruption of Intestinal Epithelial Cell Permeability. Alcohol Clin Exp Res. 2011; 35:1635-43

36. Carrozzino F, Soulie P, Huber D, Mensi N, Orci L, et al. Inducible expression of Snail selectively increases paracellular ion permeability and differentially modulates tight junction proteins. Am J Physiol Cell Physiol. 2005;289:C1002-14.

37. amak G, Aggarwal S, Rao RK. ERK is involved in EGF-mediated protection of tight junctions, but not adherens junctions, in acetaldehyde-treated Caco-2 cell monolayers. Am J Physiol Gastrointest Liver Physiol 2011;301:G50-9.

38. Radisky DC, Levy DD, Littlepage LE, Liu $H$, Nelson CM, et al. Rac1b and reactive oxygen species mediate MMP-3-induced EMT and genomic instability. Nature 2005;436:123-7.

39. Djamali A, Reese S, Yracheta J, Oberley T, Hullett D, et al. Epithelial-to-mesenchymal transition and oxidative stress in chronic allograft nephropathy. Am J Transplant 2005;5: 500-9.

40. Zhang A, Jia Z, Guo X, Yang T. Aldosterone induces epithelial-mesenchymal transition via ROS of mitochondrial origin. Am J Physiol Renal Physiol 2007;293:F723-31.

41. Thiery JP, Acloque H, Huang RY, Nieto MA. Epithelial-mesenchymal transitions in development and disease. Cell 2009;139:871-90.

42. Kalluri R, Weinberg RA. The basics of epithelial-mesenchymal transition. J Clin Invest 2009;119: 1420-8.

43. Welcker K, Martin A, Kolle P, Siebeck M, Gross M. Increased intestinal permeability in patients with inflammatory bowel disease. Eur J Med Res 2004;9:456-60. 
44. Lee S, Son SC, Han MJ, Kim WJ, Kim SH, et al. Increased intestinal macromolecular permeability and urine nitrite excretion associated with liver cirrhosis with ascites. World J Gastroenterol 2008;14: 3884-90. 


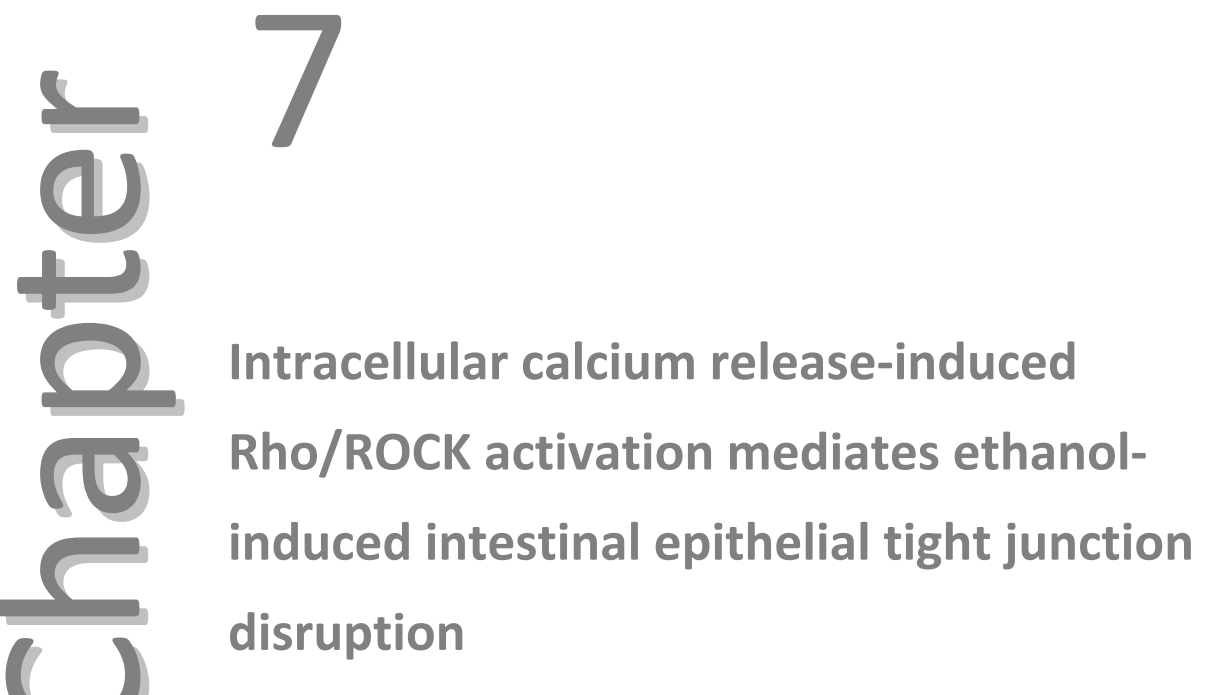

Elhaseen Elamin, Ad Masclee, Jan Dekker, Daisy Jonkers

Submitted 


\section{Abstract}

Evidence indicates that ethanol-induced intestinal barrier dysfunction and subsequent endotoxemia plays a key role in the pathogenesis of alcoholic liver disease. Recently, it has been demonstrated that ethanol induces RhoA kinase activation in intestinal epithelium, thereby disrupting barrier integrity. In this study, role of a rise in intracellular calcium concentration $\left(\left[\mathrm{Ca}^{2+}\right]_{\mathrm{i}}\right)$ in ethanol-induced Rho-associated coiledcoil forming kinase (Rho/ROCK) activation and barrier disruption was investigated in Caco-2 cell monolayers. Treatment of Caco-2 monolayers with $40 \mathrm{mmol} / \mathrm{l}$ ethanol induced $\left[\mathrm{Ca}^{2+}\right]_{i}$ release as indicated by increased relative fluorescent units of Fluo-3 from $0.06 \pm 0.02$ to $2.27 \pm 1.96 \quad(P<0.0001)$. Pretreatment with either 1,2-Bis (2-Aminophenoxy) ethane- $N, N, N^{\prime}, N^{\prime}$-tetraacetic acid (BAPTA-AM) or the inositol 1, 4, 5-triphosphate receptor $\left(\mathrm{IP}_{3} \mathrm{R}\right)$-antagonist Xestospongin $\mathrm{C}$ inhibited ethanol-induced $\left[\mathrm{Ca}^{2+}\right]_{i}$ release (from $2.27 \pm 1.96$ to $0.03 \pm 0.01 ; P<0.0001$ ) and (from $2.27 \pm 1.96$ to $1.19 \pm 1.80 ; P<0.001)$, respectively. The increase in $\left[\mathrm{Ca}^{2+}\right]_{i}$ was paralleled with increased intestinal permeability, which could be attenuated either by BAPTA-AM or Xestospongin C. Furthermore, ethanol induced Rho/ROCK activation, as indicated by increased phosphorylation of myosin binding subunit, which could be prevented either by BAPTA, Xestospongin C, or the specific Rho/ROCK inhibitor Y27632.

Finally, inhibition of Rho/ROCK kinase by Y27632 ameliorated the ethanol-induced redistribution of ZO-1 and adherence junction proteins (including E-cadherin and $\beta$-catenin), and the disorganization of F-actin. These findings suggest that ethanolinduced $\left[\mathrm{Ca}^{2+}\right]_{\mathrm{i}}$ release, mediated via the stimulation of $\mathrm{IP}_{3} \mathrm{R}$-gated $\mathrm{Ca}^{2+}$ channel, acts as signaling molecule for activation of Rho/ROCK in Caco- 2 cells and thereby contribute to ethanol-induced intestinal barrier dysfunction. 


\section{Introduction}

Intestinal epithelial barrier integrity is maintained by tight junctions (TJs), a complex of proteins formed by transmembranous and cytoplasmic proteins including occludin and zonula occludens proteins (ZO-1, 2, 3), respectively, linked to actin cytoskeleton ${ }^{1}$. In addition, adherens junction (AJs) proteins including E-cadherin and $\beta$-catenin are required for tight junction assembly, and thereby contribute to the maintenance of intestinal epithelial integrity ${ }^{2}$. TJs regulate trafficking of ions, molecules, and nutrients and act as a barrier against translocation of harmful bacteria, and their products such as endotoxins from the lumen into the circulation and mucosal immune system ${ }^{3}$. Therefore, preserving TJ integrity is important for intestinal epithelial homeostasis.

Ethanol-induced intestinal barrier dysfunction and subsequent endotoxemia is suggested to play a crucial role in the pathogenesis of alcoholic liver disease $(A L D)^{4-6}$. Moreover, detection of high endotoxin levels $(8.5-206 \mathrm{pg} / \mathrm{ml})$ and its correlation with severity and complications of ALD has been attributed to intestinal barrier dysfunction ${ }^{7-10}$. We and others have shown that ethanol at a concentration as low as low as $0.2 \%$ ( $\sim 40 \mathrm{mmol} / \mathrm{l})$, which can be achieved in blood after moderate (2-4 drinks) consumption $^{11}$, can disrupt epithelial TJ integrity and thereby increases permeability in Caco-2 three dimensional ${ }^{12}$ and two dimensional cell culture models ${ }^{11,13}$. Research on mechanisms has demonstrated that ethanol induces intestinal barrier dysfunction via mechanisms involving inducible nitric oxide synthase (iNOS)-induced oxidative stress and activation of myosin light chain kinase (MLCK) signaling pathway ${ }^{14}$, and thereby mediating disruption of the F-actin cytoskeleton and TJs ${ }^{15,16}$. Very recently, activation of RhoA kinase was found to be implicated in ethanol-induced intestinal barrier disruption ${ }^{17,18}$. The Rho kinase family, including RhoA, is one of the major regulators of actomyosin ring organization and TJ assembly in polarized epithelia ${ }^{19}$. The downstream effector of RhoA kinase, Rho-associated coiled-coil forming kinase (Rho/ROCK), has been shown to activate MLCK resulting in barrier disruption ${ }^{20-22}$. The mechanism through which ethanol activates RhoA kinase and induces subsequent disruption of intestinal barrier integrity has not been clarified. Intracellular calcium $\left(\left[\mathrm{Ca}^{2+}\right]_{\mathrm{i}}\right)$ homeostasis might be involved, as a rise in $\left[\mathrm{Ca}^{2+}\right]_{i}$ has been shown to activate RhoA kinase resulting in disruption of intercellular junctions ${ }^{23,24}$.

Therefore, this study aimed to examine the role of $\left[\mathrm{Ca}^{2+}\right]_{i}$ homeostasis and RhoA kinase activation in ethanol-induced intestinal hyperpermeability using Caco- 2 cell monolayers. We hypothesize that ethanol stimulates inositol 1, 4, 5-triphosphate receptor (IP3R)-gated intracellular calcium $\left[\mathrm{Ca}^{2+}\right]_{i}$ release, thereby causing activation of Rho/ROCK with subsequent barrier disruption. 


\section{Methods}

\section{Cell Culture}

Caco-2 cells (from passages 29-45) purchased from ATCC (Rockville, MD, USA) were grown in either T25 or T75 flasks and were maintained in Dulbecco's Modified Eagle Medium (DMEM; Lonza Benelux BV, Breda, the Netherlands) containing $4.5 \mathrm{~g} / \mathrm{l}$ glucose and L-glutamine, as described previously ${ }^{25}$.

\section{Microscopic analysis of $\left[\mathrm{Ca}^{2+}\right]_{\mathrm{i}}$}

Caco-2 $\left(5 \times 10^{3}\right)$ cells were plated on glass bottom dishes in $10 \%$ FBS-containing DMEM medium in a humidified atmosphere of $5 \% \mathrm{CO}_{2}$ at $37 \circ \mathrm{C}$ for $24 \mathrm{~h}$. Next, cells were loaded with $3 \mu \mathrm{M}$ Fluo-3-AM by incubation of the cells at $23^{\circ} \mathrm{C}$ for $60 \mathrm{~min}$ in assay buffer containing $130 \mathrm{mmol} / \mathrm{l} \mathrm{NaCl}, 5 \mathrm{mmol} / \mathrm{l} \mathrm{KCl}, 2 \mathrm{mmol} / \mathrm{CaCl}_{2}, 1 \mathrm{mmol} / \mathrm{l} \mathrm{MgSO}{ }_{4}$, $8 \mathrm{mmol} / \mathrm{l} \mathrm{NaOH}$, and $20 \mathrm{mmol} / \mathrm{I} \mathrm{HEPES}(\mathrm{pH} 7.4)$, followed by a $30 \mathrm{~min}$ incubation at $37^{\circ} \mathrm{C}$. Fluo-3-AM was chosen as a $\mathrm{Ca}^{2+}$ indicator because it exhibits a 40 -fold increase in fluorescence intensity lith $\mathrm{Ca}^{2+}$ and possesses an enhanced resistance to autobleaching ${ }^{26}$.

Next, Caco-2 monolayers were pretreated with either $10 \mu \mathrm{M}$ 1,2-Bis(2-Aminophenoxy) ethane- $N, N, N^{\prime}, N^{\prime}$-tetraacetic acid (BAPTA-AM) or $1 \mu \mathrm{M}$ Xestospongin (selective and reversible inhibitor of $\mathrm{IP}_{3}$ receptor) for $45 \mathrm{~min}^{27}$. Thereafter, cells were washed twice with $\mathrm{Ca}^{2+}$-free PBS and placed under a Leica TCS SPE confocal laser scanning microscope (Leica Microsystems $\mathrm{GmbH}$, Mannheim) where cells were excited at 488 $\mathrm{nm}$ and fluorescence emission from individual cells was collected recorded at $530 \mathrm{~nm}$. Finally, $40 \mathrm{mmol} / \mathrm{l}$ ethanol was added, and changes in $\left[\mathrm{Ca}^{2+}\right]_{i}$ was monitored over a $20 \mathrm{~min}$ period. Image acquisition frequency was set to one image every $10 \mathrm{sec}$. Fluorescence intensities were initially recorded for $300 \mathrm{sec}$ to measure basal $\left[\mathrm{Ca}^{2+}\right]_{i}$ prior to the addition of ethanol, followed by $900 \mathrm{sec}$ thereafter. Data were presented as relative fluorescence units (RFU).

\section{Measurement of transepithelial electrical resistance (TEER) and paracellular permeability}

Caco-2 cells were seeded and grown for 21 days on collagen-coated polycarbonate membrane Transwell inserts with a surface area of $0.33 \mathrm{~cm}^{2}$ and $0.4 \mu \mathrm{m}$ pore size (Costar, Cambridge, MA, USA). After developing monolayers of TEER $>600 \mathrm{Ohm} . \mathrm{cm}^{2}$, monolayers were exposed to either $40 \mathrm{mmol} / \mathrm{l}$ ethanol alone for $3 \mathrm{~h}$ or after pretreatment with either BAPTA-AM $(10 \mu \mathrm{M})$ or Xestospongin $\mathrm{C}(1 \mu \mathrm{M})$ for $15 \mathrm{~min}$. In another set of experiments, monolayers were pretreated for $1 \mathrm{~h}$ with $100 \mu \mathrm{M}$ of (+)-(R)-trans-4-(1-aminoethyl)- $N$-(4-pyridyl)cyclohexanecarboxamide (Y-27632), the specific inhibitor of both isoforms ROKa (also called ROCK2) and p160ROCK (also known as ROK $\beta$ or ROCK 1$)^{28}$. TEER of epithelial monolayers $(\Omega)$ was measured after 
$3 \mathrm{~h}$ by an Epithelial Voltohmmeter (World Precision Instruments, Berlin, Germany) in each insert and multiplied by the membrane surface area $\left(0.33 \mathrm{~cm}^{2}\right)$, corrected by subtracting background resistance of the blank membrane (no cells; approximately $30 \Omega \cdot \mathrm{cm}^{2}$ ). Data were collected from duplicate inserts per treatment in three experiments and expressed as percentage of basal TEER obtained before treatment. By the end of TEER measurements, fluorescein isothiocyanate- labeled dextran $4 \mathrm{kDa}$ (1 $\mathrm{mg} / \mathrm{ml}$ FITC-D4; Sigma-Aldrich, Amsterdam, The Netherlands) was added to the apical side of cells and incubated for $1 \mathrm{~h}$ at $37^{\circ} \mathrm{C}$. Monolayer permeability was assessed by measuring the fluorescence of FITC-D4 spectrophotometrically using SpectraMax M2 spectrofluorometer (Molecular Devices, Sunnyvale, CA, USA) at excitation and emission spectra of $485 \mathrm{~nm}$ and $540 \mathrm{~nm}$, respectively, and data were reported as relative fluorescent unit (RFU).

\section{Immunofluorescent analysis}

Cell monolayers on membranes were fixed in the inserts with $10 \%$ trichloroacetic acid (TCA), permeabilized with PBS and glycine $(30 \mathrm{mmol} / \mathrm{l})$ and $1 \%$ Triton X-100, and blocked with a blocking buffer containing PBS and glycine with 3\% FCS. Primary antibodies including mouse anti-ZO-1 (Zymed Laboratories, San Francisco, USA), rabbit anti-phosphorylated myosin binding subunit (P-MBS) known also as myosin phosphatase targeting subunit 1 (MYPT1), an indicator of Rho/ROCK activation ${ }^{29}$, (P-MBS/MYPT1, MBL International, Massachusetts, USA), mouse anti-E-cadherin (Abcam, Cambridge, UK) or rabbit anti- $\beta$-catenin (Abcam) were added 1:100 overnight in blocking buffer. Following washing, fluorochrome-conjugated secondary antibodies including AlexaFluor 488-conjugated anti-mouse (Invitrogen) and Cy3-conjugated antirabbit IgG (Invitrogen) antibodies were used as secondary antibodies (1:200). F-actin was stained with rhodamine-phalloidin (500 ng/ml; Invitrogen) at room temperature (RT). Thereafter, monolayers were stained for $5 \mathrm{~min}$ with diamidino-2-phenylindole (DAPI; 1:10,000 dilution in PBS; Sigma Chemical Co). Finally, the monolayers on the semi-permeable membrane were transferred to glass slides and mounted with VectaShield mounting medium (Vector Laboratories, Burlingame, USA). The slides were examined under a Leica TCS SPE confocal laser scanning microscope (Leica Microsystems $\mathrm{GmbH}$, Mannheim, Germany) equipped with a $50 \mathrm{~mW}$ Argon laser and a $1 \mathrm{~mW}$ HeNe laser (Leica Microsystems). Confocal images obtained were processed and analyzed by using Image J software ${ }^{30}$.

\section{Dot blotting of phosphorylated MBS/MYPT1}

Caco-2 cell lysates were prepared with radioimmunoprecipitation assay (RIPA) buffer containing ( $150 \mathrm{mM} \mathrm{NaCl}, 1.0 \%$ Triton $\mathrm{X}-100,0.5 \%$ sodium deoxycholate, $0.1 \%$ sodium dodecyl sulphate, and $50 \mathrm{mM}$ Tris, protease and phosphates inhibitors cocktail), and protein levels were determined using bicinchoninic acid protein assay (BCA) protein assay (Bio-Rad Laboratories). Using narrow-mouth pipette tips, $2 \mu \mathrm{l}$ of samples were 
spotted onto a nitrocellulose membrane and let to dry. Nonspecific sites were blocked by soaking the membrane in 5\% BSA in TBST for $1 \mathrm{~h}$ at room temperature (RT). Then, the membrane was incubated with rabbit anti-phosphorylated MBS/MYPT1 $(10 \mu \mathrm{g} / \mathrm{ml}$ dissolved in BSA/TBS, MBL international) for $30 \mathrm{~min}$ at RT. Thereafter, the membrane was washed thrice in TBS and incubated with swine anti-rabbit horseradish peroxidase (HRP)-conjugated secondary antibody (1:1000 dilution; Dako, Glostrup, Denmark) for $30 \mathrm{~min}$ at RT, followed by washing in TBST and TBS, respectively. Finally, the membrane was incubated with chemiluminescence kit (GE Healthcare Europe $\mathrm{GmbH}$, Diegem, Belgium) for 1 min, covered with Saran wrap, and proteins were visualized by chemidoc XRS (Bio-Rad, Hercules, CA). Quantification of the dots was done using Image J software ${ }^{30}$.

\section{Assessment of cellular F-actin contents}

Cellular F-actin levels were determined by a fluorescent phalloidin-binding assay as described previously ${ }^{31}$. Briefly, Caco-2 cells grown on 96 well plates (Corning BV), were rinsed with PBS and then incubated with medium only as well as $40 \mathrm{mmol} / \mathrm{l}$ ethanol alone for $3 \mathrm{~h}$ or after prior incubation with $100 \mu \mathrm{M}$ of the ROCK inhibitor, Y-27632, for $1 \mathrm{~h}$. Next, the cells were fixed with acetone/ methanol (1:1), and then actin was stained with rhodamine-phalloidin $(500 \mathrm{ng} / \mathrm{ml})$ for $20 \mathrm{~min}$. Stained cells were extracted with $200 \mu \mathrm{l}$ methanol and measured spectrophotometrically at excitation and emission wavelengths of 545 and $578 \mathrm{~nm}$, respectively.

\section{Statistical analysis}

All data analyses were conducted with GraphPad Prism software package (GraphPad Software Incorporated, CA, USA). Data are expressed as means \pm SDs of triplicate experiments. One-way analysis of variance (ANOVA) and Tukey's post-hoc tests were performed to compare between different experimental conditions, considering difference of $P$ value $<0.05$ as statistically significant.

\section{Results}

\section{Effects of ethanol on intracellular calcium $\left[\mathrm{Ca}^{2+}\right]_{i}$ and barrier disruption}

In these experiments, Caco-2 monolayers were loaded with the $\mathrm{Ca}^{2+}$ sensing indicator Fluo-3-AM, and free intracellular $\mathrm{Ca}^{2+}\left[\mathrm{Ca}^{2+}\right]_{i}$ was evaluated before and during $40 \mathrm{mmol} / \mathrm{l}$ ethanol exposure. We observed an increase in free $\left[\mathrm{Ca}^{2+}\right]_{i}$ after application of $40 \mathrm{mmol} / \mathrm{l}$ ethanol reaching a maximum by $5 \mathrm{~min}$ (Figure $7.1 \mathrm{~A}, \mathrm{~B}, \mathrm{C} ; P<0.0001$ vs. baseline). However, pretreatment with $10 \mu \mathrm{M}$ BAPTA-AM (a cell permeable $\mathrm{Ca}^{2+}$ chelator) prevented the ethanol-elicited rise in $\left[\mathrm{Ca}^{2+}\right]_{\mathrm{i}}$ (Figure 7.1A, B, C, $P<0.0001$ vs. ethanol). To verify whether the $I_{3} R$ functional activity is involved, we analyzed the 
$\mathrm{IP}_{3} \mathrm{R}$-gated $\left[\mathrm{Ca}^{2+}\right]_{\mathrm{i}}$ of release in response to stimulation with EtOH. Pretreatment of Caco-2 cells with $1 \mu \mathrm{M}$ Xestospongin $\mathrm{C}$ (Xe-C; selective and reversible $\mathrm{IP}_{3} \mathrm{R}$ antagonist for 5 min transiently delayed and partially inhibited the ethanol-induced elevation in $\left[\mathrm{Ca}^{2+}\right]_{\mathrm{i}}$ (Figure $7.1 \mathrm{~A}, \mathrm{~B}, \mathrm{C} ; P<0.001$ vs. ethanol).

A
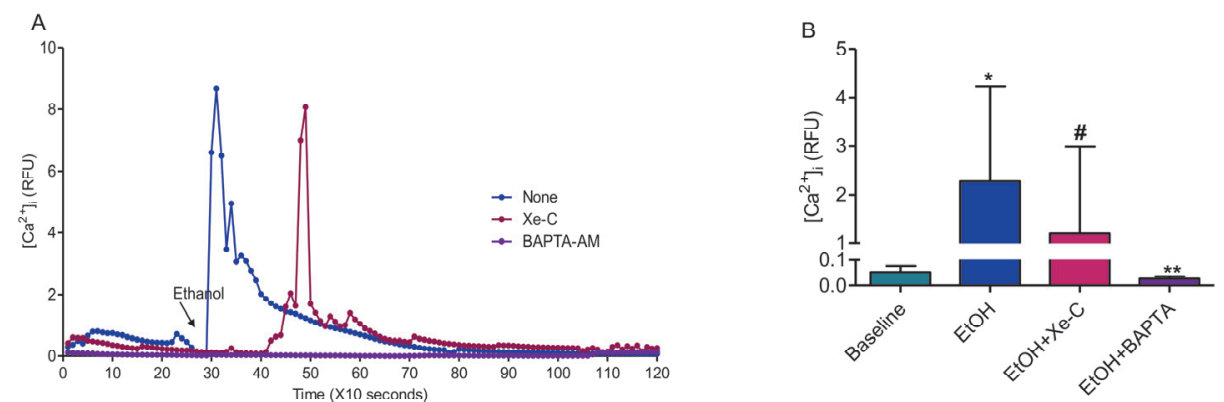

C

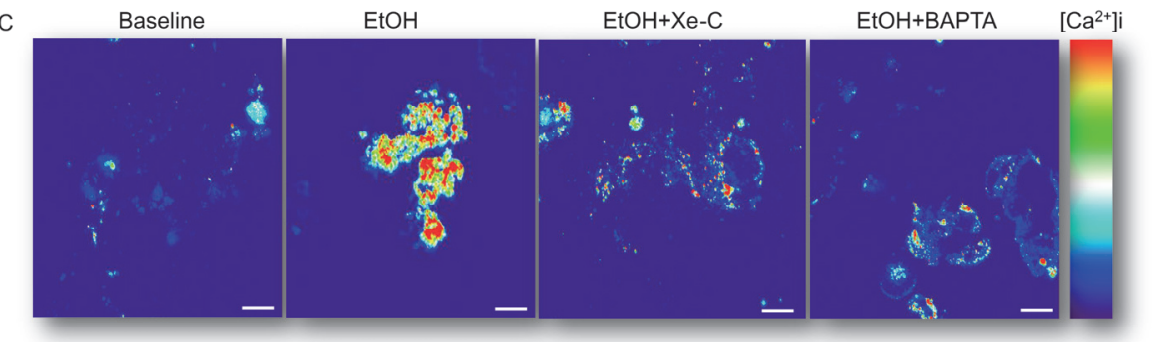

$\mathrm{EtOH}$

$\mathrm{EtOH}+\mathrm{Xe}-\mathrm{C}$

EtOH+BAPTA $\left[\mathrm{Ca}^{2+}\right] \mathrm{i}$

Figure 7.1 Ethanol increases free intracellular $\mathrm{Ca}^{2+}$ in Caco-2 cell monolayers. [A] Real time change in free intracellular calcium levels was monitored for up to $20 \mathrm{~min}$ following Fluo-3-AM loading, before and after addition of $40 \mathrm{mmol} / \mathrm{l}$ ethanol $(\mathrm{EtOH})$ in the presence or absence of $10 \mu \mathrm{M}$ BAPTA-AM or $1 \mu \mathrm{M}$ Xestospongin $\mathrm{C}(\mathrm{Xe}-\mathrm{C})$. [B] The relative fluorescence intensity levels are quantified and shown. [B] Data represent mean \pm SDs of three independent experiments. ${ }^{*} P<0.0001$ vs. baseline values, ${ }^{\#} P<0.0001$ and ${ }^{* *} P<0.001$ vs. ethanol. [C] Representative images of intracellular $\mathrm{Ca}^{2+}$ release. Caco-2 cells were loaded with Fluo-3, exposed to ethanol (EtOH) for $5 \mathrm{~min}$ as described earlier and examined by confocal microscopy. Scale bars $=10 \mu \mathrm{m}$.

Ethanol significantly reduced TEER and increased FITC-D4 permeability (Figure 7.2A and $7.2 \mathrm{~B}$; both $P<0.0001$ vs. control), which was significantly attenuated after pretreatment of cell monolayers with BAPTA-AM (Figure 7.2A and 2B; both $P<0.0001$ ). Pretreatment with BAPTA-AM also attenuated ethanol-induced redistribution of ZO-1 and occludin from the intercellular junctions into the intracellular compartment (Figure 7.2E). BAPTA treatment by itself did not have a significant effect on TEER, FITC-D4 permeation, or distribution of ZO-1 and occludin (data not shown). 


\section{$\mathrm{IP}_{3} \mathrm{R}$-gated intracellular $\mathrm{Ca}^{2+}$ release is involved in ethanol-induced TJ disruption}

Next, the effects of $I_{3} R$ inhibition on barrier function were explored. Pretreatment of cell monolayers with Xestospongin C, significantly attenuated the ethanol-induced decrease in TEER and increase in FITC-D4 permeability (Figure 7.2C and 7.2D; both $P<0.001$ vs. ethanol). Xestospongin $C$ also prevented ethanol-induced redistribution of ZO-1 and occludin from intercellular junctions to intracellular compartments (Figure 7.2E). Xestospongin C, by itself, did not alter TEER or FITC-D4 in the absence of ethanol (Figure 7.2C and 7.2D).

\section{Ethanol induced Rho/ROCK is mediated by $I \mathrm{P}_{3} \mathrm{R}$-gated $\mathrm{ER} \mathrm{Ca}{ }^{2+}$ release}

To test whether ethanol can activate ROCK and whether that Rho/ROCK activation is mediated by $\mathrm{IP}_{3} \mathrm{R}$-gated intracellular $\mathrm{Ca}^{2+}$ release, phosphorylation of MBS/MYPT1 protein was evaluated by Dot-blot analysis. The effects of ethanol on MBS/MYPT1 phosphorylation are shown in a representative dot blot (Figure 7.3A). Densitometry analysis revealed that MBS/MYPT1 phosphorylation was significantly increased in Caco-2 cells after incubation with $40 \mathrm{mmol} / \mathrm{l}$ ethanol compared to control (Figure 7.3B). The ethanol-induced MBS/MYPT1 phosphorylation was significantly attenuated by pretreatment with Xestospongin $C$ and BAPTA compared to ethanol alone (Figure 7.3A and 7.3B). In accordance with Dot-plot data, ethanol enhanced immunofluorescent staining of MBS/MYPT1 phosphorylation mainly at cortical regions and reduced on pretreatment with treatment with Xestospongin $C$ and BAPTA. 


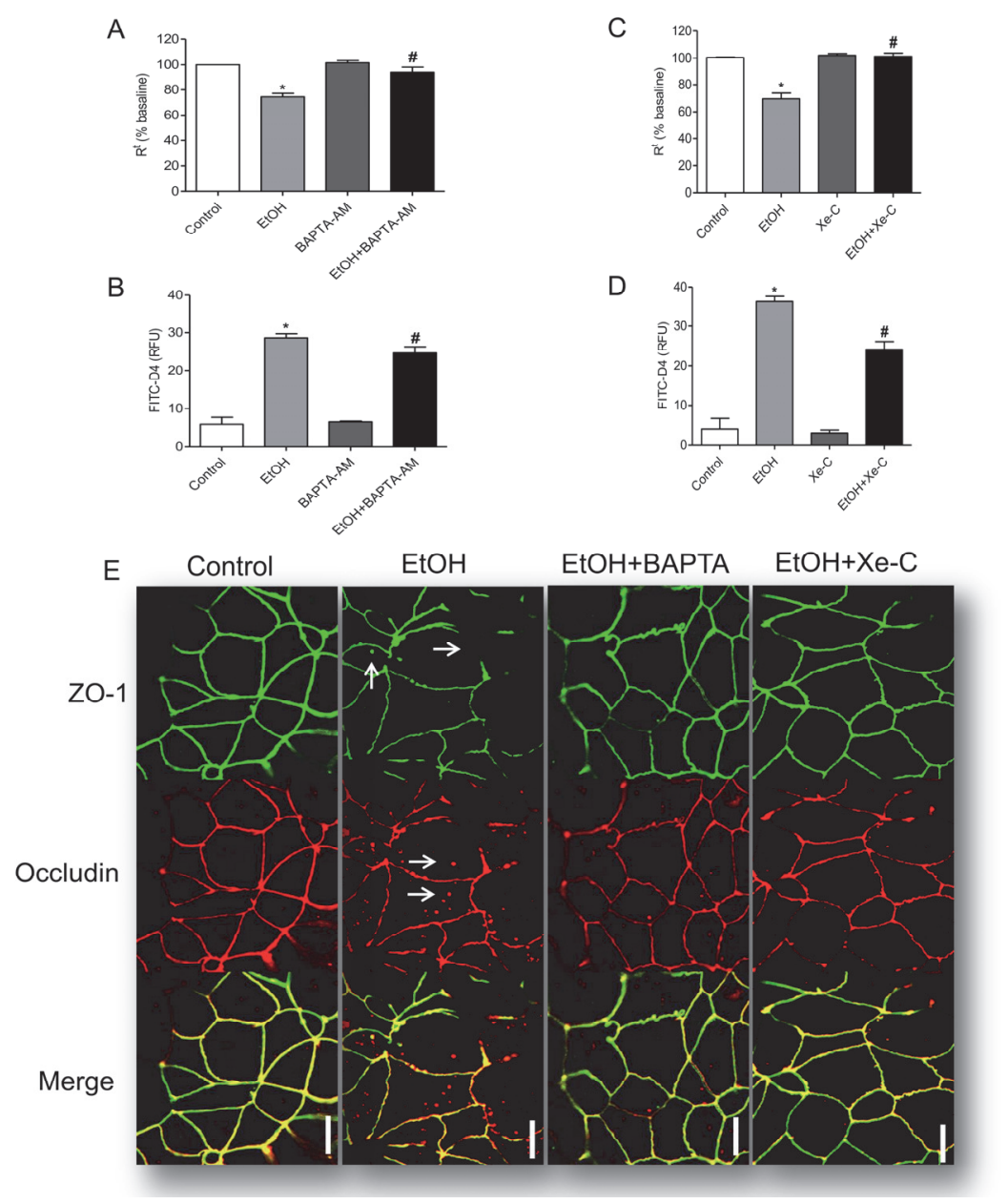

Figure 7.2 Free intracellular $\mathrm{Ca}^{2+}$ and $\mathrm{IP}_{3}$ receptor-mediated intracellular calcium release is required for ethanol-induced tight junction disruption. Caco-2 cell monolayers were pretreated with either $10 \mu \mathrm{M}$ BAPTA-AM or $1 \mu \mathrm{M}$ Xestospongin $\mathrm{C}(\mathrm{Xe}-\mathrm{C})$, followed by exposure to $40 \mathrm{mmol} / \mathrm{l}$ ethanol (EtOH) or medium only as controls for $3 \mathrm{~h}$. Thereafter, TEER [A C] and FITC-D4 permeability $[B, D]$ were measured and values represent mean \pm SDs of three independent experiments. ${ }^{*} P<0.0001$ vs. control and ${ }^{\#} P<0.0001$ vs. ethanol (EtOH). [E] Monolayers exposed to ethanol with or without BAPTA and Xe-C were fixed and stained for ZO-1(green) and occludin (red) by immunofluorescence staining. Scale bars $=10 \mu \mathrm{m}$. 

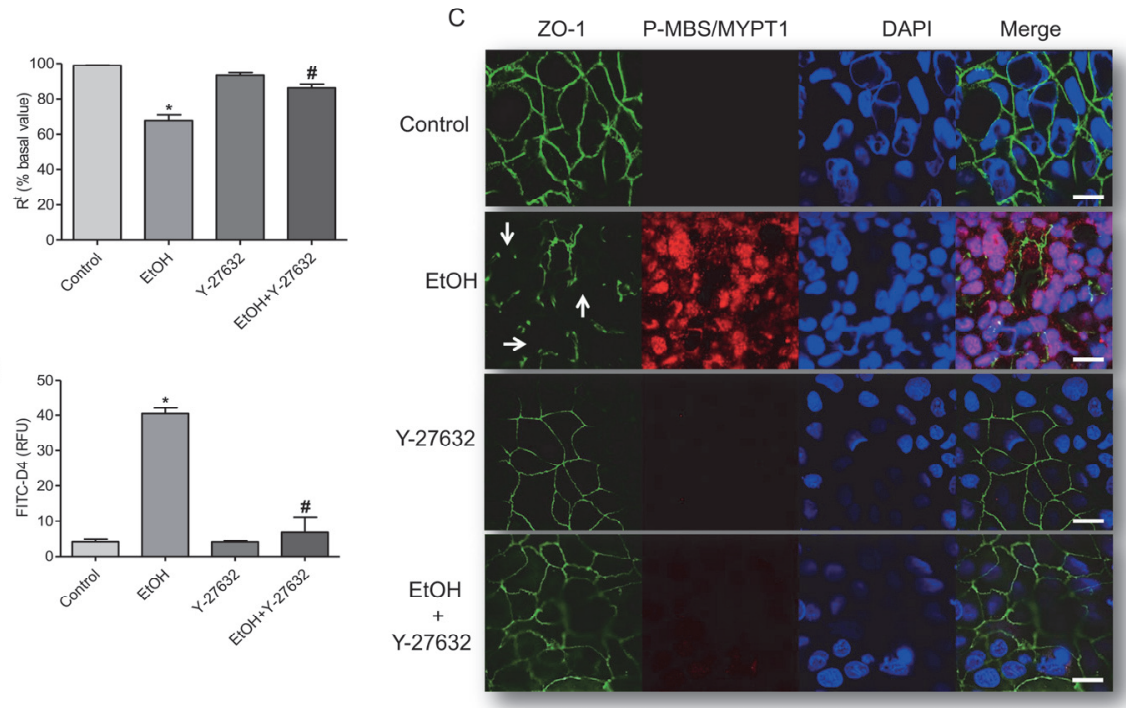

Figure 7.3 Ethanol induces MBS/MYPT1 phosphorylation (Rho/ROCK activation) by an intracellular $\mathrm{Ca}^{2+}$ dependent mechanism. [A] Caco-2 cells grown on glass bottom dishes were treated with 40 $\mathrm{mmol} / \mathrm{l}$ ethanol (EtOH) in the presence or absence of $10 \mu \mathrm{M}$ BAPTA-AM for $3 \mathrm{~h}$ and then fixed and stained with rabbit anti-phosphorylated MBS/MYPT1. Nuclei were stained with DAPI. Images are representatives from three independent experiments. Scale bar=10 $\mu \mathrm{m}$. [B] Cellbased ELISA analysis of phosphorylated MBS/MYPT1. ${ }^{*} P<0.05$ versus control and ${ }^{\#} P<0.05$ vs. ethanol-treated cells in the absence of BAPTA-AM.

\section{Rho/ROCK activation is involved in ethanol-induced barrier disruption}

In the present study, we evaluated the effect of Y27632, a potent and selective Rho/ROCK inhibitor, on ethanol-induced barrier dysfunction. Ethanol-induced decreases in TEER and increases in FITC-D4 permeability were almost completely reversed by pretreatment with Y27632 (Figure 7.4A and 7.4B, respectively) Immunofluorescence staining showed that ethanol-induced permeability was associated with ZO-1 redistribution simultaneously with increased MBS/MYPT1 phosphorylation (Figure 7.4C). In addition, ethanol exposure also resulted in redistribution of adherens junction proteins E-cadherin and B-catenin (Figure 7.5A). Y27632 attenuated ZO-1 redistribution and prevented ethanol-induced MBS/MYPT1 phosphorylation (Figure 7.4C), and ameliorated disruption of E-cadherin and B-catenin (Figure 7.5A). Y27632 by itself had no significant effect on permeability or distribution of ZO-1, E-cadherin and B-catenin. 


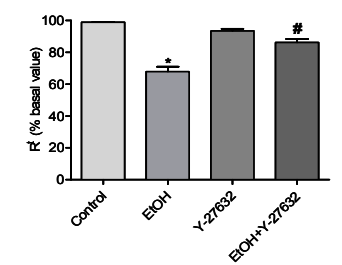

B

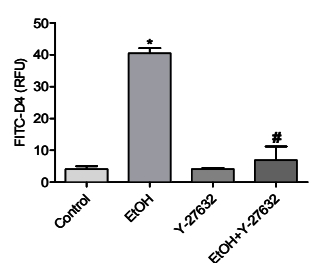

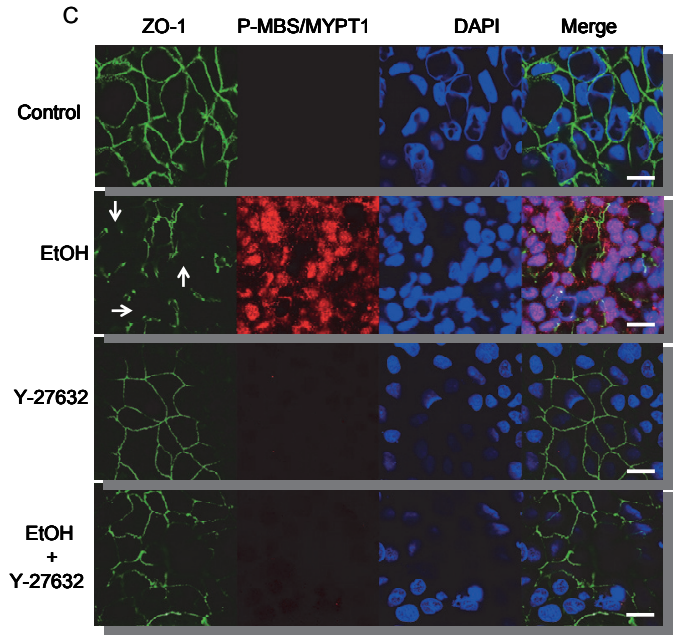

Figure 7.4 Rho/ROCK activation mediates ethanol-induced disruption of (the) tight junctions in Caco-2 (cell?) monolayers. Caco-2 monolayers were pre-treated with Rho/ROCK inhibitor Y27632 $(100 \mu \mathrm{M})$ for $1 \mathrm{~h}$, followed by exposure to ethanol $(40 \mathrm{mmol} / \mathrm{l})(\mathrm{EtOH})$ for $3 \mathrm{~h}$. TEER [A] and FITC-D4 permeation [B] were measured. Values represent means \pm SDs of three independent experiments. ${ }^{*} P<0.05$ vs. control and ${ }^{\#} P<0.05$ vs. ethanol-treated cells in the absence of Y27632. [C] Cell monolayers incubated with ethanol for $3 \mathrm{~h}$ in the presence or absence of Y27632 were fixed and stained for ZO-1 (green), phosphorylated MBS/MYPT1 (red) and nuclei (blue) by immunofluorescence. Scale bars $=10 \mu \mathrm{m}$.

\section{Rho/ROCK is involved in ethanol-induced changes in AJs and F-actin}

Since TJ formation is dependent on $\mathrm{AJs}^{32}$ and actin remodeling plays a crucial role in junction assembly ${ }^{33}$, we examined whether Rho/ROCK plays a role in ethanol-induced disruption of AJs and F-actin cytoskeleton. Immunofluorescence staining for the AJ proteins indicated that ethanol exposure induced redistribution of E-cadherin and $\beta$-catenin from the intercellular junctions into intracellular compartments, and that this effect of ethanol was attenuated by Y27632 treatment (Figure 7.5A). In addition, exposure to ethanol resulted in a significant increase in intracellular F-actin content compared to control $(P<0.0001$; Figure $7.5 \mathrm{~B})$, which was significantly reduced by pretreatment with Rho/ROCK inhibitor, Y27632 ( $P<0.05$; Figure 7.5B), and found to be comparable with the control condition. Figure $7.5 \mathrm{C}$ shows that under control condition, F-actin microfilaments were assembled into a prominent perijunctional F-actin belt that encircled cell borders. In contrast, after ethanol exposure, the F-actin microfilaments were markedly disorganized, in which the perijunctional actin belt was transformed into an array of disordered filaments and stress fiber-like bundles, which could be attenuated by pretreatment with Y27632 (Figure 7.5C). 


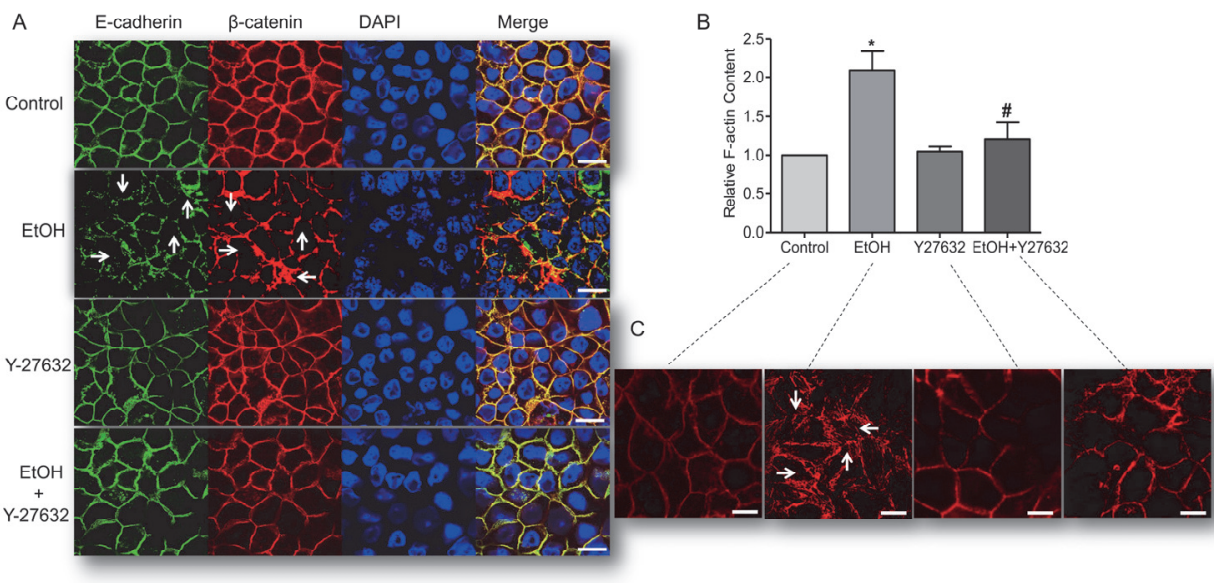

Figure 7.5 Rho/ROCK activation mediates ethanol-induced disruption of the adherens junctions in Caco-2 monolayers. Caco-2 monolayers incubated with ethanol $(40 \mathrm{mmol} / \mathrm{l})(\mathrm{EtOH})$ for $3 \mathrm{~h}$ with or without $\mathrm{Y} 27632(100 \mu \mathrm{M})$ pretreatment were fixed and double stained for E-cadherin (green), $\beta$-catenin (red), and nuclei (blue) by immunofluorescence [A]. Images are representatives of at least three independent experiments. Scale bars $=10 \mu \mathrm{m}$. F-actin contents were assessed by a fluorescent phalloidin-binding assay [B]. Data bars represent means \pm SDs of three independent experiments. ${ }^{*} P<0.05$ vs. control and ${ }^{\#} P<0.05$ vs. ethanoltreated cells in the absence of Y27632. Representative images of immunostaining of F-actin microfilaments [C] Caco-2 monolayers incubated with ethanol (EtOH) with or without Y27632 pretreatment were fixed and stained with rhodamine-phalloidin dye (red) in three independent experiments. Scale bar $=10 \mu \mathrm{m}$.

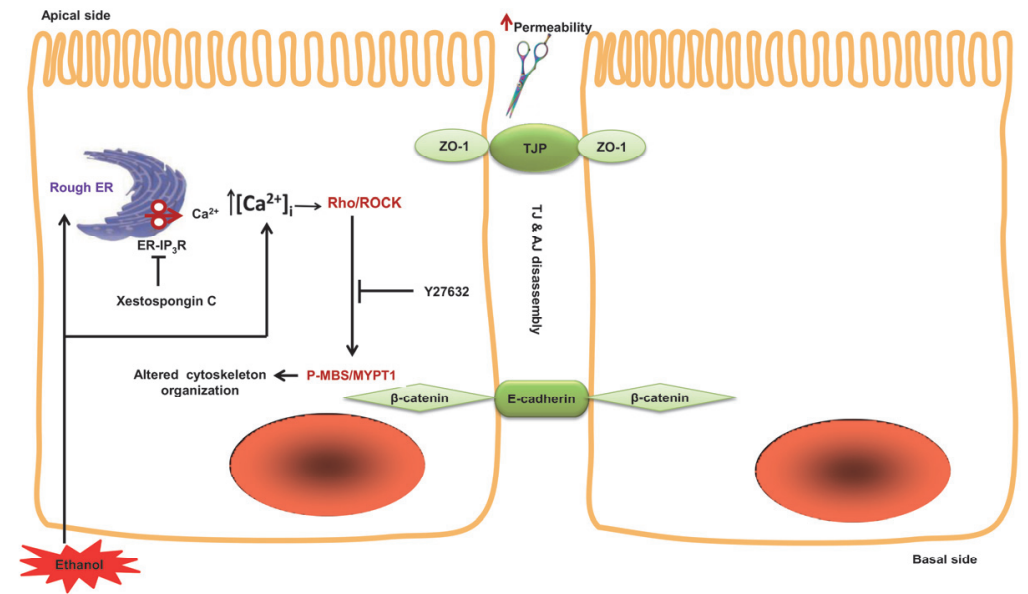

Figure 7.6 Schematic summary of mechanisms involved in ethanol-induced barrier disruption. The initial signal appears to be an increase in (free) intracellular calcium caused by $\mathrm{IP}_{3} \mathrm{R}$-mediated $\mathrm{ER}$ $\mathrm{Ca}^{2+}$ intracellular release. Rise in intracellular calcium mediates activation of Rho/ROCK, which in turn modulates the tight junctions, adherens junctions and F-actin cytoskeleton and consequently, epithelial barrier dysfunction. 


\section{Discussion}

The present study found that ethanol triggers a rise in free intracellular $\left[\mathrm{Ca}^{2+}\right]_{\mathrm{i}}$, which is mediated by inositol 1,4,5-triphosphate receptor $\left(\mathrm{IP}_{3} \mathrm{R}\right)$-gated release of $\mathrm{Ca}^{2+}$ from endoplasmic reticulum (ER). Furthermore, our study also shows that free $\left[\mathrm{Ca}^{2+}\right]_{\mathrm{i}}$ mediates ethanol-induced activation of Rho/ROCK with subsequent loss of TJ and AJ integrity and disruption of F-actin organization and consequently, barrier dysfunction.

Research on the role of $\left[\mathrm{Ca}^{2+}\right]_{i}$ in ethanol-induced cell injury has mainly focused on gastric epithelium, providing evidence that accumulation of $\left[\mathrm{Ca}^{2+}\right]_{i}$ mediates ethanolinduced gap junction dysfunction, resulting in cell shrinkage ${ }^{34}$ and gastric epithelial cell injury ${ }^{35}$. Studies investigating the role of $\left[\mathrm{Ca}^{2+}\right]_{i}$ in ethanol-induced intestinal epithelial barrier function are lacking. Herein, abolishment of ethanol-induced rapid increase in $\left[\mathrm{Ca}^{2+}\right]_{i}$ and attenuation of increased permeability by BAPTA indicate that $\left[\mathrm{Ca}^{2+}\right]_{i}$ mediates ethanol-induced TJ disruption. Our observations are in line with a few studies demonstrating that elevation in $\left[\mathrm{Ca}^{2+}\right]_{\mathrm{i}}$ disrupts $\mathrm{TJ}$ integrity in T84 and Caco-2 monolayers ${ }^{36,37}$. In addition, Samak et al. ${ }^{38}$ have recently shown that rise in $\left[\mathrm{Ca}^{2+}\right]_{\mathrm{i}}$ is required for osmotic stress-induced TJ disruption in Caco-2 monolayers.

The finding that increase in $\left[\mathrm{Ca}^{2+}\right]_{i}$ mediates ethanol-induced TJ disruption raised the question what could be the source of the observed elevation. One possibility could be the endoplasmic reticulum (ER), which can contribute to elevation of free $\left[\mathrm{Ca}^{2+}\right]_{\mathrm{i}}$ through $I P_{3} R$ channels ${ }^{38}$. $I P_{3} R$ constitutes a family of $\mathrm{Ca}^{2+}$ channels which upon activation stimulate $\mathrm{Ca}^{2+}$ release from the ER lumen to the cytoplasm ${ }^{39}$. We observed that pretreatment of Caco-2 monolayers with Xestospongin $C$, a selective antagonist of $I P_{3} R$, can attenuate the ethanol-induced increase in $\left[\mathrm{Ca}^{2+}\right]_{i}$ and $\mathrm{TJ}$ disruption, indicating involvement of $\mathrm{IP}_{3} \mathrm{R}$-operated $\mathrm{ER} \mathrm{Ca}^{2+}$ release. This interpretation is compatible with a prior study demonstrating in brain microvascular endothelial cell monolayers that $I P_{3} R$-mediated increase in $\left[\mathrm{Ca}^{2+}\right]_{i}$ is required for ethanol-induced impairment of blood brain barrier function ${ }^{40}$. In our study, the effects of antagonizing $I P_{3} R$ on ethanol-induced rise in $\left[\mathrm{Ca}^{2+}\right]_{i}$ and barrier dysfunction were partial, indicating involvement of other $\mathrm{Ca}^{2+}$ sources and other mechanism(s) in ethanol-induced barrier disruption.

Elevation of free $\left[\mathrm{Ca}^{2+}\right]_{i}$ achieved by intracellular and extracellular sources has been shown to induce Rho/ROCK kinase activation with subsequent TJ disruption ${ }^{41}$. A significant body of evidence indicates that Rho kinase regulates cytoskeleton proteins including microtubules ${ }^{42,43}$ and indirectly, assembly of the TJs in $184^{44}$ and Caco-2 cells ${ }^{45}$. Among many effectors of Rho, Rho/ROCK has been shown to mediate RhoAinduced disassembly of intercellular junctions and formation of stress fibers ${ }^{46,47}$. Such effects have been attributed to Rho/ROCK-induced phosphorylation of myosin binding subunit or myosin phosphatase targeting subunit 1 (MBS/MYPT1) ${ }^{48}$, the regulatory 
units of MLC, thereby inhibiting myosin light chain (MLC) phosphatase and subsequently, MLC phosphorylation ${ }^{49}$. In the present study, we observed that ethanol causes an increase of phosphorylated MBS/MYPT1 at Thr853. This Rho/ROCK activation could be attenuated by pretreatment with Xestospongin $C$ and BAPTA. Therefore, it was reasoned that $\left[\mathrm{Ca}^{2+}\right]_{i}$ mediates ethanol-induced ROCK activation. The observed changes can also be considered a rapid defensive response to overcome the noxious effects of ethanol. This would be in line with observations of Rao et al. ${ }^{50}$ and Ray et al. ${ }^{51}$ showing that raise in free $\left[\mathrm{Ca}^{2+}\right]_{\mathrm{i}}$ is necessary for activating $\mathrm{RhoA}$, and that activation of RhoA plays a pivotal role in polyamines-induced epithelial cell migration after wounding.

There is mounting evidence supporting a role for Rho/ROCK signaling in mediating disruption of AJs and TJs in vitro ${ }^{52}$. We confirmed that ethanol decreased TEER and increased FITC-D4 permeability in association with redistribution of ZO-1, E-cadherin, and $\beta$-catenin, which was effectively attenuated by the ROCK inhibitor Y27632. While the present work was in progress, Tong et al. ${ }^{17,18}$ have reported upregulation of RhoA mRNA expression and its activation via iNOS mediated-ethanol MLC phosphorylation and consequently TJ disruption in Caco-2 monolayers. However, in these studies, the role of the downstream effector of RhoA, ROCK, was not examined. Our study reported for the first time that ethanol-induced increase in $\left[\mathrm{Ca}^{2+}\right]_{i}$ activates Rho/ROCK resulting in loss of $\mathrm{TJ}$ and $\mathrm{AJ}$ integrity and consequently, barrier dysfunction. Furthermore, our data demonstrate that ethanol induces increase in cellular F-actin contents and disorganization of F-actin rings, which can also be abrogated by Y27632, indicating involvement of Rho/ROCK activity in ethanol-induced remodeling of the cytoskeleton. Our data are in line with previous data showing that ethanol increases paracellular permeability by disrupting F-actin rings / the F-actin ring in Caco-2 cells ${ }^{14}$, and that ROCK activity, at least in endothelial cells, is required for F-actin disruption and barrier dysfunction ${ }^{53,54}$. Figure 7.6 summarizes the putative events occurring in Caco-2 cells as a result of $\mathrm{EtOH}$ exposure resulting in stimulation of $\mathrm{IP}_{3} \mathrm{R}$-gated intracellular $\mathrm{Ca}^{2+}$ release. Release of intracellular $\mathrm{Ca}^{2+}$ triggered the activation of a signaling cascade leading to impairment of cytoskeleton organization and TJ disruption causing a loss of intestinal epithelial integrity and consequently, increased permeability.

Mechanistic studies have indicated key roles for inducible nitric oxide (iNOS)- ${ }^{15}$ and cytochrome-P450 2E1 (CYP2E1)-mediated oxidative stress ${ }^{16}$, remodeling of actin and microtubules ${ }^{12,15}$, and activation of MLCK in ethanol-induced intestinal barrier disruption $^{14,55}$. In the present study, a possible crosstalk between MLCK and Rho/ROCK pathways cannot be excluded, as each pathway can either be selectively induced or co-induced. Previously, it has been suggested that MLCK activation may initiate impairment of the epithelial barrier, which is then followed by Rho/ROCKdependent junctional disassembly and consequently, barrier disruption ${ }^{54}$. The 
mechanism(s) associated with $\mathrm{Ca}^{2+}$-induced Rho/ROCK activation, and how MLCK interacts with Rho/ROCK in ethanol-induced intestinal hyper-permeability merit further investigation.

In summary, the results of the current study demonstrate that ethanol induces a rapid increase in $\left[\mathrm{Ca}^{2+}\right]_{\text {, }}$, mediated in part by $\mathrm{IP}_{3} \mathrm{R}$-gated $\mathrm{ER} \mathrm{Ca}{ }^{2+}$ release. This increase in $\left[\mathrm{Ca}^{2+}\right]_{i}$ activates ROCK with subsequent disruption of apical junctional complex and F-actin cytoskeleton and consequently, intestinal epithelial hyperpermeability. Since the crosstalk between intracellular $\mathrm{Ca}^{2+}$ homeostasis and Rho kinase contributes to many intracellular signaling networks, further delineation of their roles in ethanolinduced gut leakiness may shed light on their potential role as therapeutic or preventive targets for ethanol-related gut-liver axis diseases including ALD. 


\section{References}

1. Fanning AS, Jameson BJ, Jesaitis LA, Anderson JM. The tight junction protein ZO-1 establishes a link between the transmembrane protein occludin and the actin cytoskeleton. J Biol Chem 1998;273: 29745-53..

2. Guo X, Rao JN, Liu L, Zou TT, Turner DJ, Bass BL, et al. Regulation of adherens junctions and epithelial paracellular permeability: a novel function for polyamines. Am J Physiol Cell Physiol 2003;285: C1174-87.

3. Baumgart DC, Dignass AU. Intestinal barrier function. Curr Opin Clin Nutr Metab Care 2002;5:685-94.

4. Bode C, Bode JC. Activation of the innate immune system and alcoholic liver disease: effects of ethanol per se or enhanced intestinal translocation of bacterial toxins induced by ethanol? Alcohol Clin Exp Res 2005;29(11 Suppl):166S-71S.

5. Keshavarzian A, Holmes EW, Patel M, Iber F, Fields JZ, Pethkar S. Leaky gut in alcoholic cirrhosis: a possible mechanism for alcohol-induced liver damage. Am J Gastroenterol 1999;94:200-7.

6. Purohit V, Bode JC, Bode C, Brenner DA, Choudhry MA, Hamilton F, et al. Alcohol, intestinal bacterial growth, intestinal permeability to endotoxin, and medical consequences: Summary of a symposium. Alcohol Fayetteville, NY. 2008;42:349-61.

7. Rao R. Endotoxemia and gut barrier dysfunction in alcoholic liver disease. Hepatology (Baltimore, Md. 2009;50:638-44.

8. Fukui H, Brauner B, Bode JC, Bode C. Plasma endotoxin concentrations in patients with alcoholic and non-alcoholic liver disease: reevaluation with an improved chromogenic assay. J Hepatol 1991;12: 162-9.

9. Hanck C, Rossol S, Bocker U, Tokus M, Singer MV. Presence of plasma endotoxin is correlated with tumour necrosis factor receptor levels and disease activity in alcoholic cirrhosis. Alcohol Alcohol 1998;33:606-8.

10. Schafer C, Parlesak A, Schutt C, Bode JC, Bode C. Concentrations of lipopolysaccharide-binding protein, bactericidal/permeability-increasing protein, soluble CD14 and plasma lipids in relation to endotoxaemia in patients with alcoholic liver disease. Alcohol Alcohol 2002;37:81-6.

11. Swanson G, Forsyth CB, Tang Y, Shaikh M, Zhang L, Turek FW, et al. Role of intestinal circadian genes in alcohol-induced gut leakiness. Alcohol Clin Exp Res 2011;35:1305-14.

12. Elamin E, Jonkers D, Juuti-Uusitalo K, van ljzendoorn S, Troost F, Duimel H, et al. Effects of ethanol and acetaldehyde on tight junction integrity: in vitro study in a three dimensional intestinal epithelial cell culture model. PLoS One 2012;7:e35008.

13. Forsyth CB, Tang Y, Shaikh M, Zhang L, Keshavarzian A. Role of Snail Activation in Alcohol-Induced iNOS-Mediated Disruption of Intestinal Epithelial Cell Permeability. Alcohol Clin Exp Res 2011;35: 1635-43.

14. Ma TY, Nguyen D, Bui V, Nguyen H, Hoa N. Ethanol modulation of intestinal epithelial tight junction barrier. Am J Physiol 1999;276:G965-74.

15. Banan A, Choudhary S, Zhang Y, Fields JZ, Keshavarzian A. Ethanol-induced barrier dysfunction and its prevention by growth factors in human intestinal monolayers: evidence for oxidative and cytoskeletal mechanisms. J Pharmacol Exp Ther 1999;291:1075-85.

16. Forsyth CB, Voigt RM, Shaikh M, Tang Y, Cederbaum Al, Turek FW, et al. Role for intestinal Cyp2e1 in alcohol-induced circadian gene-mediated intestinal hyperpermeability. Am J Physiol Gastrointest Liver Physiol 2013;305:G185-95.

17. Tong J, Wang $Y$, Chang B, Zhang D, Wang B. Evidence for the Involvement of RhoA Signaling in the Ethanol-Induced Increase in Intestinal Epithelial Barrier Permeability. Int J Mol Sci 2013;14:3946-60.

18. Tong J, Wang $Y$, Chang B, Zhang D, Liu P, Wang B. Activation of RhoA in Alcohol-Induced Intestinal Barrier Dysfunction. Inflammation 2013:36:750-8.

19. Nusrat A, Giry M, Turner JR, Colgan SP, Parkos CA, Carnes D, et al. Rho protein regulates tight junctions and perijunctional actin organization in polarized epithelia. Proc Natl Acad Sci U S A 1995;92:10629-33.

20. Wu CC, Lu YZ, Wu LL, Yu LC. Role of myosin light chain kinase in intestinal epithelial barrier defects in a rat model of bowel obstruction. BMC Gastroenterol 2010;10:39. 
21. Utech M, Ivanov AI, Samarin SN, Bruewer M, Turner JR, Mrsny RJ, et al. Mechanism of IFN-gammainduced endocytosis of tight junction proteins: myosin II-dependent vacuolarization of the apical plasma membrane. Mol Biol Cell 2005;16:5040-52.

22. Ohman L, Simren M. Pathogenesis of IBS: role of inflammation, immunity and neuroimmune interactions. Nat Rev Gastroenterol Hepatol 2010;7:163-73.

23. Shen $Q$, Rigor RR, Pivetti CD, Wu MH, Yuan SY. Myosin light chain kinase in microvascular endothelial barrier function. Cardiovasc Res 2010;87:272-80.

24. Mehta D, Rahman A, Malik AB. Protein kinase C-alpha signals rho-guanine nucleotide dissociation inhibitor phosphorylation and rho activation and regulates the endothelial cell barrier function. J Biol Chem 2001;276:22614-20.

25. Elamin E, Masclee A, Juuti-Uusitalo K, van ljzendoorn S, Troost F, Pieters HJ, et al. Fatty Acid Ethyl Esters Induce Intestinal Epithelial Barrier Dysfunction via a Reactive Oxygen Species-Dependent Mechanism in a Three-Dimensional Cell Culture Model. PLoS One 2013;8:e58561.

26. Sei $Y$, Arora PK. Quantitative analysis of calcium (Ca2+) mobilization after stimulation with mitogens or anti-CD3 antibodies. Simultaneous fluo-3 and immunofluorescence flow cytometry. J Immunol Methods 1991;137:237-44.

27. Barhoumi R, Awooda I, Mouneimne Y, Safe S, Burghardt RC. Effects of benzo-a-pyrene on oxytocininduced Ca2+ oscillations in myometrial cells. Toxicol Lett 2006;165:133-41.

28. Uehata M, Ishizaki T, Satoh H, Ono T, Kawahara T, Morishita T, et al. Calcium sensitization of smooth muscle mediated by a Rho-associated protein kinase in hypertension. Nature 1997;389:990-4.

29. Loftus EV, Jr. Clinical epidemiology of inflammatory bowel disease: Incidence, prevalence, and environmental influences. Gastroenterology 2004;126:1504-17.

30. Abramoff MD, Magelhaes PJ, Ram SJ. Image processing with Image. J. Biophotonics International. 2004;11:36-42.

31. Tao N, Sussman S, Nieto J, Tsukamoto H, Yuan JM. Demographic characteristics of hospitalized patients with alcoholic liver disease and pancreatitis in los angeles county. Alcohol Clin Exp Res 2003; 27:1798-804.

32. Gumbiner B, Stevenson B, Grimaldi A. The role of the cell adhesion molecule uvomorulin in the formation and maintenance of the epithelial junctional complex. J Cell Biol 1988;107:1575-87.

33. Ivanov Al. Actin motors that drive formation and disassembly of epithelial apical junctions. Front Biosci 2008;13:6662-81.

34. Mustonen $\mathrm{H}$, Kiviluoto $\mathrm{T}$, Paimela $\mathrm{H}$, Puolakkainen $\mathrm{P}$, Kivilaakso $\mathrm{E}$. Calcium signaling is involved in ethanol-induced volume decrease and gap junction closure in cultured rat gastric mucosal cells. Dig Dis Sci 2005;50:103-10.

35. Miller TA, Kokoska ER, Smith GS, Banan A. Role of calcium homeostasis in gastric mucosal injury and protection. Life Sciences 2001;69:3091-102.

36. Tai YH, Flick J, Levine SA, Madara JL, Sharp GW, Donowitz M. Regulation of tight junction resistance in T84 monolayers by elevation in intracellular Ca2+: a protein kinase C effect. J Membr Biol 1996;149:71-9.

37. Martinez-Palomo A, Meza I, Beaty G, Cereijido M. Experimental modulation of occluding junctions in a cultured transporting epithelium. J Cell Biol 1980;87:736-45.

38. Samak G, Narayanan D, Jaggar JH, Rao R. CaV1.3 channels and intracellular calcium mediate osmotic stress-induced $\mathrm{N}$-terminal c-Jun kinase activation and disruption of tight junctions in Caco-2 CELL MONOLAYERS. J Biol Chem 2011;286:30232-43.

39. Berridge MJ, Bootman MD, Roderick HL. Calcium signalling: dynamics, homeostasis and remodelling. Nat Rev Mol Cell Biol 2003;4:517-29.

40. Haorah J, Knipe B, Gorantla S, Zheng J, Persidsky Y. Alcohol-induced blood-brain barrier dysfunction is mediated via inositol 1,4,5-triphosphate receptor (IP3R)-gated intracellular calcium release. J Neurochem 2007;100:324-36.

41. Rao JN, Guo X, Liu L, Zou T, Murthy KS, Yuan JX, et al. Polyamines regulate Rho-kinase and myosin phosphorylation during intestinal epithelial restitution. Am J Physiol Cell Physiol 2003;284:C848-59.

42. Takai Y, Sasaki T, Tanaka K, Nakanishi H. Rho as a regulator of the cytoskeleton. Trends Biochem Sci 1995;20:227-31.

43. Terry S, Nie M, Matter K, Balda MS. Rho signaling and tight junction functions. Physiology 2010; 25:16-26. 
44. Walsh SV, Hopkins AM, Chen J, Narumiya S, Parkos CA, Nusrat A. Rho kinase regulates tight junction function and is necessary for tight junction assembly in polarized intestinal epithelia. Gastroenterology 2001;121:566-79.

45. Schlegel N, Meir M, Spindler V, Germer CT, Waschke J. Differential role of Rho GTPases in intestinal epithelial barrier regulation in vitro. J Cell Physiol 2011;226:1196-203.

46. Hall A. Rho GTPases and the actin cytoskeleton. Science1998;279:509-14.

47. Amano M, Chihara K, Kimura K, Fukata Y, Nakamura N, Matsuura Y, et al. Formation of actin stress fibers and focal adhesions enhanced by Rho-kinase. Science 1997;275:1308-11.

48. Ito M, Nakano T, Erdodi F, Hartshorne DJ. Myosin phosphatase: structure, regulation and function. Mol Cell Biochem 2004;259:197-209.

49. Kimura K, Ito M, Amano M, Chihara K, Fukata Y, Nakafuku M, et al. Regulation of myosin phosphatase by Rho and Rho-associated kinase (Rho-kinase). Science 1996;273:245-8.

50. Rao JN, Li L, Golovina VA, Platoshyn O, Strauch ED, Yuan JX, et al. Ca2+-RhoA signaling pathway required for polyamine-dependent intestinal epithelial cell migration. Am J Physiol Cell Physiol 2001;280:C993-1007.

51. Ray RM, Patel A, Viar MJ, McCormack SA, Zheng Y, Tigyi G, et al. RhoA inactivation inhibits cell migration but does not mediate the effects of polyamine depletion. Gastroenterology 2002;123: 196-205.

52. Sahai E, Marshall CJ. ROCK and Dia have opposing effects on adherens junctions downstream of Rho. Nat Cell Biol 2002;4:408-15.

53. van Nieuw Amerongen GP, Beckers CM, Achekar ID, Zeeman S, Musters RJ, van Hinsbergh VW. Involvement of Rho kinase in endothelial barrier maintenance. Arterioscler Thromb Vasc Biol 2007; 27:2332-9.

54. Ivanov Al, Parkos CA, Nusrat A. Cytoskeletal regulation of epithelial barrier function during inflammation. Am J Pathol 2010;177:512-24.

55. Ma TY, Nguyen D, Bui V, Nguyen H, Hoa N. Ethanol modulation of intestinal epithelial tight junction barrier. Am J Physiol 1999;276:G965-74. 


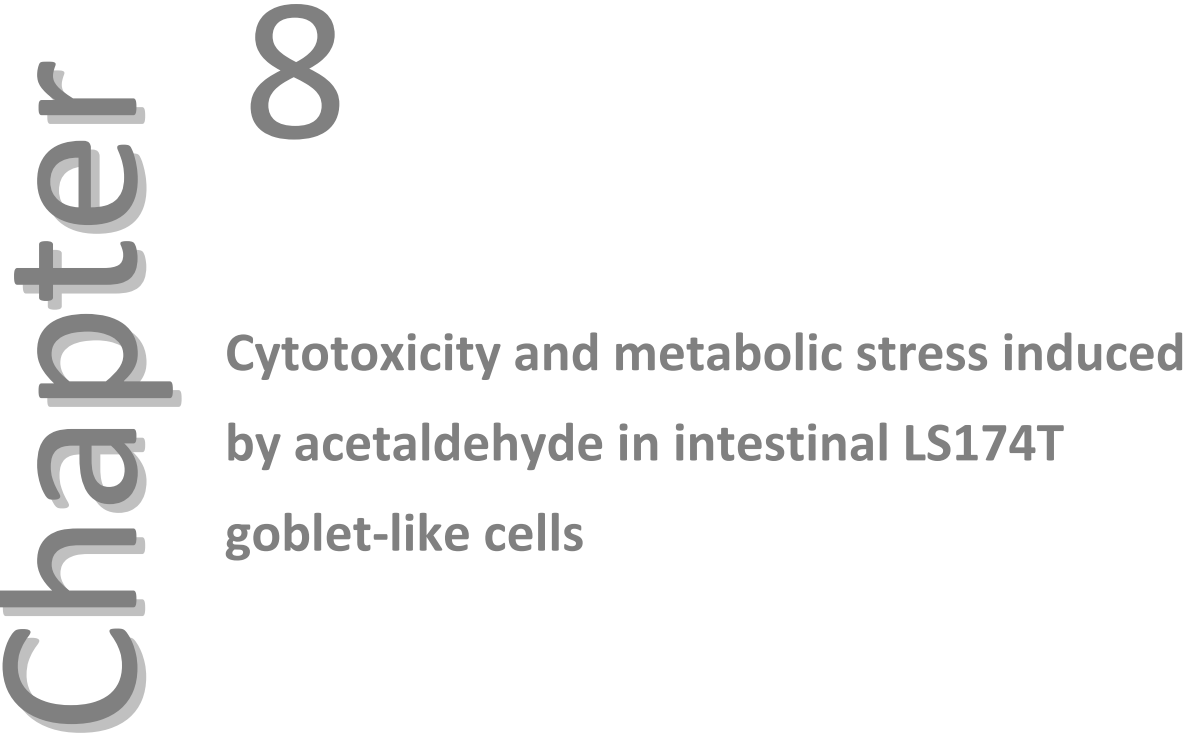

Elhaseen Elamin, Ad Masclee, Jan Dekker, Daisy Jonkers Submitted 


\section{Abstract \\ Introduction \\ Ethanol and its oxidative metabolite, acetaldehyde, can disrupt intestinal barrier function with subsequent translocation of endotoxins into portal circulation resulting in liver injury. Apart from the tight junctions, mucins secreted by goblet cells coat the intestinal epithelial surface providing an effective barrier. While ethanol has been shown to induce goblet cell injury associated with alterations in intestinal mucins glycosylation, the effects of its most injurious metabolite, acetaldehyde, remains largely unknown.}

\section{Aims}

To assess short-term effects of acetaldehyde on functional characteristics of the intestinal epithelial goblet-like cells (LS174T) in concentrations expected to occur in colon lumen after a single moderate ethanol dosage $(20 \mathrm{~g})$ administration.

\section{Methods}

Intracellular oxidative stress, mitochondrial function, ATP and intra-mitochondrial calcium $\left(\mathrm{Ca}^{2+}\right)$ accumulation were assessed by dichlorofluorescein, methyltetrazolium, bioluminescence assays, MitoTracker green and rhod-2 double-labeling, respectively. Effects of acetaldehyde $(0,25,50,75,100 \mu \mathrm{M})$ on membrane integrity of LS174T cells was evaluated by measuring lactate dehydrogenase (LDH) activity. Cell apoptosis was determined by caspase $3 / 7$ activity and caspase-mediated cytokeratin 18 (CK18) cleavage. Effects of acetaldehyde $(0,25,100 \mu \mathrm{M})$ on mucin 2 (MUC2) protein expression was determined by cell-based ELISA.

\section{Results}

Acetaldehyde significantly increased ROS generation and decreased mitochondrial function compared to untreated controls $(P<0.05)$. In addition, acetaldehyde dosedependently decreased intracellular ATP levels and induced intra-mitochondrial $\mathrm{Ca}^{2+}$ accumulation compared to negative controls $(P<0.05)$. Furthermore, acetaldehyde dose-dependently increased caspase $3 / 7$ activity and percentage of cells expressing cleaved CK18 protein and increased MUC2 protein expression compared to negative controls $(P<0.0001)$.

\section{Conclusions}

Our data demonstrate that acetaldehyde has distinct metabolic and cytotoxic effects on LS174T cells that can lead to induction of cellular apoptosis. These effects may contribute to acetaldehyde-induced intestinal barrier dysfunction and subsequently, liver injury. 


\section{Introduction}

There is compelling evidence for a gut-liver axis that is causatively linked to ethanolinduced liver disease ${ }^{1}$. Ethanol has been shown to induce intestinal hyperpermeability with subsequent translocation of endotoxins from gut lumen into the portal circulation, which can result in liver injury ${ }^{2,3}$. Therefore, loss of intestinal barrier integrity is considered to play a pivotal role in the pathogenesis of alcoholic liver disease (ALD). In addition, a decreased epithelial barrier function can result in increased susceptibility to carcinogens and thereby may contribute to increased risk of alcohol-related cancers of the gastrointestinal (GI) tract $^{4-7}$.

In addition to the apical junctional complex (AJC), GI epithelial barrier integrity is maintained by a mucus layer that is synthesized and secreted by goblet cells ${ }^{8,9}$. In the GI tract, mucus is composed of a polysaccharide called mucin that coats the intestinal epithelial surface, thereby providing lubricant medium and barrier against translocation of xenobiotics and their (e.g. endotoxins) ${ }^{10}$. Thus, the mucus layer is a critical component of the intestinal barrier limiting direct access to the intestinal epithelium. Although at least nine human mucin (MUC) genes have been identified ${ }^{11}$, MUC2 is the main structural component of the mucus gel and represents the major mucin of the small and large intestine ${ }^{8}$.

Previously, it has been shown that exposure to ethanol can result in reduction of goblet cell viability and morphological alterations in cell organelles including distortion of mitochondria and dilation of endoplasmic reticulum ${ }^{12}$. In rat, ethanol induced alterations in mucin composition by reversing the fucose/sialic acid ratio of oligosaccharide residues resulting from ethanol-induced changes in sialytransferase and fucosyltransferase activities ${ }^{13}$. These changes are suggested to influence mucus function including interactions with microorganisms ${ }^{13,14}$.

Acetaldehyde, the first metabolite of ethanol is known to be mutagenic. Intracolonic production and accumulation of acetaldehyde has been associated with colorectal carcinogenesis $^{15}$. Intracolonic production of acetaldehyde may lead to increased plasma acetaldehyde levels and subsequent hepatotoxicity ${ }^{16}$. Although evidence on effects of acetaldehyde on goblet cells is relevant to acetaldehyde-intestinal barrier dysfunction, studies investigating effects of acetaldehyde on intestinal goblet cells are lacking. Therefore, we aimed to assess short-term effects of acetaldehyde in concentrations expected to be present in the colon lumen after moderate ethanol consumption, on functional characteristics of the intestinal epithelial goblet-like cells LS174T, including cellular redox state, mitochondrial calcium $\left(\mathrm{Ca}^{2+}\right)$ homeostasis and ATP production, viability and the implications for MUC2 expression. 


\section{Methods}

\section{Cell culture}

LS174T cells, kindly provided by Dr. Sara Linden, University of Gothenburg, Sweden, were grown in either T25 or T75 flasks and were maintained in Dulbecco's Modified Eagle Medium (DMEM; Lonza Benelux BV, Breda, the Netherlands) containing $4.5 \mathrm{~g} / \mathrm{l}$ glucose and L-glutamine. The medium was supplemented with $10 \%$ fetal calf serum (Invitrogen, Breda, The Netherlands), 1\% non-essential amino acids (Invitrogen) and $1 \%$ antibiotic/antimycotic mixture $(10,000$ units of penicillin, $10,000 \mu \mathrm{g}$ of streptomycin, and $25 \mu \mathrm{g}$ of amphotericin B per ml; Invitrogen) at $37^{\circ} \mathrm{C}$ and in a $5 \% \mathrm{CO}_{2}$ atmosphere.

\section{Measurement of Reactive Oxygen Species (ROS)}

The generation of ROS was monitored by using 2',7'- dichlorodihydrofluorescein diacetate (DCF-DA, Sigma Chemical Co, Amsterdam, NL), which is non-fluorescent unless oxidized by intracellular ROS. LS174T cells were cultured in 96 well plates and were preloaded with $100 \mu \mathrm{M}$ DCF-DA for $1 \mathrm{~h}$ at $37^{\circ} \mathrm{C}$. Measurement of intracellular ROS was performed by incubating LS174T cells with either medium only as negative control or acetaldehyde $(25,50,75,100 \mu \mathrm{M})$ for $3 \mathrm{~h} . \mathrm{H}_{2} \mathrm{O}_{2}(30 \mathrm{mM})$ was used as a positive control. The monolayers were then washed twice in Hank's Balanced Salt Solution buffer (HBSS; Invitrogen) and the fluorescence (485Ex/530Em) was measured by SpectraMax M2 spectrofluorometer (Molecular Devices). Data were reported as percentage of the negative controls.

\section{Measurement of mitochondrial function}

Mitochondrial function was assessed using 3-(4.5-dimethylthiazol-2-yl)-2,5diphenyltetrazolium bromide (MTT; Sigma-Aldrich) that is cleaved into insoluble formazan by active mitochondrial succinate dehydrogenases in living cells ${ }^{17}$. Briefly, LS174T cells were cultured in 96 well plates and exposed to acetaldehyde (25-100 $\mu \mathrm{M})$ for $3 \mathrm{~h}$. Medium only and $\mathrm{H}_{2} \mathrm{O}_{2}(30 \mathrm{mM})$ were used as negative and positive control, respectively. The cells were then washed with PBS and incubated with $5 \mathrm{mg} / \mathrm{ml}$ MTT in PBS, $200 \mu \mathrm{l}$ per well for another $3 \mathrm{~h}$ at $37^{\circ} \mathrm{C}$. Thereafter the solution was aspirated and the insoluble formazan product was solubilized with $0.1 \mathrm{M} \mathrm{HCl}$ in isopropanol $(100 \mu \mathrm{l}$ per well) and incubated at RT for $30 \mathrm{~min}$. The optical density was measured at a wavelength of $560 \mathrm{~nm}$ using a spectrophotometer. Values are presented as percentage of medium only-treated cells. 


\section{Assessment of mitochondrial calcium}

For mitochondrial $\mathrm{Ca}^{2+}$ monitoring, LS174T cells were trypsinized and transferred from cell culture flasks to 8-well chamber slides (Lab-Tek ${ }^{\mathrm{TM}}$ Nunc, Rochester, NY, USA) at a density of $2.5 \times 10^{4}$ cells in $500 \mu$ cell culture medium. After a period of three days, cells were incubated with acetaldehyde $(25,50,75,100 \mu \mathrm{M})$ for $3 \mathrm{~h}$. Medium only and $\mathrm{H}_{2} \mathrm{O}_{2}$ (30 mM) were used as negative and positive control, respectively. Cells were rinsed twice in serum-free culture medium and loaded with a mixture of $5 \mu \mathrm{M}$ Rhod2/AM (Molecular Probes, Eugene, OR, USA), a fluorescent probe specific for mitochondrial $\mathrm{Ca}^{2+}$, with $01 \%$ pluronic acid for $30 \mathrm{~min}$ at $37^{\circ} \mathrm{C}$ as described previously ${ }^{18}$. Medium was removed, replaced with dye-free culture medium and incubated for an additional $60 \mathrm{~min}$ at $37^{\circ} \mathrm{C}$. Thereafter, $1 \mu \mathrm{M}$ of the fluorescent mitochondria specific dye MitoTracker ${ }^{T M}$ (green fluorescence, Molecular Probes) was added to each well for the last $30 \mathrm{~min}$ of incubation. Cells were visualized using a Leica TCS SPE confocal laser scanning microscope (Leica Microsystems GmbH, Mannheim, Germany). Excitation wavelength was $488 \mathrm{~nm}$ and fluorescence emission was recorded at $543 \mathrm{~nm}$ for Rhod-2 and $516 \mathrm{~nm}$ for MitoTracker ${ }^{\mathrm{TM}}$. Ten images were randomly chosen in selected microscopic fields from three independent experiments and fluorescence intensity was quantified by dividing the pixel intensity by the area of the spot $\left(\mu \mathrm{m}^{2}\right)$ using the Image J software ${ }^{19}$.

\section{Luminescent ATP assay}

The amount of ATP produced by metabolically active cells was quantified based on the luciferase reaction (CellTiter-Glo ${ }^{\circledR}$ Luminescent Cell Viability Assay, Promega, the Netherlands). The amount of ATP is directly proportional to the number of living cells present in the culture. Briefly, LS714T cells were cultured in 96 well plates and exposed to acetaldehyde $(25-100 \mu \mathrm{M})$ for $3 \mathrm{~h}$. Medium only and $\mathrm{H}_{2} \mathrm{O}_{2}(30 \mathrm{mM})$ were used as negative and positive control, respectively. Thereafter, plates were equilibrated at RT for $30 \mathrm{~min}$ and processed as described previously ${ }^{20}$. Intracellular ATP was calculated from the luminescent values and presented as percentage of the medium only-treated cells.

\section{Lactate dehydrogenase assay}

Cell plasma membrane integrity was evaluated by measuring lactate dehydrogenase $(\mathrm{LDH})$ release. The assay (CytoTox-ONE ${ }^{\mathrm{TM}}$ Homogeneous Membrane Integrity Assay; Promega, the Netherlands) was performed according to the manufacture instructions. Briefly, LS714T cells were cultured in 96 well plates (Corning BV) and incubated with acetaldehyde $(25-100 \mu \mathrm{M})$. Then, plates were incubated at $37^{\circ} \mathrm{C}$ for $3 \mathrm{~h}$ and equilibrated at RT for $20 \mathrm{~min}$. Thereafter, plates were processed and LDH was measured as described previously ${ }^{20}$. The percentage of LDH activity was calculated as percentage of maximum LDH release (i.e. the fully lysed cells). 


\section{Assessment of caspase 3/7 activity}

Caspase 3/7 activity was measured as a marker of apoptosis using a luminescent assay (ApoTox-Glo ${ }^{\text {TM }}$ Triplex Assay, Promega). Briefly, the assay provides a luminogenic caspase-3/7 substrate, which contains the tetrapeptide sequence DEVD, in a reagent optimized for caspase activity, luciferase activity, and cell lysis. Addition of the Caspase-Glo ${ }^{\circledR} 3 / 7$ reagent results in cell lysis, followed by caspase cleavage of the substrate and generation of luminescent signals produced by luciferase which will be proportional to the amount of caspase activity present. LS714T grown on the 96-well plates were incubated with $(25,50,75,100 \mu \mathrm{M})$ acetaldehyde or $30 \mathrm{mM} \mathrm{H}_{2} \mathrm{O}_{2}$ at $37^{\circ} \mathrm{C}$ for $3 \mathrm{~h}$ and then, $100 \mu \mathrm{l}$ of Caspase-3/7 reagent assay was added to each well, briefly mixed by orbital shaking (300-500rpm for $\sim 30$ seconds) and incubated at room temperature for $30 \mathrm{~min}$. Negative (HBSS buffer solution) control wells were also included and treated similarly as described above. The luminescence was measured by using SpectraMax M2 (Molecular Devices, Sunnyvale, CA, USA). The caspase-3/7 activity was expressed as a ratio between treated and untreated cells.

\section{Detection of caspase activity with M30 Cyto-DEATH}

Caspase activity was further investigated with the commercially available monoclonal antibody M30 cytoDEATH (Roche, Mannheim, Germany). After incubation with acetaldehyde, LS513 (passage 28) and LS714T (passage 30) cells grown on Lab-Tek 8 chamber-glass slides (Nalge Nunc International, Naperville, IL)) were washed with PBS, and fixed for $30 \mathrm{~min}$ in methanol (Merck) at $-20^{\circ} \mathrm{C}$. Fixed cells were washed twice with buffer consisting of PBS, 1\% bovine serum albumin and 0.1\% Tween 20 (Sigma, St. Louis, Mo., USA) and were subsequently incubated with M30 Cyto-DEATH for $30 \mathrm{~h}$ at room temperature. Thereafter, the cells were incubated with Alexa-488 conjugated goat anti-mouse (Invitrogen) (1:100 dilution in 3\% (w/v) BSA in PBS, pH 7.4) at RT for $30 \mathrm{~min}$. After another washing in HBSS, cells were stained for 20 min with diamidino2-phenylindole (DAPI; 1:10,000 dilution in PBS; Sigma Chemical Co). Finally, the chambers were removed, slides mounted in VectaShield mounting medium containing DAPI (Vector Laboratories, Burlingame, USA), covers slipped and sealed with a clear nail polish. The slides were examined under a Leica TCS SPE confocal laser scanning microscope (Leica Microsystems $\mathrm{GmbH}$ ). Confocal images obtained were processed and analyzed using Image $\mathrm{J}$ software ${ }^{19}$.

\section{Assessment of MUC2 protein expression}

MUC2 protein expression was assessed using a cell-based ELISA kits (RayBio $^{\circledR}$ cell-based protein phosphorylation ELISA kit; RayBiotech, Inc. Norcross, GA, USA) with minor modifications. Briefly, LS174T cells $\left(20 \times 10^{3}\right)$ were seeded in 96 well plates and incubated overnight at $37^{\circ} \mathrm{C}$ and $5 \% \mathrm{CO}_{2}$. Then, the monolayers were exposed to medium only as control or acetaldehyde $(25$ and $100 \mu \mathrm{M})$ for $3 \mathrm{~h}$ and processed for 
cell-ELISA using rabbit anti-MUC2 (1:100 dilution in the blocking solution; Abcam, Cambridge, UK) as we described previously ${ }^{20}$. Finally, $25 \mu \mathrm{l}$ of stop solution was added to each well and the optical density was read at $450 \mathrm{~nm}$ with a spectrophotometer.

\section{Statistical analysis}

All data analyses were conducted using GraphPad Prism software package (GraphPad Software Incorporated, CA, USA). Data are expressed as means \pm SD of triplicate experiments. One-way analysis of variance (ANOVA) and Tukey's post-hoc tests were performed to compare between different experimental conditions, considering difference of $P$ value $<0.05$ as statistically significant.

\section{Results}

\section{Effects of acetaldehyde on cellular redox state}

Since acetaldehyde is a potent oxidative stress inducer ${ }^{21}$, we used DCF-DA to test whether acetaldehyde can induce ROS production in LS174T goblet-like cells. We found that acetaldehyde treatment at concentrations ranging from 25-100 $\mu \mathrm{M}$ significantly increased the intracellular ROS contents of LS174T cells compared to the negative controls (all $P<0.05$; Figure $8.1 \mathrm{~A}$ ). As expected, the increase of ROS was higher after incubation with the positive control $\left(\mathrm{H}_{2} \mathrm{O}_{2}\right)$ compared to the negative control $(P<0.05$; Figure 8.1A).

\section{Effects of acetaldehyde on mitochondrial function}

Cells were incubated with various doses of acetaldehyde and mitochondrial function was assessed with the MTT assay that determines the mitochondrial complex II enzymes activity succinyl dehydrogenases. Our results revealed that exposure to 25-100 $\mu \mathrm{M}$ acetaldehyde for $3 \mathrm{~h}$ significantly reduced the mitochondrial activity compared to negative controls $(P<0.05$; Figure 8.1B). Mitochondrial function was also significantly reduced after exposure to the positive control $30 \mathrm{mM} \mathrm{H}_{2} \mathrm{O}_{2}$ compared to the negative control ( $P<0.05$; Figure 8.1B).

\section{Effects of acetaldehyde on intracellular ATP levels}

Main function of the mitochondria is the production of energy in the form of ATP via oxidative phosphorylation and oxygen consumption. We therefore assessed the amount of ATP levels in LS174T cells exposed to either acetaldehyde or $\mathrm{H}_{2} \mathrm{O}_{2}$ (positive control) for $3 \mathrm{~h}$. As noted in Figure 8.2, acetaldehyde induced a dose-dependent significant decrease in intracellular ATP compared to negative controls $(P<0.05$; Figure 8.2). 
A

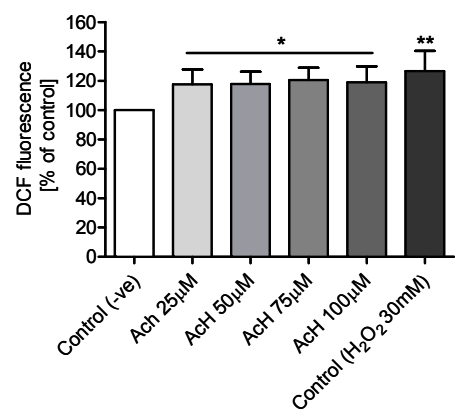

B

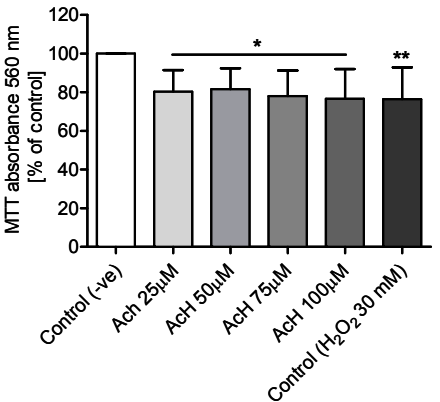

Figure 8.1 Effects of acetaldehyde on oxidative stress and mitochondrial function. LS174T cells were incubated with acetaldehyde at the indicated concentrations or medium only and $\mathrm{H}_{2} \mathrm{O}_{2}$ $30^{\circledR} \mathrm{mM}$ to serve as negative and positive controls, respectively, for $3 \mathrm{~h}$. [A] reactive oxygen species (ROS) generation was assayed using 2', 7'- dichlorodihydrofluorescein diacetate (DCF-DA) and expressed as percentage of negative control (control -ve). [B] Mitochondrial function was determined by MTT assay and absorbance was measured at a wavelength of $560 \mathrm{~nm}$. Data were reported as percentage of negative (-ve) control. Values are presented as means \pm SD. of three experiments. ${ }^{*} P<0.05$ and ${ }^{*} * P<0.01$ vs. negative (-ve) control.

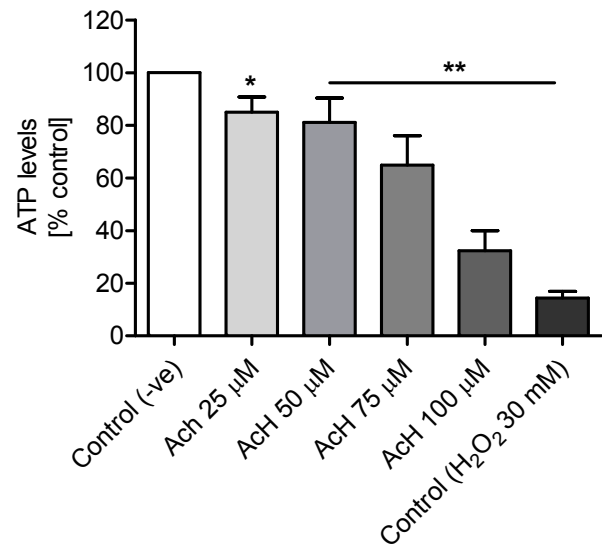

Figure 8.2 Effects of acetaldehyde on intracellular ATP levels. LS174T cells were treated with or without various concentrations of acetaldehyde at $37^{\circ} \mathrm{C}$ for $3 \mathrm{~h}$. Intracellular ATP levels were determined by a bioluminescence-based assay. Data were reported as percentage of negative (-ve) control. Data illustrated present means \pm SDs of three experiments. ${ }^{*} P<0.05$ and $* * P<0.01$ vs. negative (-ve) control.

\section{Effects of acetaldehyde on mitochondrial calcium in LS174T cells}

Next we tested whether acetaldehyde caused a change in mitochondrial $\mathrm{Ca}^{2+}$ in LS174T cells using the positively charged and cell permeant $\mathrm{Ca}^{2+}$ indicator, Rhod2/AM, which accumulates predominantly in the negatively charged matrix of the 
mitochondria $^{18}$. The dye MitoTracker ${ }^{\mathrm{TM}}$ was used to confirm the mitochondrial localization of Rhod-2. As presented in Figure 8.3A, acetaldehyde treatment of LS174T cells induced an increase in Rhod-2 fluorescence that appears predominantly in the mitochondria as demonstrated by the yellow spots of strong intensity found in the merged image. In contrast, the distribution pattern of colocalized Rhod-2 and MitoTracker ${ }^{\mathrm{TM}}$ observed in control cells revealed spots of less intensity characterized by a more diffuse distribution (Figure 8.3A). Quantification of Rhod-2 fluorescence intensity showed a significant dose-dependent increase in Rhod-2 fluorescence after treatment with acetaldehyde $(P<0.05$; Figure 8.3B).

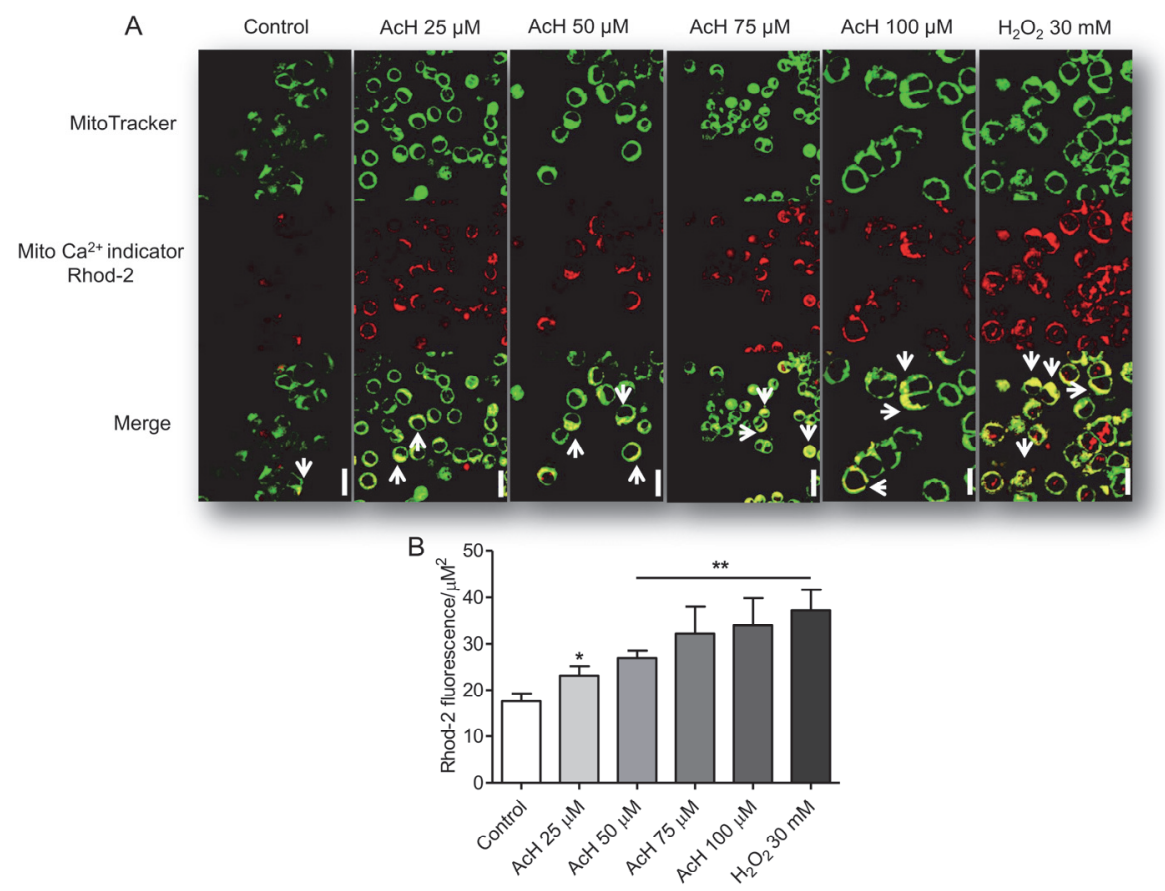

Figure 8.3 Influence of acetaldehyde on mitochondrial calcium homeostasis in LS174T cells. [A] Representative fluorescence images of LS174T cells treated with medium as controls, acetaldehyde and $\mathrm{H}_{2} \mathrm{O}_{2}$, after prior loading with the mitochondrial dye MitoTracker ${ }^{\circledR}$ (green) and the mitochondrial $\mathrm{Ca}^{2+}$ indicator Rhod-2 (red). Merged images indicate colocalization of the two dyes in the mitochondria. Mitochondrial $\mathrm{Ca}^{2+}$ accumulation is indicated by arrows. Scale bar=10 $\mu \mathrm{m}$. [B] Quantification of Rhod-2 fluorescence intensity in LS174T cells subjected to acetaldehyde or $\mathrm{H}_{2} \mathrm{O}_{2}$ treatment. Values are presented as means $\pm S D$. of three experiments. $* P<0.05$ and ${ }^{* *} P<0.01$ vs. -ve controls. 


\section{Effects of acetaldehyde on cell membrane integrity}

The membrane integrity of LS174T cells, as an indicator of cytotoxicity, was evaluated by measuring the release of the cytosolic lactate dehydrogenase (LDH) after exposure to acetaldehyde at a concentration range of $25,50,75$ and $100 \mu \mathrm{M} / \mathrm{I}$. As shown in Figure 8.4A, incubation with acetaldehyde for $3 \mathrm{~h}$ at the indicated concentrations significantly increased the LDH release compared to negative controls $(P<0.05)$.

\section{Effects of acetaldehyde on caspase-3/7 activity}

The observation that acetaldehyde induces cell necrosis as indicated by loss of membrane integrity led us to investigate cell apoptosis by determining activation of caspase-3/7 in LS174T cells ${ }^{22}$. As shown in figure 8.4B, exposure to acetaldehyde at a concentration range of $25,50,75$ and $100 \mu \mathrm{M} /$ / significantly increased caspase-3/7 activity compared to negative controls. Incubation with positive control $\mathrm{H}_{2} \mathrm{O}_{2}$ also significantly induced $3 / 7$ caspase activity versus the negative control $(P<0.05$; Figure 8.4B).
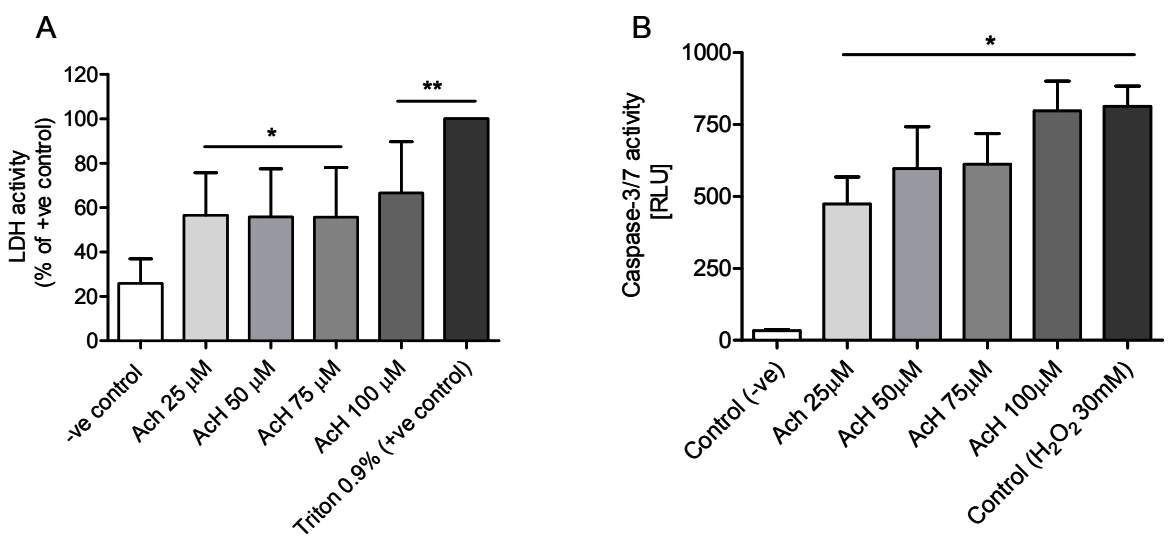

Figure 8.4. Effect of acetaldehyde on cell viability. LS174T cells were incubated with acetaldehyde at a concentration range of $25,50,75$ and $100 \mu \mathrm{M} / \mathrm{l}$ for $3 \mathrm{~h}$. Triton $0.9 \%$ to induce total cell lysis and $\mathrm{H}_{2} \mathrm{O}_{2}$ were used as positive (+ve) controls for membrane necrosis and cell apoptosis, respectively. [A] Membrane necrosis was assessed by measuring the activity of LDH Values are presented as means \pm S.D. of three independent experiments. ${ }^{*} P<0.05$ and ${ }^{*} * P<0.01$ vs. the negative (-ve) control. [B] Activity of $3 / 7$ caspase activity as a marker of cell apoptosis was evaluated using a luminescent-based assay. Values are reported as means \pm S.D. of three independent experiments. ${ }^{*} P<0.01$ vs. the negative (-ve) control.

\section{Effects of acetaldehyde on caspase-mediated cytokeratin 18 cleavage}

During apoptosis, cytoplasmic cytokeratin 18 (CK18), a major component of cytoplasmic cytokeratin filaments in epithelial cells, is cleaved by caspases, mainly caspase 3 or 7 , resulting in exposure of a neo-epitope which is detectable with the monoclonal 
antibody $\mathrm{M}^{13} 0^{13}$. To complement our data on 3/7 caspase activity, we examined CK18 cleavage using immunofluorescent staining. As shown in Figure 8.5A, acetaldehyde induced CK18 cleavage as indicated by increased immunoreactivity to M30 in LS174T cells compared to controls. Furthermore, the percentages of M30 reactive cells were significantly increased after incubation with acetaldehyde compared to controls (Figure 8.5B).

A

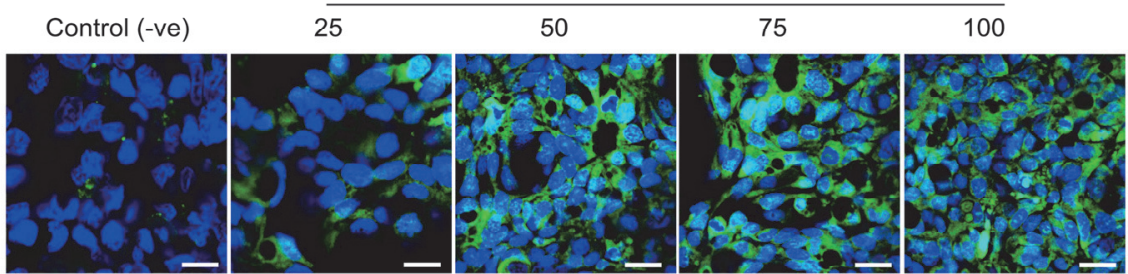

B

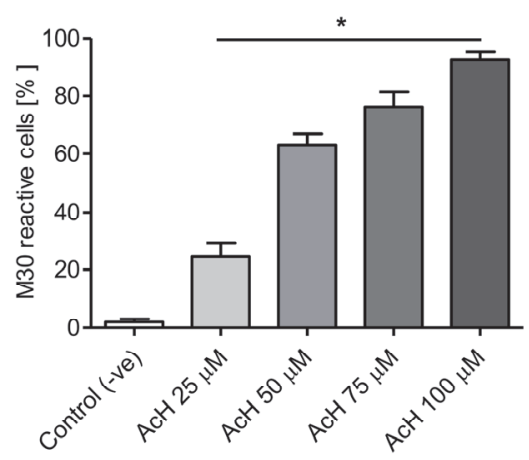

Figure 8.5 Dose effects of acetaldehyde on caspase activation. [A] Representative images of distribution of cytokeratin after staining with M30 (green) as reproduced in three independent experiments. Nuclei were counterstained with DAPI (blue). Scale bar, $10 \mu \mathrm{m}$. [B] percentage number of $M 30$ reactive cells. Data bars represent the means $\pm S D$ of three independent experiments. ${ }^{*} P<0.01$ vs. the negative (-ve) control.

\section{Effects of acetaldehyde on MUC2 protein expression}

To establish whether acetaldehyde modulates mucin production, LS174T cells were exposed to acetaldehyde at concentrations 25 and $100 \mu \mathrm{M}$ and protein levels of MUC2 was assessed by a cell based-ELISA. As shown in Figure 8.6A, protein levels of MUC2 were significantly increased after exposure to acetaldehyde in a dose dependent manner as compared to the controls $(P<0.001)$. To complement these data, dot blotting was performed. Data revealed that exposure to acetaldehyde can result in an increased MUC2 protein expression (Figure 8.6B). 
A

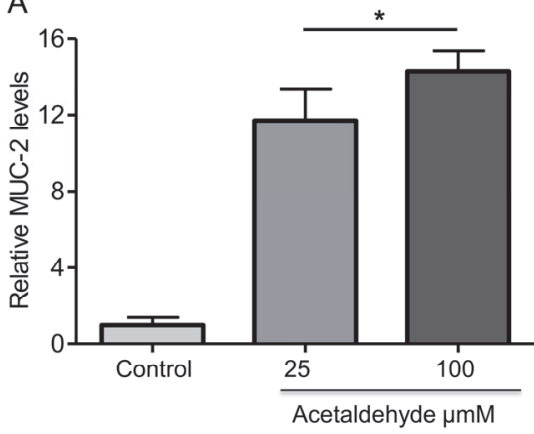

B

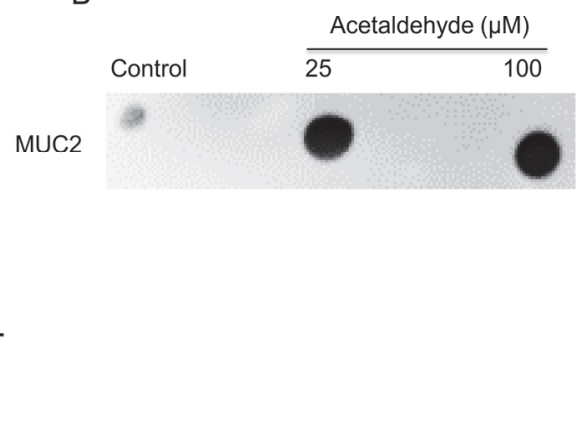

Figure 8.6 Dose effects of acetaldehyde on MUC2 protein expression. LS174T cells were treated with either $25 \mu \mathrm{M}$ or $100 \mu \mathrm{M}$ acetaldehyde for $3 \mathrm{~h}$ and then processed for assessment of MUC2 protein expression. [A] Cell-based ELISA analysis and [B] Representative dot blot analysis of MUC2 expression. ${ }^{*} P<0.01$ vs. the negative (-ve) control.

\section{Discussion}

In the present study, effects of acetaldehyde on cellular redox status, mitochondrial dysfunction, cell viability and MUC2 expression were investigated using LS174Tgobletlike cells. It was shown that acetaldehyde: (i) increases ROS production; (ii) induces intra-mitochondrial $\mathrm{Ca}^{2+}$ accumulation; (iii) dose-dependently decreases intracellular ATP levels; and (iv) dose-dependently induces loss of cell membrane integrity, caspase 3/7 activation and increases in cleaved CK18 and MUC2 protein expression.

Acetaldehyde is considered to be involved in various ethanol-related $\mathrm{Gl}$ disorders including barrier dysfunction and colorectal carcinogenesis ${ }^{1}$. The perturbations of goblet cells, especially in colon epithelium by acetaldehyde are relevant as acetaldehyde can reach high concentrations within the colon. Incubation of human colonic contents with ethanol at concentrations achievable in vivo after moderate ethanol consumption (i.e. $22 \mathrm{mM}$ and $44 \mathrm{mM}$ ) can result in generation of $58 \mu \mathrm{M}$ and $238 \mu \mathrm{M}$ acetaldehyde, respectively ${ }^{23}$. Furthermore, blood acetaldehyde levels of 20-50 $\mu \mathrm{M}$ have been reported after moderate ethanol ingestion ${ }^{24}$. Therefore, acetaldehyde concentrations used in the present study reflect concentrations that can be reached in human colon lumen following moderate ethanol consumption. Since intestinal microbiota are less capable of metabolizing acetaldehyde by aldehyde dehydrogenase $(\mathrm{ALDH})^{25}$ and levels of ALDH in colonic mucosa are rather low ${ }^{26}$, higher concentrations of acetaldehyde are expected to accumulate in the large intestine ${ }^{16}$. Previously, intracolonic production and accumulation of acetaldehyde has been linked to colorectal carcinogenesis ${ }^{15}$ and has been considered as an important determinant for blood acetaldehyde levels and subsequent hepatotoxicity ${ }^{16}$. However, little is 
known about effects of acetaldehyde on intestinal goblet cells. We used the gobletlike cell line LS174T to examine their response to acetaldehyde exposure. The LS174T cell line was established from a moderately well-differentiated primary colon adenocarcinoma ${ }^{27}$, that constitutively produces and releases large amounts of mucus glycoproteins into the culture medium ${ }^{28}$. Furthermore, LS174T cells express genes for secretory mucins that are predominant in the GI tract, including MUC2 and MUC3 ${ }^{29}$. Therefore, LS 174T cells provide a convenient in vitro model for the study of human intestinal goblet cell biology.

Since oxidative stress occurring during ethanol metabolism is a major cause of cell injury, we examined effects of its oxidative metabolite acetaldehyde on cellular redox status. Not surprisingly, we observed that acetaldehyde in the range of concentrations of 25-100 $\mu \mathrm{M}$ increased reactive oxygen species generation (ROS) in LS174T cells. These results are consistent with a recent observation by our group that acetaldehyde at concentrations as low as $25 \mu \mathrm{M}$ enhances intracellular oxidative stress in the enterocytes-like Caco-2 cell monolayers, with subsequent induction of epithelial to mesenchymal transition and consequently, barrier dysfunction ${ }^{30}$. Oxidative stress induced by ethanol in intestinal epithelium has been implicated in loss of epithelial integrity ${ }^{31,32}$. Although mitochondrion is a major source of oxidants and a target for their injurious effects ${ }^{33}$, little is known about mitochondrial response to acetaldehydeinduced oxidative stress in goblet cells. Previously, accumulation of oxidants in mitochondria has been shown to decrease ATP production ${ }^{34}$. Depletion of ATP or metabolic stress can contribute to intestinal epithelial barrier dysfunction ${ }^{35,36}$. Since cytotoxic effects of acetaldehyde might include impairment of energy generation by mitochondria, we assessed mitochondrial function and measured cellular ATP levels. Our data revealed that incubation of LS174T cells with acetaldehyde decreased mitochondrial function and induced a marked decrease in ATP levels. The effects of acetaldehyde on mitochondrial function and ATP were comparable with effects of the potent oxidant $\mathrm{H}_{2} \mathrm{O}_{2}$. These observations are in line with previous investigations showing that exposure to $\mathrm{H}_{2} \mathrm{O}_{2}$ decreases cellular ATP levels in the mucus secreting goblet-like HT-29 cells ${ }^{37}$. Thus, the fall in ATP synthesis is probably related to the observed decreases in mitochondrial metabolic activity resulting from the acetaldehyde-induced oxidative stress. In addition to ATP synthesis, mitochondria also regulate $\mathrm{Ca}^{2+}$ signals through rapid accumulation and release of $\mathrm{Ca}^{2+38}$. Although intracellular $\mathrm{Ca}^{2+}$ plays a crucial role in cellular metabolism, excessive mitochondrial $\mathrm{Ca}^{2+}$ overload has been demonstrated to trigger ROS generation, mitochondrial dysfunction and ATP depletion. In the present study, our results show that acetaldehyde is able to induce accumulation of mitochondrial $\mathrm{Ca}^{2+}$. Together with the aforementioned observations, this may eventually lead to induction of apoptosis ${ }^{38}$, which has also been observed in this study. 
At an acetaldehyde concentration of $100 \mu \mathrm{M}$, relative reduction in ATP content (by $67.7 \%$ ) was comparable to the increase in LDH activity (by $66.6 \%$ ), suggesting that the observed decrease in ATP content was reflecting reduced cell viability. Indeed, LS174T cells responded to acetaldehyde with increase in LDH release, indicating loss of membrane integrity and early necrosis. In addition, the cells showed increased caspase 3/7 activity and expression of cleaved CK18 indicating induction of early apoptosis. Since goblet cells together with the absorptive enterocytes dominate the intestinal epithelium ${ }^{39}$ and maintenance of intestinal barrier function depends on the integrity of the $\mathrm{TJ}$ and mucins $^{40}$, it can be speculated that acetaldehyde-induced metabolic stress and apoptosis in goblet cells could have major impact on intestinal barrier integrity.

MUC2, a glycoprotein synthesized by goblet cells, is the most abundantly present mucin in the upper and lower Gl tract ${ }^{41}$. Therefore, we examined effects of acetaldehyde on MUC2 protein expression. Our data revealed that exposure to acetaldehyde increased MUC2 protein levels. Previously, secretion of mucins has been reported to be increased in goblet cells in response to induction of reactive oxygen species and exposure to various noxious substrates such as endotoxins ${ }^{42,43}$. Therefore, the observed increase in MUC2 protein expression in our study may be due to acetaldehyde-induced cellular oxidative stress. Increasing mucins synthesis and secretion by goblet cells contributes to homeostasis of intestinal epithelium and protection against intestinal injury ${ }^{44}$. Nevertheless, overexpression of mucin by goblet cells is suggested to be related to a decrease in their viability ${ }^{45}$. In line with this, the observed increase in MUC2 protein in our study can be explained by acetaldehydeinduced cell apoptosis. However, whether this phenomenon should be considered as compensatory response to acetaldehyde toxicity or as direct result of acetaldehyde effects on goblet cells, cannot be answered based on our results and therefore remains to be determined. Recent studies have disclosed that altered or inappropriate mucin gene expression is related to tumor development, invasiveness, and prognosis in colorectal cancer ${ }^{46}$. Therefore, this study along with previous ones strengthens the concept that intestinal goblet cells are also important targets for the toxic effects of acetaldehyde. Since the mucus layer has been found to be modulated by ethanol ${ }^{13,14}$, it would also be interesting to evaluate effects of acetaldehyde on gene and protein expression of mucins including MUC2 and other peptides such as the trefoil factors (i.e. TFF3) in intestinal goblet cells. Furthermore, alterations in colon mucin biochemistry including decreased oligosaccharide chain length, reduced sulphation and increased sialylation have been observed in patients with inflammatory bowel disease $^{47}$. Future studies should also focus on the biochemical composition of the mucus secreted in response to acetaldehyde exposure.

In conclusions, our results demonstrate for the first time that exposure to acetaldehyde exerts distinct metabolic and cytotoxic effects on LS174T cells, which 
can lead to induction of cellular apoptosis and modulation of MUC2 protein expression. These effects may contribute to acetaldehyde-induced intestinal barrier dysfunction and consequently, liver injury. Further delineation of mechanisms involved may provide new therapeutic targets for prevention of acetaldehyde-induced intestinal goblet cell injury and its subsequent barrier disruption. Future studies evaluating intestinal barrier should more systematically take into account goblet cell function and mucin production. 


\section{References}

1. Elamin EE, Masclee AA, Dekker J, et al. Ethanol metabolism and its effects on the intestinal epithelial barrier. Nutr Rev 2013;71:483-99.

2. Parlesak A, Schafer C, Schutz T, et al. Increased intestinal permeability to macromolecules and endotoxemia in patients with chronic alcohol abuse in different stages of alcohol-induced liver disease. J Hepatol 2000;32:742-7.

3. Keshavarzian A, Fields J. Alcoholic liver disease: is it an "extraintestinal" complication of alcoholinduced intestinal injury? J Lab Clin Med 2003;142:285-7.

4. Squier CA, Cox P, Hall BK. Enhanced penetration of nitrosonornicotine across oral mucosa in the presence of ethanol. J Oral Pathol 1986;15:276-9.

5. Howie NM, Trigkas TK, Cruchley AT, et al. Short-term exposure to alcohol increases the permeability of human oral mucosa. Oral Dis 2001;7:349-54.

6. Squier CA, Kremer MJ, Wertz PW. Effect of ethanol on lipid metabolism and epithelial permeability barrier of skin and oral mucosa in the rat. J Oral Pathol Med 2003;32:595-9.

7. Wight AJ, Ogden GR. Possible mechanisms by which alcohol may influence the development of oral cancer--a review. Oral Oncol 1998;34:441-7.

8. Deplancke B, Gaskins HR. Microbial modulation of innate defense: goblet cells and the intestinal mucus layer. Am J Clin Nutr 2001;73:1131S-1141S.

9. Corfield AP, Carroll D, Myerscough N, et al. Mucins in the gastrointestinal tract in health and disease. Front Biosci 2001;6:D1321-57.

10. Usatyuk PV, Singleton PA, Pendyala S, et al. Novel role for non-muscle myosin light chain kinase (MLCK) in hyperoxia-induced recruitment of cytoskeletal proteins, NADPH oxidase activation, and reactive oxygen species generation in lung endothelium. J Biol Chem 2012;287:9360-75.

11. Aksoy N, Akinci OF. Mucin macromolecules in normal, adenomatous, and carcinomatous colon: evidence for the neotransformation. Macromol Biosci 2004;4:483-96.

12. Brozinsky S, Fani K, Grosberg SJ, et al. Alcohol ingestion-induced changes in the human rectal mucosa: light and electron microscopic studies. Dis Colon Rectum 1978;21:329-35.

13. Grewal RK, Mahmood A. The effects of ethanol administration on brush border membrane glycolipids in rat intestine. Alcohol 2010;44:515-22.

14. Grewal RK, Mahmood A. A shift in microvillus membrane fucosylation to sialylation by ethanol ingestion in rat intestine. Mol Cell Biochem 2009;331:19-25.

15. Seitz HK, Homann N. The role of acetaldehyde in alcohol-associated cancer of the gastrointestinal tract. Novartis Found Symp 2007;285:110-9; discussion 119-4, 198-9.

16. Salaspuro M. Bacteriocolonic pathway for ethanol oxidation: characteristics and implications. Ann Med 1996;28:195-200.

17. Uc A, Stokes JB, Britigan BE. Heme transport exhibits polarity in Caco-2 cells: evidence for an active and membrane protein-mediated process. Am J Physiol Gastrointest Liver Physiol 2004;287:G1150-7.

18. Taha $R$, Seidman E, Mailhot $G$, et al. Oxidative stress and mitochondrial functions in the intestinal Caco-2/15 cell line. PLoS One 2010;5:e11817.

19. Abramoff MD, Magelhaes, P.J., Ram, S.J. Image Processing with ImageJ. Biophotonics International 2004;11:36-42.

20. Robinson CE, Keshavarzian A, Pasco DS, et al. Determination of protein carbonyl groups by immunoblotting. Anal Biochem 1999;266:48-57.

21. Szuster-Ciesielska A, Plewka K, Daniluk J, et al. Zinc inhibits ethanol-induced HepG2 cell apoptosis. Toxicol Appl Pharmacol 2008;229:1-9.

22. Chan WH, Wu CC, Yu JS. Curcumin inhibits UV irradiation-induced oxidative stress and apoptotic biochemical changes in human epidermoid carcinoma A431 cells. J Cell Biochem 2003;90:327-38.

23. Jokelainen $\mathrm{K}$, Roine $\mathrm{RP}$, Vaananen $\mathrm{H}$, et al. In vitro acetaldehyde formation by human colonic bacteria. Gut 1994;35:1271-4.

24. Tsukamoto S, Muto T, Nagoya T, et al. Determinations of ethanol, acetaldehyde and acetate in blood and urine during alcohol oxidation in man. Alcohol Alcohol 1989;24:101-8.

25. Nosova T, Jokelainen K, Kaihovaara $\mathrm{P}$, et al. Characteristics of aldehyde dehydrogenases of certain aerobic bacteria representing human colonic flora. Alcohol Alcohol 1998;33:273-80. 
26. Koivisto $T$, Salaspuro M. Aldehyde dehydrogenases of the rat colon: comparison with other tissues of the alimentary tract and the liver. Alcohol Clin Exp Res 1996;20:551-5.

27. Tom BH, Rutzky LP, Jakstys MM, et al. Human colonic adenocarcinoma cells. I. Establishment and description of a new line. In Vitro 1976;12:180-91.

28. Boland CR, Roberts JA, Siddiqui B, et al. Cancer-associated colonic mucin in cultured human tumor cells and athymic (nude) mouse xenografts. Cancer Res 1986;46:5724-9.

29. Gum JR, Hicks JW, Swallow DM, et al. Molecular cloning of cDNAs derived from a novel human intestinal mucin gene. Biochem Biophys Res Commun 1990;171:407-15.

30. Elamin E, Jonkers D, Juuti-Uusitalo $K$, et al. Effects of ethanol and acetaldehyde on tight junction integrity: in vitro study in a three dimensional intestinal epithelial cell culture model. PLoS One 2012; 7:e35008.

31. Banan A, Keshavarzian A, Zhang L, et al. NF-kappaB activation as a key mechanism in ethanol-induced disruption of the F-actin cytoskeleton and monolayer barrier integrity in intestinal epithelium. Alcohol 2007;41:447-60.

32. Forsyth $C B$, Tang $Y$, Shaikh $M$, et al. Role of snail activation in alcohol-induced iNOS-mediated disruption of intestinal epithelial cell permeability. Alcohol Clin Exp Res 2011;35:1635-43.

33. Anders MW, Robotham JL, Sheu SS. Mitochondria: new drug targets for oxidative stress-induced diseases. Expert Opin Drug Metab Toxicol 2006;2:71-9.

34. Chance B, Sies H, Boveris A. Hydroperoxide metabolism in mammalian organs. Physiol Rev 1979;59: 527-605.

35. Lewis K, McKay DM. Metabolic stress evokes decreases in epithelial barrier function. Ann N Y Acad Sci 2009;1165:327-37.

36. Unno N, Menconi MJ, Salzman AL, et al. Hyperpermeability and ATP depletion induced by chronic hypoxia or glycolytic inhibition in Caco-2BBe monolayers. Am J Physiol 1996;270:G1010-21.

37. Watson AJ, Askew JN, Sandle GI. Characterisation of oxidative injury to an intestinal cell line (HT-29) by hydrogen peroxide. Gut 1994;35:1575-81.

38. Szalai G, Krishnamurthy R, Hajnoczky G. Apoptosis driven by IP(3)-linked mitochondrial calcium signals. EMBO J 1999;18:6349-61.

39. Madara JL, Trier JS. Structure and permeability of goblet cell tight junctions in rat small intestine. J Membr Biol 1982;66:145-57.

40. Nusrat A, Turner JR, Madara JL. Molecular physiology and pathophysiology of tight junctions. IV. Regulation of tight junctions by extracellular stimuli: nutrients, cytokines, and immune cells. Am J Physiol Gastrointest Liver Physiol 2000;279:G851-7.

41. Strous GJ, Dekker J. Mucin-type glycoproteins. Crit Rev Biochem Mol Biol 1992;27:57-92.

42. Verburg M, Renes IB, Van Nispen DJ, et al. Specific responses in rat small intestinal epithelial mRNA expression and protein levels during chemotherapeutic damage and regeneration. J Histochem Cytochem 2002;50:1525-36.

43. Blanchard C, Durual S, Estienne M, et al. IL-4 and IL-13 up-regulate intestinal trefoil factor expression: requirement for STAT6 and de novo protein synthesis. J Immunol 2004;172:3775-83.

44. Kim YS, Ho SB. Intestinal goblet cells and mucins in health and disease: recent insights and progress. Curr Gastroenterol Rep 2010;12:319-30.

45. Chang JX, Chen S, Ma LP, et al. Functional and morphological changes of the gut barrier during the restitution process after hemorrhagic shock. World J Gastroenterol 2005;11:5485-91.

46. Melis M, Hernandez J, Siegel EM, et al. Gene expression profiling of colorectal mucinous adenocarcinomas. Dis Colon Rectum 2010;53:936-43.

47. Shirazi T, Longman RJ, Corfield AP, et al. Mucins and inflammatory bowel disease. Postgrad Med J 2000;76:473-8. 


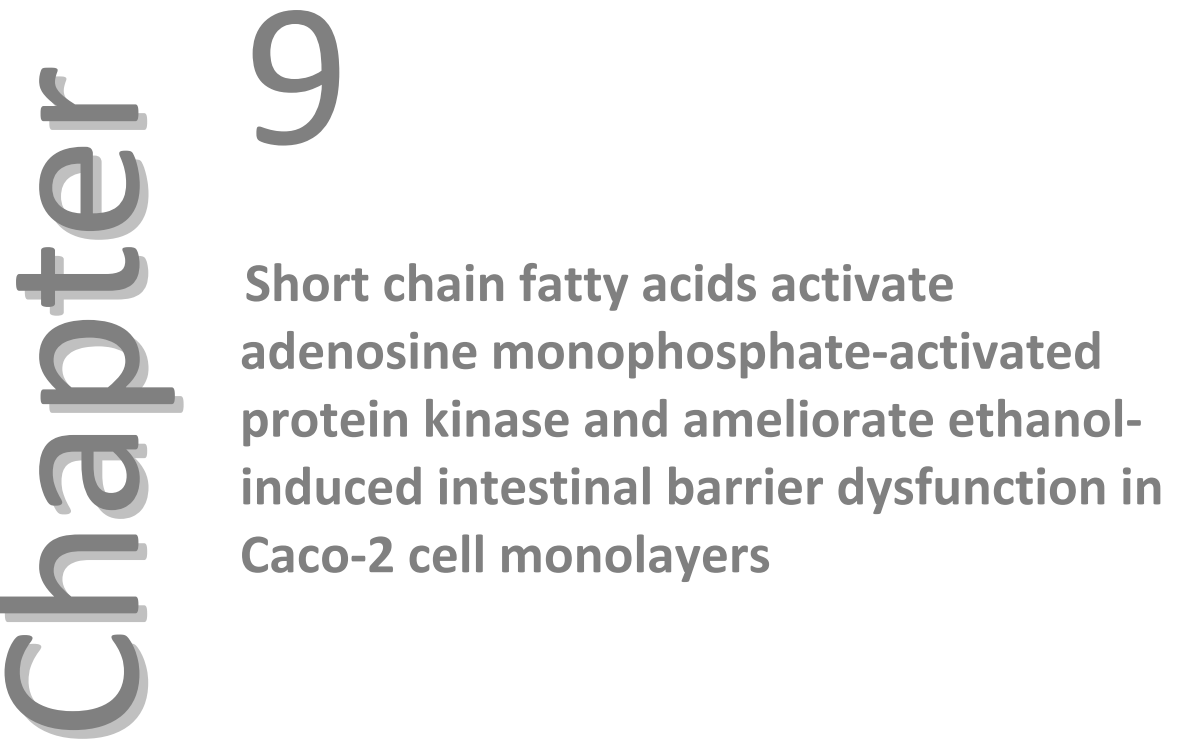

Elhaseen Elamin, Ad Masclee, Jan Dekker, Harm-Jan Pieters, Daisy Jonkers Journal of Nutrition 2013; 304-308 


\section{Abstract}

Short chain fatty acids (SCFAs) have been shown to promote intestinal barrier function but their protective effects against ethanol-induced intestinal injury and underlying mechanisms remain largely unknown. The aim of the study was to analyze the influence of SCFAs on ethanol-induced barrier dysfunction and to examine the role of adenosine monophosphate-activated protein kinase (AMPK) as a possible mechanism using Caco- 2 monolayers. The monolayers were treated apically with butyrate $(2,10$ or $20 \mathrm{mmol} / \mathrm{l})$, propionate $(4,20$ or $40 \mathrm{mmol} / \mathrm{l})$ or acetate $(8,40$ or $80 \mathrm{mmol} / \mathrm{l})$ for $1 \mathrm{~h}$, prior to ethanol $(40 \mathrm{mmol} / \mathrm{l})$ for $3 \mathrm{~h}$. Barrier function was analyzed by measurement of transepithelial resistance (TEER) and permeation of fluorescein isothiocyanate-labeled dextran (FITC-D4). Distribution of the tight junction (TJ) proteins ZO-1, occludin and F-actin was examined by immunofluorescence. Metabolic stress was determined by measuring oxidative stress, mitochondrial function and ATP using dichlorofluorescein diacetate, dimethylthiazol-2-yl)-2,5-diphenyltetrazolium bromide (MTT) and bioluminescence assay, respectively. AMPK was knocked down by siRNA and its activity was assessed by a cell-based ELISA. Exposure to ethanol significantly impaired the barrier function compared to controls $(P<0.0001)$, disrupted the TJ and F-actin cytoskeleton integrity, and induction of metabolic stress. However, pretreatment with $2 \mathrm{mmol} / \mathrm{l}$ butyrate, $4 \mathrm{mmol} / \mathrm{l}$ propionate and $8 \mathrm{mmol} / \mathrm{l}$ acetate significantly alleviated the ethanol-induced barrier dysfunction, $\mathrm{TJ}$ and F-actin disruption as well as metabolic stress compared to ethanol exposed monolayers $(P<0.0001)$. The promoting effects on barrier function were abolished by inhibiting AMPK using either compound $C$ or siRNA. These observations indicate that SCFAs exhibit protective effects against ethanol-induced barrier disruption via AMPK activation, suggesting a potential for SCFAs as prophylactic and/or therapeutic factors against ethanol-induced gut leakiness. 


\section{Introduction}

Alcohol (or ethanol) is widely consumed and associated with development of chronic liver disease and gastrointestinal cancers ${ }^{1}$. Experimental and clinical studies have demonstrated that ethanol is able to induce loss of tight junction (TJ) integrity ${ }^{2-4}$, leading to intestinal barrier dysfunction with subsequent translocation of luminal substances such as bacterial endotoxins into the portal circulation and consequently liver injury ${ }^{5-7}$. Ethanol-induced barrier dysfunction is considered to play a crucial role in the pathogenesis of alcoholic liver disease (ALD $)^{8,9}$, and can increase susceptibility to carcinogens ${ }^{10}$. Since currently no effective therapy is available for ALD other than abstinence, restoring intestinal barrier integrity could be of distinctive value in preventing and/or treating ethanol-induced gut leakiness.

In the last decade, considerable research has been rekindled in prebiotics and their beneficial effects on intestinal health. Short chain fatty acids (SCFAs) $(<C 8: 0)$ including butyrate $(\mathrm{C} 4: 0)$, propionate $(\mathrm{C} 3: 0)$, and acetate $(\mathrm{C} 2: 0)$, are generated by bacterial fermentation of undigested carbohydrates, specifically resistant starches and dietary fiber, in the large intestine ${ }^{11,12}$. Depending on diet and gut microbiota composition, intestinal concentrations can range between 60 to $130-150 \mathrm{mmol} / \mathrm{I}^{13}$, with butyrate, propionate and acetate in nearly constant molar ratios of 15:25:60, respectively ${ }^{14}$. SCFAs have been demonstrated to exert many beneficial effects on intestinal epithelium including inhibition of inflammation ${ }^{15,16}$, modulation of oxidative stress ${ }^{17}$ and prevention of colon carcinogenesis ${ }^{18,19}$. Furthermore, an improved barrier function by SCFAs has been reported in vitro ${ }^{20,21}$, ex vivo ${ }^{22}$, and in animal studies ${ }^{23}$. Mechanistic studies in Caco-2 cells have shown that butyrate enhances epithelial integrity by facilitating TJs assembly via increased activation of a number of cell signaling pathways, including adenosine monophosphate-activated protein kinase $(\mathrm{AMPK})^{24}$. AMPK plays a major role in cellular energy homeostasis and exerts cytoprotection under stressful conditions such as hypoxia, ischaemia and oxidative stress $^{25}$.

Ethanol is a potent metabolic stressor and decreases cellular ATP production ${ }^{26}$, which can be through modulation of AMPK, thereby contributing to increased intestinal permeability. However, the direct effects of the SCFAs including butyrate, propionate and acetate on ethanol-induced barrier dysfunction and their possible mechanisms are largely unknown. Therefore, we aimed to evaluate the potentially preventive effects of SCFAs on ethanol-induced TJ disruption in Caco-2 monolayers and to investigate involvement of metabolic stress and AMPK activation. 


\section{Methods}

\section{Cell line and culture conditions}

Colon adenocarcinoma cell line (Caco-2) from American Type Culture Collection (ATCC, Rockville, USA; passage 39-48) were maintained in Dulbecco's Modified Eagle Medium (DMEM; Lonza Benelux BV, Breda, the Netherlands) containing $4.5 \mathrm{~g} / \mathrm{l}$ glucose and $0.29 \mathrm{~g} / \mathrm{l}$ L-glutamine. The medium was supplemented with $10 \%(\mathrm{v} / \mathrm{v})$ fetal calf serum (Invitrogen, Breda, the Netherlands), $1 \%$ non-essential amino acids (Invitrogen) and $1 \%$ antibiotic/antimycotic mixture $(10,000$ units of penicillin, 10,000 $\mu \mathrm{g}$ of streptomycin, and $25 \mu \mathrm{g}$ of amphotericin B per $\mathrm{ml}$ (Invitrogen) at $37^{\circ} \mathrm{C}$ and in a $95 \%$ air/ $5 \% \mathrm{CO}_{2}$ atmosphere.

\section{Transepithelial electrical resistance (TEER) measurement}

Caco- 2 cells were grown for 21 days on collagen-coated permeable polycarbonate filters with a surface area of $0.33 \mathrm{~cm}^{2}$ and $0.4 \mu \mathrm{m}$ pore size (Costar, Cambridge, MA, USA). After developing TEER $>600 \Omega \bullet \mathrm{cm}^{2}$, monolayers were exposed from the basal side to either $40 \mathrm{mmol} / \mathrm{l}$ ethanol for $3 \mathrm{~h}$ in medium with or without luminal pretreatment with butyrate $(2,10,20 \mathrm{mmol} / \mathrm{l}$; Sigma-Aldrich, Amsterdam, the Netherlands), propionate (4, 20, $40 \mathrm{mmol} / \mathrm{l}$; Sigma-Aldrich), or acetate (8, 40, $80 \mathrm{mmol} / \mathrm{l}$; Sigma-Aldrich) solutions in medium with $\mathrm{pH}$-values ranging from 7.73 to 8.98 during incubation for $1 \mathrm{~h}$. Since ethanol is volatile at $37^{\circ} \mathrm{C}$, ethanol solutions were prepared at $4^{\circ} \mathrm{C}$ prior to the final working concentration, and thereby counteracting evaporation. Next, Caco-2 monolayers were exposed in partly plastic tape-sealed plates and ethanol in medium was replaced each hour to compensate for evaporation. In some experiments, monolayers were incubated with $0.01 \mathrm{mmol} / \mathrm{l}$ (6-[4-(2- pi peridin-1-yl-ethoxy)-phenyl)] 3-pyridin-4-yl-pyrazolo [1,5-a] Pyrimidine (Sigma Aldrich), a specific inhibitor of AMPK (known as Compound C (CC)) or $0.5 \mathrm{mmol} / \mathrm{l}$ of 5aminoimidazole-4-carboxamide riboside (AICAR; Sigma Aldrich), an AMPK activator ${ }^{27}$ for $1 \mathrm{~h}$. TEER of epithelial monolayers $(\Omega)$ was measured after 60 or 180 min by an Epithelial Voltohmmeter (World Precision Instruments, Berlin, Germany) in each insert and multiplied by the membrane surface area $\left(0.33 \mathrm{~cm}^{2}\right)$, corrected by subtracting background resistance of the blank membrane (no cells; approximately $30 \Omega \bullet \mathrm{cm}^{2}$ ). Data were collected from duplicate inserts per treatment in three experiments and expressed as percentage of basal TEER obtained before treatment.

\section{Determination of the paracellular permeability}

Caco-2 cells monolayers were grown on Trans-well plates and treated as described above. By the end of TEER measurements, fluorescein isothiocyanate-labeled dextran $4 \mathrm{KDa}$ ( $1 \mathrm{mg} / \mathrm{ml}$ FITC-D4; Sigma-Aldrich) was added to the apical compartment and incubated for $1 \mathrm{~h}$ at $37^{\circ} \mathrm{C}$. Then, $50 \mu \mathrm{l}$ of medium from the apical and basal 
compartments were collected in 96 well plates and FITC-D4 was measured spectrophotometrically at an excitation wavelength of $498 \mathrm{~nm}$ and an emission wavelength of $540 \mathrm{~nm}$. Monolayers permeability was quantified as percentage of FITC-D4 permeating from the apical to the basal compartment.

\section{Immunofluorescent analysis of ZO-1, occludin and F-actin localization}

Following incubation with ethanol with or without prior SCFAs incubation, Caco-2 monolayers were fixed on the inserts for $10 \mathrm{~min}$ with $4 \%(\mathrm{w} / \mathrm{v})$ paraformaldehyde and permeabilized with $0.1 \%(\mathrm{v} / \mathrm{v})$ Triton $\mathrm{X}-100$ in PBS at room temperature (RT) for 40 min. Subsequently, mouse anti-ZO-1 (\# 33-9100), rabbit anti-occludin (\# 71-1500) (both 1:100 dilution in 3\% w/v BSA in PBS, pH 7.4; Zymed Laboratories, San Francisco, USA), and Texas Red-X phalloidin (\# T7471; 1:500 dilution in PBS, pH 7.4; Invitrogen) were used for immunofluorescent staining of ZO-1, occludin and F-actin, respectively, as described previously ${ }^{3}$.

\section{Determination of cellular F-actin contents}

The relative content of F-actin was determined by a fluorescent phalloidin-binding assay as described previously ${ }^{28}$. Briefly, Caco-2 cells grown on 96 well plates (Corning BV, Amsterdam, the Netherlands) were rinsed with PBS and then incubated with medium only as well as ethanol $(40 \mathrm{mmol} / \mathrm{l})$ in medium for $3 \mathrm{~h}$ or after prior incubation with butyrate $(2 \mathrm{mmol} / \mathrm{l})$, propionate $(4 \mathrm{mmol} / \mathrm{l})$, or acetate $(8 \mathrm{mmol} / \mathrm{l})$, respectively, for $1 \mathrm{~h}$. Next, the cells were fixed with acetone/ methanol (1:1), and then actin was stained with rhodamine-phalloidin (\# R415, Invitrogen) (1:500) diluted in PBS for $20 \mathrm{~min}$. Stained cells were extracted with $200 \mu \mathrm{l}$ methanol and measured spectrophotometrically at excitation and emission wavelengths of 545 and $578 \mathrm{~nm}$, respectively.

\section{Detection of reactive oxygen species (ROS)}

Generation of $\mathrm{H} 2 \mathrm{O} 2$ was monitored by using $2^{\prime}, 7^{\prime}$ - dichlorodihydrofluorescein diacetate (DCF-DA, Sigma-Aldrich), which is non-fluorescent unless oxidized intracellularly by reactive oxygen species (ROS). Briefly, Caco-2 cells were cultured in 96 well plates and were loaded with $100 \mu \mathrm{M}$ DCF-DA for $1 \mathrm{~h}$ at $37^{\circ} \mathrm{C}$. Then, cells were exposed to either $40 \mathrm{mmol} / \mathrm{l}$ ethanol for $3 \mathrm{~h}$ with or without prior treatment with $2 \mathrm{mmol} / \mathrm{l}$ butyrate, $4 \mathrm{mmol} / \mathrm{l}$ propionate, or $8 \mathrm{mmol} / \mathrm{l}$ acetate, respectively, for $1 \mathrm{~h}$. Medium only and $40 \mathrm{mmol} / \mathrm{I} \mathrm{H}_{2} \mathrm{O}_{2}$-treated cells were used as control conditions. Caco2 cells were then washed twice in Hank's Balanced Salt Solution buffer and the fluorescence was measured spectrophotometrically at excitation and emission wavelengths of 485 and $540 \mathrm{~nm}$, respectively. 


\section{Assessment of mitochondrial function}

Mitochondrial function was assessed using 3-(4.5-dimethylthiazol-2-yl)-2,5diphenyltetrazolium bromide (MTT; Sigma-Aldrich) that is cleaved into insoluble formazan by active mitochondrial succinate dehydrogenases in living cells ${ }^{29}$. Briefly, Caco-2 cells were cultured in 96 well-plates and exposed to either $40 \mathrm{mmol} / \mathrm{l}$ ethanol in medium for $3 \mathrm{~h}$ or after prior treatment with $2 \mathrm{mmol} / \mathrm{l}$ butyrate, $4 \mathrm{mmol} / \mathrm{l}$ propionate or $8 \mathrm{mmol} / \mathrm{l}$ acetate, respectively, for $1 \mathrm{~h}$. Medium only and $40 \mathrm{mmol} / \mathrm{l}$ $\mathrm{H}_{2} \mathrm{O}_{2}$ were used as negative and positive control, respectively. The cells were washed with PBS and incubated with $5 \mathrm{mg} / \mathrm{ml} \mathrm{MTT}$ in PBS, $200 \mu \mathrm{l}$ per well for another $3 \mathrm{~h}$ at $37^{\circ} \mathrm{C}$. Then, the solution was aspirated and the insoluble formazan product was solubilized with $0.1 \mathrm{M} \mathrm{HCl}$ in isopropanol $(100 \mu \mathrm{l}$ per well), incubated at RT for $30 \mathrm{~min}$. The optical density was measured at a wavelength of $560 \mathrm{~nm}$. Values are presented as percentage of medium only-treated cells.

\section{Luminescent ATP assay}

The amount of ATP produced by metabolically active cells was quantified based on the luciferase reaction (CellTiter-Glo ${ }^{\circledR}$ Luminescent Cell Viability Assay, Promega, the Netherlands). Briefly, Caco-2 cells were cultured in 96 well-plates and exposed to either $40 \mathrm{mmol} / \mathrm{l}$ ethanol in medium or after treatment for $3 \mathrm{~h}$ with $2 \mathrm{mmol} / \mathrm{l}$ butyrate, $4 \mathrm{mmol} / \mathrm{l}$ propionate, or $8 \mathrm{mmol} / \mathrm{l}$ acetate, respectively, for $3 \mathrm{~h}$. Then, plates were equilibrated at RT for $30 \mathrm{~min}$. Thereafter, $100 \mu$ of the assay reagent was added to each well. Medium only and $40 \mathrm{mmol} / / \mathrm{H}_{2} \mathrm{O}_{2}$ were used as negative and positive control, respectively. Plates were placed on an orbital shaker for $2 \mathrm{~min}$ to induce cell lysis, and then were incubated at RT for 10 min to stabilize the luminescent signal. The luminescence was measured spectrophotometrically. Intracellular ATP was calculated from the luminescent values and presented as percentage of the medium only-treated cells.

\section{Assessment of adenosine monophosphate-activated protein kinase (AMPK) activity}

The activity of AMPK was assessed using a cell-based ELISA assay (RayBio cell-based protein phosphorylation ELISA kit; RayBiotech, Inc. Norcross, GA, USA) according to manufacturer's instructions. Briefly, Caco-2 cells $\left(20 \times 10^{3}\right)$ were seeded in 96 wellplates and incubated overnight at $37^{\circ} \mathrm{C}$ and $5 \% \mathrm{CO}_{2}$. Then, they were exposed to medium only as control and either $40 \mathrm{mmol} / \mathrm{l}$ ethanol in medium for $3 \mathrm{~h}$ or after prior treatment with $2 \mathrm{mmol} / \mathrm{l}$ butyrate, $4 \mathrm{mmol} / \mathrm{l}$ propionate or $8 \mathrm{mmol} / \mathrm{l}$ acetate, respectively, for $1 \mathrm{~h}$. Cells exposed to $0.01 \mathrm{mmol} / \mathrm{l}$ compound C (Sigma Aldrich), and $0.5 \mathrm{mmol} / \mathrm{I}$ AICAR (Sigma Aldrich) were used as negative and positive controls, respectively. After washing with PBS, $100 \mu$ l fixative solution was added to each well and incubated for $20 \mathrm{~min}$ at RT with shaking. Then the plate was incubated with a 
quenching buffer for $20 \mathrm{~min}$ at RT. After that, a blocking solution was added and the plate was incubated for $1 \mathrm{~h}$ at $37^{\circ} \mathrm{C}$. Next, the plate was washed thrice and $50 \mu \mathrm{l}$ of either rabbit anti-AMPK- $\alpha 2$ (\# 2532L; cell Signaling, Inc)) or rabbit anti-phosphorylated AMPK- $\alpha 2$ (\# 2535L; (cell Signaling, Inc, Thr172, pAMPK- $\alpha 2$; 1:100 dilution in the blocking solution; Cell Signaling Technology, Inc, MA, USA) was added and incubated for $1 \mathrm{~h}$ at RT with shaking. Next, $50 \mu \mathrm{l}$ of HRP-conjugated mouse anti-rabbit IgG (1:100 dilution in the blocking solution; Dako Netherlands BV, Heverlee, Belgium) was added and incubated for $1 \mathrm{~h}$ at RT. After washing thrice, $100 \mu \mathrm{l} \mathrm{3,} \mathrm{3',} \mathrm{5,} \mathrm{5'-}$ tetramethylbenzidine (TMB) was added to each well and incubated for 30 min with shaking at $\mathrm{RT}$ in the dark. Finally, $50 \mu \mathrm{l}$ stop solution $\left(2 \mathrm{~N} \mathrm{H}_{2} \mathrm{SO}_{4}\right)$ was added and the optical density was read at excitation wavelength of $450 \mathrm{~nm}$.

\section{Transfection of cells with adenosine monophosphate-activated protein kinase (AMPK) small Interfering RNA (siRNA)}

Caco-2 $\left(10^{5}\right.$ cells) at about $50 \%$ confluency were transfected with specific siRNA targeting the mRNA encoding AMPK- $\alpha 2$ (Cell Signaling Technology, Inc. Danvers, USA) or control nonspecific siRNA (Santa Cruz Biotechnology, CA), using Accell siRNA reagents (Thermo Scientific Dharmacon), according to manufacturer's protocol. Briefly, $10^{2}$ cells grown on either 96 well-plate or 8 well chambers, and $10^{5}$ cells grown on transwell inserts (Costar, Cambridge, MA) were incubated in serum- and antibioticfree medium for $24 \mathrm{~h}$. Then, cells were transfected with $50 \mathrm{nmol} / \mathrm{ml}$ of either AMPK- $\alpha 2$ siRNA or control nonspecific siRNA in Accell siRNA delivery medium (Thermo Scientific Dharmacon), gently shaken, and incubated at $37^{\circ} \mathrm{C}$ for $48 \mathrm{~h}$ and replaced thereafter with Accell delivery media. Cell-based ELISA assay with rabbit antiAMPK- $\alpha 2$ (cell Signaling, Inc) was performed to monitor the efficiency of AMPK- $\alpha 2$ knockdown. In preliminary experiments, use of nonspecific siRNA resulted in no change in the cellular content of total AMPK- $\alpha 2$ or in the amount of pAMPK- $\alpha 2$ after AICAR exposure, and the transfection after $48 \mathrm{~h}$ was found to have $76 \%$ efficiency. The optimal concentration of siRNA was $50 \mathrm{pmol} / \mathrm{ml}$ as higher concentrations resulted in cell death. Finally, cells were treated with medium only, butyrate, propionate, and acetate, AICAR for $1 \mathrm{~h}$, with or without ethanol exposure for another $3 \mathrm{~h}$, followed by assessment of paracellular permeability.

\section{Statistical analysis}

Data is expressed as means \pm SD of triplicate experiments. The One-way ANOVA and when appropriate, Student's $t$ test and 2-way ANOVA were used for statistical analysis. Groups were compared by Tukey's post hoc test, considering a $P$ value $<0.05$ as statistically significant. All data analyses were conducted with a GraphPad Prism software package (GraphPad Software). Groups were compared by Tukey's post hoc test, considering a $P$ value $<0.05$ as statistically significant. All data analyses were 
conducted with a GraphPad Prism software package (GraphPad Software Incorporated, CA, USA).

\section{Results}

\section{Effects of SCFAs on the barrier function in Caco-2 cell monolayers}

Caco-2 monolayers were treated with various concentrations of SCFAs to evaluate their effects on paracellular barrier function. Incubation with $2 \mathrm{mmol} / \mathrm{l}$ butyrate, $4 \mathrm{mmol} / \mathrm{l}$ propionate, or $8 \mathrm{mmol} / \mathrm{l}$ acetate led to a significant increase in TEER, and decrease in FITC-D4 permeation in Caco- 2 monolayers (compared to controls, $P<0.05$; Figure 9.1A and 9.1B). No significant differences were found for the other concentrations, apart from $80 \mathrm{mmol} / \mathrm{l}$ acetate, which significantly decreased TEER and increased FITC-D4 permeation ( $P<0.05$, Figure $9.1 \mathrm{~A}$ and $9.1 \mathrm{~B})$. The $\mathrm{pH}$ of each SCFA at the indicated concentrations measured by using a $\mathrm{pH}$ meter had no effect on Caco-2 monolayers permeability, apart from $80 \mathrm{mmol} / \mathrm{l}$ acetate ( $\mathrm{pH} 8.47$, data not shown). Subsequent experiments were carried out using butyrate, propionate and acetate at concentration of $2 \mathrm{mmol} / \mathrm{l}, 4 \mathrm{mmol} / \mathrm{l}$ and $8 \mathrm{mmol} / \mathrm{l}$, respectively.

A

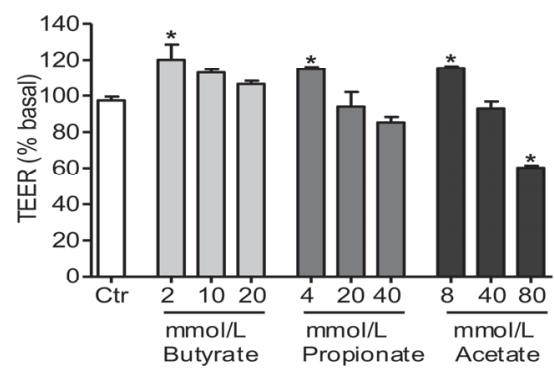

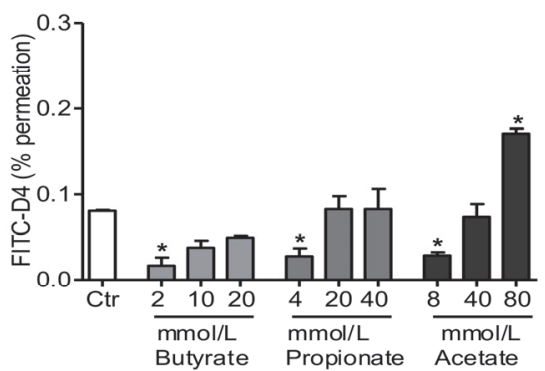

Figure 9.1 Effects of butyrate, propionate and acetate on b - - - - - ? cell monolayers. [A] Percentage of basal transepithelial electrical $r \quad$ srcentage of FITC-D4 permeation. Values are means $\pm \mathrm{SDs}, \mathrm{n}=9$. Asterisk $(*)$ indicates the values that are significantly different $(P<0.05)$ from the control $(C t r)$.

\section{Adenosine monophosphate-activated protein kinase (AMPK) activation is involved in the SCFAs' regulation of the barrier function}

To study the involvement of AMPK, we examined the phosphorylation status of AMPK- $\alpha 2$ after stimulation with SCFAs. As shown in Figure 9.2A, the ratio of phosphorylated to total AMPK- $\alpha 2$ (PAMPK/total) increased significantly after treatment with butyrate, propionate, acetate or AICAR (different from control, $P<0.05)$. Pretreatment with $0.01 \mathrm{mmol} / \mathrm{l}$ Cc significantly decreased PAMPK- $\alpha 2$ /total 
ratios (different from treatment with butyrate, propionate, acetate or AICAR, $P<0.05$; Figure 9.2A). Incubation with $2 \mathrm{mmol} / \mathrm{l}$ butyrate, $4 \mathrm{mmol} / /$ propionate, or $8 \mathrm{mmol} / \mathrm{I}$ acetate as well as with AICAR also led to a significant increase in TEER (different from control, $P<0.05$; Figure 9.2B) and a significant decrease in FITC-D4 permeation (different from control, $P<0.05$; Figure 9.2C). These effects on TEER and FITC-D4 permeation were significantly abolished by pretreatment with Cc (different from treatment with butyrate, propionate, acetate or AICAR, $P<0.05$; Figure 9.2B and Figure $9.2 \mathrm{C})$, respectively.

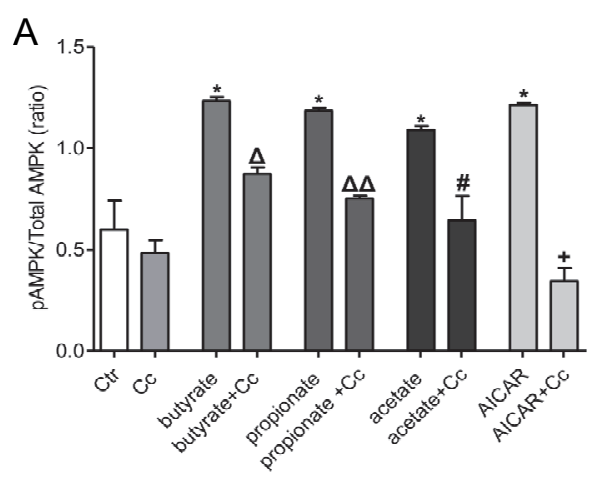

B

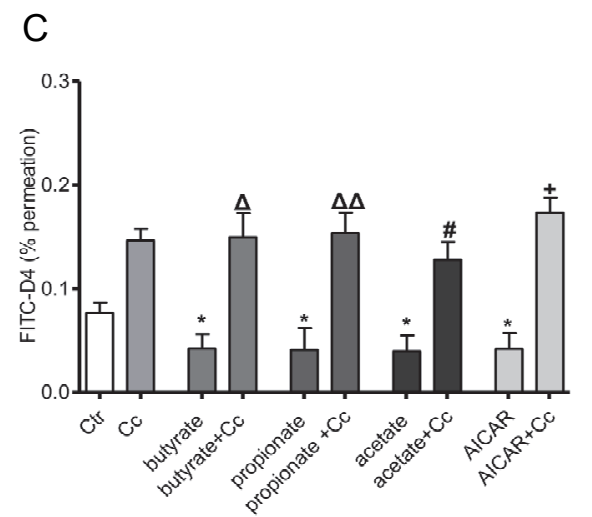

Figure 9.2 Effects of butyrate, propionate, acetate and $(0.5 \mathrm{mmol} / \mathrm{l})$ AICAR on AMPK activity and barrier function in Caco-2 cell monolayers with or without pretreatment with $(0.01 \mathrm{mmol} / \mathrm{l})$ compound C (Cc). [A] AMPK activity expressed as ratio of phosphorylated (PAMPK) to total protein (total AMPK). [B] Percentage of transepithelial electrical resistance (TEER). [C] Percentage of FITC-D4 permeation. Values are means \pm SDs, $n=3$. Asterisks $(*)$ indicate the values that are significantly different $(P<0.05)$ from the control (Ctr). The symbols, $(\Delta),(\Delta \Delta)$, (\#) and + , indicate the values that are significantly different $(P<0.05)$ from butyrate, propionate, acetate, and AICAR, respectively. 


\section{Effect of SCFAs on ethanol-induced changes in permeability}

To establish whether SCFAs have potential to prevent ethanol-induced disruption of epithelial barrier function, the effects of butyrate, propionate and acetate on increase of intestinal epithelial TJ permeability induced by ethanol were investigated. Exposure to $40 \mathrm{mmol} / \mathrm{l}$ ethanol for $3 \mathrm{~h}$ significantly decreased TEER and increased FITC-D4 permeation of Caco-2 monolayers compared to medium-treated controls $(P<0.05$, Figure 9.3A and 9.3B). Pretreatment with $2 \mathrm{mmol} / \mathrm{l}$ butyrate, $4 \mathrm{mmol} / \mathrm{l}$ propionate, or $8 \mathrm{mmol} / \mathrm{l}$ acetate for $1 \mathrm{~h}$, significantly prevented this drop in TEER and significantly decreased FITC-D4 permeation (different from treatment with ethanol, $P<0.05$; Figure 9.3A and 9.3B).

\section{Effect of SCFAs on ethanol-induced changes in TJs proteins}

In the absence of any treatment, microscopic analysis of immunofluorescently-labeled ZO-1 and occludin showed that the distribution of ZO-1 was localized mainly in cell boundaries and was tightly arranged with sharp, continuous smooth edges, and showing a typical 'chicken wire' shape without abnormalities (Figure 9.3C). Similarly, occludin was sharply localized around cell borders co-localizing with ZO-1 (Figure 9.3C). Exposure to $40 \mathrm{mmol} / \mathrm{l}$ ethanol disrupted both ZO-1 and occludin networks, resulted in loss of co-localization and apparent gap formation between the cells (Figure 9.3C, arrowheads). Pretreatment with butyrate, propionate, or acetate attenuated the changes induced by ethanol exposure (Figure 9.3C).

\section{Effects of SCFAs on ethanol-induced changes in F-actin organization and content}

Since TJ disassembly can be induced by remodeling of perijunctional actin filaments, we next investigated whether the SCFAs can prevent changes in actin cytoskeleton junctions in ethanol-treated intestinal epithelial cells. Figure 9.3D shows that under control condition, apical F-actin microfilaments were assembled into a prominent perijunctional F-actin belt that encircled cell borders. Compared to controls, after ethanol exposure, the apical F-actin microfilaments were markedly disorganized, in which the perijunctional actin belt was transformed into an array of disordered filaments and stress fiber-like bundles (Figure 9.3D, arrowheads). Such effects were attenuated by pretreatment with the SCFAs (Figure 9.3D). In addition, exposure to ethanol as well as to the positive control $\mathrm{H}_{2} \mathrm{O}_{2}$ resulted in a significant increase in the intracellular F-actin content (different from control, $P<0.05$; Figure 9.3E). Pretreatment with SCFAs significantly reduced F-actin protein levels (different from treatment with ethanol, $P<0.05$; Figure 9.3E). 
A

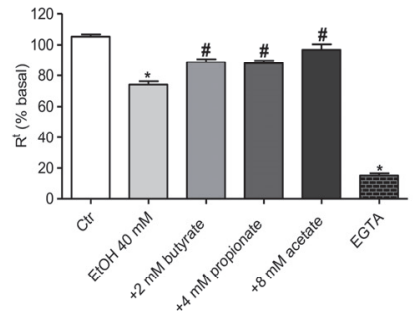

$\mathrm{B}$

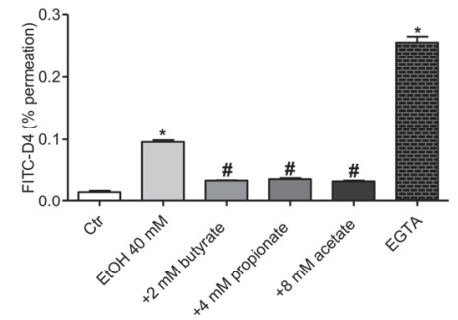

$\mathrm{EtOH}$
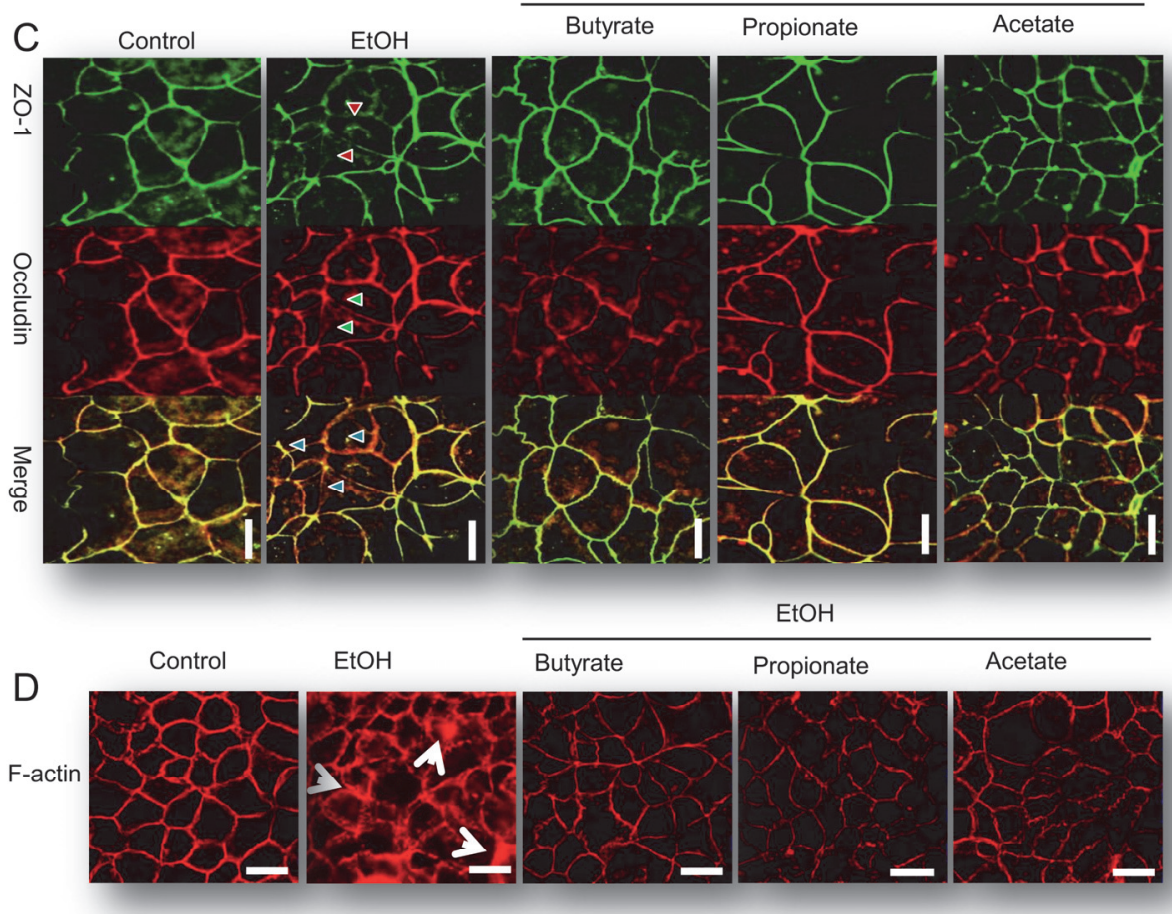

$E$

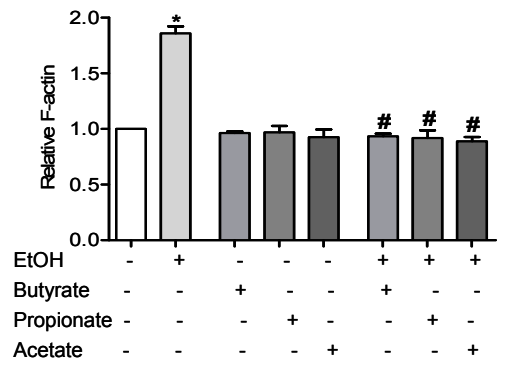

Figure 9.3 Effects of butyrate, propionate and acetate on ethanol-induced loss of tight junction integrity in Caco-2 monolayers. Ethylene glycol tetraacetic acid (EGTA) was added as a control to destroy the tight junctions and to induce maximal reduction in TEER and FITC-D4 permeation. [A] Percentage of basal transepithelial electrical resistance (TEER). [B] Percentage of FITC-D4 permeation. Values are means $\pm \mathrm{SDs}, \mathrm{n}=9$. Asterisks $(*)$ indicate the values that are 
significantly different $(P<0.05)$ from the control $(C t r)$. The symbol $(\#)$ indicates the values that are significantly different $(P<0.05)$ from ethanol. [C] Representative images of immunostaining of ZO-1 (green) and occludin (red) as reproduced in three independent experiments, discontinuous staining and absence of ZO-1 and occludin colocalization, and gap formation are indicated by arrowheads in monolayers treated with ethanol. Scale bar, $10 \mu \mathrm{m}$. [D] Distribution of F-actin in Caco-2 monolayers after staining with phalloidin rhodamine dye (red) as reproduced in three independent experiments, condensation of F-actin and stress fiber-like bundles formation are indicated by arrowheads in monolayers treated with ethanol. Scale bar, $10 \mu \mathrm{m}$. [E] F-actin contents in Caco-2 monolayers. Data bars represent the means \pm SDs, $\mathrm{n}=3$. Asterisks $(*)$ indicate the values that are significantly different $(P<0.05)$ from the control. The symbol $(\#)$ indicates the values that are significantly different $(P<0.05)$ from ethanol.

\section{Effects of SCFAs on ethanol-induced cell metabolic stress}

To evaluate the protective effects of SCFAs against ethanol-induced cellular metabolic stress, ROS production, mitochondrial function, and intracellular ATP levels were assessed. Exposure to $40 \mathrm{mmol} / \mathrm{l}$ ethanol or to the positive control $\mathrm{H}_{2} \mathrm{O}$, significantly increased intracellular ROS generation and decreased mitochondrial function and ATP levels (different from negative control, $P<0.05$; Figure 9.4A, 9.4B and 9.4C). However, pretreatment of Caco-2 monolayers with $2 \mathrm{mmol} / \mathrm{l}$ butyrate, $4 \mathrm{mmol} / /$ propionate, or $8 \mathrm{mmol} / \mathrm{l}$ acetate significantly prevented this ethanol-induced metabolic stress (different from treatment with ethanol, $P<0.05$; Figure 9.4A, 9.4B and 9.4C).

\section{Effects of adenosine monophosphate-activated protein kinase (AMPK) inhibition on SCFAs-promoting effects on barrier function}

To determine whether AMPK is involved in promotion of barrier function by SCFAs in ethanol-treated monolayers, the effects of the SCFAs on ethanol-induced TEER decrease and FD4 permeation in Caco- 2 cell monolayers were compared with ethanol in medium, in absence or presence of $0.01 \mathrm{mmol} / \mathrm{l} \mathrm{Cc}$. Incubation with $40 \mathrm{mmol} / \mathrm{l}$ ethanol for $3 \mathrm{~h}$ led to significant decrease in TEER and to an increase in FITC-D4 permeation (different from control, $P<0.05$, Figure 9.5A and Figure 9.5B, respectively). Pretreatment with $2 \mathrm{mmol} / \mathrm{l}$ butyrate, $4 \mathrm{mmol} / \mathrm{l}$ propionate, or $8 \mathrm{mmol} / \mathrm{l}$ acetate for 1 $\mathrm{h}$ significantly increased TEER values and decreased FITC-D4 permeation (different from ethanol, $P<0.05$; Figure $9.5 \mathrm{~A}$ and $9.5 \mathrm{~B}$, respectively). These observations were significantly abolished by treatment with $\mathrm{Cc}$ (different from exposure to ethanol after pretreatment with SCFAs, $P<0.05$, Figure 9.5A and 9.5B, respectively). 

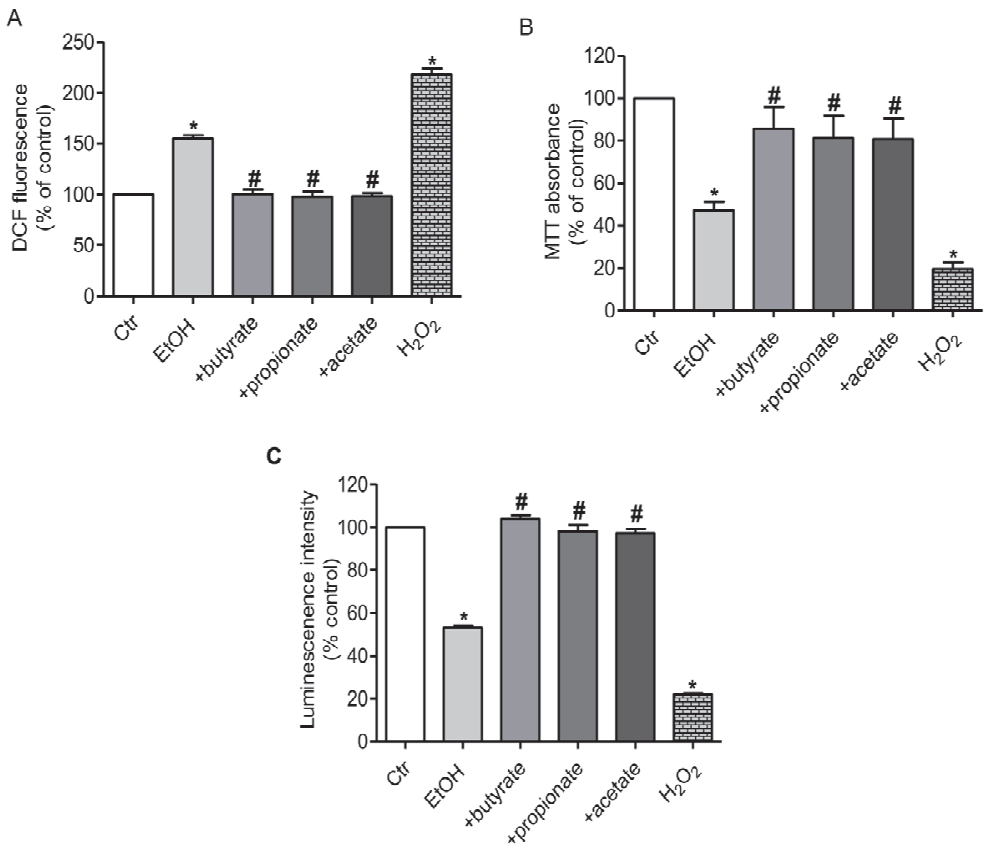

Figure 9.4 Effect of SCFAs on ethanol-induced cellular metabolic stress in Caco-2 monolayers incubated with butyrate, propionate and acetate for $1 \mathrm{~h}$ followed by ethanol for $3 \mathrm{~h}$. [A] Intracellular reactive oxygen species (ROS) generation expressed as percentage of medium only-treated control (Ctr). [B] Mitochondrial function and [C] intracellular ATP levels. Values are presented as means \pm SDs of three independent experiments. Asterisks $(*)$ indicate the values that are significantly different $(P<0.05)$ from the control $(C t r)$. The symbol $(\#)$ indicates the values that are significantly different $(P<0.05)$ from $40 \mathrm{mmol} / \mathrm{l}$ ethanol.
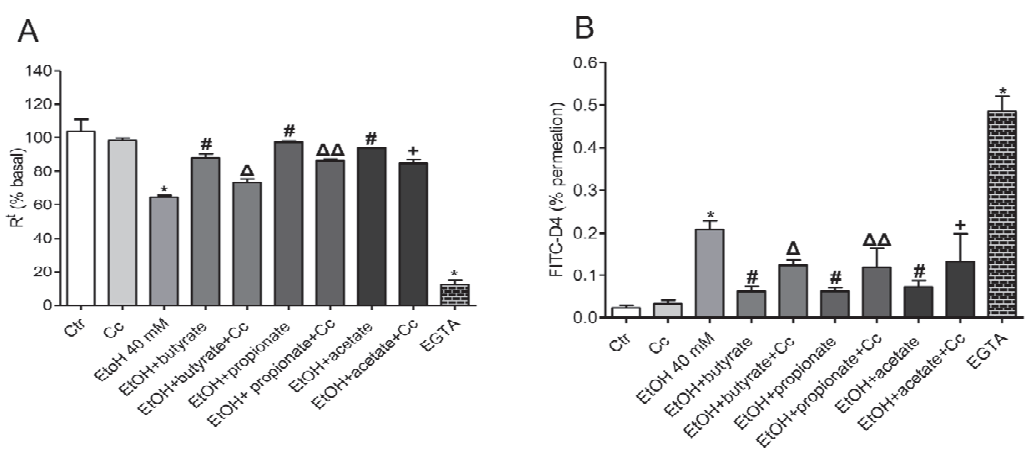

Figure 9.5 Effects of (AMPK) inhibition by compound C (Cc) on SCFAs-promoted effects on barrier function in Caco-2 monolayers treated with $0.01 \mathrm{mmol} / \mathrm{l}$ of $\mathrm{Cc}$ in the presence or absence of ethanol for $3 \mathrm{~h}$. [A] Effects of butyrate, propionate, or acetate on ethanol-induced decrease in TEER and [B] Increase in FITC-D4 permeation were evaluated. Values are presented as means \pm SDs, $n=6$. Asterisks $(*)$ indicate the values that are significantly different $(P<0.05)$ from the control (Ctr). The symbol (\#) indicates the values that are significantly different $(P<0.05)$ from ethanol. The symbols, $(\Delta),(\Delta \Delta)$, and $(+)$, indicate the values that are significantly different $(P<0.05)$ from ethanol after pretreatment with butyrate, propionate and acetate, respectively. 

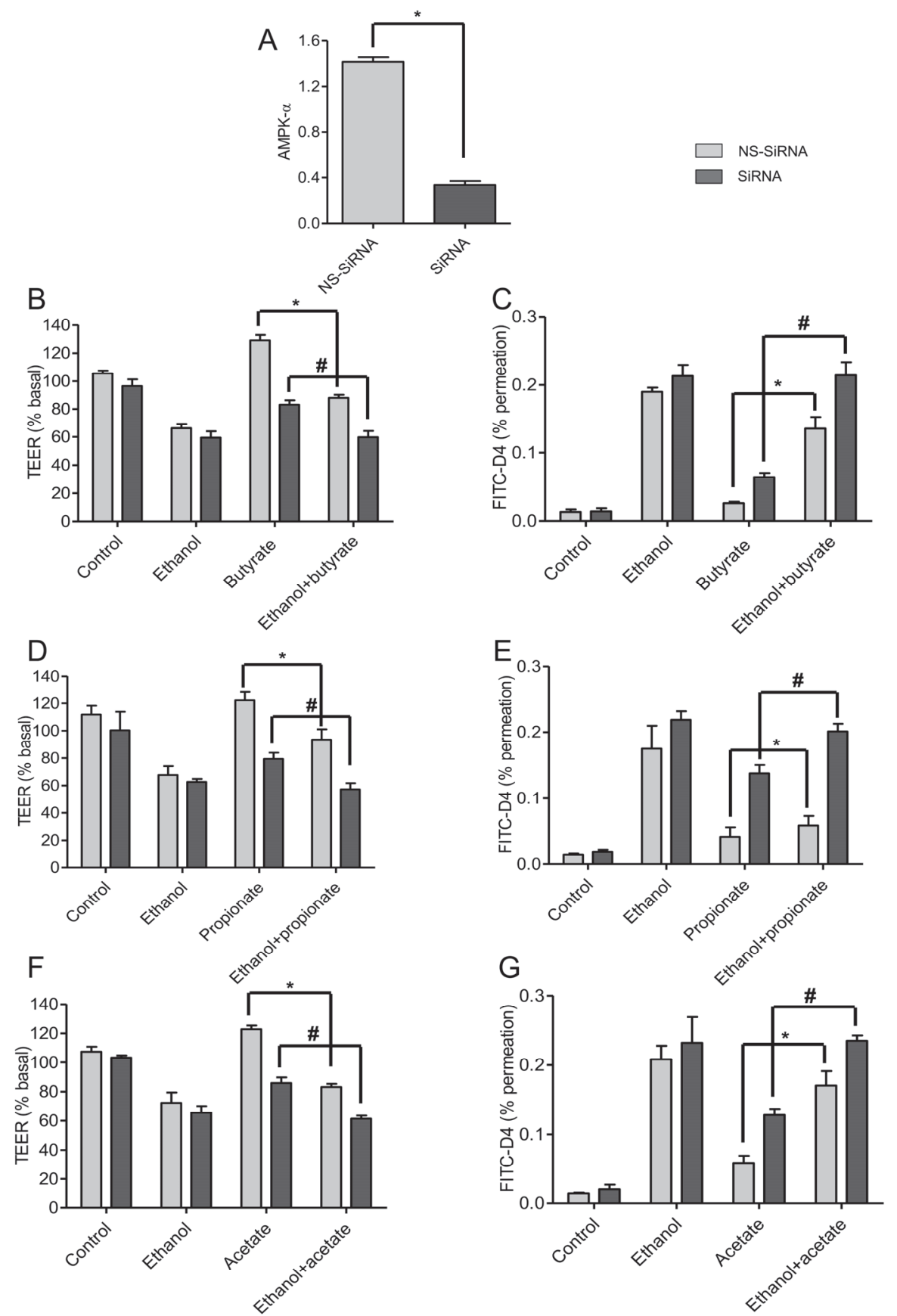

Figure 9.6 Effects of AMPK- $\alpha 2$ knockdown on SCFAs-promoted effects on barrier function in ethanoltreated monolayers after transfection of AMPK- $\alpha 2$ with either specific siRNA or nonspecific RNA (NS-RNA). [A] AMPK protein levels, values are means \pm SD $(n=3) . * P<0.01$ is significantly 
different from the value for NS-RNA. [B] Percentage of basal transepithelial electrical resistance (TEER) measured after treatment with ethanol in medium with or without pretreatment with butyrate, [C] propionate and [D] acetate, values are means $\pm S D(n=3)$. ${ }^{*} P<0.05$ vs. corresponding ethanol-exposed monolayers and ${ }^{\#} P<0.01$ vs. corresponding NS-RNA. [E] Percentage of FITC-D4 permeation measured after $3 \mathrm{~h}$ of exposure to ethanol in medium with or without pretreatment with butyrate, $[\mathbf{F}]$ propionate and $[\mathbf{G}]$ acetate, values are means \pm SD $(n=3)$. ${ }^{*} P<0.05$ vs. ethanol-exposed monolayers and ${ }^{\#} P<0.05$ vs. corresponding NS-RNA.

In order to complement the above observations, AMPK was knocked down by transfecting cells with specific siRNA targeting AMPK- $\alpha 2$. AMPK- $\alpha 2$ protein level was significantly reduced $(76 \%)$ by specific siRNA transfection $(P<0.01$; Figure $9.6 \mathrm{~A})$. Compared to monolayers transfected with nonspecific siRNA, knock down of AMPK$\alpha 2$ with specific siRNA significantly abolished the ability of butyrate, propionate and acetate (all $P<0.01$ ) to mitigate the ethanol-induced TEER decrease (Figure 9.6B, 9.6C and 9.6D, respectively). Furthermore, siRNA specific for AMPK- $\alpha 2$, but not control siRNA, also significantly dampened the ability of butyrate, propionate and acetate (all $P<0.01$ ) to alleviate the ethanol-induced FITC-D4 permeation (Figure 9.6E, 9.6F and $9.6 \mathrm{G}$, respectively).

\section{Discussion}

The present study demonstrates that butyrate, propionate and acetate attenuate ethanol-induced intestinal epithelial TJ barrier dysfunction in Caco-2 monolayers. SCFAs did also partially prevent the displacement of TJ proteins and stress fiber formation as well as the ethanol-induced cellular oxidative and metabolic stress. We found that this beneficial effect of SCFAs was mediated by the activation of AMPK pathway.

In the current study, we found that incubation of intestinal Caco-2 cells with $40 \mathrm{mmol} / \mathrm{l}$ ethanol increased monolayers permeability, altered morphologic appearance of the TJ and increased F-actin protein expression. The concentration of ethanol used in our study is not cytotoxic as shown previously that ethanol at concentration of $0.2 \% \mathrm{v} / \mathrm{v}(\sim 40 \mathrm{mmol} / \mathrm{l})$, which can be achieved in blood after moderate (2-4 drinks; 1 standard drink $\sim 14$ g ethanol) consumption ${ }^{30,31}$, can disrupt epithelial TJ integrity in a Caco-2 three dimensional cell culture model without compromising cell viability ${ }^{3}$. Our findings are also with prior observations from others showing that ethanol can disrupt the TJs integrity resulting in increased paracellular permeability $^{30,32-34}$

Cellular metabolic stress including increase in oxidative stress and decrease in ATP production is suggested to be involved in loss of TJ integrity ${ }^{35}$. Here, we present 
evidence that ethanol not only disrupts paracellular permeability, but also induces increase in ROS generation, mitochondrial dysfunction and a decrease in intracellular ATP levels. Our data are in line with numerous studies documenting that ROS and nitrogen oxygen species generation can induce oxidation and nitration of cytoskeletal proteins, respectively, with subsequent increase in intestinal permeability ${ }^{2,36-38}$. Although not tested in this study, the potential mechanisms of ethanol-induced ROS generation are most likely to involve a number of ROS-related pathways. Previously, it has been demonstrated that activation of intestinal inducible nitric oxide synthase (iNOS) $^{2}$, cytochrome-P450 2E1 (CYP2E1) ${ }^{31}$ and xanthine oxidase ${ }^{39}$ mediate ethanolinduced ROS production and consequently, barrier dysfunction. In the current investigation, we demonstrated that SCFAs protected intestinal monolayers against ethanol and restored normal barrier function. Our data support observations in vitro and in animals that SCFAs can enhance intestinal barrier function ${ }^{22,24,40}$. The SCFA concentrations used in the present study were based on those found in the intestinal lumen after dietary fiber supplementation ${ }^{41}$, and taking into account the relative molar ratios ${ }^{14}$. Furthermore, Suzuki et al. have shown that butyrate, propionate and acetate at concentrations similar to those we used are able to promote epithelial barrier function in rat large intestine ${ }^{22}$. Interestingly, in our study, treatment with $80 \mathrm{mmol} / \mathrm{l}$ acetate $(\mathrm{pH}$ 8.47) significantly increased permeability via mechanisms independent of the $\mathrm{pH}$, indicating its potential cytotoxicity. Previously, exposure to acetate $>12.5 \mathrm{mmol} / \mathrm{l}$ for $72 \mathrm{~h}$ was shown to compromise human gastric epithelial cell viability ${ }^{42}$. The discrepancy with our data from $40 \mathrm{mmol} / \mathrm{l}$ acetate can be explained by differences in cell type and duration of exposure. Since osmolality can also be involved in effects of 40 and $80 \mathrm{mmol} / \mathrm{l}$ acetate, only the $8 \mathrm{mmol} / \mathrm{l}$ concentration was used in further analyses.

The ethanol-induced abnormal localization of TJs, disorganization and increase in F-actin protein levels, could partially be prevented by SCFAs, suggesting that the facilitating effects of the SCFAs on barrier function may involve reorganization of F-actin, and indirectly, assembly of the TJs. These findings are akin to previous data demonstrating that butyrate can attenuate deoxycholic acid-induced actin cytoskeleton remodeling and actin stress in colonic epithelial cells ${ }^{43}$. Furthermore, SCFAs have been reported to enhance intestinal barrier by stabilizing TJs integrity ${ }^{24}$. We speculate that the attenuating effects of SCFAs on ethanol-induced barrier dysfunction in Caco-2 monolayers might be due to SCFAs-facilitated F-actin ring reorganization and a decrease of stress fiber formation.

Using comparable concentrations to those used in our study, it has been reported that butyrate (C4:0) as well as propionate (C3:0), and acetate (C2:0) can enhance TEER in Caco-2 monolayers ${ }^{22,44}$. However, the effects propionate and acetate on barrier function were observed with higher concentrations when compared to butyrate, indicating that chain length may determine bioactivity of the SCFAs. Increasing carbon chain length has also been shown to influence the potential effects of SCFAs with 
regard to e.g. inflammation, carcinogenesis and barrier function ${ }^{45}$. This may partially be related to the ability of SCFAs to cross cell membranes because of the reduced lipid solubility with decreasing chain length ${ }^{46}$.

In this study, ethanol induced oxidative stress in Caco-2 cells, and SCFAs were able to inhibit ethanol-induced ROS generation. These findings are in line with previously reported data on the antioxidant potential of SCFAs ${ }^{17}$. Increased ROS production and consequently impaired mitochondrial function may cause ATP depletion, a factor that can further contribute to barrier dysfunction ${ }^{35,47}$. We also demonstrated that SCFAs can attenuate and prevent ethanol-induced mitochondrial dysfunction and ATP depletion, indicating the potential capacity of SCFAs to protect the intestinal epithelial cells from ethanol-mediated cell metabolic stress. In line with these findings, butyrate has previously been shown to increase ATP stores in Caco- 2 cells ${ }^{48}$. Particularly intriguing are the recent observations in a rat model of ALD, showing that oats supplementation attenuates ethanol-induced intestinal hyperpermeability and alcoholic steatohepatitis $^{49}$ via anti-oxidant mechanisms. These observations raise the possibility that SCFAs, as produced from fibers as in oats, could protect the intestinal epithelium against ethanol-induced gut leakiness, endotoxemia, and subsequent liver injury in humans.

Since SCFAs constitute a major energy source in the colon and ethanol can interfere with ATP production ${ }^{50}$, the role of AMPK activation in effects of SCFAs on ethanolinduced barrier dysfunction has been explored. This serine/ threonine protein kinase is activated upon cellular stress resulting in elevation of intracellular ATP ${ }^{51}$. In addition, AMPK has been shown to modulate the TJs integrity in MDCK cell monolayers ${ }^{52,53}$. Our data revealed that the SCFAs can induce AMPK activation (phosphorylation) in a magnitude comparable to the effects of AICAR, which has previously been found to promote epithelial barrier function through AMPK activation $^{52}$. Pretreatment with CC inhibited the SCFAs-induced AMPK activation, and abolished the ability of the SCFAs to improve the barrier function, indicating involvement of AMPK. Furthermore, using siRNA targeting AMPK under the same conditions supported the role of AMPK as a regulatory protein of intestinal barrier protection by SCFAs. Our data confirm previous reports demonstrating that AMPK activity is required for butyrate-facilitated TJs assembly ${ }^{24}$, and provides new evidence that AMPK activation is also required for the promoting effects of propionate and acetate on barrier function. Since the inhibitory effect of knock down of AMPK on barrier function was partial, alternative mechanisms underlying the SCFA promotive effects have to be considered.

Caco-2 cell monolayer model is widely used to assess effects of ethanol and its metabolites such as acetaldehyde on intestinal permeability ${ }^{2,32,34-56}$, but has some limitations. For instance, other cells involved in intestinal epithelium homeostasis including goblet and immune cells were not taken into account. Therefore, further in 
vitro experiments using co-culture models and in vivo interventional studies, with e.g. fermentable fibers, should evaluate the effects of SCFAs, separately or in combination, on ethanol as well as its other metabolites including acetaldehyde on intestinal epithelial barrier function. In addition, using intestinal cells in a co-culture model will be a useful tool to examine effects of SCFAs on acetaldehyde-induced carcinogenesis. In summary, the present study provides evidence that SCFAs can attenuate ethanolinduced intestinal barrier dysfunction and metabolic stress with possible underlying mechanisms including facilitation of the TJ assembly and F-actin cortical ring rearrangement. Furthermore, the positive effects of SCFAs on barrier function seem to involve, at least in part, AMPK activation. Since increased intestinal permeability can be associated with inflammatory bowel disease and ALD, elucidation of the exact mechanisms underlying these beneficial effects may form a basis for the design of therapeutic or preventive in vivo strategies, enabling SCFAs as potential nutrients to treat and/or prevent ethanol-induced intestinal barrier dysfunction. 


\section{References}

1. Bujanda L. The effects of alcohol consumption upon the gastrointestinal tract. Am J Gastroenterol 2000;95:3374-82.

2. Banan A, Choudhary S, Zhang $Y$, et al. Ethanol-induced barrier dysfunction and its prevention by growth factors in human intestinal monolayers: evidence for oxidative and cytoskeletal mechanisms. J Pharmacol Exp Ther 1999;291:1075-85.

3. Elamin E, Jonkers D, Juuti-Uusitalo K, et al. Effects of ethanol and acetaldehyde on tight junction integrity: in vitro study in a three dimensional intestinal epithelial cell culture model. PLoS One 2012; 7:e35008.

4. Keshavarzian A, Fields JZ, Vaeth J, et al. The differing effects of acute and chronic alcohol on gastric and intestinal permeability. Am J Gastroenterol 1994;89:2205-11.

5. Bjarnason I, Peters TJ, Wise RJ. The leaky gut of alcoholism: possible route of entry for toxic compounds. Lancet 1984;1:179-82.

6. Parlesak A, Schafer C, Schutz T, et al. Increased intestinal permeability to macromolecules and endotoxemia in patients with chronic alcohol abuse in different stages of alcohol-induced liver disease. J Hepatol 2000;32:742-7.

7. Bode C, Kugler V, Bode JC. Endotoxemia in patients with alcoholic and non-alcoholic cirrhosis and in subjects with no evidence of chronic liver disease following acute alcohol excess. J Hepatol 1987;4: 8-14.

8. Keshavarzian A, Holmes EW, Patel M, et al. Leaky gut in alcoholic cirrhosis: a possible mechanism for alcohol-induced liver damage. Am J Gastroenterol 1999;94:200-7.

9. Rao RK, Seth A, Sheth P. Recent Advances in Alcoholic Liver Disease I. Role of intestinal permeability and endotoxemia in alcoholic liver disease. Am J Physiol Gastrointest Liver Physiol 2004;286:G881-4.

10. Poschl G, Seitz HK. Alcohol and cancer. Alcohol Alcohol 2004;39:155-65.

11. Hamer HM, Jonkers $D$, Venema $K$, et al. Review article: the role of butyrate on colonic function. Aliment Pharmacol Ther 2008;27:104-19.

12. Cook SI, Sellin JH. Review article: short chain fatty acids in health and disease. Aliment Pharmacol Ther 1998;12:499-507.

13. Hill MJ. Bacterial fermentation of complex carbohydrate in the human colon. Eur J Cancer Prev 1995;4:353-8.

14. D'Argenio G, Mazzacca G. Short-chain fatty acid in the human colon. Relation to inflammatory bowel diseases and colon cancer. Adv Exp Med Biol 1999;472:149-58.

15. Meijer K, de Vos P, Priebe MG. Butyrate and other short-chain fatty acids as modulators of immunity: what relevance for health? Curr Opin Clin Nutr Metab Care 2010;13:715-21.

16. Huang N, Wu GD. Short chain fatty acids inhibit the expression of the neutrophil chemoattractant, interleukin 8, in the Caco-2 intestinal cell line. Adv Exp Med Biol 1997;427:145-53.

17. Hamer HM, Jonkers DM, Bast A, et al. Butyrate modulates oxidative stress in the colonic mucosa of healthy humans. Clin Nutr 2009;28:88-93.

18. Hijova E, Chmelarova A. Short chain fatty acids and colonic health. Bratisl Lek Listy 2007;108:354-8.

19. Clausen MR, Bonnen H, Mortensen PB. Colonic fermentation of dietary fibre to short chain fatty acids in patients with adenomatous polyps and colonic cancer. Gut 1991;32:923-8.

20. Van Deun K, Pasmans F, Van Immerseel F, et al. Butyrate protects Caco-2 cells from Campylobacter jejuni invasion and translocation. Br J Nutr 2008;100:480-4.

21. Peng L, He Z, Chen W, et al. Effects of butyrate on intestinal barrier function in a Caco-2 cell monolayer model of intestinal barrier. Pediatr Res 2007;61:37-41.

22. Suzuki T, Yoshida S, Hara H. Physiological concentrations of short-chain fatty acids immediately suppress colonic epithelial permeability. Br J Nutr 2008;100:297-305.

23. Mariadason JM, Catto-Smith A, Gibson PR. Modulation of distal colonic epithelial barrier function by dietary fibre in normal rats. Gut 1999;44:394-9.

24. Peng L, Li ZR, Green RS, et al. Butyrate enhances the intestinal barrier by facilitating tight junction assembly via activation of AMP-activated protein kinase in Caco-2 cell monolayers. J Nutr 2009;139: 1619-25. 
25. Corton JM, Gillespie JG, Hardie DG. Role of the AMP-activated protein kinase in the cellular stress response. Curr Biol 1994;4:315-24.

26. Manzo-Avalos S, Saavedra-Molina A. Cellular and mitochondrial effects of alcohol consumption. Int J Environ Res Public Health 2010;7:4281-304.

27. Corton JM, Gillespie JG, Hawley SA, et al. 5-aminoimidazole-4-carboxamide ribonucleoside. A specific method for activating AMP-activated protein kinase in intact cells? Eur J Biochem 1995;229:558-65.

28. Tao N, Sussman S, Nieto J, et al. Demographic characteristics of hospitalized patients with alcoholic liver disease and pancreatitis in los angeles county. Alcohol Clin Exp Res 2003;27:1798-804.

29. Uc A, Stokes JB, Britigan BE. Heme transport exhibits polarity in Caco-2 cells: evidence for an active and membrane protein-mediated process. Am J Physiol Gastrointest Liver Physiol 2004;287:G1150-7.

30. Swanson G, Forsyth $C B$, Tang $Y$, et al. Role of intestinal circadian genes in alcohol-induced gut leakiness. Alcohol Clin Exp Res 2011;35:1305-14.

31. McCarroll JA, Phillips PA, Park S, et al. Pancreatic stellate cell activation by ethanol and acetaldehyde: is it mediated by the mitogen-activated protein kinase signaling pathway? Pancreas 2003;27:150-60

32. Forsyth $C B$, Tang $Y$, Shaikh $M$, et al. Alcohol stimulates activation of Snail, epidermal growth factor receptor signaling, and biomarkers of epithelial-mesenchymal transition in colon and breast cancer cells. Alcohol Clin Exp Res 2010;34:19-31.

33. Banan A, Smith GS, Rieckenberg CL, et al. Protection against ethanol injury by prostaglandin in a human intestinal cell line: role of microtubules. Am J Physiol 1998;274:G111-21.

34. Zhong W, Zhao Y, McClain CJ, et al. Inactivation of hepatocyte nuclear factor-4\{alpha\} mediates alcohol-induced downregulation of intestinal tight junction proteins. Am J Physiol Gastrointest Liver Physiol 2010;299:G643-51.

35. Lewis K, McKay DM. Metabolic stress evokes decreases in epithelial barrier function. Ann N Y Acad Sci 2009;1165:327-37.

36. Forsyth $\mathrm{CB}$, Farhadi A, Jakate $\mathrm{SM}$, et al. Lactobacillus $\mathrm{GG}$ treatment ameliorates alcohol-induced intestinal oxidative stress, gut leakiness, and liver injury in a rat model of alcoholic steatohepatitis. Alcohol 2009;43:163-72.

37. Keshavarzian A, Farhadi A, Forsyth $C B$, et al. Evidence that chronic alcohol exposure promotes intestinal oxidative stress, intestinal hyperpermeability and endotoxemia prior to development of alcoholic steatohepatitis in rats. J Hepatol 2009;50:538-547.

38. Zhong $\mathrm{W}, \mathrm{McClain} \mathrm{CJ}$, Cave $\mathrm{M}$, et al. The role of zinc deficiency in alcohol-induced intestinal barrier dysfunction. Am J Physiol Gastrointest Liver Physiol 2010;298:G625-33.

39. Lieber CS. Ethanol metabolism, cirrhosis and alcoholism. Clin Chim Acta 1997;257:59-84.

40. Wang HB, Wang PY, Wang $X$, et al. Butyrate enhances intestinal epithelial barrier function via upregulation of tight junction protein Claudin-1 transcription. Dig Dis Sci 2012;57:3126-35.

41. Topping DL, Clifton PM. Short-chain fatty acids and human colonic function: roles of resistant starch and nonstarch polysaccharides. Physiol Rev 2001;81:1031-64.

42. Sun J, Bi L, Chi Y, et al. Effect of sodium acetate on cell proliferation and induction of proinflammatory cytokines: a preliminary evaluation. Food Chem Toxicol 2005;43:1773-80.

43. Looby E, Long A, Kelleher D, et al. Bile acid deoxycholate induces differential subcellular localisation of the PKC isoenzymes beta 1 , epsilon and delta in colonic epithelial cells in a sodium butyrate insensitive manner. Int J Cancer 2005;114:887-95.

44. Mariadason JM, Barkla DH, Gibson PR. Effect of short-chain fatty acids on paracellular permeability in Caco-2 intestinal epithelium model. Am J Physiol 1997;272:G705-12.

45. Fauser JK, Prisciandaro LD, Cummins AG, et al. Fatty acids as potential adjunctive colorectal chemotherapeutic agents. Cancer Biol Ther 2011;11:724-31.

46. DeSoignie R, Sellin JH. Propionate-initiated changes in intracellular $\mathrm{pH}$ in rabbit colonocytes. Gastroenterology 1994;107:347-56

47. Unno N, Menconi MJ, Salzman AL, et al. Hyperpermeability and ATP depletion induced by chronic hypoxia or glycolytic inhibition in Caco-2BBe monolayers. Am J Physiol 1996;270:G1010-21.

48. Wang A, Si H, Liu D, et al. Butyrate activates the cAMP-protein kinase A-cAMP response elementbinding protein signaling pathway in Caco-2 cells. J Nutr 2012;142:1-6

49. Tang $Y$, Forsyth $C B$, Banan A, et al. Oats supplementation prevents alcohol-induced gut leakiness in rats by preventing alcohol-induced oxidative tissue damage. J Pharmacol Exp Ther 2009;329:952-8. 
50. Cunningham CC, Van Horn CG. Energy availability and alcohol-related liver pathology. Alcohol Res Health 2003;27:291-9.

51. Hardie DG. The AMP-activated protein kinase pathway--new players upstream and downstream. J Cell Sci 2004;117:5479-87.

52. Zhang L, Li J, Young LH, et al. AMP-activated protein kinase regulates the assembly of epithelial tight junctions. Proc Natl Acad Sci U S A 2006;103:17272-7.

53. Zheng B, Cantley LC. Regulation of epithelial tight junction assembly and disassembly by AMPactivated protein kinase. Proc Natl Acad Sci U S A 2007;104:819-22.

54. Asai K, Buurman WA, Reutelingsperger CP, et al. Modular effects of estradiol on ethanol-induced apoptosis in human intestinal epithelial cells. Scand J Gastroenterol 2005;40:326-35.

55. Ma TY, Nguyen D, Bui V, et al. Ethanol modulation of intestinal epithelial tight junction barrier. Am J Physiol 1999;276:G965-74.

56. Rao RK. Acetaldehyde-induced barrier disruption and paracellular permeability in Caco-2 cell monolayer. Methods Mol Biol 2008;447:171-83. 
190 


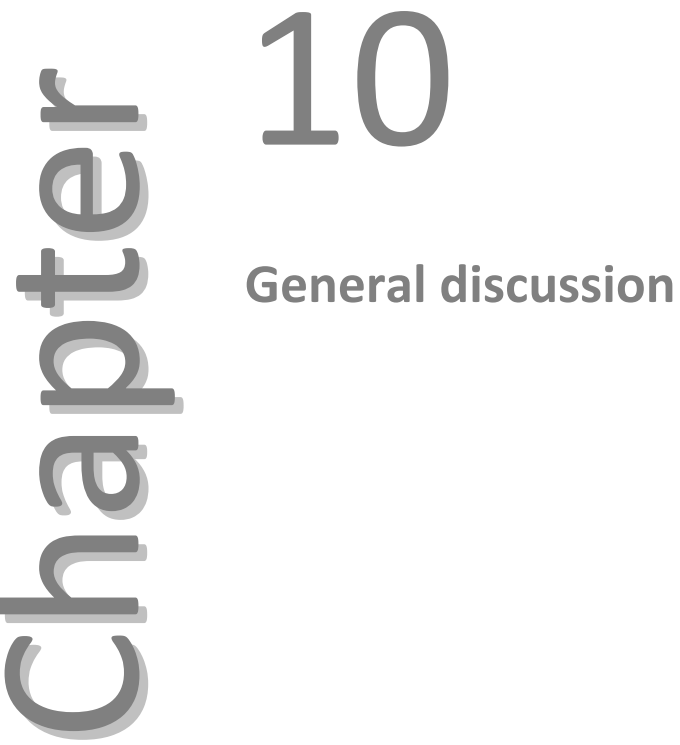




\section{Introduction}

Ethanol consumption and its consequences, including alcoholic liver disease (ALD), represent substantial health problems worldwide ${ }^{1}$. In addition, excessive ethanol intake is associated with several gastrointestinal (GI) diseases such as alcoholic pancreatitis and peptic ulcer disease, and has long been recognized as a risk factor for colorectal carcinoma ${ }^{2}$. A number of studies have provided compelling evidence that ethanol-induced intestinal barrier dysfunction enables harmful bacteria and their products such as endotoxins to enter the systemic and portal circulation resulting in inflammatory liver injury, and thereby contributing to ALD pathogenesis ${ }^{3,4}$. Injurious effects of ethanol on intestinal epithelial integrity have mainly been described in chronic alcoholics dealing with upper GI barrier dysfunction ${ }^{5-11}$. Effects of heavy and long-term ethanol intake on the Gl barrier function have extensively been studied (chapter 2). However, only few studies have investigated the modulating effects of moderate ethanol consumption in healthy subjects. This is relevant since ethanol is consumed on regular basis in a light to moderate drinking pattern by a substantial percentage of the general population (chapter 2). Furthermore, after moderate ethanol ingestion, ethanol and its metabolites such as acetaldehyde and fatty acid ethyl esters (FAEEs) can reach the upper and the lower GI tract including the terminal ileum and colon. Knowledge about interplay between these metabolites in disrupting intestinal barrier function is currently lacking. Therefore, the in vivo and in vitro studies described in this thesis focus on investigating effects of ethanol administered in a moderate dosage on both small and large intestinal epithelial barrier integrity, aiming to obtain mechanistic insights on effects of its metabolites including acetaldehyde and fatty acid ethyl esters (FAEEs) on mucosal barrier function, and to explore protective effects of short chain fatty acids against ethanol-induced intestinal epithelial injury. In this summary chapter, our main findings and implications will be discussed in light of these concepts. Finally, overall conclusions will be drawn and directions for future research will be suggested.

\section{Ethanol and intestinal permeability}

Epidemiologic investigations have shown that progressive and advanced liver disorders such as alcoholic steatohepatitis (ASH) and liver cirrhosis develops in only about $30 \%$ of alcoholics, indicating that other factors in addition to chronic ethanol consumption are required for development of $\mathrm{ASH}^{12}$. Evidence is accumulating that impairment of intestinal barrier and subsequent endotoxaemia are the earliest events that play a crucial role in the development of ALD (chapter 2). The molecular pathophysiology of ALD involves several inflammatory key processes including many reactions at cellular and subcellular level. One of the driving forces of inflammation is activation of hepatic Kupffer cells through the receptor Cluster of Differentiation-14 
(CD-14) and Toll-like receptors- 4 (TLR- 4$)^{13}$, thereby initiating a cascade of events leading to reactive oxygen species production (ROS) and cytokine release, including TNF- $\alpha^{14-16}$, and consequently, hepatocyte injury. In addition to activating Kupffer cells, endotoxins may also activate hepatic stellate cells (HSCs), thereby contributing to hepatic necro-inflammation and fibrosis. In accordance with the above mentioned data which emphasizes the importance of intestinal hyperpermeability in ALD, in chapter 3 the effects of ethanol administration on small and large intestinal permeability were examined in healthy subjects. In that study, a short-term challenge with $20 \mathrm{~g}$ ethanol at $5 \%$ concentration (equivalent to 2 standard drinks), directly perfused in the upper small intestine (i.e. duodenum and proximal jejunum) via a naso-intestinal tube was used to explore its effects on intestinal mucosal barrier function in a homogenous group of male Caucasians. By using this approach, we tried to overcome the interindividual variation in ethanol absorption and metabolism in the oral cavity and stomach ${ }^{17}$. Intraduodenal administration of $20 \mathrm{~g}$ ethanol in healthy volunteers did not increase gastroduodenal permeability as indicated by urinary excretion of sucrose, and this absence of effect is most likely due to bypassing the stomach and direct perfusion of ethanol into the duodenum. Previous studies have shown in humans that administration of either a single dose $(0.4 \mathrm{~g} / \mathrm{kg})$ or moderate ethanol consumption increases gastroduodenal permeability ${ }^{8,18}$. The lack of effect of ethanol administration on gastroduodenal permeability in our study is probably due use of nasointestinal tube and bypassing stomach. Compared to placebo, a significant increase in urinary lactulose/rhamnose ratio (L/R) and sucralose/erythritol ratio (S/E) ratios was observed after ethanol administration, indicating increased small intestinal and colon permeability, respectively. Thus, the findings presented in chapter $\mathbf{3}$ of this thesis suggest that moderate ethanol intake may induce mucosal barrier dysfunction the small intestine and colon, which might enhance translocation of endotoxins. Effects of administration of a single ethanol dosage on intestinal permeability have been evaluated in previously published studies. For instance, Millan et al. administered a higher dosage $(45 \mathrm{~g})$ of ethanol in humans and found histological changes including loss of epithelium at the tips of the villi and hemorrhagic erosions ${ }^{19}$. Although ethanol-induced mucosal damage will impair intestinal barrier function, these authors did not report on changes in intestinal barrier function. Subsequently, Robinson and co-workers have observed that oral administration of $19 \mathrm{~g}$ ethanol increases small intestinal permeability in healthy volunteers as reflected by increased absorption of polyethylene glycol 400 (PEG 400) ${ }^{6}$. Recently, Swanson et al. ${ }^{18}$ have shown that moderate red wine consumption ( $20 \mathrm{~g}$ ethanol/day) can increase small intestinal permeability in patients with Crohn's disease and colon permeability in patients with inactive ulcerative colitis, evaluated by $L / R$ ration and sucralose excretion in urine, respectively. The above results and our own findings indicate that a single, moderate ethanol intake interferes with small intestinal and colon epithelial integrity. These effects may be transient ${ }^{6}$, but this does not exclude that prolonged changes in permeability may occur after repetitive exposure. Furthermore, a transient 
increase in intestinal permeability can increase absorption of drugs when taken simultaneously ${ }^{20}$ and result in elevation of plasma endotoxins ${ }^{21}$, thereby increasing the risk of toxicity and second hit to the intestinal barrier, and potentiate liver injury.

One of the potential limitations of the validity of the utilized human model of ethanolinduced intestinal hyperpermeability is related to the method of ethanol administration. In our study, ethanol was administered directly into the duodenum instead of by oral intake. Although our approach with bypassing the stomach is not physiological, it has been chosen deliberately to overcome the interindividual variations in ethanol metabolism in the upper GI tract (chapter 3). Another limitation refers to a possible lack of site-specific information regarding the exact small intestinal or colon region of ethanol-induced mucosal impairment. Sugar probes such as lactulose and rhamnose undergo bacterial fermentation in the large intestine and, therefore, yield only information about permeability of the small intestine, but not about its subregions (i.e. duodenum, jejunum, ileum) ${ }^{22}$. Moreover, sucralose and erythritol reflect colon permeability but not its subregions (i.e. ascending, transverse, descending colon). A final potential limitation of the sugar permeability test is the assumption that, when administering two sugars of different size, both molecules will be equally affected by pre-absorptive factors such as gastric emptying and intestinal transit, as well as by post-absorptive factors such as systemic distribution and renal clearance $^{23,24}$. However, because of the crossover design of our study, interindividual variations pre- and post-absorptive factors are irrelevant. We conclude that the observed effects of intraduodenally administered ethanol on both small intestinal and colon warrant further investigation also with more physiological approaches.

\section{Mechanisms of ethanol and its metabolites-induced intestinal barrier dysfunction}

Evidence on basal understanding of underlying mechanisms of ethanol and its metabolite acetaldehyde-induced loss of intestinal epithelial barrier integrity originate almost entirely from animal and in vitro studies, using relatively high concentrations of ethanol ${ }^{25,26}$. Overall results indicate that loss of intestinal barrier integrity by ethanol is mediated via a number of mechanisms including disruption of the adherens junctional complex (AJC) including the tight junctions (TJS) and adherens junctions (AJs), inducible nitric oxide synthase (iNOS) ${ }^{26}$ and cytochrome-P450 2E1 (CYP2E1)mediated oxidative stress ${ }^{27}$, remodeling of cytoskeleton and activation of various cell signaling pathways including myosin light chain kinase (MLCK), protein tyrosine kinase (PTK) and protein phosphatase 2A (PP2A), and inhibition of protein tyrosine phosphatase (PTP) ${ }^{3}$. However, mechanisms involved in the detrimental effects of exposure to moderate ethanol dosage $(20-40 \mathrm{~g})$ and its highly reactive metabolite 
acetaldehyde and the non-oxidative metabolites fatty acid ethyl esters (FAEEs) on intestinal epithelium remain to be further elucidated.

\section{Role of mitogen activated protein kinase (MAPK)}

Regulation of epithelial barrier integrity involves several cell signaling pathways, of which activation of MAPKs is of pivotal importance ${ }^{28}$. To obtain more mechanistic insights in effects of moderate ethanol intake on intestinal epithelial barrier dysfunction, we used an ex vivo approach to examine the status of TJs and to explore the role of MAPKs in duodenal mucosal biopsies obtained after ethanol administration. It is worthwhile noting that these mucosal biopsies were obtained during the peak of ethanol and fatty acid ethyl esters in blood. Using immunofluorescence, protein and gene expression assays, we demonstrate in chapter 3 that ethanol administration induces alterations in localization of TJ proteins ZO-1 and occludin, associated with down-regulation of ZO-1 and up-regulation of MLCK gene expression, paralleled with activation of MAPK isoforms including p38, ERK1/2 and JNK. These finding were examined further in vitro using a human-derived colon adenocarcinoma (Caco-2) cell line. Upon full differentiation, these cells develop a polarized monolayer, lose their tumorigenic phenotype, and express many functional and morphological features of mature enterocytes of the small intestinal mucosa such as brush borders enzymes and microvilli ${ }^{29}$. Thus, fully differentiated Caco-2 monolayers constitute an appropriate culture model to study intestinal epithelial cell biology. Comparable to the data of mucosal biopsies, obtained after moderate ethanol administration, we have shown that incubating Caco-2 monolayers with ethanol for $3 \mathrm{~h}$ at a concentration of $40 \mathrm{mM}$ can result in stimulation of MAPK, associated with MAPK-dependent activation of MLCK, resulting in barrier dysfunction. These observations are in line with previous data reporting that ethanol-induced intestinal epithelial hyperpermeability is mediated via MLCK activation ${ }^{25}$, and actin cytoskeleton disruption $^{30}$. Therefore, our data suggest a crosstalk between MAPKs and MLCK in mediating ethanol-induced intestinal barrier dysfunction. In agreement with literature ${ }^{31,32}$, activation of MAPK in Caco-2 monolayers was ROS-dependent, as it could be reversed by the anti-oxidant L-cysteine. Although MAPKs have been demonstrated to mediate intestinal epithelial barrier dysfunction by other stimuli including osmotic stress ${ }^{33,34}$, no data are available so far on their role in ethanolinduced intestinal barrier dysfunction. Therefore, our study described in chapter $\mathbf{3}$ is the first to examine the TJs at both protein and gene levels, and to explore and highlight a potential role for MAPK pathway in disruption of the intestinal epithelial barrier following administration of a moderate ethanol dosage.

\section{Role of modification of cytoskeletal proteins}

Remodeling of cytoskeletal proteins including microtubules and F-actin have been implicated in ethanol-induced barrier dysfunction (chapter 2). In chapter 4, effects of 
ethanol as well as its oxidative metabolite acetaldehyde on barrier function and hyperacetylation of the microtubule $\alpha$-tubulin were examined using a three dimensional (3D) cell culture model of Caco-2 cells. In contrast to the conventional two dimensional (2D) intestinal cell monolayers, intestinal epithelial cells cultured in extra-cellular matrix proteins forms spheroids with a central lumen, recapulating specific morphological and biochemical characteristics of intestinal epithelium in vivo such as formation of microvilli and expression of brush border enzymes ${ }^{35}$. In our study, we have shown that both ethanol $(10-40 \mathrm{mmol} / \mathrm{l})$ and acetaldehyde (25-200 $\mu \mathrm{mol} / \mathrm{l})$ dose-dependently and additively increase paracellular permeability. In addition, they induced ZO-1 and occludin redistribution simultaneously with microtubule hyperacetylation. Since the effects on permeability were neither dependent on cytotoxicity nor on altered TJ gene expression, we assume that hyperacetylation of microtubule is one of the major contributing factor to ethanoland acetaldehyde-induced loss of TJ integrity. Our data confirm that ethanol (chapter 3) and acetaldehyde (chapter 6) disrupt intestinal epithelial barrier function and we describe a novel mechanism involving hyperacetylation of microtubule.

\section{Role of oxidative stress in fatty acid ethyl ester (FAEE)-induced loss of TJ integrity}

In addition to acetaldehyde, ethanol is metabolized into FAEEs including ethyl oleate and ethyl palmitate which also are potentially injurious to epithelial cell (chapter 2). Data of the study described in chapter $\mathbf{3}$ on blood levels of FAEEs following ethanol administration gave rise to an intriguing question whether these metabolites interfere with intestinal epithelial integrity. Since effects of FAEEs on intestinal barrier function have never been investigated before, in the study described in chapter $\mathbf{5}$, we used the 3D Caco-2 cell culture model to examine effects of ethyl oleate and ethyl palmitate on intestinal barrier function. Our findings show for the first time that ethyl oleate and ethyl palmitate at clinically relevant concentrations, dose-dependently disrupt the TJs and AJs integrity and increase paracellular permeability, increase intracellular oxidative stress, and decrease mitochondrial function, which could be inhibited by the nutritional antioxidant resveratrol (3, 5, 4'-trihydroxy-trans-stilbene). These findings support a role for FAEEs in ethanol-induced intestinal injury, most likely through ROSdependent mechanism. In line with these observations, oxidative stress has been implicated in mediating FAEEs-induced cell injury ${ }^{36}$ as well as in ethanol ${ }^{26}$ and acetaldehyde-induced intestinal barrier dysfunction (chapter 6). In our study, ethyl oleate showed more potential than ethyl palmitate in increasing the paracellular permeability of Caco-2 spheroids. In addition, ethyl oleate induced a larger decrease in ZO-1 and occludin protein levels and a higher ROS levels compared with ethyl palmitate. Hence, it is conceivable that ethyl oleate has more influence on barrier function than ethyl palmitate. This observation indicates that ethyl oleate generated after ethanol consumption has implication for the potential injury to the intestinal 
epithelium in vivo. Previously, ethyl oleate has been shown to induce a larger decrease in proliferation and protein synthesis in human hepatoblastoma cells (HepG2) compared with ethyl arachidonate, pointing to its potential cytotoxicity ${ }^{37}$. Since FAEEs found in plasma of human subjects after ethanol ingestion are predominantly ethyl oleate and ethyl palmitate ${ }^{38}$, their combined presence might have additive or even synergistic effects on epithelial integrity. Therefore, evaluation of injurious effects of combined FAEEs could be highly important in understanding the mechanism of ethanol-induced intestinal injury. In our study a 2', 7'-dichlorofluorescin diacetate (DCFH-DA) method was used to determine intracellular hydrogen peroxide in Caco-2 cells. In brief, DCFH-DA is diffused into the cell and is deacetylated by esterases inside the cell to nonfluorescent 2', 7'-dichlorofluorescin (DCFH), which is rapidly oxidized to highly fluorescent $2^{\prime}, 7^{\prime}$-dichlorofluorescein (DCF) in the presence of hydrogen peroxide $\left(\mathrm{H}_{2} \mathrm{O}_{2}\right)$ and peroxidase. DCFH-DA is highly specific for detection of oxidative stress but it does not discriminate between types of ROS involved. However, the observations that effects of FAEEs mimic those induced by the positive control $\mathrm{H}_{2} \mathrm{O}_{2}$ strongly suggest that $\mathrm{H}_{2} \mathrm{O}_{2}$ is the major free radical factor contributing to FAEEinduced barrier disruption. Previously, an increase in oxidative stress has been shown to disrupt mucosal barrier function of intestinal epithelial cells through mechanisms involving oxidation, nitration, disassembly, and instability of the actin cytoskeleton ${ }^{39,40}$ and cellular microtubules ${ }^{41}$. In addition, increased ROS production has been implicated in membrane damage and subsequent amino acid transport reduction that is necessary for protein core synthesis ${ }^{42}$. Prior studies have demonstrated that FAEEs inhibit cellular machineries involved in protein synthesis in acinar cells ${ }^{43}$ and hepatocytes ${ }^{37}$. Since we observed a ROS-dependent decrease in TJ and AJ protein levels, we speculated that one possible mechanism by which FAEEs impair intestinal barrier integrity is ROS-mediated decrease in TJ and AJ protein synthesis. Based on our in vitro data, the attenuation of decrease in TJ and AJ protein levels by resveratrol indicates that it may have the potential to prevent ethanol and its metabolitesinduced intestinal cell injury, thereby offering opportunities for intervention strategies. Since ethanol and acetaldehyde exert additive effects on barrier function (chapter 4), it is conceivable to assume that more deleterious effects on intestinal integrity might occur in the presence of FAEEs. Therefore, future interventional studies are required to further delineate preventive effects of resveratrol on ethanol and its metabolites-induced intestinal epithelial barrier dysfunction.

\section{Role of the epithelial to mesenchymal transition factor Snail in acetaldehyde-induced intestinal barrier disruption}

In the GI tract, the first and most toxic metabolite of ethanol metabolism acetaldehyde is generated by mucosal and/or microbial alcohol dehydrogenase ${ }^{44}$, and it can reach high concentrations $(250 \mu \mathrm{M})$ in colon mucosa (chapter 2 ). Although it is linked to increased risk of colorectal carcinogenesis associated with ethanol 
consumption, effects of acetaldehyde on the transcription factor of epithelial to mesenchymal-transition (EMT) Snail is lacking. In the study described in chapter 5, we have demonstrated that exposure to $25 \mu \mathrm{mol} / \mathrm{l}$ acetaldehyde increases ROS production, ROS-dependently induces redistribution of TJ and AJ proteins and increases paracellular permeability. It was also observed that acetaldehyde ROSdependently activates Snail and it can be reversed by L-cysteine. The role of Snail activation in acetaldehyde-induced barrier disruption was confirmed by knocking down the gene coding for Snail using small interfering RNA (siRNA) technology. These observations confirm our prior data described in chapter $\mathbf{3}$ and report for the first time that acetaldehyde-induced cellular oxidative stress triggers Snail activation with subsequent loss of TJs and AJs integrity and consequently results in barrier dysfunction. In line with these findings, up-regulation of iNOS with subsequent cellular oxidative stress has been shown to activate Snail resulting in induction of EMT in different cell types, including Caco-2 cells with subsequent intestinal barrier dysfunction ${ }^{45}$. In addition, our data support previous findings that TJs and AJsare major targets of Snail activation and subsequent EMT induction ${ }^{46}$ and are in agreement with recent data showing that ethanol is capable of activating Snail resulting in loss of TJs integrity in Caco-2 monolayers ${ }^{45,47}$. Although Caco-2 monolayers express carrier proteins similar to the small intestine ${ }^{48-50}$ fully differentiated monolayers form an epithelial membrane with a barrier function similar to the human colon $^{51}$. In addition, Caco-2 cells develop high transepithelial electrical resistance and poor paracellular permeability properties resembling those of colonocytes ${ }^{52}$. Therefore, using Caco-2 monolayers combined with acetaldehyde concentrations that can be found in colon may largely represent colon exposure to acetaldehyde in vivo. Since acetaldehyde is a potent ROS generator, and highly mutagenic and Snailmediated EMT is a hallmark in carcinogenesis ${ }^{53}$ and cancer progression ${ }^{54}$, future studies investigating the role of Snail in intestinal barrier function associated with various $\mathrm{Gl}$ and liver disorders, including inflammatory bowel disease ${ }^{55}$ and liver cirrhosis $^{4,56}$, are warranted.

\section{Role of free intracellular calcium $\left(\left[\mathrm{Ca}^{2+}\right]_{\mathrm{i}}\right)$ and Rho-associated coiled-coil forming kinase (Rho/ROCK) in ethanol-induced barrier disruption}

One of the possible effects of ethanol-induced barrier dysfunction could be rise in free intracellular calcium $\left[\mathrm{Ca}^{2+}\right]_{i}$ and subsequent Rho-associated coiled-coil forming kinase (Rho/ROCK) activation. In Chapter 6 we have demonstrated that ethanol triggers a rise in free $\left[\mathrm{Ca}^{2+}\right]_{\text {i, }}$, which is mediated by inositol 1,4,5-triphosphate receptor $\left(\mathrm{IP}_{3} \mathrm{R}\right)$ gated release of $\mathrm{Ca}^{2+}$ from endoplasmic reticulum (ER), thereby mediating ethanolinduced activation of Rho/ROCK with subsequent loss of TJ and AJ integrity, and disruption of F-actin organization and consequently, barrier dysfunction. Our observations are in line with a few studies demonstrating that elevation in $\left[\mathrm{Ca}^{2+}\right]_{\mathrm{i}}$ disrupts TJ integrity in T84 and Caco-2 monolayers ${ }^{57,58}$. In addition, Samak et al..$^{33}$ have 
recently shown that rise in $\left[\mathrm{Ca}^{2+}\right]_{i}$ is required for osmotic stress-induced TJ disruption in Caco-2 monolayers. The observation that $\mathrm{IP}_{3} \mathrm{R}$-operated $\mathrm{ER} \mathrm{Ca}{ }^{2+}$ release contributes to elevation of free $\left[\mathrm{Ca}^{2+}\right]_{\text {, }}$, is in line with a prior study demonstrating that $\mathrm{PP}_{3} \mathrm{R}$ mediated increase in $\left[\mathrm{Ca}^{2+}\right]_{i}$ is required for ethanol-induced impairment of endothelial barrier function ${ }^{59}$. Rho kinases regulate cytoskeleton proteins including microtubules ${ }^{60,61}$ and indirectly, assembly of the $T \mathrm{~J}^{62}$. Among many effectors of Rho kinases, Rho/ROCK has been shown to mediate Rho kinase A (RhoA)-induced disassembly of intercellular junctions and formation of stress fibers ${ }^{63,64}$. Tong et al. ${ }^{65,66}$ have reported up-regulation of RhoA mRNA expression and activation via iNOS mediate-ethanol MLCK activation in Caco-2 monolayers, (chapter 3) and consequently, TJ disruption. However these studies did not investigate the role of the downstream effector of RhoA, ROCK. Our study is extended and reports for the first time that ethanol-induced increase in $\left[\mathrm{Ca}^{2+}\right]_{i}$ activates Rho/ROCK resulting in loss of $\mathrm{TJ}$ and AJ integrity and consequently, barrier dysfunction. Furthermore, our data demonstrate that ethanol induces increase in cellular F-actin contents, and disorganization of F-actin ring (chapter 3 , chapter $\mathbf{8}$ ), which can also be abrogated by the inhibitor Y27632, indicating involvement of Rho/ROCK activity. A crosstalk between MLCK and Rho/ROCK pathways cannot be excluded in our study, as it has been suggested that MLCK activation may initiate impairment of epithelial barrier, followed by Rho/ROCK-dependent barrier disruption ${ }^{67}$. However, how MLCK interacts with Rho/ROCK in ethanol-induced intestinal hyperpermeability merits further investigation.

\section{Effects of acetaldehyde on mucus-secreting goblet-like cells}

Apart from the TJs, goblet cells play a protective role in the intestinal epithelium by secreting a continuous viscoelastic mucus rich in mucins that prevents the access of a variety of exogenous or endogenous agents, including pathogens and chemical irritants $^{68}$ (chapter 2). In chapter 8 we have presented an in vitro study investigating the cytotoxic effect of acetaldehyde, in concentrations expected in colon lumen $(25-200 \mu \mathrm{mol} / \mathrm{l})$ after oral intake of a single moderate ethanol dosage $(20 \mathrm{~g})$, on intestinal epithelial goblet-like cells. For that purpose, we used LS174T cell line. LS174T cells contain mucus granules, produce significant amounts of secretory mucin, and have a resemblance to goblet cells ${ }^{69}$. In our study, acetaldehyde at the indicated concentrations dose-dependently induces loss of cell membrane integrity and increases apoptosis as indicated by increased caspase $3 / 7$ activity and the percentage of cells expressing the cleaved CK18 protein. In addition, acetaldehyde significantly increased ROS generation and induced intra-mitochondrial $\mathrm{Ca}^{2+}$ accumulation, accompanied with decrease in mitochondrial function and dose-dependent decrease in intracellular ATP levels. Since toxicity of acetaldehyde includes combined effects on metabolic activity and membrane integrity, adverse effects on metabolic activity are 
likely a key event triggering a general impairment of structure and function of LS174T cells. Since goblet cells together with absorptive enterocytes dominate the intestinal epithelium $^{70}$, apoptotic cell death may contribute to acetaldehyde-induced intestinal barrier dysfunction. Therefore, these disaggregating effects of acetaldehyde on intestinal goblet cells may at least in part explain the intestinal hyperpermeability and endotoxaemia disorders observed in humans after ethanol consumption. In addition, repetitive goblet cell injury may potentiate the risk of acetaldehyde-related carcinoma. Recent studies have disclosed that altered or inappropriate mucin gene expression is related to tumor development, tumor invasiveness, and prognosis in colorectal cancer ${ }^{71}$. Therefore, this study along with previous ones strengthens the concept that in addition to ethano ${ }^{72}$, intestinal goblet cells are important targets for the toxic effects of acetaldehyde.

\section{Modulation of ethanol-induced barrier dysfunction by short chain fatty acids (SCFAs)}

Preservation of intestinal epithelial barrier function may prevent translocation of endotoxins from colon lumen into the portal vein, which in turn may attenuate endotoxin-induced tissue injury. Several studies have indicated that dietary fibers and their fermentation products short chain fatty acids (SCFAs) including butyrate (C4), propionate (C3) and acetate (C2), can promote intestinal barrier function ${ }^{73}$. In chapter $\mathbf{9}$, the capability SCFAs to protect against ethanol- induced barrier dysfunction was investigated using Caco-2 cell monolayers. Our results have revealed that exposure to $40 \mathrm{mmol} / \mathrm{l}$ ethanol induces barrier dysfunction (chapter 3, chapter 4, chapter 7). Changes in permeability were associated with abnormal localization and distribution of ZO-1 and occludin, disarrangement of F-actin ring, and increased cellular F-actin contents (chapter 3). Furthermore, ethanol induced oxidative stress, decreased mitochondrial function and decreased intracellular ATP (chapter 8). However, pretreatment with either with $2 \mathrm{mmol} / \mathrm{l}$ butyrate, $4 \mathrm{mmol} / \mathrm{l}$ propionate or 8 $\mathrm{mmol} / \mathrm{l}$ acetate significantly attenuates ethanol-induced barrier dysfunction. In addition, we observed that SCFAs can attenuate ethanol-induced oxidative stress, a finding which is in line with previously reported data on the antioxidant potential of SCFAs $^{74}$. The mechanisms and source of ROS generation have not been examined in our studies. However, it has been demonstrated that activation of intestinal iNOS $^{26}$, cytochrome-P450 2E1 (CYP2E1) ${ }^{27}$, and xanthine oxidase ${ }^{75}$ mediate ethanol-induced ROS production and consequently, barrier dysfunction (chapter 3, chapter 4, chapter 7). Increased ROS production (chapter 5, chapter 6 and chapter 8) and consequently impaired mitochondrial function (chapter 5, chapter 8), may cause ATP depletion (chapter 8), a factor that can further contribute to barrier dysfunction ${ }^{76,77}$. We also have demonstrated that SCFAs are able to attenuate and prevent ethanolinduced mitochondrial dysfunction and ATP depletion, indicating the potential 
capacity of SCFAs to protect the intestinal epithelial cells from ethanol-mediated cellular metabolic stress. In line with these findings, butyrate has previously been shown to increase ATP stores in Caco-2 cells $^{78}$. Since SCFAs constitute a major energy source in the colon and ethanol can interfere with ATP production ${ }^{79}$, the role of adenosine monophosphate activated protein kinase (AMPK) activation in SCFAs effects on ethanol-induced barrier dysfunction has been explored. Our data revealed that the SCFAs are able to induce AMPK activation (phosphorylation), and thereby promoting epithelial barrier function. The role AMPK in SCFAs effects on ethanolinduced barrier dysfunction was confirmed by using pharmacological as well as siRNA approaches. Pretreatment with compound $\mathrm{C}$ and knocking down AMPK abolished the ability of SCFAs to improve barrier function. Since the inhibitory effect of AMPK knockdown on barrier function was partial, alternative mechanisms underlying the SCFA promotive effects have to be considered. The beneficial effects of propionate and acetate were observed using higher concentrations when compared with butyrate. The difference in magnitude between these SCFAs indicates that chain length is a major determinant of their bioactivity, as increasing carbon chain length has been shown to influence the potential effects of SCFAs ${ }^{80}$. This may be ascribed to the inability of SCFAs with decreased chain length to cross cell membranes as a result of reduced lipid solubility ${ }^{81}$. In addition, while butyrate is most potent energy source in colonocytes, acetate and propionate have more metabolic effects in liver ${ }^{82}$.

Several strategies have been applied previously in an attempt to counteract the detrimental effects of ethanol and its oxidative metabolite acetaldehyde on intestinal epithelial integrity. For instance, resveratrol (chapter 5), L-cysteine (chapter 6), epidermal growth factor ${ }^{83}$ and L-glutamine ${ }^{84}$ have been demonstrated to preserve intestinal paracellular permeability by attenuating ethanol and acetaldehyde-induced barrier disruption ${ }^{85}$. In a mouse model of ALD, zinc supplementation has been shown to attenuate ethanol-induced increases in serum endotoxin levels and liver injury, which could be ascribed to preservation of intestinal morphology and permeability ${ }^{6,86}$, most likely due to its antioxidant effect ${ }^{87}$. Moreover, Christopher et al ${ }^{88}$ have demonstrated that feeding rats the probiotic lactobacillus GG bacteria (LGG) significantly blunts ethanol-induced oxidative stress (chapter 8), improves ethanolinduced gut leakiness and ameliorates alcoholic steatohepatitis. In the same model, Tang et al. $^{89}$ and Keshavarzian et $a l^{90}$ have demonstrated that oat supplementation prevents increased intestinal hyperpermeability and steatohepatitis in long-term ethanol fed rats via anti-oxidant mechanisms ${ }^{90,91}$. Based on these data, our study suggest that consumption of prebiotics i.e. dietary fibers, and possibly probiotics i.e. live organisms, prior to ethanol consumption may preserve Gl epithelial integrity, and thereby provides a scientific rationale for highly recommended human intervention studies. 


\section{Conclusion and further perspectives}

The knowledge about involvement of ethanol-induced gut leakiness in the development of ALD has considerably expanded over the recent years. Our findings in the human intervention study have provided evidence for the principle that moderate ethanol consumption impairs intestinal barrier function via modulating epithelial TJs in the duodenal mucosa at both gene and protein levels (chapter 3). However, future research should also focus on human colon, and try to elucidate the possible mechanisms involved in loss of TJs integrity. Since ethanol consumption promotes bacterial overgrowth (chapter 2), studies investigating whether moderate ethanol intake can promote intestinal bacterial growth and whether this is associated with increased production and enhanced translocation of endotoxin production and other toxic bacterial products such as peptidoglycan and flagellin, are warranted. In addition, investigating effects of moderate ethanol intake in subjects with abnormal body mass index (BMI>25) appear warranted to address wheather there is an additive or synergistic effects on intestinal barrier function and whether it might be necessary to formulate BMI-based recommendations for safe ethanol consumption. Our observations concerning barrier function in the Caco-2 three dimensional (3D) cell culture model are very convincing (chapter 3, chapter 4). Therefore, this model provides an elegant tool to study regulation of intestinal epithelial barrier under physiological and pathological conditions. With the possibilities to co-culture enterocytes with goblet cells and immune cells such as monocytes and mast cells, contribution of these cells to ethanol and its metabolites-induced hyperpermeability in an integrated 3D model of intestinal epithelial barrier can be studied in more depth. Our in vitro studies have shown that ethanol and its metabolites including acetaldehyde and FAEEs increases intestinal epithelial permeability via several mechanisms involving loss of TJ and AJ integrity and disruption F-actin cytoskeleton which are largely mediated via hyperacetylation of microtubules (chapter 4), increased ROS generation (chapter 5), rise in intracellular calcium-dependent Rho/ROCK stimulation (chapter 7), as well as ROS-dependent mitogen activated protein kinase (chapter $\mathbf{3}$ ), and Snail activation (chapter $\mathbf{6}$ ). The effects of ethanol and its metabolites on intestinal barrier function and proposed mechanisms are summarized in Figure 10.1.

Acetaldehyde exerts detrimental effects on intestinal goblet cells including rise in intra-mitochondrial calcium, metabolic stress and oxidative stress associated with induction of apoptosis (chapter 8). Further studies are required to discern underlying mechanisms by which acetaldehyde makes intestinal goblet cells more prone to apoptosis. In addition, while ethanol has been shown to induce alterations in intestinal mucin glycosylation ${ }^{92}$, the effects of acetaldehyde on mucin biochemistry remain unknown. Furthermore, an intriguing research question is related to modulating effects of acetaldehyde on major mucins present in colon, including MUC1, MUC2, MUC3, and MUC4, and their stabilizers trefoils factors. 


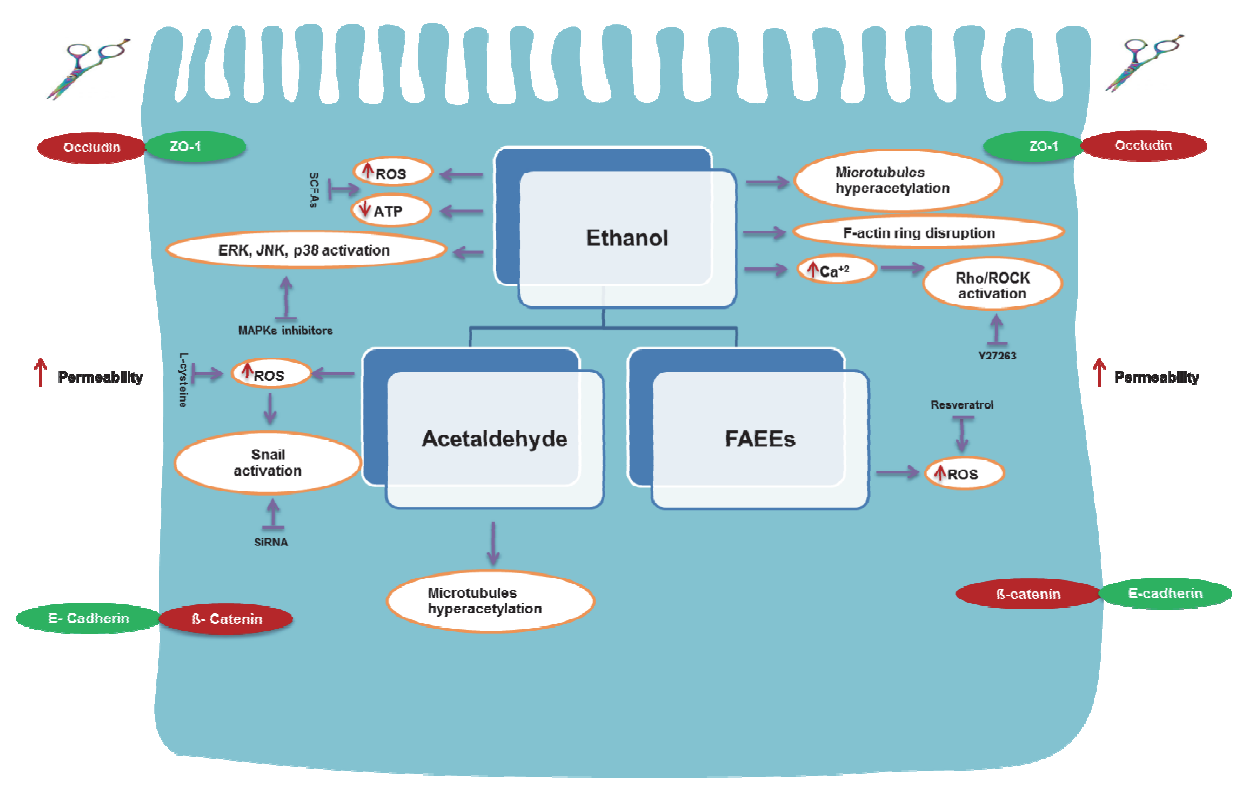

Figure 10.1. Schematic representation of possible mechanisms underlying ethanol-, acetaldehyde- and fatty acid ethyl esters- induced disruption of the apical junctional complex in intestinal epithelium Ethanol-induced increased levels of reactive oxygen species (ROS), and decrease in ATP activates mitogen activated protein kinase (p38, ERK1/2 and JNK) resulting in loss of integrity of the tight junction proteins (TJ) ZO- 1 and occludin as well adherens junctions (AJ) E-cadherin and $\beta$-catenin. In addition, ethanol-induced hyperacetylation of microtubules, reorganization of $\mathrm{F}$-actin cytoskeleton and rise in intracellular calcium $\left(\mathrm{Ca}^{2+}\right)$ with subsequent Rho-associated coiled-coil forming kinase (Rho/ROCK) activation also disrupts TJ and AJ integrity. Acetaldehyde-induced hyperacetylation of microtubules and ROS-dependent activation of Snail also can result in loss of junctional integrity. Finally, the non-oxidative metabolites fatty acid ethyl esters (FAEE)-induced ROS can disrupt the barrier integrity. These processes can be attenuated by pretreatment with short chain fatty acids (SCFAs), L-cysteine, MAPKs and Rho/ROCK inhibitors, chelating cytosolic $\mathrm{Ca}^{2+}$ with bis aminophenoxyethane-tetraacetic acid (BAPTA), and antagonizing the inositol 1, 4, 5-triphosphate receptor $\left(\mathrm{IP}_{3} \mathrm{R}\right)$ by xestospongin (Xe-C).

Knowledge on how to manipulate ethanol and its metabolites-induced gut barrier dysfunction will help to provide us with new preventive/ and or therapeutic tools in the future.

Based on in vitro and animal studies, various functional fermentation products from prebiotics including SCFAs (chapter 9), and probiotics have shown capabilities to reduce or even prevent ethanol-induced loss of intestinal barrier integrity. Pretreatment with SCFAs not only attenuates ethanol-induced barrier disruption in Caco-2 cell monolayers, but also diminishes metabolic stress and oxidative stress (chapter 9). Therefore, further in vitro experiments using co-culture models and in vivo interventional studies, e.g. with fermentable fibers, should evaluate effects of 
SCFAs, either each acid alone or in combination with others, on ethanol and acetaldehyde-induced intestinal epithelial barrier dysfunction. In addition, using intestinal cells in a co-culture model will be a useful tool to examine effects of SCFAs on acetaldehyde-induced carcinogenesis. Future human studies are warranted to determine usefulness of these strategies for application in healthy volunteers and chronic alcoholics to dampen ethanol-induced gut leakiness, and thereby preventing ALD. 


\section{References}

1. WHO Global Status Report on Alcohol 2004. Geneva: Department of Mental Health and Substance Abuse: World Health Organisation, 2004.

2. Bujanda L. The effects of alcohol consumption upon the gastrointestinal tract. Am J Gastroenterol 2000;95:3374-82.

3. Purohit V, Bode JC, Bode C, et al. Alcohol, intestinal bacterial growth, intestinal permeability to endotoxin, and medical consequences: Summary of a symposium. Alcohol 2008;42:349-61.

4. Keshavarzian A, Holmes EW, Patel M, et al. Leaky gut in alcoholic cirrhosis: a possible mechanism for alcohol-induced liver damage. Am J Gastroenterol 1999;94:200-7.

5. Hirsch S, Chaves $\mathrm{G}$, Gotteland $\mathrm{M}$, et al. Intestinal permeability in alcoholic patients without liver damage. Rev Med Chil 1997;125:653-8.

6. Robinson $\mathrm{GM}$, Orrego $\mathrm{H}$, Israel $\mathrm{Y}$, et al. Low-molecular-weight polyethylene glycol as a probe of gastrointestinal permeability after alcohol ingestion. Dig Dis Sci 1981;26:971-7.

7. Bjarnason I, Peters TJ, Wise RJ. The leaky gut of alcoholism: possible route of entry for toxic compounds. Lancet 1984;1:179-82.

8. Keshavarzian A, Fields JZ, Vaeth J, et al. The differing effects of acute and chronic alcohol on gastric and intestinal permeability. Am J Gastroenterol 1994;89:2205-11.

9. Parlesak A, Schafer C, Schutz T, et al. Increased intestinal permeability to macromolecules and endotoxemia in patients with chronic alcohol abuse in different stages of alcohol-induced liver disease. J Hepatol 2000;32:742-7.

10. Farhadi A, Keshavarzian A, Kwasny MJ, et al. Effects of aspirin on gastroduodenal permeability in alcoholics and controls. Alcohol 2010;44:447-56.

11. Lee S, Son SC, Han MJ, et al. Increased intestinal macromolecular permeability and urine nitrite excretion associated with liver cirrhosis with ascites. World J Gastroenterol 2008;14:3884-90.

12. Grant BF, Dufour MC, Harford TC. Epidemiology of alcoholic liver disease. Semin Liver Dis 1988;8:1225.

13. Adachi Y, Bradford BU, Gao W, et al. Inactivation of Kupffer cells prevents early alcohol-induced liver injury. Hepatology 1994;20:453-60.

14. Nagata K, Suzuki H, Sakaguchi S. Common pathogenic mechanism in development progression of liver injury caused by non-alcoholic or alcoholic steatohepatitis. J Toxicol Sci 2007;32:453-68.

15. Park PH, Thakur V, Pritchard MT, et al. Regulation of Kupffer cell activity during chronic ethanol exposure: role of adiponectin. J Gastroenterol Hepatol 2006;21 Suppl 3:S30-3.

16. Thakur V, Pritchard MT, McMullen MR, et al. Chronic ethanol feeding increases activation of NADPH oxidase by lipopolysaccharide in rat Kupffer cells: role of increased reactive oxygen in LPS-stimulated ERK1/2 activation and TNF-alpha production. J Leukoc Biol 2006;79:1348-56.

17. Halsted $\mathrm{CH}$, Robles EA, Mezey E. Distribution of ethanol in the human gastrointestinal tract. Am J Clin Nutr 1973;26:831-4.

18. Swanson GR, Tieu V, Shaikh M, et al. Is moderate red wine consumption safe in inactive inflammatory bowel disease? Digestion 2011;84:238-44

19. Millan MS, Morris GP, Beck IT, et al. Villous damage induced by suction biopsy and by acute ethanol intake in normal human small intestine. Dig Dis Sci 1980;25:513-25.

20. Weathermon R, Crabb DW. Alcohol and medication interactions. Alcohol Res Health 1999;23:40-54.

21. Shibayama Y, Asaka S, Nakata K. Endotoxin hepatotoxicity augmented by ethanol. Exp Mol Pathol 1991;55:196-202.

22. Meddings JB, Gibbons I. Discrimination of site-specific alterations in gastrointestinal permeability in the rat. Gastroenterology 1998;114:83-92.

23. Travis S, Menzies I. Intestinal permeability: functional assessment and significance. Clin Sci (Lond) 1992;82:471-88.

24. Bjarnason I, MacPherson A, Hollander D. Intestinal permeability: an overview. Gastroenterology 1995;108:1566-81.

25. Ma TY, Nguyen D, Bui V, et al. Ethanol modulation of intestinal epithelial tight junction barrier. Am J Physiol 1999;276:G965-74. 
26. Banan A, Choudhary S, Zhang $Y$, et al. Ethanol-induced barrier dysfunction and its prevention by growth factors in human intestinal monolayers: evidence for oxidative and cytoskeletal mechanisms. J Pharmacol Exp Ther 1999;291:1075-85.

27. McCarroll JA, Phillips PA, Park S, et al. Pancreatic stellate cell activation by ethanol and acetaldehyde: is it mediated by the mitogen-activated protein kinase signaling pathway? Pancreas 2003;27:150-60.

28. Dambacher J, Beigel F, Seiderer J, et al. Interleukin 31 mediates MAP kinase and STAT1/3 activation in intestinal epithelial cells and its expression is upregulated in inflammatory bowel disease. Gut 2007; 56:1257-65.

29. Kiechl S, Willeit J, Rungger G, et al. Alcohol consumption and atherosclerosis: what is the relation? Prospective results from the Bruneck Study. Stroke 1998;29:900-7.

30. Banan A, Keshavarzian A, Zhang L, et al. NF-kappaB activation as a key mechanism in ethanol-induced disruption of the F-actin cytoskeleton and monolayer barrier integrity in intestinal epithelium. Alcohol 2007; 41:447-60.

31. Owuor ED, Kong AN. Antioxidants and oxidants regulated signal transduction pathways. Biochem Pharmacol 2002;64:765-70.

32. Zhou $Y$, Wang $Q$, Mark Evers B, et al. Oxidative stress-induced intestinal epithelial cell apoptosis is mediated by p38 MAPK. Biochem Biophys Res Commun 2006;350:860-5.

33. Samak G, Narayanan D, Jaggar JH, et al. CaV1.3 channels and intracellular calcium mediate osmotic stress-induced $\mathrm{N}$-terminal c-Jun kinase activation and disruption of tight junctions in Caco-2 cell monolayers. J Biol Chem 2011;286:30232-43.

34. Rosales-Reyes R, Skeldon AM, Aubert DF, et al. The Type VI secretion system of Burkholderia cenocepacia affects multiple Rho family GTPases disrupting the actin cytoskeleton and the assembly of NADPH oxidase complex in macrophages. Cell Microbiol 2012;14:255-73.

35. Juuti-Uusitalo K, Klunder LJ, Sjollema KA, et al. Differential effects of TNF (TNFSF2) and IFN-gamma on intestinal epithelial cell morphogenesis and barrier function in three-dimensional culture. PLoS One 2011;6:e22967.

36. Wu H, Cai P, Clemens DL, et al. Metabolic basis of ethanol-induced cytotoxicity in recombinant HepG2 cells: role of nonoxidative metabolism. Toxicol Appl Pharmacol 2006;216:238-47.

37. Szczepiorkowski ZM, Dickersin GR, Laposata M. Fatty acid ethyl esters decrease human hepatoblastoma cell proliferation and protein synthesis. Gastroenterology 1995;108:515-22.

38. Dan L, Laposata M. Ethyl palmitate and ethyl oleate are the predominant fatty acid ethyl esters in the blood after ethanol ingestion and their synthesis is differentially influenced by the extracellular concentrations of their corresponding fatty acids. Alcohol Clin Exp Res 1997;21:286-92.

39. Banan A, Zhang Y, Losurdo J, et al. Carbonylation and disassembly of the F-actin cytoskeleton in oxidant induced barrier dysfunction and its prevention by epidermal growth factor and transforming growth factor alpha in a human colonic cell line. Gut 2000;46:830-7.

40. Banan A, Zhang $L$, Shaikh M, et al. Novel effect of NF-kappaB activation: carbonylation and nitration injury to cytoskeleton and disruption of monolayer barrier in intestinal epithelium. Am J Physiol Cell Physiol 2004;287:C1139-51.

41. Elamin E, Jonkers D, Juuti-Uusitalo $K$, et al. Effects of ethanol and acetaldehyde on tight junction integrity: in vitro study in a three dimensional intestinal epithelial cell culture model. PloS one 2012;7:e35008.

42. Reilly ME, Patel VB, Peters TJ, et al. In vivo rates of skeletal muscle protein synthesis in rats are decreased by acute ethanol treatment but are not ameliorated by supplemental alpha-tocopherol. J Nutr 2000;130:3045-9.

43. Waszkiewicz N, Szajda SD, Zalewska A, et al. Alcohol abuse and glycoconjugate metabolism. Folia Histochem Cytobiol 2012;50:1-11.

44. Seitz HK, Oneta CM. Gastrointestinal alcohol dehydrogenase. Nutr Rev 1998;56:52-60.

45. Forsyth $C B$, Tang $Y$, Shaikh $M$, et al. Role of Snail Activation in Alcohol-Induced iNOS-Mediated Disruption of Intestinal Epithelial Cell Permeability. Alcohol Clin Exp Res 2011.

46. Thiery JP, Sleeman JP. Complex networks orchestrate epithelial-mesenchymal transitions. Nat Rev Mol Cell Biol 2006; 7:131-42.

47. Forsyth $\mathrm{CB}$, Tang $\mathrm{Y}$, Shaikh $\mathrm{M}$, et al. Alcohol stimulates activation of Snail, epidermal growth factor receptor signaling, and biomarkers of epithelial-mesenchymal transition in colon and breast cancer cells. Alcohol Clin Exp Res 2010;34:19-31. 
48. Baker SS, Baker RD, Jr. Antioxidant enzymes in the differentiated Caco-2 cell line. In Vitro Cell Dev Biol 1992;28A:643-7.

49. Hidalgo IJ. Cultured intestinal epithelial cell models. Pharm Biotechnol 1996;8:35-50.

50. Hidalgo IJ, Raub TJ, Borchardt RT. Characterization of the human colon carcinoma cell line (Caco-2) as a model system for intestinal epithelial permeability. Gastroenterology 1989;96:736-49.

51. Artursson $P$, Ungell AL, Lofroth JE. Selective paracellular permeability in two models of intestinal absorption: cultured monolayers of human intestinal epithelial cells and rat intestinal segments. Pharm Res 1993;10:1123-9.

52. Grasset E, Pinto M, Dussaulx E, et al. Epithelial properties of human colonic carcinoma cell line Caco2: electrical parameters. Am J Physiol 1984;247:C260-7

53. Thiery JP, Acloque H, Huang RY, et al. Epithelial-mesenchymal transitions in development and disease. Cell 2009;139:871-90.

54. Kalluri R, Weinberg RA. The basics of epithelial-mesenchymal transition. J Clin Invest 2009;119:14208.

55. Welcker $\mathrm{K}$, Martin A, Kolle $\mathrm{P}$, et al. Increased intestinal permeability in patients with inflammatory bowel disease. Eur J Med Res 2004;9:456-60.

56. Lee S, Son SC, Han MJ, et al. Increased intestinal macromolecular permeability and urine nitrite excretion associated with liver cirrhosis with ascites. World J Gastroenterol 2008;14:3884-90.

57. Tai YH, Flick J, Levine SA, et al. Regulation of tight junction resistance in T84 monolayers by elevation in intracellular Ca2+: a protein kinase C effect. J Membr Biol 1996;149:71-9.

58. Martinez-Palomo A, Meza I, Beaty G, et al. Experimental modulation of occluding junctions in a cultured transporting epithelium. J Cell Biol 1980;87:736-45.

59. Schafer C, Parlesak A, Schutt C, et al. Concentrations of lipopolysaccharide-binding protein, bactericidal/permeability-increasing protein, soluble CD14 and plasma lipids in relation to endotoxaemia in patients with alcoholic liver disease. Alcohol Alcohol 2002;37:81-6.

60. Takai Y, Sasaki T, Tanaka K, et al. Rho as a regulator of the cytoskeleton. Trends Biochem Sci 1995;20:227-31.

61. Terry S, Nie M, Matter K, et al. Rho signaling and tight junction functions. Physiology (Bethesda) 2010;25:16-26.

62. Schlegel N, Meir M, Spindler V, et al. Differential role of Rho GTPases in intestinal epithelial barrier regulation in vitro. J Cell Physiol 2011;226:1196-203.

63. Hall A. Rho GTPases and the actin cytoskeleton. Science 1998;279:509-14.

64. Amano $\mathrm{M}$, Chihara K, Kimura K, et al. Formation of actin stress fibers and focal adhesions enhanced by Rho-kinase. Science 1997;275:1308-11.

65. Thomasson HR. Gender differences in alcohol metabolism. Physiological responses to ethanol. Recent Dev Alcohol 1995;12:163-79.

66. Kevil CG, Oshima T, Alexander B, et al. $\mathrm{H}(2) \mathrm{O}(2)$-mediated permeability: role of MAPK and occludin. Am J Physiol Cell Physiol 2000;279:C21-30.

67. Ivanov Al, Parkos CA, Nusrat A. Cytoskeletal regulation of epithelial barrier function during inflammation. Am J Pathol 2010;177:512-24.

68. Kevil CG, Oshima T, Alexander JS. The role of p38 MAP kinase in hydrogen peroxide mediated endothelial solute permeability. Endothelium 2001;8:107-16.

69. Kevil CG, Payne DK, Mire E, et al. Vascular permeability factor/vascular endothelial cell growth factormediated permeability occurs through disorganization of endothelial junctional proteins. J Biol Chem 1998;273:15099-103.

70. Madara JL, Trier JS. Structure and permeability of goblet cell tight junctions in rat small intestine. J Membr Biol 1982;66:145-57.

71. Kevil CG, Ohno N, Gute DC, et al. Role of cadherin internalization in hydrogen peroxide-mediated endothelial permeability. Free Radic Biol Med 1998;24:1015-22

72. Brozinsky S, Fani K, Grosberg SJ, et al. Alcohol ingestion-induced changes in the human rectal mucosa: light and electron microscopic studies. Dis Colon Rectum 1978;21:329-35.

73. Hamer HM, Jonkers D, Venema K, et al. Review article: the role of butyrate on colonic function Aliment Pharmacol Ther 2008;27:104-19.

74. Hamer HM, Jonkers DM, Bast A, et al. Butyrate modulates oxidative stress in the colonic mucosa of healthy humans. Clin Nutr 2009;28:88-93. 
75. Lieber CS. Ethanol metabolism, cirrhosis and alcoholism. Clin Chim Acta 1997;257:59-84.

76. Lewis K, McKay DM. Metabolic stress evokes decreases in epithelial barrier function. Ann N Y Acad Sci 2009;1165:327-37.

77. Unno N, Menconi MJ, Salzman AL, et al. Hyperpermeability and ATP depletion induced by chronic hypoxia or glycolytic inhibition in Caco-2BBe monolayers. Am J Physiol 1996;270:G1010-21.

78. Wang A, Si H, Liu D, et al. Butyrate activates the cAMP-protein kinase A-cAMP response elementbinding protein signaling pathway in Caco-2 cells. J Nutr 2012;142:1-6.

79. Cunningham CC, Van Horn CG. Energy availability and alcohol-related liver pathology. Alcohol Res Health 2003;27:291-9.

80. Fauser JK, Prisciandaro LD, Cummins AG, et al. Fatty acids as potential adjunctive colorectal chemotherapeutic agents. Cancer Biol Ther 2011;11:724-31.

81. DeSoignie R, Sellin JH. Propionate-initiated changes in intracellular pH in rabbit colonocytes. Gastroenterology 1994;107:347-56.

82. Bloemen JG, Venema K, van de Poll MC, et al. Short chain fatty acids exchange across the gut and liver in humans measured at surgery. Clin Nutr 2009;28:657-61.

83. Sheth $\mathrm{P}$, Seth $\mathrm{A}$, Thangavel $\mathrm{M}$, et al. Epidermal growth factor prevents acetaldehyde-induced paracellular permeability in Caco-2 cell monolayer. Alcohol Clin Exp Res 2004;28:797-804.

84. Seth A, Basuroy $S$, Sheth $P$, et al. L-Glutamine ameliorates acetaldehyde-induced increase in paracellular permeability in Caco-2 cell monolayer. Am J Physiol Gastrointest Liver Physiol 2004;287: G510-7.

85. Basuroy S, Sheth P, Mansbach CM, et al. Acetaldehyde disrupts tight junctions and adherens junctions in human colonic mucosa: protection by EGF and L-glutamine. Am J Physiol Gastrointest Liver Physiol 2005;289:G367-75.

86. Lambert JC, Zhou Z, Wang L, et al. Prevention of alterations in intestinal permeability is involved in zinc inhibition of acute ethanol-induced liver damage in mice. J Pharmacol Exp Ther 2003;305:880-6.

87. Li J, Hu W, Baldassare JJ, et al. The ethanol metabolite, linolenic acid ethyl ester, stimulates mitogenactivated protein kinase and cyclin signaling in hepatic stellate cells. Life Sci 2003;73:1083-96.

88. Forsyth $\mathrm{CB}$, Farhadi A, Jakate SM, et al. Lactobacillus GG treatment ameliorates alcohol-induced intestinal oxidative stress, gut leakiness, and liver injury in a rat model of alcoholic steatohepatitis. Alcohol 2009;43:163-72.

89. Tang $Y$, Forsyth $C B$, Banan A, et al. Oats supplementation prevents alcohol-induced gut leakiness in rats by preventing alcohol-induced oxidative tissue damage. J Pharmacol Exp Ther 2009.

90. Keshavarzian A, Choudhary S, Holmes EW, et al. Preventing gut leakiness by oats supplementation ameliorates alcohol-induced liver damage in rats. J Pharmacol Exp Ther 2001;299:442-8.

91. Tang $Y$, Forsyth CB, Banan A, et al. Oats supplementation prevents alcohol-induced gut leakiness in rats by preventing alcohol-induced oxidative tissue damage. J Pharmacol Exp Ther 2009;329:952-8.

92. Okayama N, Kevil CG, Correia L, et al. Nitric oxide enhances hydrogen peroxide-mediated endothelial permeability in vitro. Am J Physiol 1997;273:C1581-7. 


\section{Summary}




\section{Summary}

Ethanol consumption is known to exert injurious effects in on the gastrointestinal (GI) tract and is associated with a number of disorders including colorectal carcinoma, acute and chronic pancreatitis, and alcoholic liver disease (ALD). ALD is the most prevalent cause of advanced liver disease worldwide. A significant body of evidence indicates that endotoxemia and endotoxin-mediated hepatocellular damage play a crucial role in the pathogenesis of ALD as a close correlation between endotoxemia and the severity of ethanol-induced liver injury is reported in a number of clinical and experimental studies. Ethanol- and its metabolite acetaldehyde-induced intestinal epithelial barrier dysfunction with subsequent increase in intestinal permeability can ultimately enhance translocation of endotoxins resulting in endotoxaemia. A few numbers of studies have shown that both a single high dose and chronic ethanol consumption disrupts epithelial barrier integrity, and thereby increases upper GI permeability. However, little is known about effects of moderate ethanol intake on small as well as large intestinal barrier function including the possible mechanisms behind. Therefore, studies addressing effects of moderate ethanol consumption and its metabolites including acetaldehyde and fatty acid ethyl esters on intestinal barrier and the protective factors are critically important in the investigations toward the search of preventive and therapeutic strategies for ALD.

In Chapter 1, the general introduction of this thesis, the above topics such as the pathways of ethanol metabolism and related gastrointestinal (GI) diseases, regulation of intestinal epithelial barrier and harmful effects of ethanol on intestinal barrier integrity including the proposed mechanisms are outlined. Several reviews have addressed the effects of ethanol and its oxidative metabolite, acetaldehyde, on the GI tract, focusing on carcinogenic effects or ALD. In Chapter 2 the current knowledge on ethanol metabolism and its effects of ethanol on $\mathrm{Gl}$ barrier function is reviewed. Based on this review, it can be concluded that both ethanol and its oxidative metabolite, acetaldehyde can impair small intestinal barrier integrity, thereby contributing to $\mathrm{Gl}$ and liver diseases. Limited evidence also points to increased colon permeability following exposure to ethanol or acetaldehyde. However, most of the data described in previous studies have mainly been obtained in animal and in vitro models. Only limited numbers of human studies have been performed, which have all been carried out in chronic alcoholics and mainly focus on effects of long-term ethanol consumption. There are several mechanisms, obtained mainly in vitro, have been proposed to be involved in ethanol- and acetaldehyde-induced barrier disruption, including oxidative stress, a remodeling of the cytoskeleton and activation of different cell-signaling pathways. Although a number of in vitro studies have investigated effects of acetaldehyde on epithelial tight junctions, effects of the nonoxidative metabolites fatty acid ethyl esters on barrier function have never been studied. Furthermore, studies investigating effects of moderate ethanol consumption on intestinal microbiota in healthy subjects are lacking. Overall, the prior studies 
suggest that ethanol and its metabolites may act additively or even synergistically. Therefore, in vivo studies investigating the effects of ethanol and its byproducts on intestinal permeability are warranted.

In Chapter $\mathbf{3}$ effects of intraduodenal administration of $20 \mathrm{~g}$ ethanol on both small and large intestinal epithelial integrity was investigated in 12 healthy volunteers in a randomized placebo controlled cross-over study, and the role of mitogen activated protein kinase (MAPK) as a possible mechanism was explored ex vivo and in vitro using Caco-2 cells. It is known that Caco-2 cells in long-term (21 days) culture differentiate into enterocyte-like small intestinal epithelial cells exhibiting fully polarized cell monolayer and intercellular junctions. In the study, each subject participated in two experiments with one week wash-out in between (placebo, ethanol). Placebo or ethanol (20 g; $150 \mathrm{ml}, 5 \% \mathrm{v} / \mathrm{v}$ ) was administered into the duodenum through a Bengmark-type naso-intestinal tube. Intestinal permeability was assessed by the sugar absorption test, that is, ingestion of a test drink containing sucrose $(1 \mathrm{~g})$, lactulose $(1 \mathrm{~g})$ and rhamnose $(0.5 \mathrm{~g})$, sucralose $(1 \mathrm{~g})$ and erythritol $(1 \mathrm{~g})$ followed by 5 - and 24 -h collection of total urine. Urinary excretion of these sugars was determined by high pressure liquid chromatography (HPLC). The urinary sucrose, lactulose/rhamnose (L/R) excretion and sucralose/erythritol (S/E) ratios are sensitive measures of GI permeability changes and increased sucrose, L/R and S/E ratios implies increased gastroduodenal, small and colon permeability, respectively. The results of obtained from this combined in vivo, ex vivo and in vitro studies showed that the intervention with $20 \mathrm{~g}$ ethanol significantly increased small intestinal and also colon permeability, supported by changes in localization of TJ proteins and gene expression associated with MAPK activation. Furthermore, we have shown that oxidative stressmediated activation of MAPK and MAPK-dependent myosin light chain kinase (MLCK) are involved in ethanol-induced loss of epithelial barrier integrity. Taken together, we concluded that administration of ethanol into the upper small intestine increases small and colon intestinal permeability mediated via a crosstalk between both MAPK and MLCK pathways. The study has potential implication for the pathogenesis of ALD, as a better understanding of the molecular mechanisms involved in ethanol-induced gut leakiness may provide targets for the development of preventive strategies.

In an attempt to provide better insight into the mechanisms, we described in Chapter 4 in vitro experiments evaluating the effects of ethanol and acetaldehyde on intestinal epithelial barrier function focusing on posttranslational modification of cytoskeleton, TJ protein and encoding gene expression, utilizing a three dimensional (3D) intestinal epithelial cell culture model of Caco-2 cells. In 3D culture, Caco-2 cells assemble into spheroids of fully differentiated epithelium displaying intercellular apical TJ. The results of the study indicated that basolateral exposure of Caco-2 spheroids to ethanol at concentrations found in blood after moderate ethanol consumption, acetaldehyde and in combination, dose-dependently and additively increase paracellular permeability. Furthermore, ethanol and acetaldehyde induced redistribution of TJ proteins without interfering with gene expression, paralleled with 
lysine residue and microtubule hyperacetylation. These observations suggest that the ethanol- and acetaldehyde-induced changes in intestinal permeability may be mediated, at least in part, by direct effects on the TJ and hyperacetylation of microtubules rather than altered TJ gene expression. In addition to ethanol itself and its oxidative metabolite acetaldehyde, the nonoxidative metabolites fatty acid ethyl esters (FAEEs) can also be injurious to the intestinal epithelium. In Chapter 5, effects of two FAEEs that are commonly found in blood after ethanol consumption, ethyl oleate an ethyl palmitate, on intestinal barrier function in the 3D Caco-2 cell culture model were described. Our study has demonstrated that the FAEEs can disrupt intestinal barrier function, mediated via ROS-induced loss of TJs integrity. The FAAEsinduced oxidative stress and subsequent barrier dysfunction could be alleviated by the anti-oxidant resveratrol. Therefore, our findings provide new evidence on the role of the non-oxidative metabolism in ethanol-induced intestinal injury. This may be relevant in chronic alcoholics as non-oxidative metabolism pathways are more active than the oxidative ones. Furthermore, involvement of oxidative stress in FAEEsinduced barrier dysfunction might have the potential to test antioxidants as therapeutic target to reduce the noxious effects of ethanol on intestinal epithelium.

Exposure to acetaldehyde is associated with intestinal barrier dysfunction and risk of malignant transformation in the gastro-intestinal tract. Epithelial to mesenchymal transition (EMT) is a developmental program induced by its transcription factor Snail and is shown to play a role in loss of epithelial integrity, cancer progression and metastases. Therefore, Chapter 6 describes a mechanistic study investigating effects of acetaldehyde, being mutagenic, on cellular redox state and activation of the transition of epithelium to mesenchymal transcription factor Snail, and its consequences on barrier function were investigated in Caco-2 cell monolayers. Exposure to acetaldehyde induced oxidative stress and oxidant-dependently activated Snail. Similar to our previous experiments (chapter 4), it was shown that acetaldehyde significantly increased the paracellular permeability in association with redistribution and decrease of TJ and AJ protein levels, which could be attenuated by either the antioxidant L-cysteine or by knockdown of Snail using siRNA. Accordingly, it was concluded that oxidative stress-mediated Snail activation is likely a novel mechanism contributing to acetaldehyde-induced impairment of intestinal barrier function. Further experiments on effects of acetaldehyde on Snail in human colon mucosa are warranted.

An increase in free intracellular calcium may activate signal-transduction pathways that regulate the TJs including Rho kinases which may in turn modulate the barrier function. In Chapter 7, this hypothesis was studied using Caco-2 monolayers. Data revealed that ethanol triggers a rise in free intracellular $\left[\mathrm{Ca}^{2+}\right]_{i}$ via activation of inositol 1,4,5-triphosphate receptor $\left(I_{3} R\right)$-gated release of $\mathrm{Ca}^{2+}$ from endoplasmic reticulum (ER), with subsequent Rho/ROCK and MLCK activation and consequently, intestinal 
epithelial barrier dysfunction. The data indicate a cross talk between intracellular $\mathrm{Ca}^{2+}$ homeostasis, Rho kinase and MLCK signaling pathways and therefore, further delineation of their roles in ethanol-induced intestinal barrier dysfunction may shed light on their potential as preventive targets for ethanol-related gut-liver axis diseases including ALD.

While from Chapter 3-7 it has become evident that ethanol itself as well as its metabolites acetaldehyde and FAAE induce intestinal epithelial injury, ethanol was also found to exert injurious effects on goblet cells which secrete the mucus layer that beside the TJs, maintains intestinal epithelial integrity is by goblet cells. In Chapter 8 effects of acetaldehyde on goblet cells focusing on cytotoxicy were investigated. Our data have demonstrated that acetaldehyde has distinct metabolic and cytotoxic effects on LS174T goblet-like cells that can lead to induction of cellular apoptosis. These observation are important as loss of goblet cells may result in barrier disruption with subsequent intestinal hyperpermeability and thereby, contributing to liver injury. Since the mucus layer has been found to be modulated by ethanol, it is interesting to evaluate the effects of acetaldehyde on gene and protein expression of mucins including MUC2 and other peptides such as the trefoil factors i.e. TFF3. In addition, future studies should also focus on the biochemical composition of the mucus secreted in response to acetaldehyde exposure. Our findings in combination with the intriguing and disturbing observation that already moderate ethanol consumption increases intestinal permeability necessitates preservation of the gut barrier in order to attenuate alcoholic gut-liver injury.

One of the potential routes through which this can be accomplished is by nutritional modulation of ethanol-induced loss of TJs integrity. In Chapter 9, the capability of the short chain fatty acids (SCFAs) butyrate, propionate and acetate to protect against ethanol-induced metabolic stress and barrier dysfunction in Caco- 2 cell monolayers were investigated. Results showed that SCFAs are able to enhance the barrier function and induce adenosine monophosphate protein kinase (AMPK) activation. In line with results in Chapter 3, $\mathbf{4}$ and $\mathbf{7}$, ethanol impaired epithelial barrier function. In addition, ethanol induced oxidative stress, decreased mitochondrial function and decreased intracellular ATP levels. However, pretreatment with the SCFAs alleviated ethanolinduced barrier dysfunction, attenuated oxidative stress, improved mitochondrial function, and replenished ATP stores. We finally showed that both pharmacological inhibition with compound $\mathrm{C}$ and siRNA knockdown of AMPK abolished the promoting effects of the SCFAs on barrier function, indicating involvement of AMPK. These data imply that SCFAs possess cytoprotective effects against ethanol-induced metabolic stress and intestinal barrier dysfunction, most likely mediated by AMPK activation and thereby showing promise as preventive factors against ethanol-induced gut leakiness.

In conclusion, the studies described in this thesis support the rationale for investigating effects of moderate ethanol intake and its oxidative and non-oxidative 
metabolites on intestinal epithelium. Better understanding of modulating effects of ethanol and its metabolites on the TJ and its regulatory cell signaling pathways will allow the development of therapeutic targets to improve the gut barrier function. Although results were obtained in vitro, this thesis shows beneficial effects for the products of non-digestible fermentable dietary fibers SCFAs as preventive tools against ethanol-related barrier dysfunction. However, large human intervention trials are needed to evaluate whether increased colon SCFAs levels in moderate ethanol consumers and in chronic alcoholics can improve intestinal barrier function. 
Samenvatting 


\section{Samenvatting}

Het is bekend dat inname van alcohol (ethanol) leidt tot schadelijke effecten in het maagdarmkanaal en is geassocieerd is met een aantal aandoeningen, waaronder colorectaal kanker, acute en chronische pancreatitis en alcoholische leverziekte. Alcoholische leverziekte is wereldwijd de meest voorkomende oorzaak van levercirrose. Endotoxemie en endotoxine-gemedieerde hepatocellulaire schade spelen een belangrijke rol in de pathogenese van alcoholische leverziekte. Dit wordt ondersteund door een aantal klinische en experimentele studies die een sterke correlatie tonen tussen endotoxemie en de ernst van ethanol-geïnduceerde leverschade. Deze translocatie van endotoxines en endotoxemie kan worden veroorzaakt door een verstoring va de intestinale epitheliale barrière door ethanol en zijn metaboliet aceetaldehyde.

Een klein aantal studies heeft aangetoond dat zowel een éénmalige hoge dosis ethanol alsook chronisch ethanolgebruik, de integriteit van de intestinale epitheliale barrière aantast en daarmee de intestinale permeabiliteit verhoogt. Er is echter weinig bekend over de effecten van matig ethanolgebruik op de barrièrefunctie van zowel de dunne als de dikke darm en de mogelijke achterliggende mechanismen. Wereldwijd zijn er veel mensen die op regelmatige basis enkele glazen alcohol drinken, hetgeen gedefinieerd kan worden als 'matig alcoholgebruik. Studies die zich richten op de effecten van matig ethanolgebruik en op de metabolieten van ethanol, waaronder aceetaldehyde en vetzuurethylesters (FAEEs), zijn belangrijk in de zoektocht naar strategieën ter voorkoming en behandeling van alcoholische leverziekte.

In de algemene introductie (Hoofdstuk 1), wordt kort ingegaan op de belangrijkste routes betrokken bij de omzetting van ethanol, ethanol-gerelateerde gastrointestinale en leverziekten, de regulatie van de intestinale epitheliale barrière, de schadelijke effecten van ethanol op deze barrière en worden de hoofdlijnen van dit proefschrift aangegeven.

Verscheidene reviews hebben de effecten van ethanol en zijn oxidatieve metaboliet aceetaldehyde op het maagdarmkanaal behandeld, waarbij de focus lag op de carcinogene effecten danwel op alcoholische leverziekte. In Hoofdstuk 2 wordt een overzicht gegeven van de huidige stand van zaken betreffende het metabolisme van ethanol en de effecten van ethanol op de gastro-intestinale barrière. Aan de hand van dit overzicht werd geconcludeerd dat zowel ethanol als zijn oxidatieve metaboliet aceetaldehyde de epitheliale integriteit van de dunne darm kan beschadigen en zo bij kan dragen aan gastro-intestinale en leverziekten. Er zijn echter maar weinig gegevens bekend van het effect van ethanol en aceetaldehyde op de permeabiliteit van het colon. Ook zijn er geen studies die de effecten van matig alcoholgebruik op de intestinale barrière hebben onderzocht. Daarnaast zijn de meeste data afkomstig van dierstudies en in vitro onderzoek en is slechts een beperkt aantal humane studies 
uitgevoerd. Deze humane studies betreft onderzoek in alcoholisten, waarbij de nadruk lag op de effecten van langdurig ethanolgebruik.

Op basis van in vitro onderzoek, zijn ook een aantal mechanismen beschreven die betrokken lijken te zijn bij ethanol- en aceetaldehyde-geïnduceerde barrièreverstoring. Dit betreft onder andere oxidatieve stress, remodelering van het cytoskelet en activatie van signaaltransductie routes. Hoewel diverse in vitro studies ook de effecten van aceetaldehyde hebben onderzocht, zijn de effecten van de nietoxidatieve metabolieten, de vetzuurethylesters (FAEEs), op de intercellulaire tight junctions (TJs) van intestinale epitheelcellen nog nooit bekeken. Eerdere studies, die suggereren dat de effecten van ethanol en zijn metabolieten additief of zelf synergistisch kunnen zijn, rechtvaardigen in vivo studies naar de effecten van ethanol en zijn metabolieten op de intestinale permeabiliteit.

In Hoofdstuk 3 werden de resultaten beschreven van een humane studie waarbij de effecten van intra-duodenale toediening van $20 \mathrm{~g}$ ethanol op de epitheliale integriteit van zowel de dunne als de dikke darm werd onderzocht in 12 gezonde vrijwilligers. Het betrof een gerandomiseerde placebo-gecontroleerde cross-over studie. Hierbij werd ex vivo en in vitro met behulp van Caco-2 cellen, ook de rol van mitogeengeactiveerde proteïne kinases (MAPKs) onderzocht als een mogelijk mechanisme voor de ethanol-geïnduceerde barrière disfunctie. Caco-2 cellen in kweek (21 dagen) differentiëren in op enterocyt-gelijkende, dunne darmepitheelcellen met een volledig gepolariseerde monolaag en intercellulaire tight junctions (TJs).

In de studie nam iedere proefpersoon deel aan twee testdagen (placebo of ethanol in een willekeurige volgorde) met daartussen een wash-out periode van 1 week. Placebo of ethanol ( $20 \mathrm{~g}$ in $150 \mathrm{ml} ; 5 \% \mathrm{v} / \mathrm{v}$ ) werd intra-duodenaal toegediend met behulp van een Bengmark naso-intestinale sonde. De intestinale permeabiliteit werd bepaald met behulp van een mulit-sugar test. Hierbij wordt door de proefpersoon een suikerdrankje ingenomen dat bestaat uit sucrose $(1 \mathrm{~g})$, lactulose $(1 \mathrm{~g})$, rhamnose $(0,5$ $\mathrm{g})$, sucralose $(1 \mathrm{~g})$ en erythritol $(1 \mathrm{~g})$ en wordt 5 en 24 uurs urine verzameld. Uitscheiding van deze suikers via de urine werd gemeten met de high pressure liquid chromatography (HPLC). De excretie van sucrose, de lactulose/rhamnose (L/R) ratio en sucralose/erythritol (S/E) ratio werden gebruikt als indicator van respectievelijk de gastro-duodenale, dunne darm- en colonpermeabiliteit. De resultaten van deze gecombineerde in vivo, ex vivo en in vitro studie, lieten zien dat toediening van $20 \mathrm{~g}$ ethanol resulteert in een toename van de permeabiliteit van zowel de dunne darm als het colon. Deze bevinding werd ondersteund door veranderingen in de lokalisatie en transcriptie van TJ-eiwitten en de activatie van MAPKs. Ook konden we aantonen dat activatie van MAPKs en MAPKs-afhankelijk myosin light chain kinase (MLCK) door oxidatieve stress, betrokken is bij deze ethanol-geïnduceerde verstoring van de epitheliale barrière. Aan de hand van deze bevindingen concludeerden we dat toediening van ethanol in het duodenum, resulteerde in een toename van de 
permeabiliteit van de dunne darm en van het colon, middels cross-talk tussen MAPKs en MLCK pathways.

In een poging om meer inzicht te verkrijgen in de onderliggende mechanismen worden in Hoofdstuk 4 in vitro experimenten beschreven die het effect van ethanol en aceetaldehyde op de intestinale barrière functie onderzochten waarbij de nadruk lag op post-translatie modificatie van het cytoskelet en TJ-proteïnen en de genexpressie van deze eiwitten. Hierbij werd gebruik gemaakt van een driedimensionaal (3D) celkweekmodel met Caco-2 cellen.

In een 3D kweek vormen Caco-2 cellen bolvormige structuren ("sferoïden') van volledig gedifferentieerd epitheelcellen met intercellulair tight junctions. De resultaten van deze studie toonden aan dat basolaterale blootstelling van deze Caco-2 sferoïden aan ethanol en aceetaldehyde in concentraties die in het bloed gevonden worden na matige alcohol consumptie, leiden tot een dosisafhankelijke toename van de paracellulaire permeabiliteit. De combinatie van ethanol en aceetaldehyde resulteerde in een additief effect. De bevindingen gingen gepaard met een herverdeling van de TJ eiwitten zonder een effect op de genexpressie. Daarnaast werd hyperacetylatie aangetoond van lysine residuen en de microtubuli.

Naast ethanol en zijn oxidatieve metaboliet aceetaldehyde, kunnen ook de nonoxidatieve metabolieten van ethanol, de vetzuurethylesters (FAEEs), leiden tot schade aan het darmepitheel. De vetzuurethylesters ethyloleaat en ethylpalmetaat, kunnen worden aangetoond in het bloed na de inname van alcohol. In Hoofdstuk $\mathbf{5}$ wordt het effect van deze FAEEs op de paracellulaire permeabiliteit onderzocht in het 3D celkweek model. Onze studie toonde aan dat de FAEEs de barrièrefunctie verstoorden door verlies van de integriteit van de TJ ten gevolge van oxidatieve stress. Deze FAEEsgeïnduceerde oxidatieve stress en barrière disfunctie kon worden verminderd door de anti-oxidant resveratrol. Hiermee lieten deze bevindingen zien dat ook non-oxidatieve metabolieten bij kunnen dragen aan de ethanol-geïnduceerde darmschade. Dit is metname van belang voor chronische alcoholici, waarbij de non-oxidatieve pathways actiever zijn dan de oxidatieve pathways. De rol van oxidatieve stress in de FAEEsgeïnduceerde barrière disfunctie toont tevens aan dat het interessant is om te testen of antioxidanten de schadelijke effecten van alcohol op de darm zouden kunnen verminderen.

Het is bekend dat blootstelling aan aceetaldehyde geassocieerd is met barrière disfunctie en met maligne transformatie in het maagdarmkanaal. De epitheliale mesenchymale transitie is een ontwikkelingsprogramma dat wordt geïnduceerd door de transcriptiefactor Snail en is betrokken bij verlies van epitheliale integriteit, kanker progressie en metastase. Daarom werd in Hoofdstuk 6 een mechanistische studie uitgevoerd om de effecten van het mutagene aceetaldehyde op de cellulaire redox status, de activatie van Snail en op de epitheliale barrière te onderzoeken in Caco-2 cel monolayers. Blootstelling aan aceetaldehyde induceerde oxidatieve stress, 
hetgeen resulteerde in de activatie van Snail. In lijn met onze vorige experimenten (Hoofdstuk 4), vonden we een significante toename van de paracellulaire permeabiliteit en een herverdeling en afname van de TJ en adherence junction eiwitten na blootstelling aan aceetaldehyde. Deze effecten konden worden verminderd door toediening van de anti-oxidant L-Cysteine of na uitschakeling van Snail met behulp van siRNA. Hieruit hebben we geconcludeerd dat oxidatieve stressgemedieerde activatie van Snail mogelijk een nieuw mechanisme is dat bij kan dragen aan de aceetaldehyde-geïnduceerde barrière dysfunctie. Verder onderzoek is nodig naar de effecten van aceetaldehyde op Snail in de humane darmmucosa.

Een toename van vrij intracellulair calcium zou signaal-transducties pathways kunnen activeren, zoals bijvoorbeeld de Rho kinases, die de TJ reguleren en daardoor de barrière functie kunnen moduleren. Deze hypothese is in vitro onderzocht met Caco-2 cellen en beschreven in Hoofdstuk 7. De data toonden aan dat ethanol leidt tot een toename van vrij intracellulair $\left[\mathrm{Ca}^{2+}\right]_{i}$ vanuit het endoplasmatisch reticulum via activatie van inositol 1,4,5-trifosfaat receptor $\left(I_{3} R\right)$, vervolgens tot activatie van RhoROCK en MCLK en tenslotte resulteert in een verstoring van de epitheliale barrière. Hieruit hebben we geconcludeerd dat er een interactie is tussen de intracellulaire $\mathrm{Ca}^{2+}$ homeostase, Rho kinase en MLCK signaling pathways.

In Hoofdstuk 3-7 lieten we zien dat ethanol zelf, alsook de metabolieten aceetaldehyde en FAEEs kunnen leiden tot schade aan intestinale epitheelcellen. Alcohol zou echter ook een schadelijk effect kunnen hebben op de goblet cellen. Deze scheiden mucus uit, hetgeen naast de TJs belangrijk is voor het handhaven van de epitheliale integriteit. In Hoofdstuk 8 zijn de effecten van aceetaldehyde op goblet cellen beschreven. Aceetaldehdye heeft diverse metabole en cytotoxische effecten op LSS174T goblet-like cellen, die kunnen leiden tot apoptose. Deze bevindingen zijn belangrijk omdat verlies van goblet cellen kan leiden tot een verminderde barrière functie, en dus verhoogde intestinale permeabiliteit die kan bijdragen aan het ontstaan van leverschade.

Omdat bekend was dat de mucuslaag kon worden gemoduleerd oor ethanol, het is interessant om het effect van aceetaldehyde op de gen- en eiwitexpressie van mucines (te weten het MUC2) en andere eiwitten zoals trefoil factors (te weten TFF3) te ontdekken. Toekomstige studies zouden zich ook moeten richten op de effecten van aceetaldehyde op de biochemische samenstelling van het mucussecreet.

De effecten van een matige hoeveelheid ethanol op zowel de goblet cellen als op de epitheelcellen, ondersteunen eens te meer dat het nodig is om onderzoek te doen naar mogelijkheden om de darm barrière functie te handhaven en daarmee alcoholgeïnduceerde darm- en leverschade te beperken. Een van de mogelijke manieren waarop dit bereikt zou kunnen worden is middels nutritionele modulatie van ethanolgeïnduceerd verlies van de TJ integriteit. In Hoofdstuk 9 werd onderzocht of de korte 
ketenvetzuren (SCFAs), butyraat, propionaat en acetaat bescherming konden bieden tegen de ethanol-geïnduceerde metabole stress en barrière disfunctie in Caco-2 cel monolayers. De resultaten lieten zien dat SCFAs de barrièrefunctie kunnen versterken en adenosine-monofosfaat-proteinekinases (AMPK) kan activeren. In lijn met de bevindingen in Hoofdstuk 3, 4 en 7 vonden we dat ethanol de barrière functie verstoort, alsook resulteert in de inductie van oxidatieve stress, verminderde mitochondriële functie en verminderde intracellulaire ATP levels. Een voorbehandeling met SCFAs verminderde deze ethanol-geïnduceerde barrière disfunctie, verminderde oxidatieve stress, verbeterde de mitochondriële functie en resulteerde in een toename van ATP levels. Tenslotte vonden we dat een farmacologische inhibitie met compound $\mathrm{C}$ of knockdown van AMPK middels siRNA deze gunstige effecten van SCFAs verminderde. Onze data lieten dus zien dat SCFAs een cytoprotectief effect hebben tegen ethanol-geïnduceerde metabole stress en barrière disfunctie, wat mogelijk gemedieerd wordt door activatie van AMPK.

De studies die zijn beschreven in dit proefschrift ondersteunen de rationale om het effect van ethanol alsook van zijn oxidatieve en non-oxidatieve metabolieten, op de intestinale barrière te onderzoeken, in concentraties die gevonden worden in de darm na inname van 2 eenheden alcohol. Meer kennis van de schadelijke effecten van ethanol en zijn metabolieten op de tight juncions en diens regulatoire signaaltransductie routes kan bijdragen aan de ontwikkelingen van preventieve en therapeutische strategieën om de barrièrefunctie te verbeteren.

Alhoewel de resultaten met SCFAs waren gebaseerd op in vitro onderzoek, lieten deze zien dat SCFAs als belangrijke fermentatieproducten van onverteerbare oligosacchariden een gunstig effect zouden kunnen hebben. Grote humane interventie studies zijn echter nodig om te evalueren of een toename van SCFAs in de darm van matige drinkers en alcoholici de barrièrefunctie zouden kunnen verbeteren. 
Acknowledgement 


\section{Acknowledgement}

And then now... the most difficult part of this thesis, the acknowledgments! The work conducted in this thesis would not have been made without the support I have got from a number of people.

I would like to express my deep sense of gratitude to my $1^{\text {st }}$ promoter Prof. Dr. Ad Masclee, for trusting my capabilities and giving me the opportunity to become a member of his research team and to explore the field of Gastroenterology and Hepatology. Dear Ad, thank you so much for your tutelage, advice, and guidance during the past years. Your sense of direction in science helped me enormously as well as your observations and corrections, which you have done in a very pleasant way. Thanks for all.

I am also indebted to my $2^{\text {nd }}$ promoter Dr. Daisy Jonkers. Dear Daisy, proper guidance, frequent meetings and dedication, and your availability when I needed help were indispensable for this thesis to see the light. We had regular discussions during which you were always $100 \%$ up-to-date, clear, very sharp and concise. (Linking and shortening sentences!), thanks here for! In one sentence, you were the right person behind the button. I was wondering how you can be so powerful and strong in handling many projects at the same time, and always be so sharp, critical and informative about each project. You are a great Master!

The members of the evaluation committee, Prof. Dr. C.H.C. Dejong, Prof. Dr. J.P.H. Drenth, Prof. Dr. J.W.M. Heemskerk, Prof. Dr. F.C.S. Ramaekers and Prof. Dr. H.K. Seitz, thank you very much for critical reading, interest and revision of my thesis.

The studies described in this thesis were done within the framework of Top Institute Food and Nutrition (TIFN). I would like to thank Rianne Hermus for her administrative support and Dr. Jan Dekker for the proper management and his scientific input.

Also special thanks to the members of Maastricht TIFN group (Gastroenterology and General Surgery) for the fruitful discussions we had.

I am also indebted to our collaborators, especially Dr. Sven van ljzendoorn (Universiteit Groningen) for hosting me in his lab and his scientific contribution to my work. I would also like to thank those from abroad, Dr. Kati Juuti-Uusitalo (Institute of Biomedical Technology, University of Tampere and BioMediTech, Tampere, Finland) for teaching me how to work with intestinal cells and Dr. Katarina Aleksa (Division of Clinical Pharmacology and Toxicology, Hospital for Sick Children, Toronto, Canada) for assessment of fatty acid ethyl esters in blood samples. 
Without the pleasant working atmosphere at the division of Gastroenterology and Hepatology, finishing this thesis might be too difficult. Staff members, registrars (AIOs), and people at the Endoscopy Unit, functiekamer, sisters and nurses: thank you for your contribution to the human study.

Elly en Mietsie, thanks a lot for support and help with administrative and secretarial work and more.

Tiny, thank you for the layout and helping with printing this thesis, it is highly appreciated!

People at HRM, thank you very much Marjo Zwanenburg and Yves Engelen for patiently answering my questions related to my employment contract and IND regulations during the last 5 years.

I would also like to thank the students who contributed to my work; Thomas van der Velden, Anne Schmidt, Timo Olieslagers and Salem Alghamdi. Co-supervising you has been a pleasure and good luck in your future career.

Eveline, my first roommate, thank you very much for your tips during my first weeks in Maastricht. Your help with buying my great bikes and dealing with computer dilemmas are unforgettable. You are such a cheerful person to work with; I wish you all the best in your training and hope you become a brilliant gastroenterologist.

Thomas thanks for the legal consultations we had. I do really like your sense of humor and I appreciate you always talking in Dutch, which has been definitely a good practice for me.

And now my colleagues, new and alumni researchers at the division of Gastroenterology and Hepatology, Mark, Kirsten VDB, Kirsten Pijls, Tim, Corrine, Bouke, Bas, Steven, Chantal, Fedde, Ellen, Harm-Jan, Montserrat, Zlatan, Sander, Paul, Renske, Sanne, Mariëlle, Samefko, Martine, Freddy, Esther, Andrea, Karen, Steven VH, Henrieke, Caroline, Annemieke and Daniel. I will never ever forget (de vlaaien en de vakgroep uitstapjes). Thank you for intellectuality and all inspiration in knowledge, and for the great time we had during lunch, coffee and national and international conferences.

I would like to thank my paranymphs, Samefko Ludidi and Harm-Jan Pieters for accepting my request and standing beside me. Samefko, I always admire your peaceful and energetic character, I have enjoyed a lot chatting and laughing with you in past years! Harm, I really hope I can give all your kindness and support back one day! 
Khaya, thank you so much for the-state-of-the-art work and this beautiful thesiscover. Your effort is highly appreciated.

Back in Sudan, I would like to thank Prof. Abdalla Ali, Prof. Dr. Mohammed Kheir and Prof. Dr. Azhari Omer, and Sudanese Ministry of Higher Education for giving me the opportunity to join Vrije Universiteit Amsterdam to obtain my master degree. Also special thanks to those who help me during my master in Amsterdam including but not limited to Mr. Ahmed Hassan Mosmar, Dr. Rieky van Walraven, Dr. Nathalie Bravenboer and Prof. Paul Lips, and Assenbroek stitching. I am also grateful to Prof. Dr. Marten Durieux who left our world but his great efforts in training Sudanese physicists and Sudanese students in the Netherlands will not be forgotten.

I have been supported by many friends here in the Netherlands, as well as in other European countries. In Maastricht, special thanks to Mutassim-Manal, Dr. MokhayerDr. Aziza, Medina, Amna, Nafesa, Osman-Awatif, Faris-Widad, Izzeldien-Hyat, KhalidHanan, Sahal-Wafa, Shaban-Jameela, Salah, Elnezier, Kamil, Dr. Hassan-Dr. Shiraz, Fattah-Hind, Yassir, Diyaelddien, Bakri-Samah, Arif-Tahani, Gootelqoloob-Dr. Malik, Musab, Noon, Amani and their families for their advice and for the great time we had. I am also indebted to Dr. Tarig-Wafa (Amsterdam), Dr. Sami-Dr. Hala (Eindhoven), Dr. Gamer-Najla (Best; Albaha), Dr. Ahmad Haj Elhussien (Albaha), Dr. Mohasen-Dina (Eindhoven), Dr. Amir-Dr. Asjad (Eindhoven), Dr. Omer-Wijdan (Eindhoven), Dr. MuezDr. Lama (Utrecht), Ayman-Dr. Sara (Rotterdam), Dr. Ali-Malak (Rotterdam), MujahidMarwa (Ijmuiden), Dr. Mursi-Noon), Dr. Hala Artoli-Abdelmuniem (Utrecht-Albaha), Obai-Hadeel (Hilversum-Paris) for their help during my first moths in the Netherlands and more. Those from abroad, Dr. Tarig-Rania, Dr. Amjad-Wafa, Dr. Khalid-Eman, Dr. Hassan Elmubarak-Memi, Elshazali, Hassan, Mohammed Elfatih, Dr. Ala eldien and Nadir for their support during my stay in Giessen-Germany. Also I am grateful to my colleagues in Ireland Dr. Farazdaq-Dr. Azahir, Dr. Khalid, Dr. Musab, Dr. Hisham, Dr. Abdelmutaal, Dr. Jodat and Dr. Abusalma for their helpful advices. For those whose names are not mentioned here due to space constraints, thank you all.

My uncle (Ahmed), it is a while that you have left us but for me you are always alive, you have been and will be my greatest father and I am still getting inspired your memories. I know how much you admired me if you were here today. May Allah Almighty rest your soul in peace and place of shohada.

My uncles, ants, grandmother (Hajja Elsara), father- and mother-in-low, my cousins and their families, lots of thanks and appreciation for your kindness and support you have given to me. I know you are far away, but I am sure that you will be always there for me, whenever I need you. 
I am so grateful to my parents who did their best to help me during my career; Um Elhaseen (Sit Elhusn), my lovely mother; you have been the biggest source of inspiration in my life. Without you, I could not own any of the things I have today. You are basically my route of being here, I love you so much.

Abu Elhaseen (Elesaid), I have always been your eldest son, and I know you have always been proud of me, thank you for farming under the hot sun to make the road to the medical faculty possible for your son. My brothers Abdurrahman and his family, Elamin and my sisters Farha and her daughter, Samah and Sara, you are the love and fun of my life. Thank you for being part of it and wish you all the best.

Finally, my lovely wife Abier, you are now almost 6 years beside me. I know that tolerating my working style is not an easy job for a woman but you have hit the right cord. I am looking forward to have a joyful life with you and our lovely kids Mohammed and Shahd. This work is dedicated to you and them. 
226 


\section{Curriculum Vitae}


228 


\section{Curriculum Vitae}

Elhaseen Elesaid Elamin was born op March 06th 1976 in Elhilalia, a small town in the State of Gezira, Sudan. He started his high school at Elmirain High Secondary School in Elhilalia. After his graduation in 1998, he started his medical training at the Faculty of Medicine, University of Gezira from August 1998 to December 2003. Next, he practiced medicine for 2 years as a junior house officer in many hospitals including Umdawanban, Soba, Bashair, and Ahmed Gasim Pediatric Hospital and Kassala Teaching Hospital. Thereafter, he started his academic career as a teaching assistant at the Department of Medical Physiology, Faculty of Medicine and Health Sciences, University of Kassala, Sudan. After being elected with scholarship by Sudanese Ministry of Higher Education and Scientific Research, he travelled to the Netherlands in August 2006 to pursue a master degree in Molecular Cell biology at Vrije Universiteit Amsterdam. During that period he did an internship at the Division of Endocrinology, Department of Internal Medicine, University Medical Center of Vrije Universiteit Amsterdam (VUmc) under supervision of Prof. Dr. Paul Lips MD PhD. As a $2^{\text {nd }}$ internship, he performed additional training in molecular biology of lung medicine at Justus Liebig University Lung Center in Giessen, Germany. End of 2008, he returned back to Sudan and he obtained a position as a lecturer in human physiology at University of Kassala. In February 2009, Elhaseen came back to the Netherlands and started his PhD project at the Division of Gastroenterology and Hepatology, Department of Internal Medicine, Maastricht University Medical Center (MUMC ${ }^{+}$), under supervision of Prof. Dr. Ad Masclee MD PhD and Dr. Daisy Jonkers PhD for Top Institute Food and Nutrition in Wageningen. Multiple studies were performed, of which data have been presented and published both nationally and internationally. In July 2013, the scientific work described in this thesis was completed and Elhaseen started working as post-doctoral fellow at the Division of Gastroenterology and Hepatology, $\left(\mathrm{MUMC}^{+}\right)$. 
230 
List of publications 
232 


\section{Scientific output}

Elamin E, Jonkers D, Juuti-Uusitalo K, van ljzendoorn S, Troost F, Duimel H, Broers J, Verheyen F, Dekker J, Masclee A. Effects of ethanol and acetaldehyde on tight junction integrity: in vitro study in a three dimensional intestinal epithelial cell culture model. PLoS One 2012.

Elamin E, Masclee A, Juuti-Uusitalo K, van ljzendoorn S, Troost F, Pieters HJ, Dekker J, Jonkers D. Fatty acid ethyl esters induce intestinal epithelial barrier dysfunction via a reactive oxygen species-dependent mechanism in a three-dimensional cell culture model. PlosOne 2013.

Elamin E, Masclee AA, Dekker J, Jonkers DM. Ethanol metabolism and its effects on the intestinal epithelial barrier. Nutr Rev 2013.

Elamin E, Masclee A, Troost F, Dekker J, Jonkers D. Activation of the Epithelial-toMesenchymal Transition Factor Snail Mediates Acetaldehyde-Induced Intestinal Epithelial Barrier Disruption. Alcoholism: Clinical and Experimental Research 2013.

Elamin E, Jonkers D, Masclee A, Dekker J, Pieters HJ, Jonkers D. Short chain fatty acids ameliorate ethanol-induced intestinal barrier dysfunction in Caco-2 cell monolayers. Journal of Nutrition 2013.

Elamin E, Masclee A, Dekker J, Jonkers D. Intracellular calcium release-induced Rho/ROCK activation mediates ethanol-induced intestinal epithelial tight junction disruption. Am J Physiol Gastrointest Liver Physiol 2013. Under revision.

Elamin E, Masclee A, Troost F, Pieters HJ, Keszthelyi D, Aleksa K, Dekker J, Jonkers D. Ethanol impairs intestinal barrier function in humans through mitogen activated protein kinase signaling: a combined in vivo and in vitro approach. Journal of clinical investigations 2013. Submitted.

Pijls KE, Jonkers DM, Elamin EE, Masclee AA, Koek GH. Intestinal epithelial barrier function in liver cirrhosis: an extensive review of the literature. Liver Int. 2013.

\section{Scientific presentations}

Elamin E, Jonkers D, Troost F, Juuti-Uusitalo K, van IJzendoorn S, Duimel H, Broers J, Verheyen F, Dekker J, Masclee A. Effects of ethanol and acetaldehyde on epithelial integrity in a three dimensional (3D) epithelial cell culture model. Dutch Society of Gastroenterology and Hepatology (NVGE) meeting, Veldhoven, October 2010. Digestive Disease Week, May 2010, New Orleans, Louisiana, USA. 
Elamin E, Jonkers D, Troost F, Juuti-Uusitalo K, van IJzendoorn S, Broers J, Dekker J, Masclee A. Modulation of Intestinal Epithelial Barrier Function by Fatty Acid Ethyl Esters in a Three Dimensional (3D) Epithelial Cell Culture Model: Role of Nonoxidative Ethanol Metabolism. (Oral) Dutch Society of Gastroenterology and Hepatology (NVGE) meeting, Veldhoven, March 2012. European Digestive Disease Week, October 2011, Stockholm, Sweden.

E. Elamin, D. Jonkers, F. Troost, J. Dekker, A. Masclee. Short Chain Fatty Acids Ameliorate Ethanol-Induced Intestinal Barrier dysfunction in Caco-2 Cell Monolayers. Digestive Disease Week, May 2012, San Diego, USA.

Elamin E, Jonkers D, Troost F, Dekker J, Masclee A. Moderate dosage of ethanol increases small and large intestinal permeability in healthy volunteers. Digestive Disease Week, May 2012, San Diego, USA. (Oral) Dutch Society of Gastroenterology and Hepatology (NVGE) meeting, Veldhoven, October 2012.

Elamin E, Jonkers D, Dekker J, Masclee A. Acetaldehyde induces metabolic stress, cytotoxicity and apoptosis in intestinal goblet cells. To be presented during the coming European Digestive Disease Week, October 2012, Amsterdam, The Netherlands.

Elamin E, Masclee A, Troost F, Dekker J, Jonkers D. Activation of the Epithelial-toMesenchymal Transition Factor Snail Mediates Acetaldehyde-Induced Intestinal Epithelial Barrier Disruption. Digestive Disease Week, May 2013, Orlando, USA. (Oral) Dutch Society of Gastroenterology and Hepatology (NVGE) meeting, Veldhoven, March 2013.

\section{Grands and awards}

2010 Travel Grant Duch Gastroenterology Federation (NVGE) to attend the Digestive Disease Week, New Orleans, Louisiana, USA.

2012 Travel Grant European Digestive Disease Week, Amsterdam, the Netherlands.

2013 Nomination for Pèlerin prize, Maastricht University Medical Center, the Netherlands 


\section{List of abbreviations}


236 


\section{List of abbreviations}

2D

3D

$\mathrm{ADH}$

AJC

AJs

ALD

ALDH

ALT

ANOVA

BAC

BAPTA-AM

$\left[\mathrm{Ca}^{2+}\right]_{\mathrm{i}}$

CYP2E1

DCF-DA

EGTA

EMT

ERK

EVOM

FAEES

FITC-D4

GF-AFC

GI

iNO

$\mathrm{IP}_{3} \mathrm{R}$

$L / R$

$\mathrm{LDH}$

MAPK

MBS/MYPT1

MEOS

MLCK

MTT

MUC2

PEG

PEth

PP2A

PTK

Rho/ROCK
Two dimensional

Three dimensional

Alcohol dehydrogenase

Apical junctional complex

Adherens junctions

Alcoholic liver disease

Aldehyde dehydrogenase

Alanine aminotransferase

Analysis of variance

Blood alcohol concentration

1,2-Bis(2-Aminophenoxy) ethane- $\mathrm{N}, \mathrm{N}, \mathrm{N}^{\prime}, \mathrm{N}^{\prime}$-tetraacetic

acid

Intracellular calcium

Cytochrome P450 2E1

2', 7'- dichlorodihydrofluorescein diacetate

Ethylene glycol tetra acetic acid

Epithelial to mesenchymal transition

Extracellular signal-regulated kinase

Epithelial Volt-ohm-meter

Fatty acid ethyl esters

Fluorescein isothiocyanate-labeled dextran 4 KD

Glycyl-phenylalanyl-amino-fluorocoumarin

Gastrointestinal

Inducible nitric oxide synthase

Inositol 1, 4, 5-triphosphate receptor

Lactulose/rhamnose

Lactate dehydrogenase

Mitogen activated protein kinase

Myosin-binding subunit/myosin phosphatase target subunit 1

Microsomal ethanol oxidizing system

Myosin light chain kinase

3-(4.5-dimethylthiazol-2-yl)-2,5-diphenyltetrazolium bromide

Mucin 2

Polyethylene glycol

Phosphatidylethanol

Protein phosphatase 2A

Protein tyrosine kinase

Rho-associated coiled-coil forming kinase 
ROS

S/E

SAPK/JNK

SCFAS

SIgA

SiRNA

TCA

TEER

TEM

TJS

WHO

ZO-1, ZO-2, ZO-3

$\gamma \mathrm{GT}$
Reactive oxygen species

Sucralose/erythritol

Stress activated kinase/C-Jun N-terminal kinase

Short chain fatty acids

Secretory immunoglobulin A

Small interfering RNA (siRNA)

Trichloroacetic acid

Transepithelial electrical resistance

Transmission electron microscopy

Tight junctions

World Health Organization

Zonula occludens 1, 2, 3

$\mathrm{v}$-glutamyltransferas 
240 